National Water-Quality Assessment

\title{
A Field Study of Selected U.S. Geological Survey Analytical Methods for Measuring Pesticides in Filtered Stream Water, June-September 2012
}

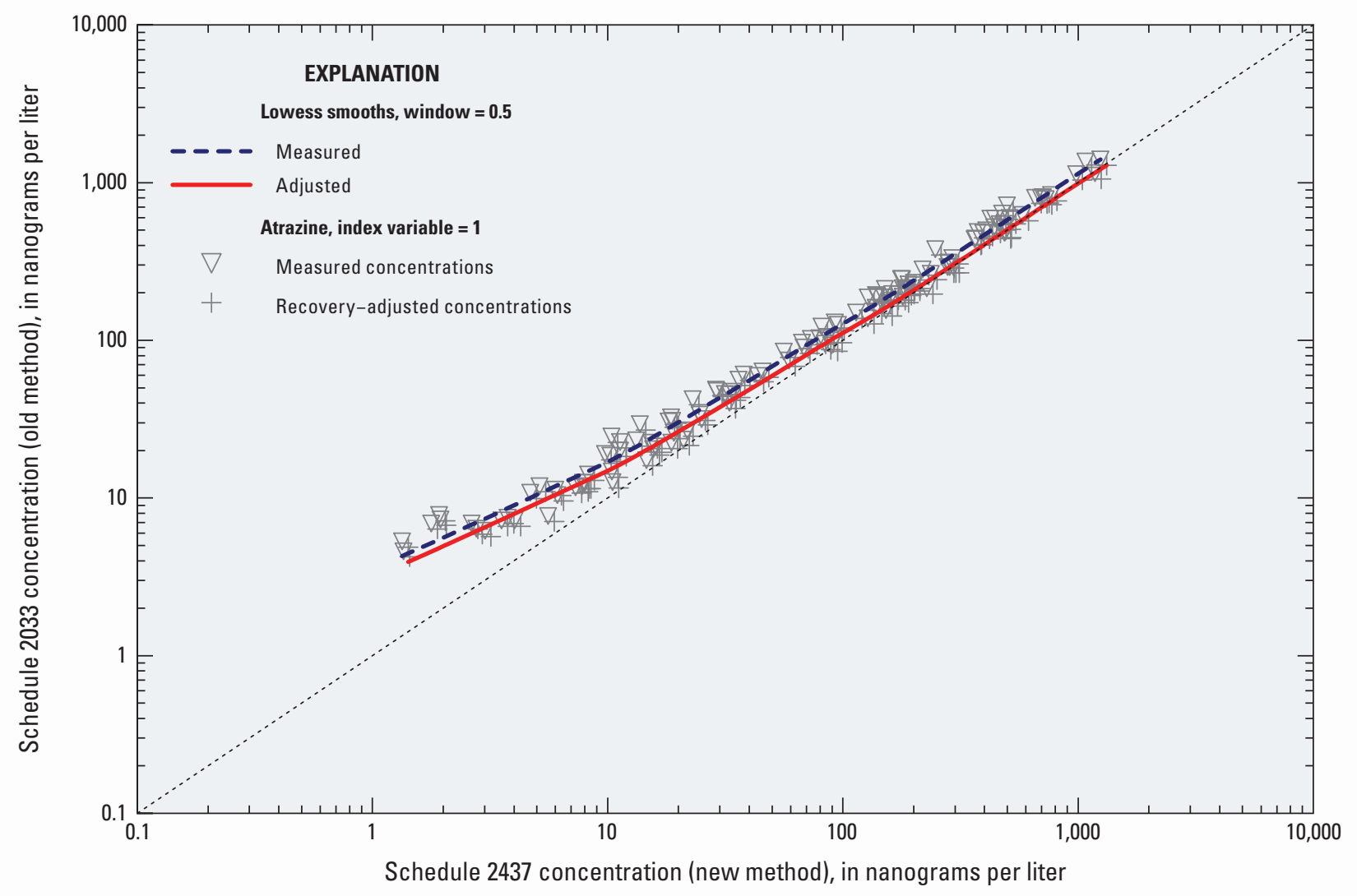

Scientific Investigations Report 2017-5049 



\section{A Field Study of Selected U.S. Geological Survey Analytical Methods for Measuring Pesticides in Filtered Stream Water, June-September 2012}

By Jeffrey D. Martin, Julia E. Norman, Mark W. Sandstrom, and Claire E. Rose

National Water-Quality Assessment

Scientific Investigations Report 2017-5049 


\title{
U.S. Department of the Interior \\ RYAN K. ZINKE, Secretary
}

\section{U.S. Geological Survey William H. Werkheiser, Acting Director}

\author{
U.S. Geological Survey, Reston, Virginia: 2017
}

For more information on the USGS - the Federal source for science about the Earth, its natural and living resources, natural hazards, and the environment-visit https://www.usgs.gov/ or call 1-888-ASK-USGS.

For an overview of USGS information products, including maps, imagery, and publications, visit https://store.usgs.gov.

Any use of trade, firm, or product names is for descriptive purposes only and does not imply endorsement by the U.S. Government.

Although this information product, for the most part, is in the public domain, it also may contain copyrighted materials as noted in the text. Permission to reproduce copyrighted items must be secured from the copyright owner.

Suggested citation:

Martin, J.D., Norman, J.E., Sandstrom, M.W., and Rose, C.E., 2017, A field study of selected U.S. Geological Survey analytical methods for measuring pesticides in filtered stream water, June-September 2012: U.S. Geological Survey Scientific Investigations Report 2017-5049, 106 p., https://doi.org/10.3133/sir20175049. 


\title{
Foreword
}

Sustaining the quality of the Nation's water resources and the health of our diverse ecosystems depends on the availability of sound water-resources data and information to develop effective, science-based policies. Effective management of water resources also brings more certainty and efficiency to important economic sectors. Taken together, these actions lead to immediate and long-term economic, social, and environmental benefits that make a difference to the lives of the almost 400 million people projected to live in the United States by 2050.

In 1991, Congress established the National Water-Quality Assessment (NAWQA) to address where, when, why, and how the Nation's water quality has changed, or is likely to change in the future, in response to human activities and natural factors. Since then, NAWQA has been a leading source of scientific data and knowledge used by national, regional, State, and local agencies to develop science-based policies and management strategies to improve and protect water resources used for drinking water, recreation, irrigation, energy development, and ecosystem needs (https://water.usgs.gov/nawqa/applications/). Plans for the third decade of NAWQA (2013-23) address priority water-quality issues and science needs identified by NAWQA stakeholders, such as the Advisory Committee on Water Information and the National Research Council, and are designed to meet increasing challenges related to population growth, increasing needs for clean water, and changing land-use and weather patterns.

U.S. Geological Survey monitoring programs extensively used two analytical methods, gas chromatography/mass spectrometry and liquid chromatography/mass spectrometry, to measure pesticides in filtered water samples during 1992-2012. In October 2012, the monitoring programs began using direct aqueous-injection liquid chromatography tandem mass spectrometry as a new analytical method for pesticides. A field study was designed to document performance of the new method in a variety of stream-water matrices and to quantify any potential changes in measurement bias or variability that could be attributed to changes in analytical methods. The results of the field study identified several challenges for the analysis and interpretation of data produced by both old and new methods, particularly when data span the change in methods and are combined for analysis of temporal trends in water quality. All NAWQA reports are available online at https://water.usgs.gov/nawqa/bib/.

We hope this publication will provide you with insights and information to meet your waterresource needs and will foster increased citizen awareness and involvement in the protection and restoration of our Nation's waters. The information in this report is intended primarily for those interested or involved in resource management and protection, conservation, regulation, and policymaking at the regional and national levels.

\author{
Dr. Donald W. Cline \\ Associate Director for Water \\ U.S. Geological Survey
}





\section{Contents}

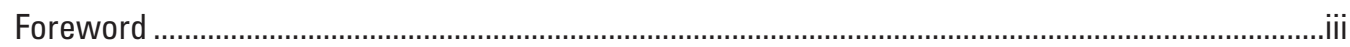

Abstract

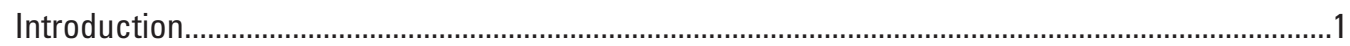

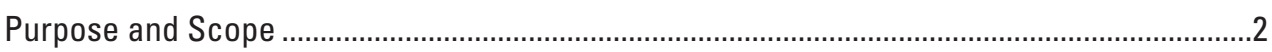

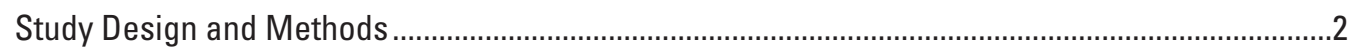

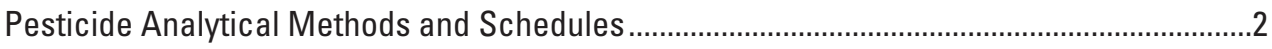

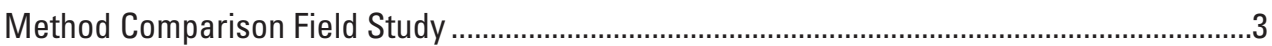

Data Compilation, Data Review, and Calculation of Recovery.................................................11

Adjustment of Environmental Pesticide Concentrations for Recovery ....................................11

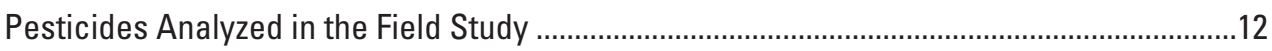

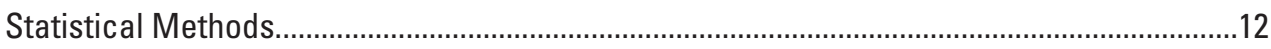

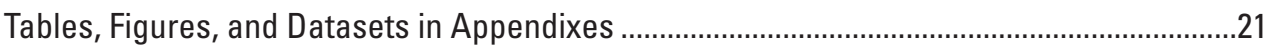

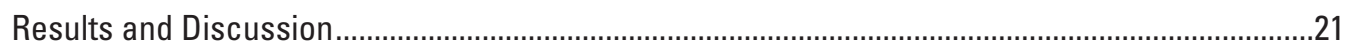

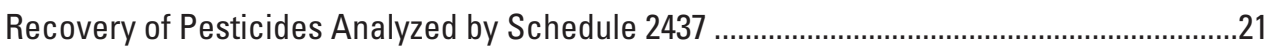

Stream-Water Matrix Spikes ........................................................................................21

Stream-Water Matrix Spikes versus Laboratory Reagent Spikes...................................21

Stream-Water Matrix Characteristics that Influence Recovery......................................29

Comparisons of Pesticides Analyzed by Old and New Methods..........................................29

Recovery in Stream-Water Matrix Spikes..................................................................29

Detections in Paired Environmental Stream-Water Samples ........................................57

Concentrations in Paired Environmental Stream-Water Samples .................................57

Contamination in Field Blank Water Samples..............................................................63

Variability of Pesticides Analyzed by Schedule 2437............................................................63

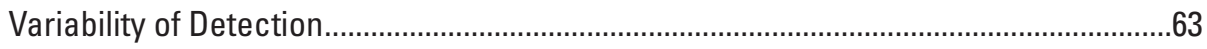

Variability of Concentrations...............................................................................................63

Considerations for Analysis and Interpretation of Data Analyzed by Old and

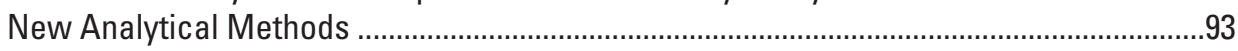

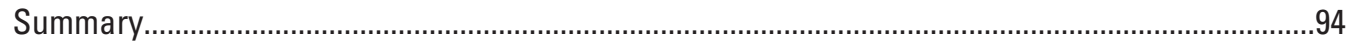

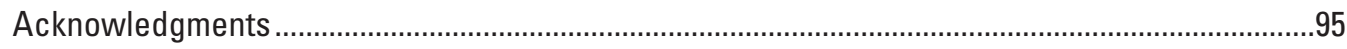

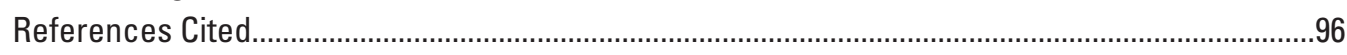

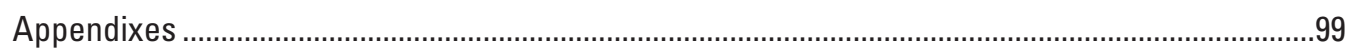

\section{Figures}

1. Map showing location of stream-water sites selected for the field study ........................4

2. Explanation of a boxplot that is used to depict the distribution of recovery ....................21

3. Graphs showing recovery of pesticides in stream-water matrix spikes analyzed by schedule 2437.

4. Graph showing distribution of recovery of atrazine in field matrix spikes and laboratory reagent spikes analyzed by the new analytical method (schedule 2437) 
5. Graphs showing distribution of recovery of pesticides in stream-water matrix spikes analyzed by schedule 2033 (old method) and by schedule 2437

(new method).

6. Graphs showing comparison of recovery of atrazine in stream-water matrix spikes analyzed by schedule 2033 and by schedule 2437 by study unit, station number, and site visit

7. Graphs showing distribution of recovery of pesticides in stream-water matrix spikes analyzed by schedule 2060 (old method) and by schedule 2437 (new method)

8. Graphs showing comparison of recovery of atrazine in stream-water matrix spikes analyzed by schedule 2060 and by schedule 2437 by study unit, station number, and site visit

9. Graphs showing comparison of atrazine detections in paired environmental stream-water samples analyzed by both schedule 2033 and schedule 2437 62

10. Graphs showing comparison of atrazine detections in paired environmental stream-water samples analyzed by both schedule 2060 and schedule 2437

11. Graphs showing comparison of atrazine concentrations in paired environmental stream-water samples analyzed by both schedule 2033 and schedule 2437 68

12. Graphs showing comparison of atrazine concentrations in paired environmental stream-water samples analyzed by both schedule 2060 and schedule 2437

\section{Tables}

1. National Water-Quality Assessment study-unit identifiers ...............................................

2. Stream-water sites selected for the field study ...............................................................

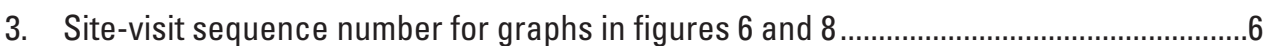

4. Types of water samples, analytical schedules, and data-management strategy for samples collected for the field study ......................................................................10

5. Pesticides analyzed for the field study.....

6. Recovery of pesticides in stream-water matrix spikes analyzed by schedule 2437

7. Comparison of median recovery of pesticides in stream-water matrix spikes and laboratory reagent-water spikes analyzed by schedule 2437 .

8. Comparison of variability of recovery of pesticides in stream-water matrix spikes and laboratory reagent-water spikes analyzed by schedule 2437 .35

9. Comparison of median recovery of pesticides in stream-water matrix spikes analyzed by both schedule 2033 and schedule 2437

10. Comparison of variability of recovery of pesticides in stream-water matrix spikes analyzed by both schedule 2033 and schedule 2437

11. Comparison of median recovery of pesticides in stream-water matrix spikes analyzed by both schedule 2060 and schedule 2437

12. Comparison of variability of recovery of pesticides in stream-water matrix spikes analyzed by both schedule 2060 and schedule 2437.

13. Comparison of pesticide detections in paired environmental stream-water samples analyzed by both schedule 2033 and schedule 2437

14. Comparison of pesticide detections in paired environmental stream-water samples analyzed by both schedule 2060 and schedule 2437 
15. Comparison of pesticide concentrations in paired environmental stream-water samples analyzed by both schedule 2033 and schedule 2437

16. Comparison of pesticide concentrations in paired environmental stream-water samples analyzed by both schedule 2060 and schedule 2437

17. Summary of pesticide detections in field blank water samples analyzed by schedule 2033, schedule 2060, and schedule 2437

18. Concentrations of pesticides detected in field blank water samples analyzed by schedule 2033, schedule 2060, and schedule 2437

19. Variability of pesticide detections in field duplicate environmental water samples analyzed by schedule 2437 .

20. Variability of pesticide concentrations in field duplicate environmental water samples analyzed by schedule 2437

21. Typical variability of pesticide concentrations in field duplicate environmental water samples analyzed by schedule 2437

\section{Conversion Factors}

International System of Units to U.S. customary units

\begin{tabular}{lcl}
\hline \multicolumn{1}{c}{ Multiply } & By & To obtain \\
\hline liter $(\mathrm{L})$ & Volume & \\
microliter $(\mu \mathrm{L})$ & 33.81402 & ounce, fluid (fl. oz) \\
& $0.3882 \times 10^{-4}$ & ounce, fluid (fl. oz) \\
\hline microgram $(\mu \mathrm{g})$ & Mass & \\
nanogram $(\mathrm{ng})$ & $0.3527 \times 10^{-7}$ & ounce, avoirdupois (oz) \\
\hline
\end{tabular}

\section{Supplemental Information}

Concentrations of chemical constituents in water are given in either milligrams per liter (mg/L) or micrograms per liter $(\mu \mathrm{g} / \mathrm{L})$. 


\section{Abbreviations}

$\begin{array}{ll}\text { ASR } & \text { analytical services request form } \\ \text { BOS } & \text { Branch of Quality Systems } \\ \text { DAI } & \text { direct aqueous-injection } \\ \text { GC-MS } & \text { gas chromatography/mass spectrometry } \\ \text { HPLC } & \text { high-performance liquid chromatograph } \\ \text { LC-MS } & \text { liquid chromatography/mass spectrometry } \\ \text { LC-MS/MS } & \text { liquid chromatography tandem mass spectrometry } \\ \text { NASQAN } & \text { National Stream Quality Accounting Network } \\ \text { NAWQA } & \text { National Water-Quality Assessment } \\ \text { NFM } & \text { National Field Manual } \\ \text { NMN } & \text { National Monitoring Network } \\ \text { NWIS } & \text { National Water Information System } \\ \text { NWOL } & \text { National Water Quality Laboratory } \\ \text { OBW } & \text { organic blank water } \\ \text { OA } & \text { quality assurance } \\ \text { OC } & \text { quality control } \\ \text { RSD } & \text { relative standard deviation } \\ \text { SD } & \text { standard deviation } \\ \text { USGS } & \text { U.S. Geological Survey } \\ & \end{array}$




\title{
A Field Study of Selected U.S. Geological Survey Analytical Methods for Measuring Pesticides in Filtered Stream Water, June-September 2012
}

\author{
By Jeffrey D. Martin, Julia E. Norman, Mark W. Sandstrom, and Claire E. Rose
}

\section{Abstract}

U.S. Geological Survey monitoring programs extensively used two analytical methods, gas chromatography/ mass spectrometry and liquid chromatography/mass spectrometry, to measure pesticides in filtered water samples during 1992-2012. In October 2012, the monitoring programs began using direct aqueous-injection liquid chromatography tandem mass spectrometry as a new analytical method for pesticides. The change in analytical methods, however, has the potential to inadvertently introduce bias in analysis of datasets that span the change.

A field study was designed to document performance of the new method in a variety of stream-water matrices and to quantify any potential changes in measurement bias or variability that could be attributed to changes in analytical methods. The goals of the field study were to (1) summarize performance (bias and variability of pesticide recovery) of the new method in a variety of stream-water matrices; (2) compare performance of the new method in laboratory blank water (laboratory reagent spikes) to that in a variety of stream-water matrices; (3) compare performance (analytical recovery) of the new method to that of the old methods in a variety of streamwater matrices; (4) compare pesticide detections and concentrations measured by the new method to those of the old methods in a variety of stream-water matrices; (5) compare contamination measured by field blank water samples in old and new methods; (6) summarize the variability of pesticide detections and concentrations measured by the new method in field duplicate water samples; and (7) identify matrix characteristics of environmental water samples that adversely influence the performance of the new method. Stream-water samples and a variety of field quality-control samples were collected at 48 sites in the U.S. Geological Survey monitoring networks during June-September 2012. Stream sites were located across the United States and included sites in agricultural and urban land-use settings, as well as sites on major rivers.

The results of the field study identified several challenges for the analysis and interpretation of data analyzed by both old and new methods, particularly when data span the change in methods and are combined for analysis of temporal trends in water quality. The main challenges identified are large (greater than 30 percent), statistically significant differences in analytical recovery, detection capability, and (or) measured concentrations for selected pesticides. These challenges are documented and discussed, but specific guidance or statistical methods to resolve these differences in methods are beyond the scope of the report. The results of the field study indicate that the implications of the change in analytical methods must be assessed individually for each pesticide and method.

Understanding the possible causes of the systematic differences in concentrations between methods that remain after recovery adjustment might be necessary to determine how to account for the differences in data analysis. Because recoveries for each method are independently determined from separate reference standards and spiking solutions, the differences might be due to an error in one of the reference standards or solutions or some other basic aspect of standard procedure in the analytical process. Further investigation of the possible causes is needed, which will lead to specific decisions on how to compensate for these differences in concentrations in data analysis. In the event that further investigations do not provide insight into the causes of systematic differences in concentrations between methods, the authors recommend continuing to collect and analyze paired environmental water samples by both old and new methods. This effort should be targeted to seasons, sites, and expected concentrations to supplement those concentrations already assessed and to compare the ongoing analytical recovery of old and new methods to those observed in the summer and fall of 2012.

\section{Introduction}

The National Water-Quality Assessment (NAWQA) and National Stream Quality Accounting Network (NASQAN) are U.S. Geological Survey (USGS) monitoring programs that measure pesticide concentrations in the Nation's streams and rivers, herein collectively referred to as streams. NAWQA began monitoring pesticides in 1992 and NASQAN began monitoring pesticides in 1995 . The programs were recently 
merged to form the USGS National Water Quality Network for Rivers and Streams. Water samples are analyzed for pesticides by the USGS National Water Quality Laboratory (NWQL) using methods developed by the NWQL's Methods Research and Development team. Two analytical methods for pesticides, gas chromatography/mass spectrometry (GC-MS) and liquid chromatography/mass spectrometry (LC-MS), were historically used to measure pesticides in filtered water samples. In October 2012, both programs changed analytical methods and began using a new analytical method for pesticides. The new analytical method is direct aqueous-injection (DAI) liquid chromatography tandem mass spectrometry (LC-MS/MS). The new analytical method (DAI LC-MS/MS) has many advantages over the previously used methods, including small sample volumes, no sample preparation or extraction procedures, and many more pesticides and pesticide degradates analyzed (Sandstrom and others, 2015, p. 46). The change in analytical methods, however, has the potential to inadvertently introduce bias in analysis of datasets that span the change.

\section{Purpose and Scope}

A field study was designed and implemented to help assess potential measurement bias between old and new analytical methods. A variety of environmental and qualitycontrol water samples were collected by field teams during summer and fall of 2012 and were submitted for analyses by both old and new analytical methods. This report statistically assesses measurement bias and variability of the analytical methods during summer and fall of 2012, describes general patterns of bias and variability between methods, and provides detailed information in tables and appendixes for the hundreds of pesticides assessed. In addition, datasets supporting this analysis are provided in Martin and Baker (2017).

\section{Study Design and Methods}

This section describes pesticide analytical methods and schedules, the design of the field study, compilation and review of data, and calculations and statistical methods used to summarize and compare analytical results from the three pesticide methods.

\section{Pesticide Analytical Methods and Schedules}

The USGS monitoring programs have extensively used two analytical methods (GC-MS and LC-MS) to measure pesticides and pesticide degradates (hereafter called pesticides) in water from 1992 to 2012. USGS field teams select the analytical method for the samples they submit by requesting NWQL analytical "schedules," which are specific lists of pesticides that are analyzed by particular types of instrumentation and methods (Timme, 1995, p. 22). Knowledge of the
NWQL schedule is particularly important for the GC-MS method because, even though the analytical method is the same, the particular lists of pesticides measured changes among the schedules.

The most widely used method was GC-MS, where pesticides are isolated from 1-liter filtered water samples by solidphase extraction and analyzed by capillary-column GC-MS with selected-ion monitoring (Zaugg and others, 1995; Lindley and others, 1996; Madsen and others, 2003). This version of the GC-MS method is known as NWQL schedule 2001, provides measurements of 52 pesticides, and was used primarily from 1992 to 2004. In 1999, the same GC-MS analytical techniques and instrumentation were used to measure 77 different pesticides (Sandstrom and others, 2001). This version of the GC-MS method is known as NWQL schedule 2002 and it had moderate use from 1999 to 2003. Subsequent GC-MS schedules combined pesticides from NWQL schedules 2001 and 2002. NWQL schedule 2003 (64 pesticides) was used primarily in 2003-05 and NWQL schedule 2033 (83 pesticides) was used primarily from 2005 to 2012 . Schedule 2033 is the version of the GC-MS method used in this report.

The second most widely used method was LC-MS, where pesticides are isolated from 1-liter filtered water samples by graphitized carbon-based solid-phase extraction and analyzed by liquid chromatography with electrospray ionization/mass spectrometry (Furlong and others, 2001). The LC-MS method is known as NWQL schedule 2060, provides measurements of 60 pesticides, and was used primarily from 1999 to 2012.

The new analytical method is direct aqueous-injection liquid chromatography tandem mass spectrometry (DAI LCMS/MS) (Sandstrom and others, 2015). Unlike the old methods, the new analytical method only requires a 20 -milliliter filtered sample. No other sample preparation procedures (extraction) other than filtration are required, so differences in bias and variability were expected. The DAI method is known as NWQL schedule 2437, provides measurements of 119 pesticides and 120 pesticide degradates, and has been used as the primary analytical method since October 2012. Subsequent to the field study and final method approval by USGS, 12 analytes were deleted from the new method for poor performance (U.S. Geological Survey, 2015). Data for these poor-performing analytes are presented in this report and these poor-performing analytes are identified in table $5 .{ }^{1}$

The three analytical methods discussed in this report do not have specified "detection limits" for each pesticide analyte. Compounds detected and conclusively identified by retention time and mass spectral characteristics are quantified and reported (Zaugg and others, 1995, p. 19-21; Furlong and others, 2001, p. 37; Sandstrom and others, 2015, p. 17). Nondetections of pesticides (analyses that do not meet identification criteria based on retention time and mass

\footnotetext{
${ }^{1}$ The three relevant schedules for the field study will be abbreviated as sh2033, sh2060, and sh2437 in the subsequent text.
} 
spectral characteristics) are reported as less than the reporting level for that method and analyte (for example, less than $[<] 5$ nanograms per liter $[\mathrm{ng} / \mathrm{L}])$. The numerical values of the reporting levels are method- and analyte-specific and are based on estimates of the Long-Term Method Detection Level (Childress and others, 1999; Sandstrom and others, 2015, p. 21-22). Reporting levels may change through time, typically at the start of the water year, in response to changes in the ability of the method to quantify low-level concentrations in laboratory reagent-water spikes. Reporting levels for sh2437 typically are similar to those for sh2033 but are smaller than those for sh2060. A small number of environmental samples have "matrix effects" (characteristics of the environmental water sample) or other analytical difficulties that interfere with the measurement of pesticide retention time or mass spectral characteristics. Under conditions of interference, pesticides (1) cannot be identified/detected if they are present at concentrations less than the level of interference and (2) are reported as nondetections less than a "raised" reporting level (for example, $<30 \mathrm{ng} / \mathrm{L}$, six times greater than the reporting level discussed above). Nondetections at raised reporting levels indicate the maximum possible concentration of the pesticide that could be present based on the magnitude of the interference.

Quality-control (QC) procedures for analytical data produced by the NWQL are described at https://nwql.usgs. gov/quality.shtml. In addition to internal QC programs used by the NWQL, the quality of the analytical data produced by the NWQL is independently monitored by the USGS Branch of Quality Systems (BQS) (https://bqs.usgs.gov/). Blind QC samples are prepared by BQS and submitted to the NWQL as routine environmental samples. The bias and variability of analytical results are reported for each pesticide by schedule (https://bqs.usgs.gov/obsp/). The frequency and magnitude of contamination also is measured (https://bqs.usgs.gov/ibsp/ charts.php).

Pesticide data quality is routinely monitored by the collection of field QC samples. Field QC procedures are presented in Mueller and others (1997) and require the collection of field blank water samples, field replicate (duplicate) water samples, and field matrix-spike water samples. Data quality for the GC-MS method for selected periods has been published previously. Contamination in field blank water samples was summarized for 1992-95 in Martin and others (1999). Variability of pesticide detections and concentrations in field replicate water samples was summarized for 1992-97 in Martin (2002). Pesticide recovery in laboratory reagent spikes and field matrix spikes was summarized for 1992-2006 in Martin and others (2009) and for 1992-2010 in Martin and Eberle (2011). Field QC assessments for the LC-MS method have not been published.

\section{Method Comparison Field Study}

Changes in analytical methods may introduce changes in data quality. A field study was designed to document performance of the new method in a variety of stream-water matrices and to quantify any potential changes in measurement bias or variability that could be attributed to changes in analytical methods. The goals of the field study were to (1) summarize performance (bias and variability of pesticide recovery) of the new method in a variety of stream-water matrices; (2) compare performance of the new method in laboratory blank water (laboratory reagent spikes) to that in a variety of streamwater matrices; (3) compare performance of the new method (sh2437) to that of the old methods (sh2033 and sh2060) in a variety of stream-water matrices; (4) compare pesticide detections and concentrations measured by the new method to those of the old methods in a variety of stream-water matrices; (5) compare contamination measured by field blank water samples in old and new methods; (6) summarize the variability of pesticide detections and concentrations measured by the new method in field duplicate water samples; and (7) identify matrix characteristics of environmental water samples that adversely influence the performance of the new method.

Stream-water samples were collected at 48 sites in the USGS monitoring network during June-September 2012. Stream sites were located across the United States and included sites in agricultural and urban land-use settings, as well as sites on major rivers and reference sites (fig. 1, tables 1 and 2). Most sites were sampled on three dates (site visits) for a total of 150 site visits (table 3 ). Instructions for the collection and processing of the field-study samples are provided in appendix 1.

For each site visit, a single, large-volume water sample was collected and processed into three sets of two samples (an environmental sample and a matrix spike). A method-specific spike solution (100 microliters $[\mu \mathrm{L}])$ was added to each matrix spike sample. The three sets of samples were then analyzed, each by one of the three analytical methods - sh2437, sh2033, and sh2060. At one site visit for each site, additional QC samples were collected: (1) three field blank water samples (one for each analytical method), (2) a duplicate environmental water sample for analysis by sh2437, and (3) a duplicate field matrix spike for analysis by $\operatorname{sh} 2437 .^{2}$

Spiking typically increased the concentration of pesticides by approximately 0.1 microgram per liter $(\mu \mathrm{g} / \mathrm{L})$ in sh 2033 samples, by $0.25 \mu \mathrm{g} / \mathrm{L}$ in sh2060 samples, and by $250 \mathrm{ng} / \mathrm{L}(0.25 \mu \mathrm{g} / \mathrm{L})$ in sh2437 samples. The types of water samples, analytical schedules, and data-management strategy for samples collected for the field study are described in table 4.

${ }^{2}$ Except for the section "Variability of Pesticides Analyzed by Schedule 2437," duplicate water samples and duplicate field matrix spikes were not used in statistical summaries or tests to avoid biasing results to the specific sites and conditions when the duplicates were collected. 


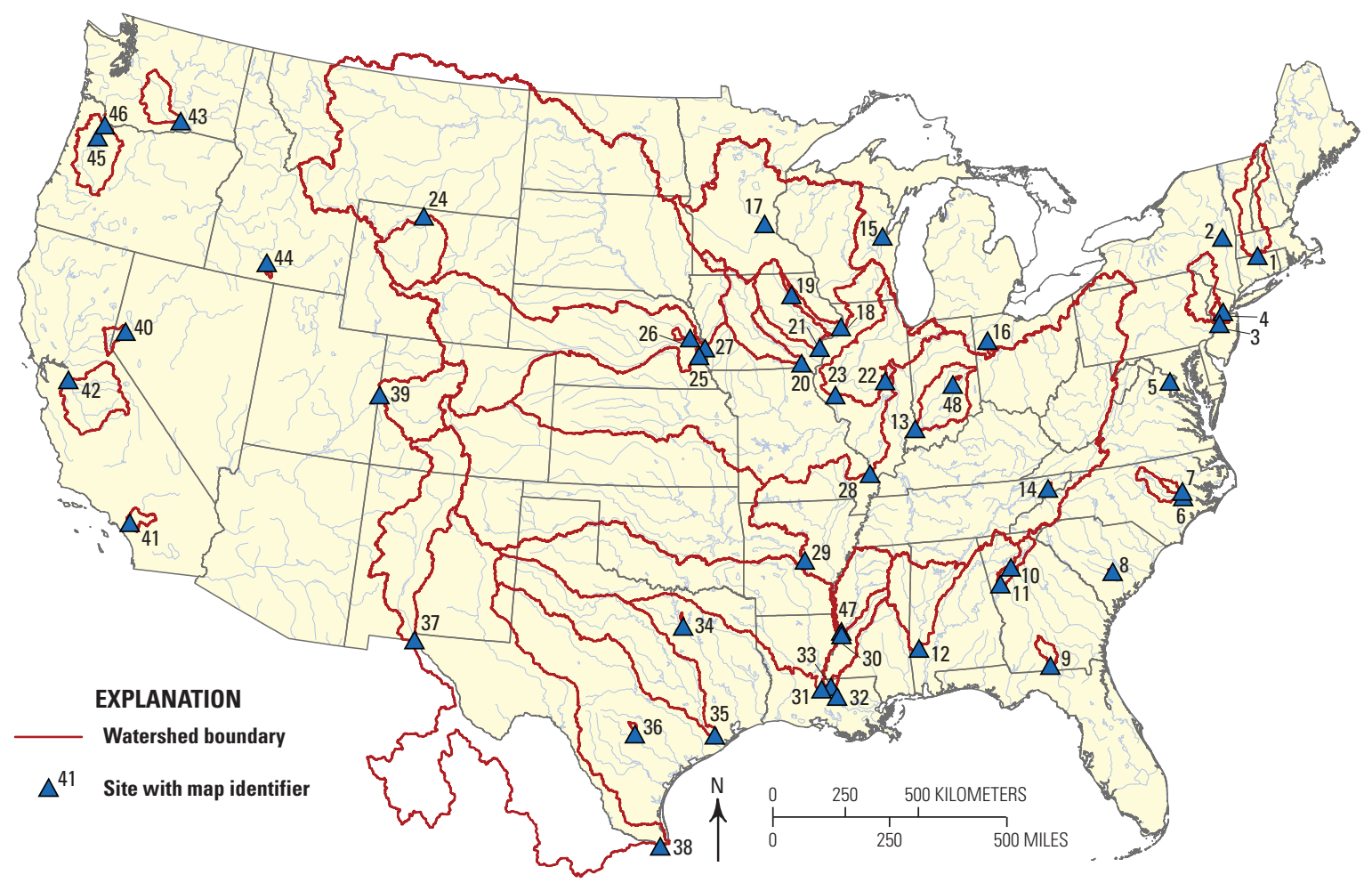

Figure 1. Location of stream-water sites selected for the field study.

Table 1. National Water-Quality Assessment study-unit identifiers.

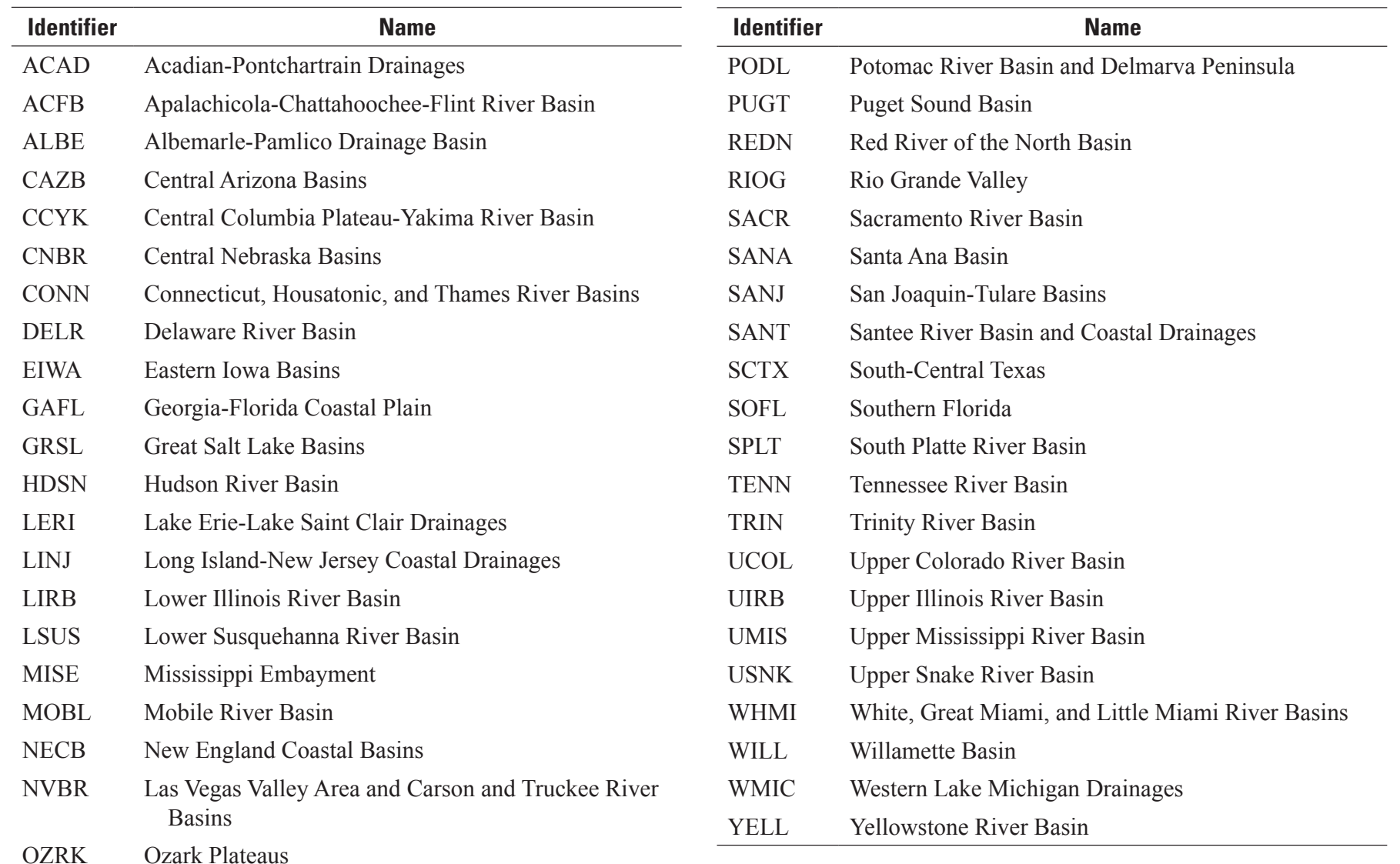

OZRK Ozark Plateaus 
Table 2. Stream-water sites selected for the field study.

[Sequence numbers were assigned by sorting sites by study unit abbreviation, station number, and date. CT., Connecticut; NY, New York; NJ, New Jersey; VA, Virginia; NC, North Carolina; SC, South Carolina; US, United States; GA, Georgia; R, river; BL, below; L\&D, lock and dam; IN, Indiana; TN, Tennessee; WI, Wisconsin; OH, Ohio; MN, Minnesota; IA, Iowa; IL, Illinois; WY, Wyoming; NE, Nebraska; NEBR., Nebraska; @, at; AR, Arkansas; NR, near; MS, Mississippi; ST., Saint; LA, Louisiana; (COE), Corps of Engineers; RV, River; TX, Texas; CK, creek; NV, Nevada; CA, California; WA, Washington; AB, above; HWY, Highway; XING, crossing; ID, Idaho; MT, Mount; OR, Oregon; CO RD, county road; S, south]

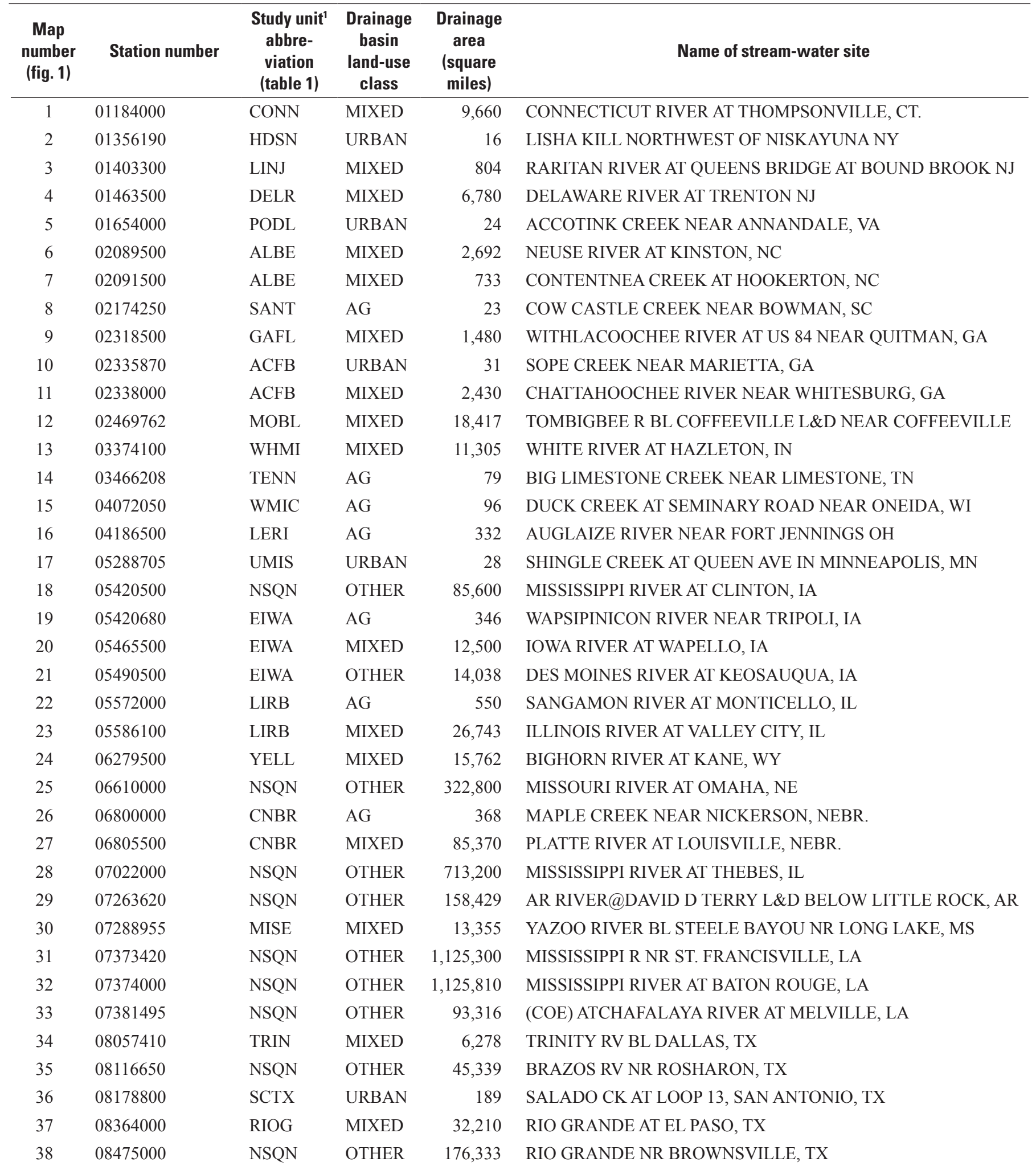


Table 2. Stream-water sites selected for the field study.-Continued

[Sequence numbers were assigned by sorting sites by study unit abbreviation, station number, and date. CT., Connecticut; NY, New York; NJ, New Jersey; VA, Virginia; NC, North Carolina; SC, South Carolina; US, United States; GA, Georgia; R, river; BL, below; L\&D, lock and dam; IN, Indiana; TN, Tennessee; WI, Wisconsin; OH, Ohio; MN, Minnesota; IA, Iowa; IL, Illinois; WY, Wyoming; NE, Nebraska; NEBR., Nebraska; @, at; AR, Arkansas; NR, near; MS, Mississippi; ST., Saint; LA, Louisiana; (COE), Corps of Engineers; RV, River; TX, Texas; CK, creek; NV, Nevada; CA, California; WA, Washington; AB, above; HWY, Highway; XING, crossing; ID, Idaho; MT, Mount; OR, Oregon; CO RD, county road; S, south]

\begin{tabular}{clllrl}
\hline $\begin{array}{c}\text { Map } \\
\text { number } \\
\text { (fig. 1) }\end{array}$ & Station number & $\begin{array}{c}\text { Study unit' } \\
\text { abbre- } \\
\text { viation } \\
\text { (table 1) }\end{array}$ & $\begin{array}{c}\text { Drainage } \\
\text { basin } \\
\text { land-use } \\
\text { class }\end{array}$ & $\begin{array}{c}\text { Drainage } \\
\text { area } \\
\text { (square } \\
\text { miles) }\end{array}$ & \multicolumn{1}{l}{} \\
\hline 39 & 09163500 & UCOL & MIXED & 17,849 & COLORADO RIVER NEAR COLORADO-UTAH STATE LINE \\
40 & 10350340 & NVBR & MIXED & 1,580 & TRUCKEE RV NR TRACY, NV \\
41 & 11074000 & SANA & MIXED & 2,258 & SANTA ANA R BL PRADO DAM CA \\
42 & 11303500 & SANJ & MIXED & 13,536 & SAN JOAQUIN R NR VERNALIS CA \\
43 & 12510500 & CCYK & MIXED & 5,615 & YAKIMA RIVER AT KIONA, WA \\
44 & 13092747 & USNK & AG & 259 & ROCK CREEK AB HWY 30/93 XING AT TWIN FALLS ID \\
45 & 14201300 & WILL & AG & 15 & ZOLLNER CREEK NEAR MT ANGEL, OR \\
46 & 14211720 & WILL & MIXED & 11,200 & WILLAMETTE RIVER AT PORTLAND, OR \\
47 & 322023090544500 & NSQN & OTHER & & MISSISSIPPI RIVER ABOVE VICKSBURG AT MILE 438, MS \\
48 & 394340085524601 & WHMI & AG & 93 & SUGAR CREEK AT CO RD 400 S AT NEW PALESTINE, IN \\
\hline
\end{tabular}

'National Stream Quality Accounting Network sites are coded "NSQN."

Table 3. Site-visit sequence number for graphs in figures 6 and 8 .

[Sequence numbers were assigned by sorting sites by study unit abbreviation, station number, and date. GA, Georgia; NC, North Carolina; WA, Washington; NEBR., Nebraska; CT., Connecticut; NJ, New Jersey; IA, Iowa; US, United States; NY, New York; OH, Ohio; IL, Illinois; BL, below; NR, near; MS, Mississippi; R, river; L\&D, lock and dam; NE, Nebraska; @, at; AR, Arkansas; ST., Saint; LA, Louisiana; COE, Corps of Engineers; RV, River; TX, Texas; NV, Nevada; VA, Virginia; CA, California; SC, South Carolina; CK, Creek; TN, Tennessee; MN, Minnesota; AB, above; HWY, Highway; XING, crossing; ID, Idaho; IN, Indiana; CO RD, County Road; S, south; MT, Mount; OR, Oregon; WI, Wisconsin; WY, Wyoming]

\begin{tabular}{|c|c|c|c|c|c|}
\hline $\begin{array}{l}\text { Site-visit } \\
\text { sequence } \\
\text { number }\end{array}$ & $\begin{array}{c}\text { Map } \\
\text { number } \\
\text { (fig. 1) }\end{array}$ & $\begin{array}{l}\text { Study unit }{ }^{1} \\
\text { abbreviation } \\
\text { (table 1) }\end{array}$ & Station number & $\begin{array}{l}\text { Date of site } \\
\text { visit (month/ } \\
\text { day/year) }\end{array}$ & Name of stream-water site \\
\hline 1 & 10 & ACFB & 02335870 & $6 / 27 / 2012$ & SOPE CREEK NEAR MARIETTA, GA \\
\hline 2 & 10 & ACFB & 02335870 & $7 / 25 / 2012$ & SOPE CREEK NEAR MARIETTA, GA \\
\hline 3 & 10 & $\mathrm{ACFB}$ & 02335870 & $8 / 23 / 2012$ & SOPE CREEK NEAR MARIETTA, GA \\
\hline 4 & 11 & ACFB & 02338000 & $7 / 10 / 2012$ & CHATTAHOOCHEE RIVER NEAR WHITESBURG, GA \\
\hline 6 & 11 & $\mathrm{ACFB}$ & 02338000 & 9/6/2012 & CHATTAHOOCHEE RIVER NEAR WHITESBURG, GA \\
\hline 7 & 6 & ALBE & 02089500 & $7 / 10 / 2012$ & NEUSE RIVER AT KINSTON, NC \\
\hline 8 & 6 & ALBE & 02089500 & $8 / 9 / 2012$ & NEUSE RIVER AT KINSTON, NC \\
\hline 9 & 6 & ALBE & 02089500 & $9 / 4 / 2012$ & NEUSE RIVER AT KINSTON, NC \\
\hline 10 & 7 & ALBE & 02091500 & $7 / 10 / 2012$ & CONTENTNEA CREEK AT HOOKERTON, NC \\
\hline 14 & 43 & CCYK & 12510500 & $8 / 6 / 2012$ & YAKIMA RIVER AT KIONA, WA \\
\hline 15 & 43 & CCYK & 12510500 & $9 / 5 / 2012$ & YAKIMA RIVER AT KIONA, WA \\
\hline 16 & 26 & CNBR & 06800000 & $6 / 27 / 2012$ & MAPLE CREEK NEAR NICKERSON, NEBR. \\
\hline 17 & 26 & CNBR & 06800000 & $7 / 24 / 2012$ & MAPLE CREEK NEAR NICKERSON, NEBR. \\
\hline
\end{tabular}


Table 3. Site-visit sequence number for graphs in figures 6 and 8.-Continued

[Sequence numbers were assigned by sorting sites by study unit abbreviation, station number, and date. GA, Georgia; NC, North Carolina; WA, Washington; NEBR., Nebraska; CT., Connecticut; NJ, New Jersey; IA, Iowa; US, United States; NY, New York; OH, Ohio; IL, Illinois; BL, below; NR, near; MS, Mississippi; R, river; L\&D, lock and dam; NE, Nebraska; @, at; AR, Arkansas; ST., Saint; LA, Louisiana; COE, Corps of Engineers; RV, River; TX, Texas; NV, Nevada; VA, Virginia; CA, California; SC, South Carolina; CK, Creek; TN, Tennessee; MN, Minnesota; AB, above; HWY, Highway; XING, crossing; ID, Idaho; IN, Indiana; CO RD, County Road; S, south; MT, Mount; OR, Oregon; WI, Wisconsin; WY, Wyoming]

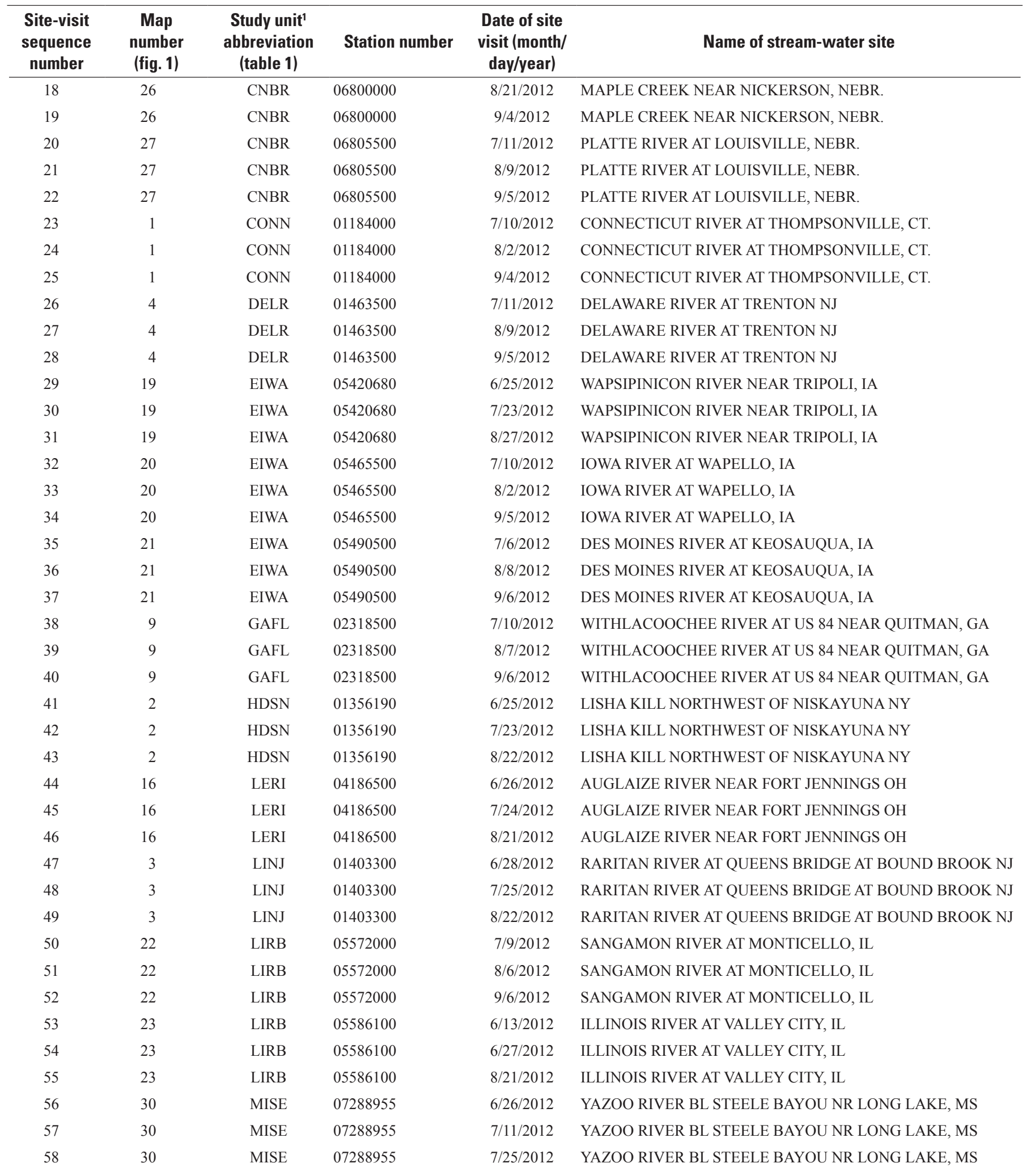


Table 3. Site-visit sequence number for graphs in figures 6 and 8.-Continued

[Sequence numbers were assigned by sorting sites by study unit abbreviation, station number, and date. GA, Georgia; NC, North Carolina; WA, Washington; NEBR., Nebraska; CT., Connecticut; NJ, New Jersey; IA, Iowa; US, United States; NY, New York; OH, Ohio; IL, Illinois; BL, below; NR, near; MS, Mississippi; R, river; L\&D, lock and dam; NE, Nebraska; @, at; AR, Arkansas; ST., Saint; LA, Louisiana; COE, Corps of Engineers; RV, River; TX, Texas; NV, Nevada; VA, Virginia; CA, California; SC, South Carolina; CK, Creek; TN, Tennessee; MN, Minnesota; AB, above; HWY, Highway; XING, crossing; ID, Idaho; IN, Indiana; CO RD, County Road; S, south; MT, Mount; OR, Oregon; WI, Wisconsin; WY, Wyoming]

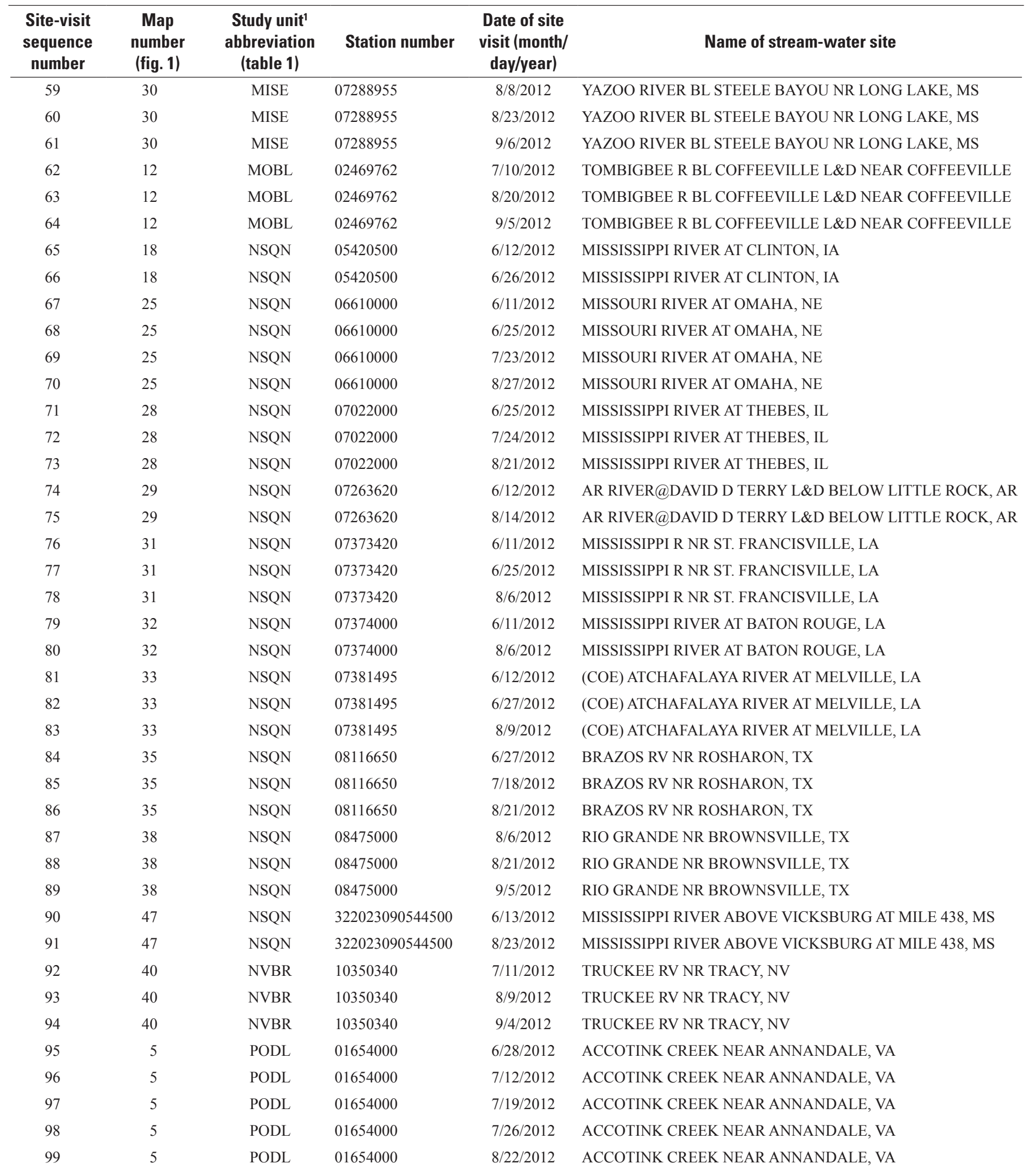


Table 3. Site-visit sequence number for graphs in figures 6 and 8.-Continued

[Sequence numbers were assigned by sorting sites by study unit abbreviation, station number, and date. GA, Georgia; NC, North Carolina; WA, Washington; NEBR., Nebraska; CT., Connecticut; NJ, New Jersey; IA, Iowa; US, United States; NY, New York; OH, Ohio; IL, Illinois; BL, below; NR, near; MS, Mississippi; R, river; L\&D, lock and dam; NE, Nebraska; @, at; AR, Arkansas; ST., Saint; LA, Louisiana; COE, Corps of Engineers; RV, River; TX, Texas; NV, Nevada; VA, Virginia; CA, California; SC, South Carolina; CK, Creek; TN, Tennessee; MN, Minnesota; AB, above; HWY, Highway; XING, crossing; ID, Idaho; IN, Indiana; CO RD, County Road; S, south; MT, Mount; OR, Oregon; WI, Wisconsin; WY, Wyoming]

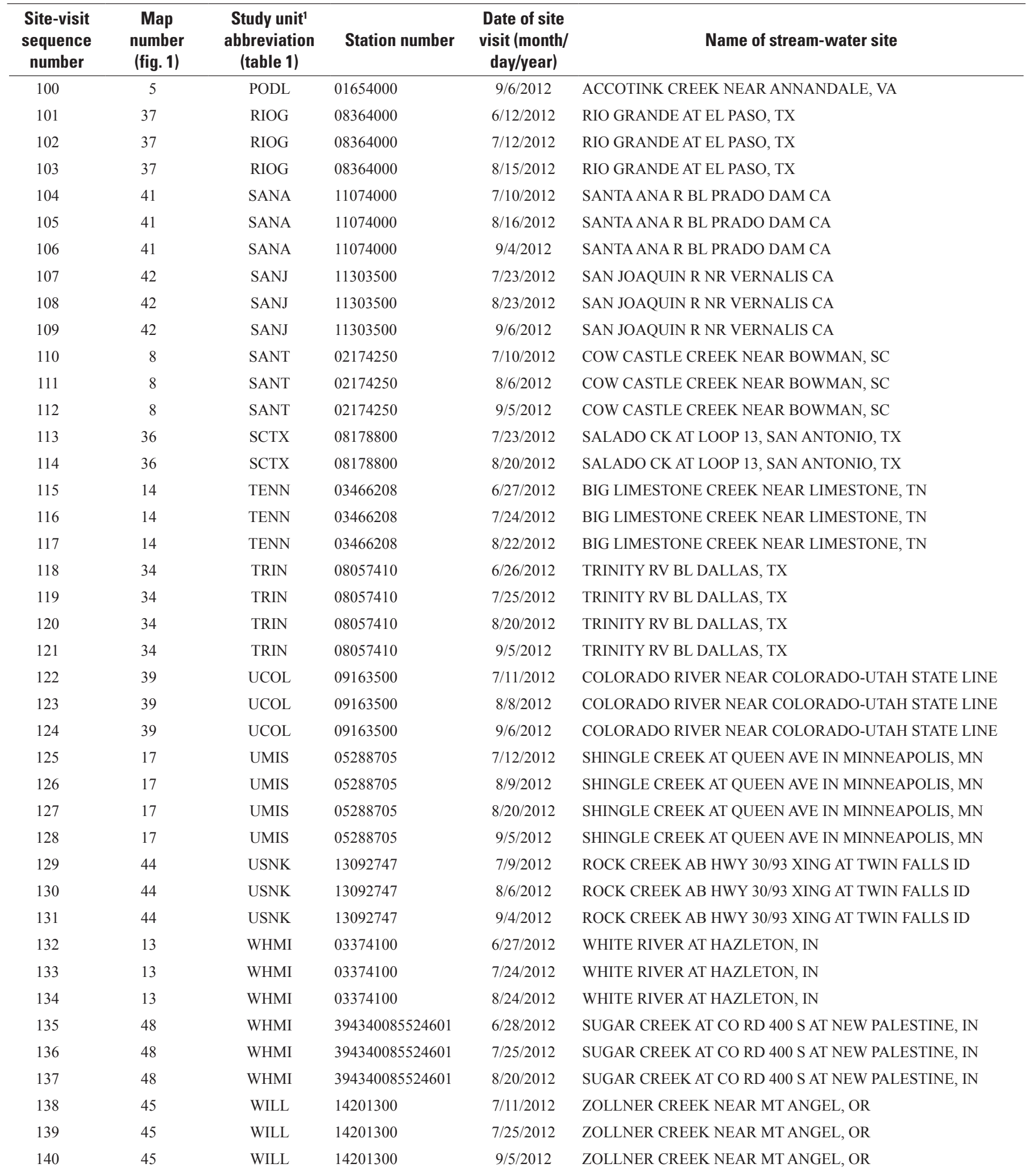


Table 3. Site-visit sequence number for graphs in figures 6 and 8.-Continued

[Sequence numbers were assigned by sorting sites by study unit abbreviation, station number, and date. GA, Georgia; NC, North Carolina; WA, Washington; NEBR., Nebraska; CT., Connecticut; NJ, New Jersey; IA, Iowa; US, United States; NY, New York; OH, Ohio; IL, Illinois; BL, below; NR, near; MS, Mississippi; R, river; L\&D, lock and dam; NE, Nebraska; @, at; AR, Arkansas; ST., Saint; LA, Louisiana; COE, Corps of Engineers; RV, River; TX, Texas; NV, Nevada; VA, Virginia; CA, California; SC, South Carolina; CK, Creek; TN, Tennessee; MN, Minnesota; AB, above; HWY, Highway; XING, crossing; ID, Idaho; IN, Indiana; CO RD, County Road; S, south; MT, Mount; OR, Oregon; WI, Wisconsin; WY, Wyoming]

\begin{tabular}{cccccc}
\hline $\begin{array}{c}\text { Site-visit } \\
\text { sequence } \\
\text { number }\end{array}$ & $\begin{array}{c}\text { Map } \\
\text { number } \\
\text { (fig. 1) }\end{array}$ & $\begin{array}{c}\text { Study unit }{ }^{1} \\
\text { abbreviation } \\
\text { (table 1) }\end{array}$ & Station number & $\begin{array}{c}\text { Date of site } \\
\text { visit (month/ } \\
\text { day/year) }\end{array}$ & Name of stream-water site \\
\hline 141 & 46 & WILL & 14211720 & $7 / 12 / 2012$ & WILLAMETTE RIVER AT PORTLAND, OR \\
142 & 46 & WILL & 14211720 & $8 / 21 / 2012$ & WILLAMETTE RIVER AT PORTLAND, OR \\
143 & 46 & WILL & 14211720 & $9 / 4 / 2012$ & WILLAMETTE RIVER AT PORTLAND, OR \\
144 & 15 & WMIC & 04072050 & $6 / 26 / 2012$ & DUCK CREEK AT SEMINARY ROAD NEAR ONEIDA, WI \\
145 & 15 & WMIC & 04072050 & $7 / 24 / 2012$ & DUCK CREEK AT SEMINARY ROAD NEAR ONEIDA, WI \\
146 & 15 & WMIC & 04072050 & $8 / 23 / 2012$ & DUCK CREEK AT SEMINARY ROAD NEAR ONEIDA, WI \\
147 & 15 & WMIC & 04072050 & $9 / 6 / 2012$ & DUCK CREEK AT SEMINARY ROAD NEAR ONEIDA, WI \\
148 & 24 & YELL & 06279500 & $6 / 14 / 2012$ & BIGHORN RIVER AT KANE, WY \\
149 & 24 & YELL & 06279500 & $7 / 9 / 2012$ & BIGHORN RIVER AT KANE, WY \\
150 & 24 & YELL & 06279500 & $8 / 9 / 2012$ & BIGHORN RIVER AT KANE, WY \\
\hline
\end{tabular}

'National Stream Quality Accounting Network sites are coded "NSQN."

Table 4. Types of water samples, analytical schedules, and data-management strategy for samples collected for the field study.

[Jcode, a code assigned by the authors to facilitate the identification of sample type and analytical method; sample time offset, the number of minutes added to the initial sample time; NWIS, National Water Information System; WS, environmental surface water; WSQ, quality-control surface water; OAQ, quality-control artificial]

\begin{tabular}{cclcccc}
\hline Jcode & $\begin{array}{c}\text { Analytical } \\
\text { schedule }\end{array}$ & Type of water sample & $\begin{array}{c}\text { Sample } \\
\text { time } \\
\text { offset }\end{array}$ & $\begin{array}{c}\text { NWIS } \\
\text { sample } \\
\text { medium } \\
\text { code }\end{array}$ & $\begin{array}{c}\text { NWIS } \\
\text { sample } \\
\text { type code }\end{array}$ & $\begin{array}{c}\text { Sample } \\
\text { collected } \\
\text { every site } \\
\text { visit? }\end{array}$ \\
\hline a & 2033 & Environmental & 0 & WS & 9 & Yes \\
b & 2033 & Matrix spike & 0 & WSQ & 1 & Yes \\
c & 2033 & Field blank & 0 & OAQ & 2 & No \\
d & 2060 & Environmental & 1 & WS & 9 & Yes \\
e & 2060 & Matrix spike & 1 & WSQ & 1 & Yes \\
f & 2060 & Field blank & 1 & OAQ & 2 & No \\
g & 2437 & Environmental & 2 & WSQ & 7 or B & Yes \\
h & 2437 & Matrix spike & 3 & WSQ & 1 & Yes \\
i & 2437 & Field blank & 4 & OAQ & 2 & No \\
j & 2437 & Field replicate & 4 & WSQ & 7 & No \\
k & 2437 & Matrix spike replicate & 4 & WSQ & 1 & No \\
\hline
\end{tabular}

${ }^{1}$ Except for the section "Variability of Pesticides Analyzed by Schedule 2437," duplicate water samples and duplicate field-matrix spikes were not used in statistical summaries or tests to avoid biasing results to the specific sites and conditions when the duplicates were collected. 


\section{Data Compilation, Data Review, and Calculation of Recovery}

Water-quality data collected for USGS monitoring programs are stored in USGS National Water Information System (NWIS) databases located in the individual State Water Science Centers (WSCs). Water-quality data are periodically retrieved from the individual NWIS systems and aggregated into the NAWQA Data Warehouse (DWH) located in the Wisconsin WSC (the DWH is no longer active). Data aggregations are subjected to automated data-checking routines intended to identify erroneous or incomplete sample coding. Analytical data for the field study were retrieved from the DWH on July 29, 2013. Pesticide recovery in sh2437 laboratory reagent set spikes for the period of analysis of field-study samples were provided by NWQL on March 31, 2014.

Analytical data for the field study were reviewed to ensure that samples had the appropriate pesticides measured by the appropriate schedules. The number of detections in a sample was assessed to ensure that environmental samples, field blanks, and matrix spikes were analyzed by the appropriate schedule and had a reasonable number of detections, and that matrix spike samples were spiked with the appropriate spike solutions and amount of spike solution. Data-review issues were resolved by changes in sample coding (variable jcode, table 4), or samples and (or) analytical results were flagged in the large data set (Martin and Baker, 2017, dataset 1) and not selected for use in the smaller data set used for the field study (Martin and Baker, 2017, dataset 2). The metadata for dataset 1 explains the wide variety of reasons why samples or results were not selected for use in the field study.

Recovery is the ratio of a measured concentration divided by a theoretical or "expected" concentration and is the principal measure of analytical method performance. The expected concentration of a pesticide in a spiked sample is calculated as

$$
\text { Cexpected }=\text { Csolution } \times \text { Vsolution } / \text { Vsample }
$$

unspiked, environmental water sample. Recovery in field matrix spikes is calculated as follows:

$$
R=[(\text { Cspiked }- \text { Cunspiked }) / \text { Cexpected }] \times 100 \%
$$

where

$\begin{array}{rc}R & \begin{array}{c}\text { is pesticide recovery, in percent; } \\ \text { is the measured concentration of the pesticide } \\ \text { in the spiked sample, in micrograms (or } \\ \text { nanograms) per liter; }\end{array} \\ \text { is the measured concentration of the pesticide } \\ \text { in the unspiked sample, in micrograms (or } \\ \text { nanograms) per liter; and } \\ \text { is the expected concentration of the pesticide } \\ \text { in the spiked sample, in micrograms (or } \\ \text { nanograms) per liter. }\end{array}$

Nondetections of pesticides in the samples were assumed to be zero concentration for the calculation of recovery.

High background concentrations of pesticides resulted in invalid estimates of recovery for some matrix spikes. In the presence of high background concentrations, the additional concentration from spiking may be indistinguishable from the normal analytical variability of measurements at high concentrations. Recoveries calculated from matrix spikes under these conditions may be much higher or lower (even negative) than is typical for the method. Martin and others $(2009$, p. 6) determined that the incidence of very high or low recoveries for the GC-MS method was more common when background concentrations were more than 5 times the expected concentrations. On the basis of plots of recovery versus background concentration for the field study, a lower threshold for background concentration is used in this report. Calculated recoveries where background concentrations were greater than 3 times the expected concentration were flagged in the dataset and not selected for use in the analysis of recovery for the field study.

\section{Adjustment of Environmental Pesticide Concentrations for Recovery}

Large differences in analytical recovery between old and new methods could be a cause of differences in measured concentrations between methods. Comparisons of environmental concentrations between methods were made using both recovery-adjusted concentrations and the original (unadjusted) concentrations. Concentrations were adjusted using a similar procedure to that used in Martin and others (2009, p. 17), except that the median recovery, rather than the lowessmodeled recovery, was used to adjust concentrations. Lowessmodeled recovery was not done for the field study because the 3-month time frame was very short and the lowess model was very sensitive to the recoveries measured at the start and before the spike solution is added. These "background" concentrations are determined by analysis of the associated, 
end of the 3-month period. Concentrations were adjusted as follows:

$$
\text { Cadjusted }=(\text { Cmeasured } /[\text { Rmedian / 100] })
$$

where
Cadjusted
$\begin{gathered}\text { is the recovery-adjusted concentration of } \\ \text { the pesticide in the water sample, in } \\ \text { micrograms (or nanograms) per liter; } \\ \text { is the measured concentration of the pesticide } \\ \text { in the water sample, in micrograms (or } \\ \text { nanograms) per liter; and }\end{gathered}$
is the median recovery of field matrix spikes,
in percent (the medians reported in
appendixes 3 and 4$){ }^{3}$.

Censored concentrations (nondetections) at the routine reporting level were not adjusted for recovery. Censored concentrations at raised reporting levels were adjusted for recovery (Martin and others, 2009, p. 15-17).

\section{Pesticides Analyzed in the Field Study}

The three analytical schedules used in the field study provided data for 283 pesticides (table 5). Analytical data stored in NWIS and DWH are primarily managed by a 5 -digit numerical parameter code. Parameter codes for the common pesticides measured by sh2437 are different than those for sh2033 and sh2060 because the units of measurement are different for sh2437 (nanograms per liter) than for sh2033 or sh2060 (micrograms per liter). A variable (index) was created to facilitate management of data for pesticides with different parameter codes (table 5). Indexes 1-6 are pesticides common to all three schedules. Indexes 7-61 are pesticides common to $\operatorname{sh} 2437$ and sh2033 (61 common pesticides). Indexes 62-93 are pesticides common to sh2437 and sh2060 (38 common pesticides). Indexes $94-283$ are pesticides analyzed only by sh2437, sh2033, or sh2060 (table 5).

\section{Statistical Methods}

The UNIVARIATE procedure of SAS, version 8 (SAS Institute, Inc., 1990, p. 617-634) was used to calculate the mean, median, standard deviation (SD), relative standard deviation (RSD), percentiles, and other common descriptive statistics for the data in this report. S-PLUS, version 8.1.1 (Venables and Ripley, 1999) was used to produce boxplots (Tukey, 1977; Helsel and Hirsch, 1992, p. 24-25) of the

\footnotetext{
${ }^{3}$ The median recoveries reported in tables 9 and 11 are for paired matrix spikes analyzed by old and new methods and are slightly different than the medians for all matrix spikes.
}

distributions of recovery. Boxplots are explained in figure 2. The lowess procedure (Cleveland, 1979; Cleveland and McGill, 1985, p. 833), as implemented in S-PLUS, was used to show the relation between two variables in scatterplots. The lowess smoothing window used was a function of the number of data points in the plots: 1 for 4-25 points, 0.75 for 26-45 points, and 0.5 for more than 45 points. No lowess smooth was done for less than 4 points. S-PLUS was used to make all graphs in the report.

SAS was used to calculate one-sided, 90-percent upper confidence bounds for the percentage of duplicate sets with inconsistent detections (Hahn and Meeker, 1991, p. 104-105; Mueller and others, 2015, p. 32). Pooled estimates of SD and RSD were calculated using the procedure given in Anderson (1987, p. 44-45). SAS was used to calculate one-sided, 90-percent upper confidence bounds for the pooled estimates of SD and RSD (Hahn and Meeker, 1991, p. 55-56; Anderson, 1987, p. 47-50).

The NPAR1WAY procedure of SAS (SAS Institute, Inc., 1999 , p. 2,507-2,552) was used to calculate the Wilcoxon rank-sum test (Helsel and Hirsch, 1992, p. 118-121), which tests whether one group tends to produce larger values than the second group and was used to identify differences in median recovery between field matrix spikes and laboratory reagent spikes. The sign test (Helsel and Hirsch, 1992, p. 137-142) tests whether one group tends to produce larger values than the second group, but is used for paired samples. The sign test was used to determine if recovery in paired field matrix spikes analyzed by old and new methods was different. The sign test also was used to identify differences in pesticide detections and concentrations in paired environmental water samples analyzed by old and new methods. The UNIVARIATE procedure of SAS (SAS Institute, Inc., 1990, p. 629) was used to calculate the sign test.

Differences in variance of recovery between field matrix spikes and laboratory reagent spikes and between field matrix spikes analyzed by old and new methods were identified by Levene's test for equality of variance (Levene, 1960). Levene's test was done using the GLM procedure (SAS Institute, Inc., 1999, p. 1,553-1,554). The magnitude of differences in concentrations in paired environmental water samples analyzed by old and new methods was estimated by calculating the logical relative percent difference (Tornqvist and others, 1985). Differences in the percentages of field blank water samples with detections of pesticides analyzed by old and new methods were assessed using the method of Natrella (1963, p. 8-16).

A threshold of 5 percent (alpha $=0.05$ ) was used to identify statistically significant differences for the tests described above. 


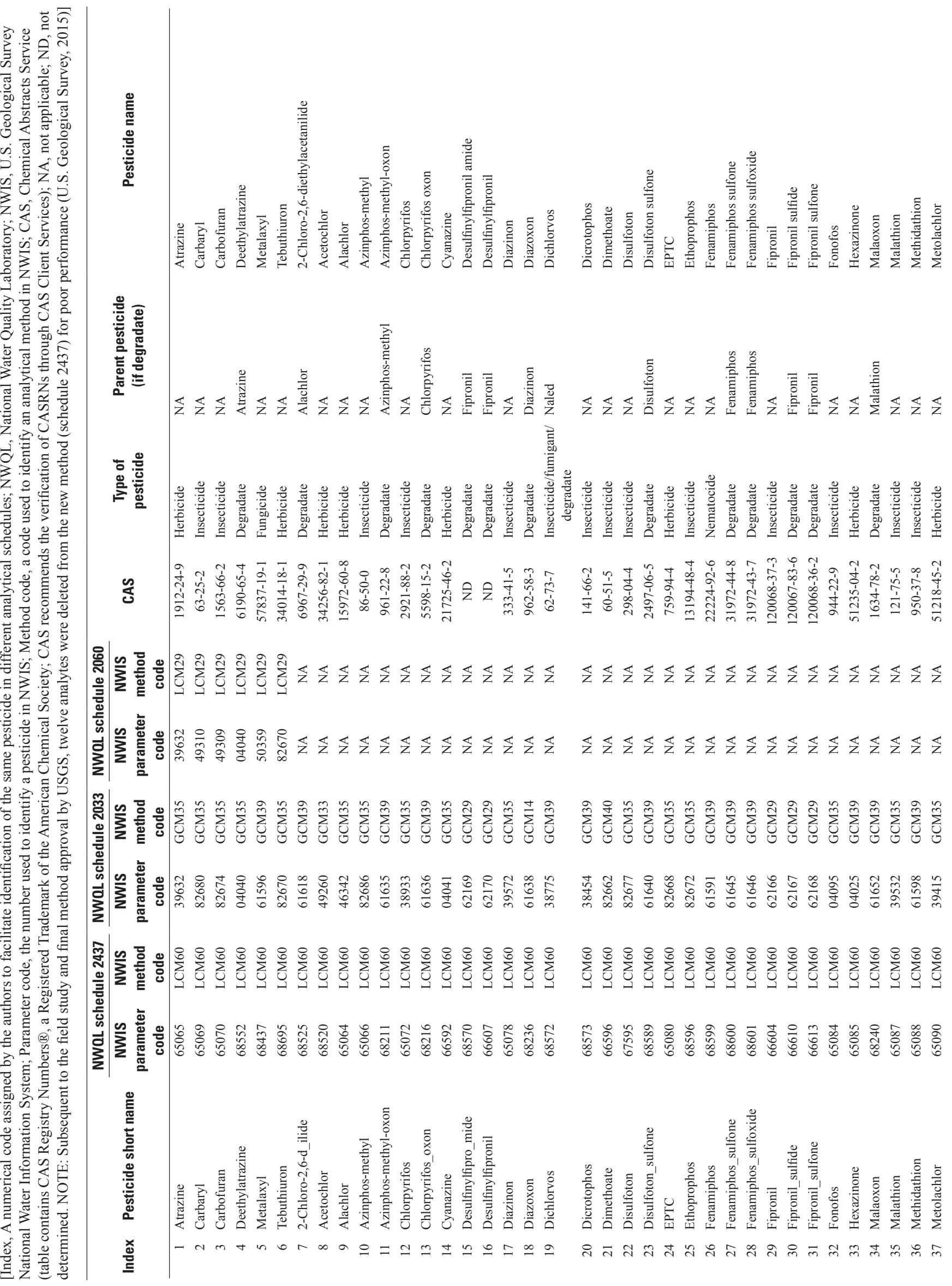



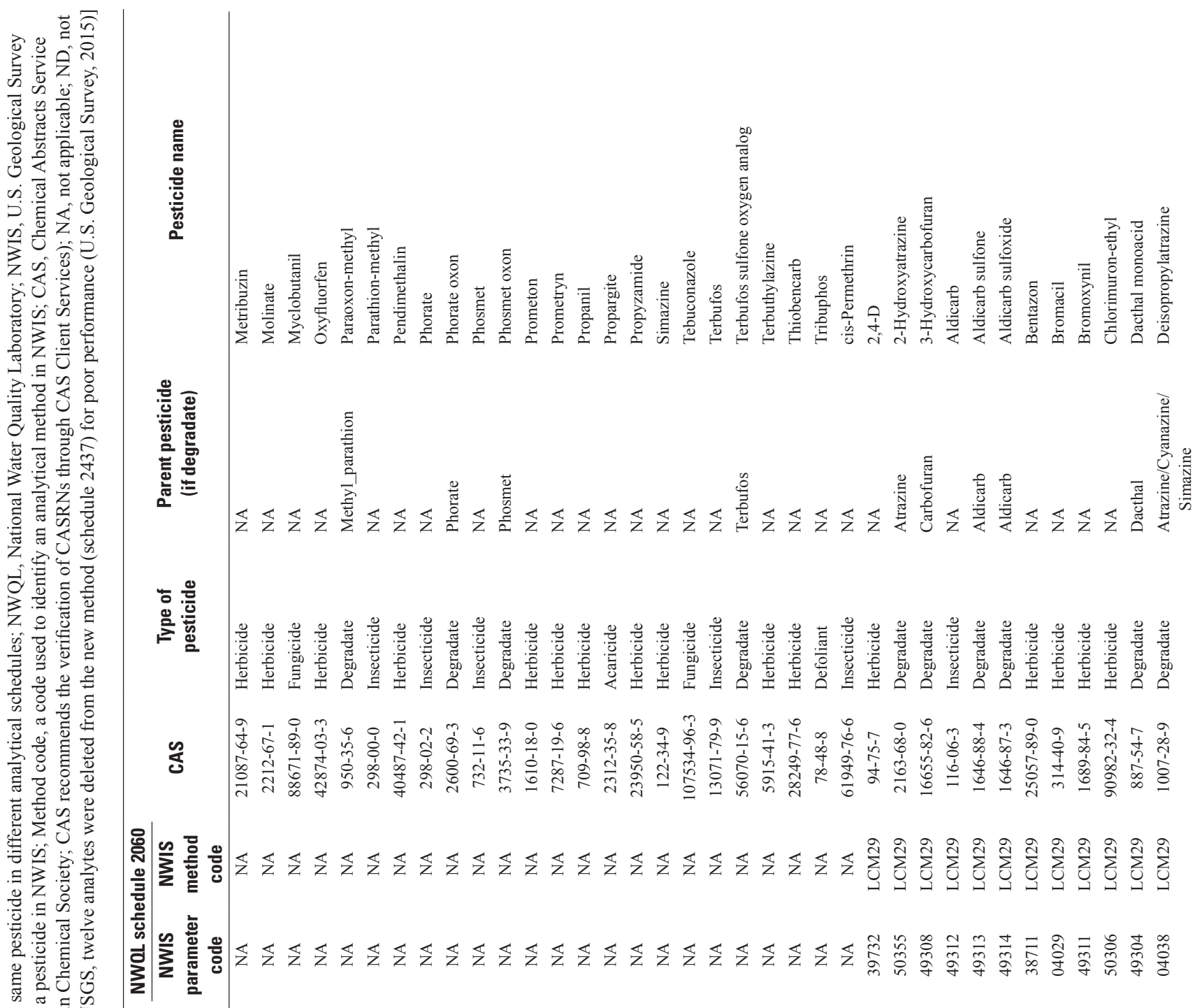

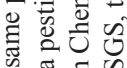

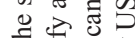

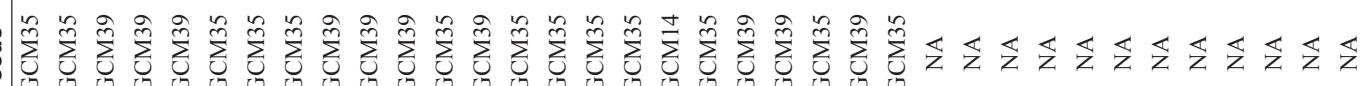




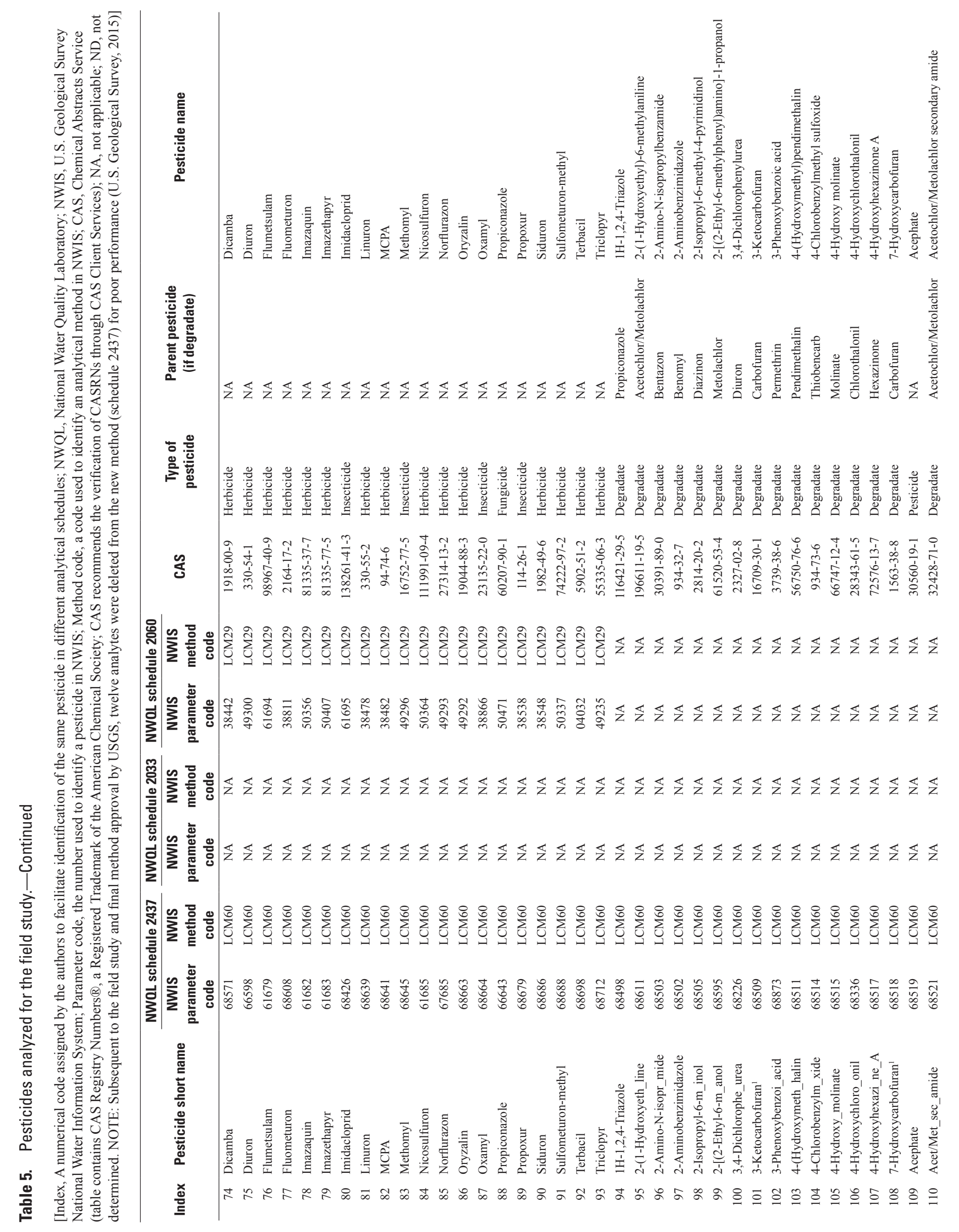



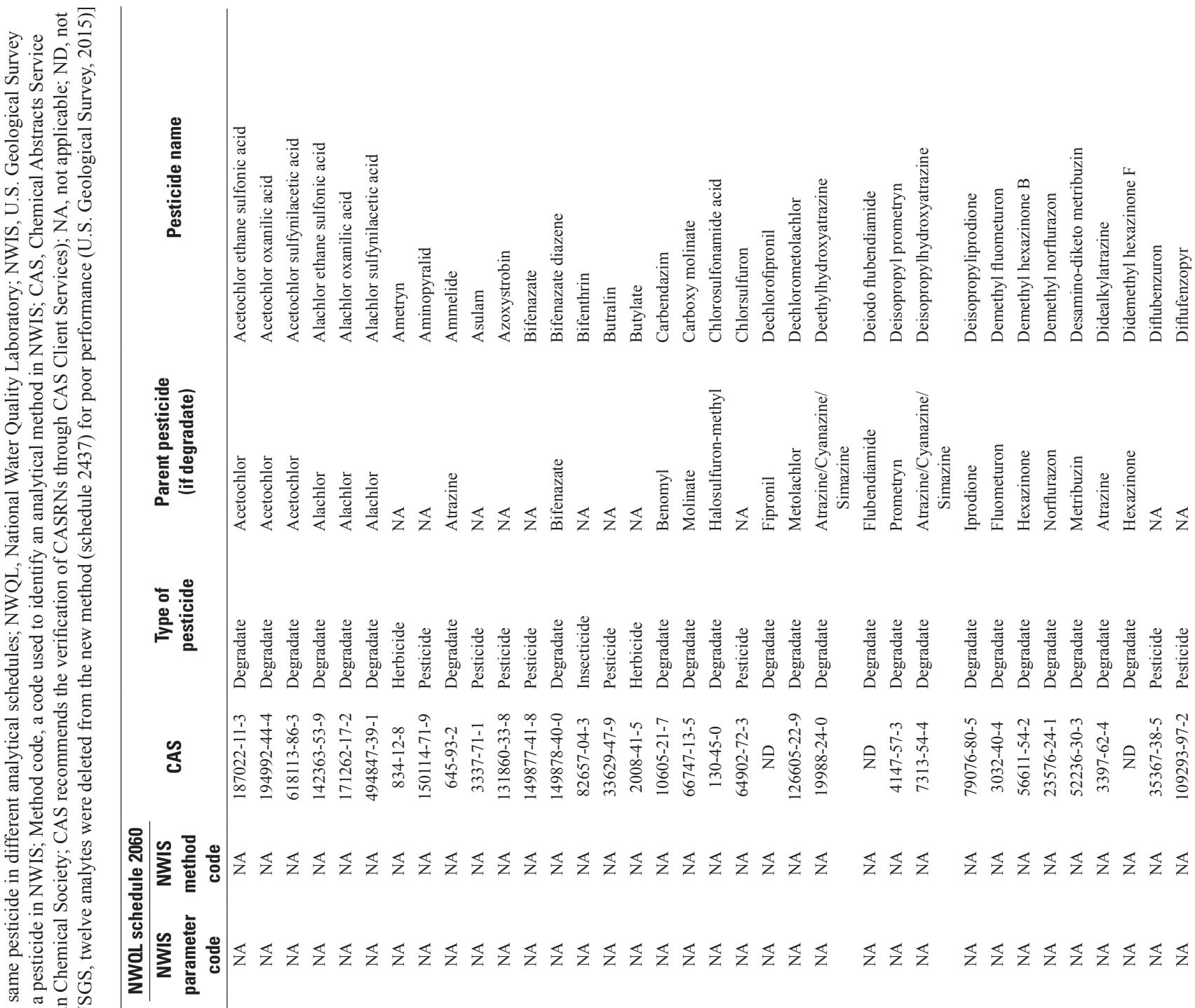

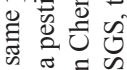

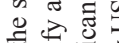

के

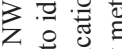

के

웡

过 of

苍远

䒕 ठ

苞焉出离

$\ddot{\theta} \ddot{\theta}$

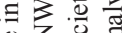

긍

용

坷主

氖总

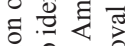

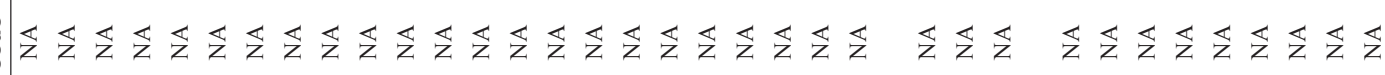

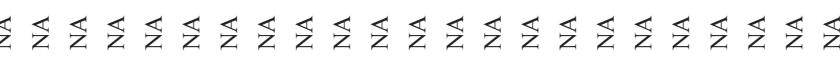

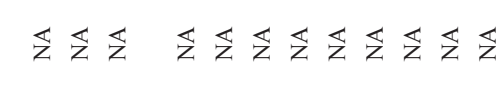




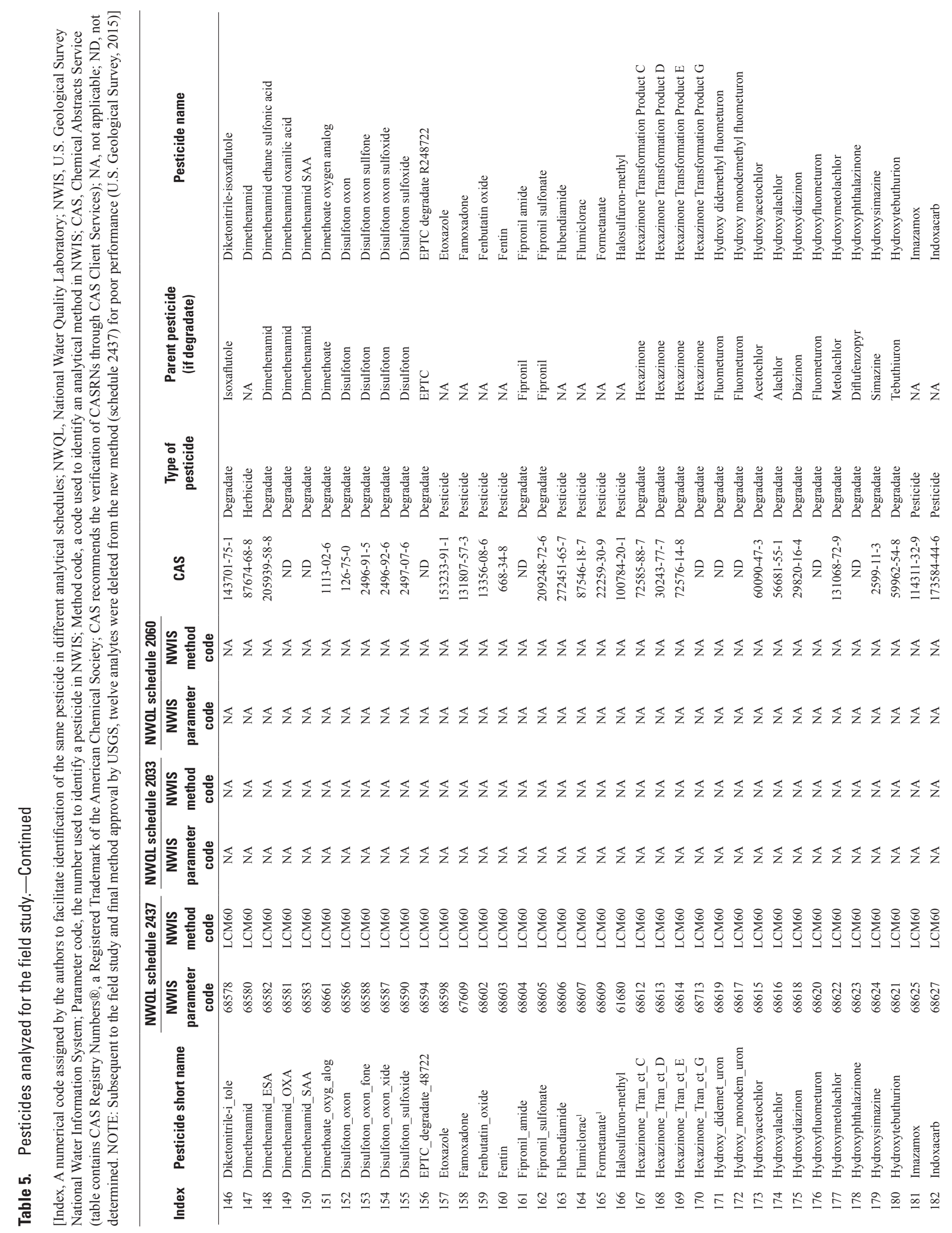



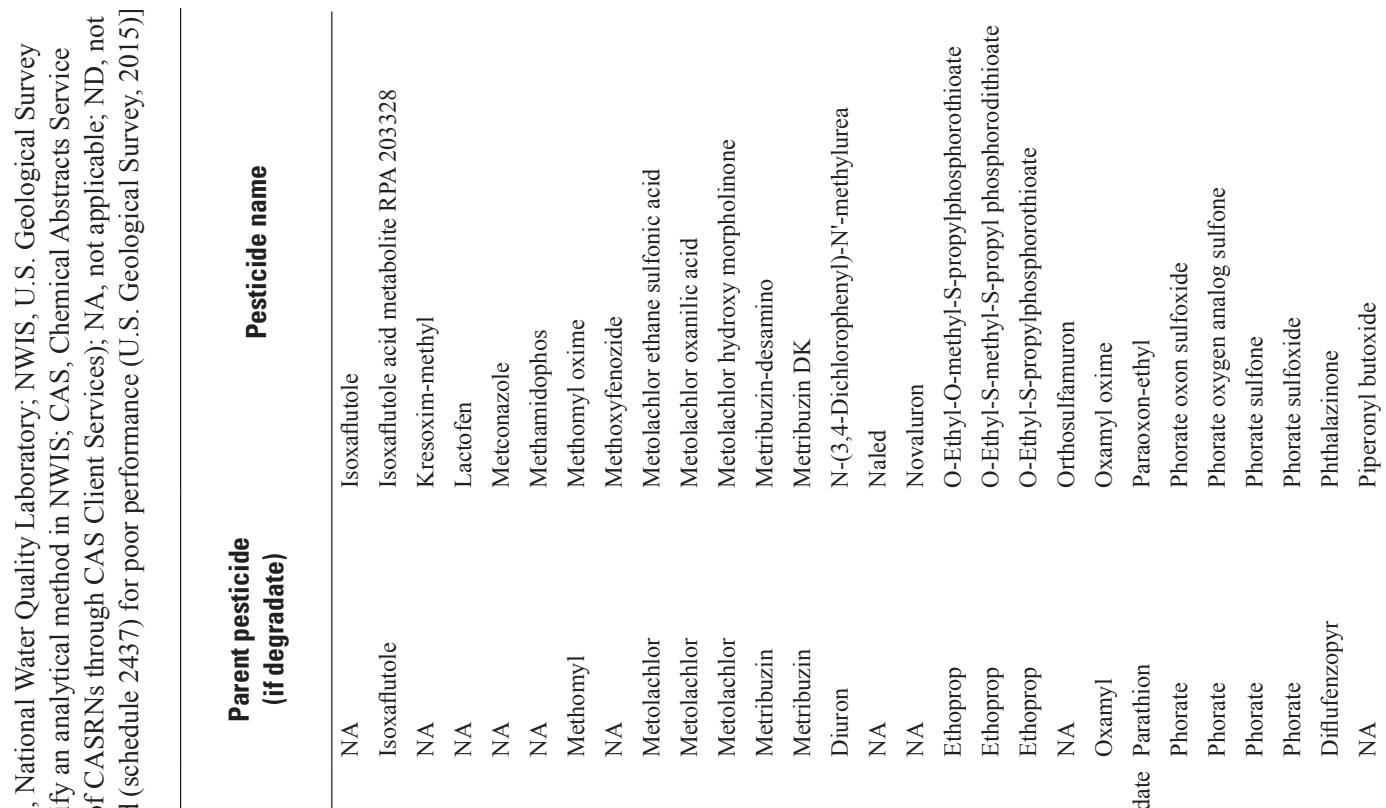

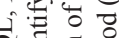

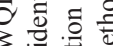

胥

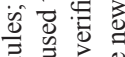

월

¿ 0 o

过艺

䒕 ठ

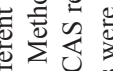

$\because \ddot{\theta}$

$\Xi 3 . \frac{0}{\pi}$

긍

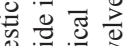

.

跑

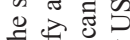

을

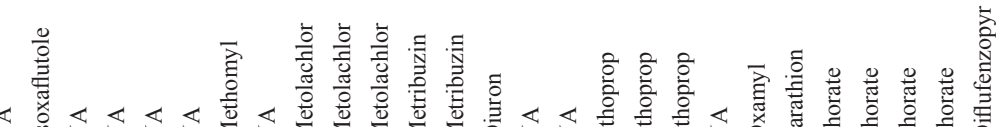

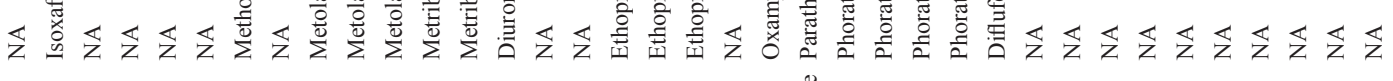
它蒂

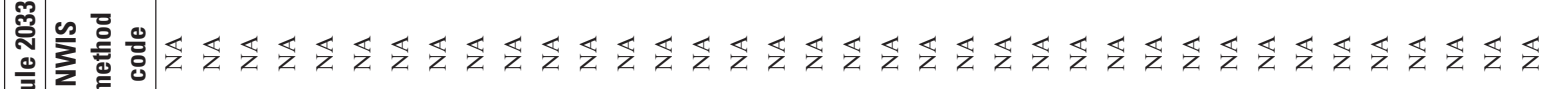

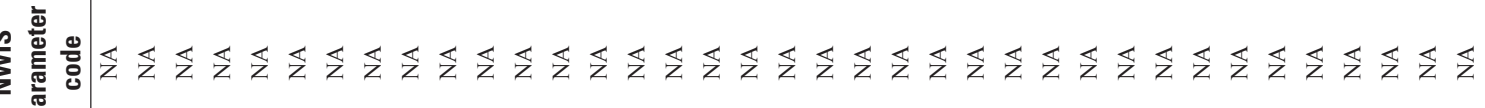

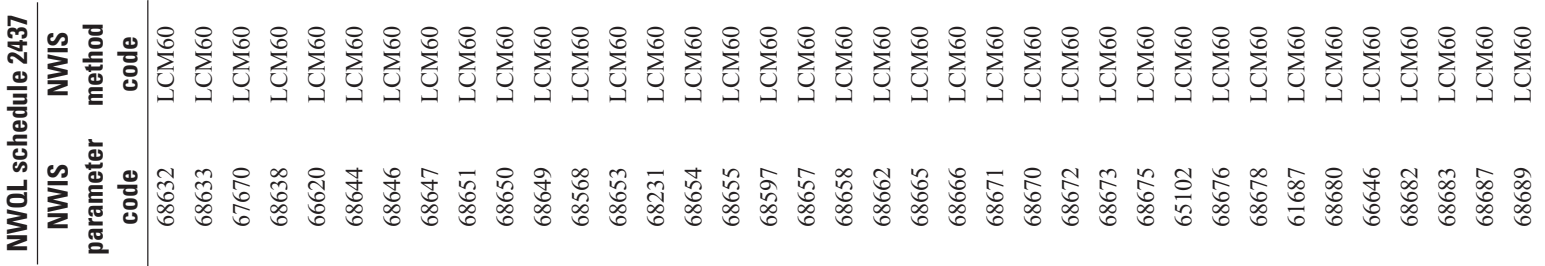



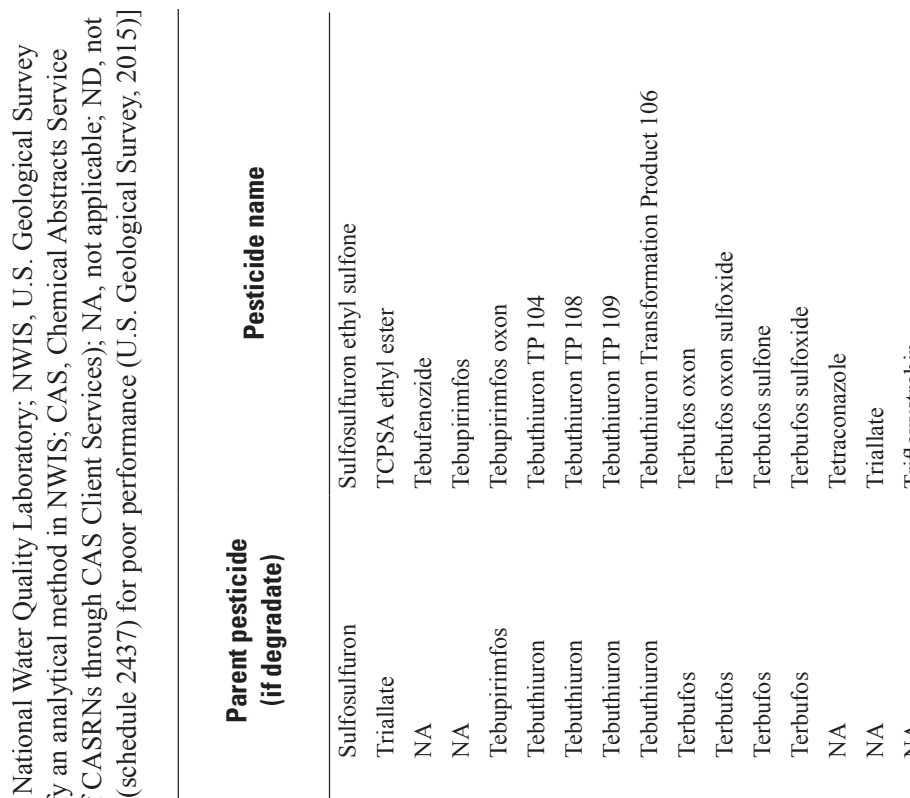

\section{$\frac{\dot{6}}{\frac{2}{2}}$}

$$
\begin{aligned}
& \text { ?: } \\
& \text { 暠 }
\end{aligned}
$$

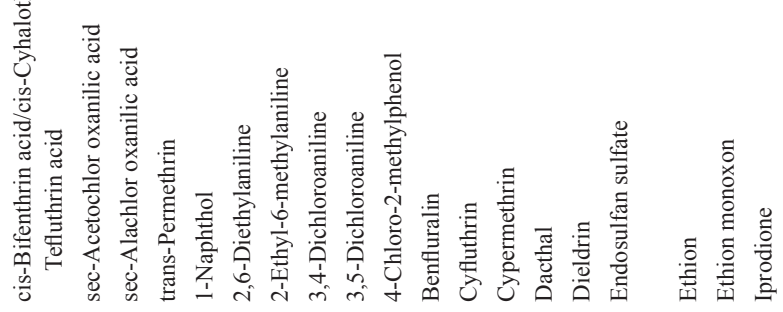

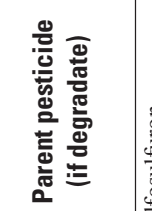

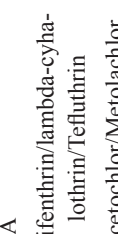

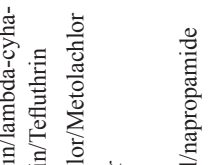

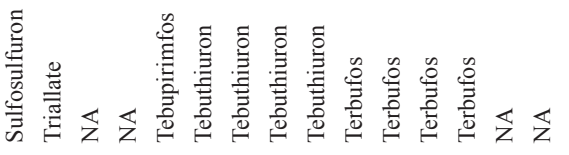

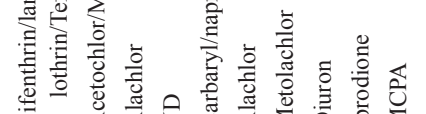

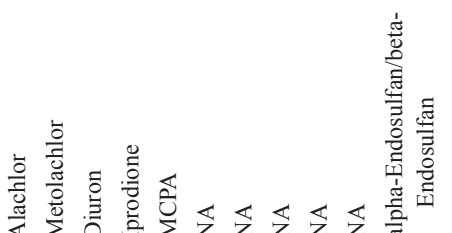

空

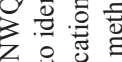

is 步

항

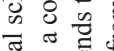

政

बे

ब

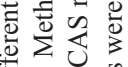

$\forall \ddot{y}$

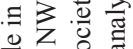

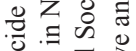

के बु $\frac{7}{0}$

.

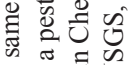

赵.

岁 흘

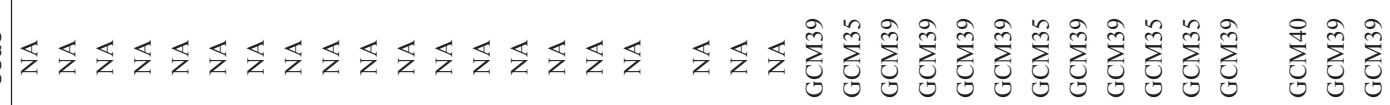

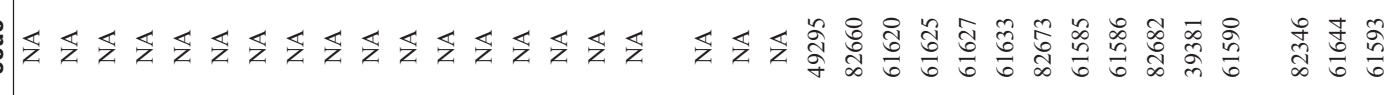

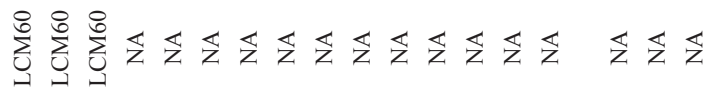



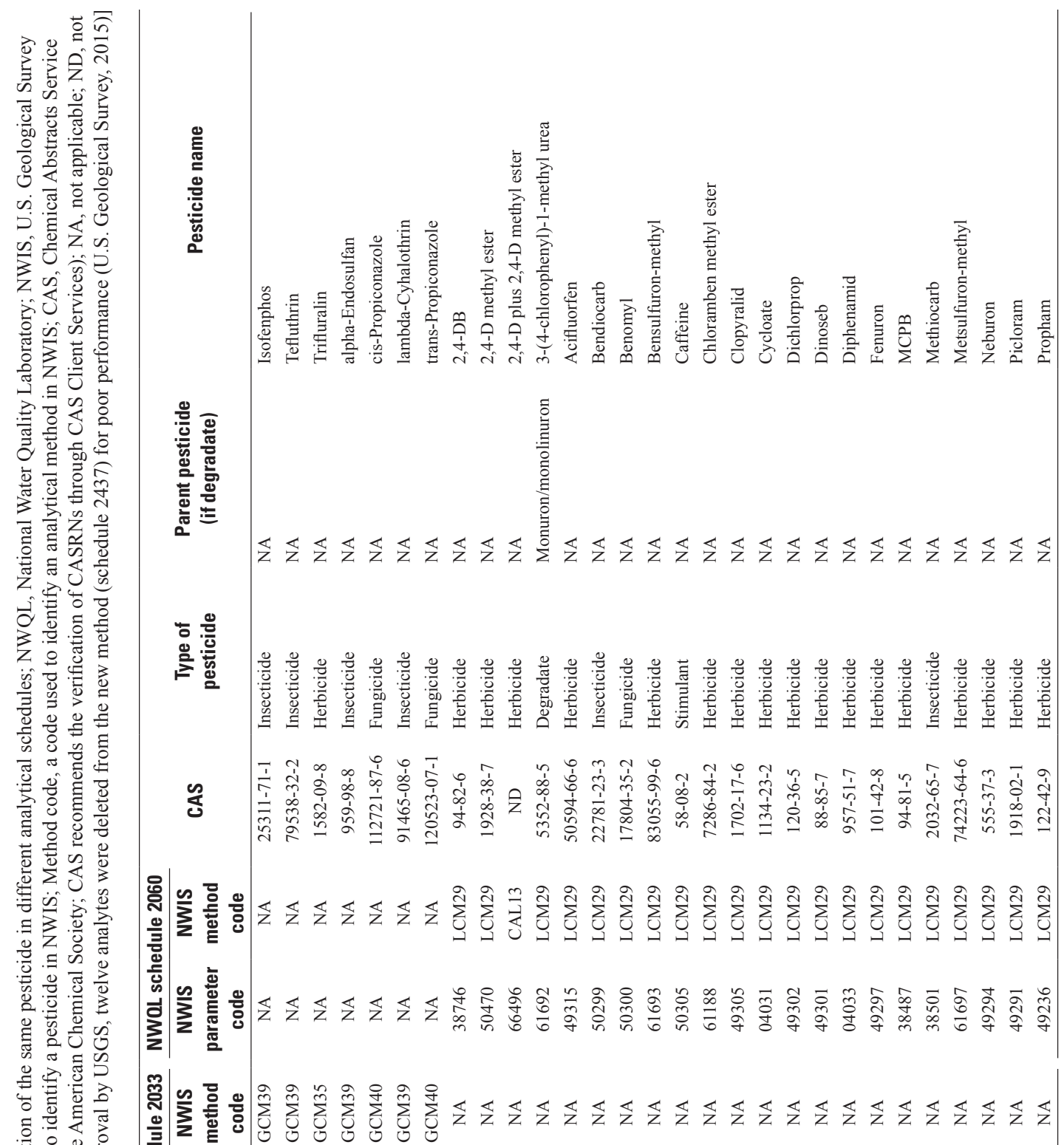

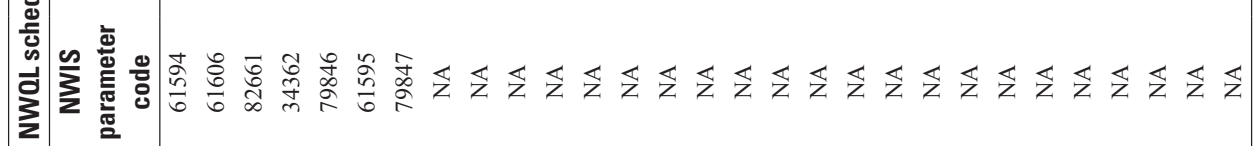

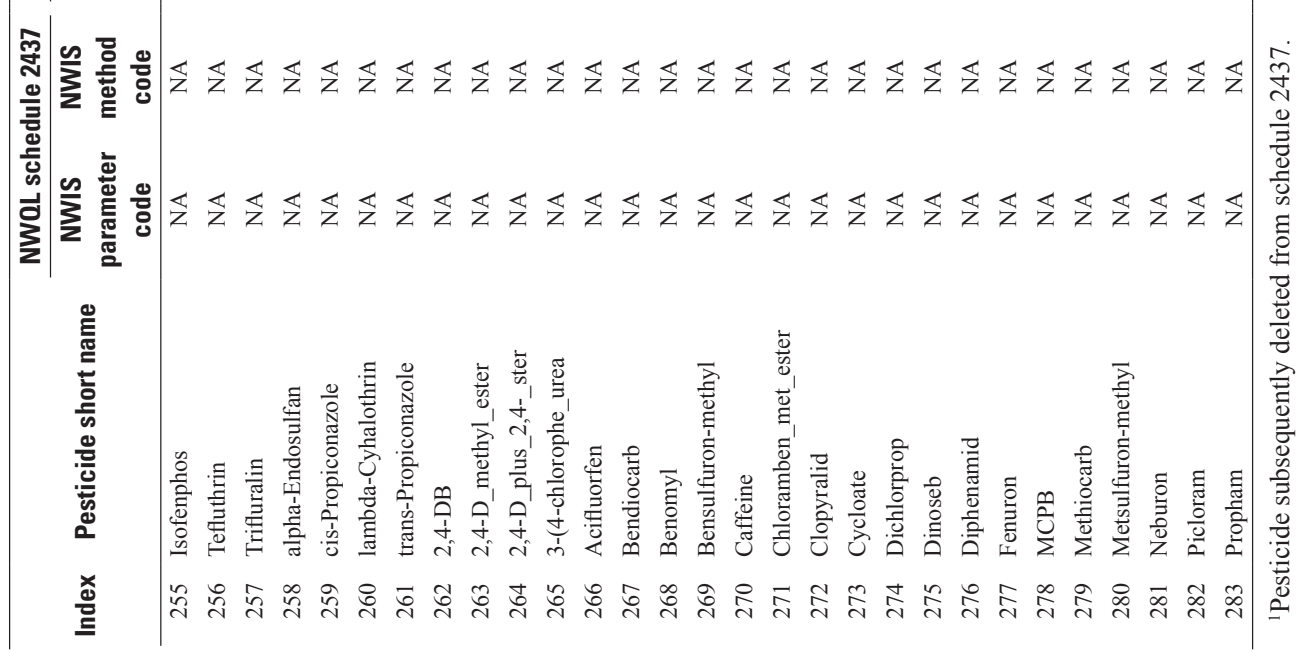




\section{Tables, Figures, and Datasets in Appendixes}

The large number of pesticides, analytical methods, and comparisons in this report provides challenges for presenting the information concisely in the text. Figures comparing recovery in field matrix spikes and laboratory reagent spikes; and comparing recovery, detections, or concentrations by pesticides analyzed by old and new analytical methods generated hundreds of pages of figures. For these figures, one example pesticide (atrazine) is provided in the text but all pesticides are shown in the figures in the appendixes. In general, pesticides in the figures and tables are presented by the index variable (table 5). In tables presenting statistical results, however, pesticides are sorted by the test statistic. Data files used to calculate recovery from analytical data, to compare recovery among methods, to compare detections and concentrations among methods, to calculate variability of detections and concentrations for sh2437, and to investigate matrix effects that might influence recovery are provided in (Martin and Baker, 2017).

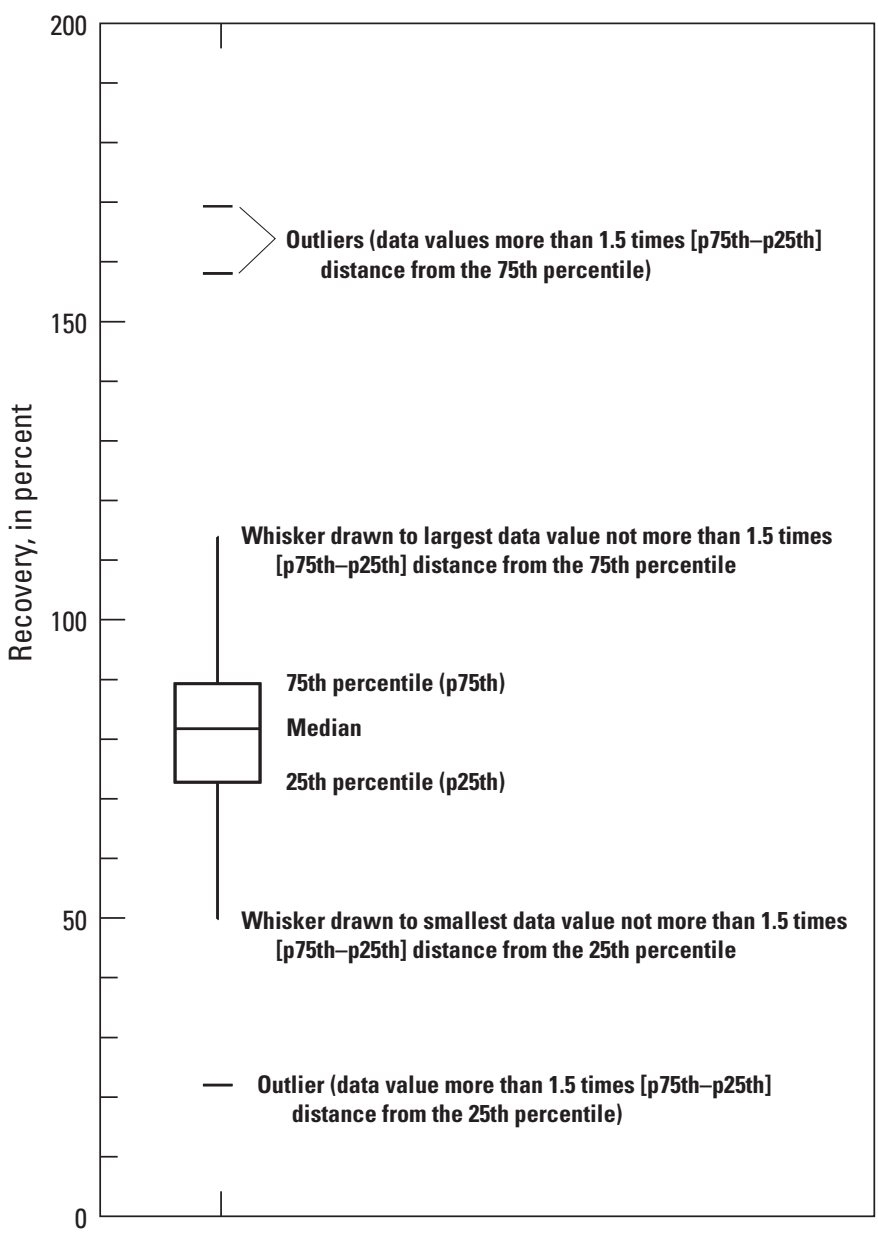

Figure 2. Explanation of a boxplot that is used to depict the distribution of recovery.

\section{Results and Discussion}

\section{Recovery of Pesticides Analyzed by Schedule 2437}

This section summarizes pesticide recovery in streamwater matrix spikes analyzed by sh2437, compares recovery in stream-water matrix spikes to recovery in laboratory reagent spikes, and presents a dataset for the analysis of matrix characteristics that might influence recovery.

\section{Stream-Water Matrix Spikes}

The median recoveries of pesticides in stream-water matrix spikes analyzed by sh 2437 ranged from 0 percent for 3-ketocarbofuran, ${ }^{4}$ ammelide, ${ }^{4}$ and phosmet_oxon ${ }^{4}$ to 209.6 percent for didealkylatrazine (table 6). The median recovery for 237 pesticides was 91.3 percent (there were no recovery data for acetochlor_ESA [index 111] or alachlor ESA [index 114]). Relative standard deviations of pesticide recovery in stream-water matrix spikes analyzed by sh 2437 ranged from 9.8 percent for hexazinone to 369.5 percent for ammelide $^{4}$ (RSD for phosmet_oxon ${ }^{4}$ [index 48] could not be calculated because the mean and standard deviation of recovery were 0 percent). The distributions of pesticide recovery in stream-water matrix spikes analyzed by sh2437 are shown in figure 3.

\section{Stream-Water Matrix Spikes versus Laboratory Reagent Spikes}

Pesticide recovery in stream-water matrix spikes was compared to recovery in laboratory reagent spikes in order to determine if recovery in laboratory reagent spikes would suitably characterize recovery in stream water. Laboratory reagent spikes typically are more numerous than field matrix spikes and if recovery is similar between the types of spikes, laboratory QC data could be used to characterize performance in stream water. Martin and others (2009, p. 10) observed that recovery in matrix spikes was much greater than in laboratory reagent spikes for most pesticides analyzed by GC-MS. The distributions of recovery in field matrix spikes compared to laboratory reagent spikes are shown in side-by-side boxplots for 237 pesticides in appendix 2 and for atrazine in figure 4. The laboratory reagent spikes are those that were analyzed during the same time period as the field matrix spikes for the field study. Analytical data and calculated recoveries for all background environmental pesticide concentrations and for all the associated field matrix spikes are provided in Martin and Baker (2017, dataset 1). Analytical data and calculated recoveries for background environmental pesticide concentrations and for the associated field matrix spikes that met the criteria

${ }^{4}$ These compounds were subsequently deleted from the method. 
Table 6. Recovery of pesticides in stream-water matrix spikes analyzed by schedule 2437 .

[Index, a numerical code assigned by the authors to facilitate identification of the same pesticide in different analytical schedules; nc, not calculated]

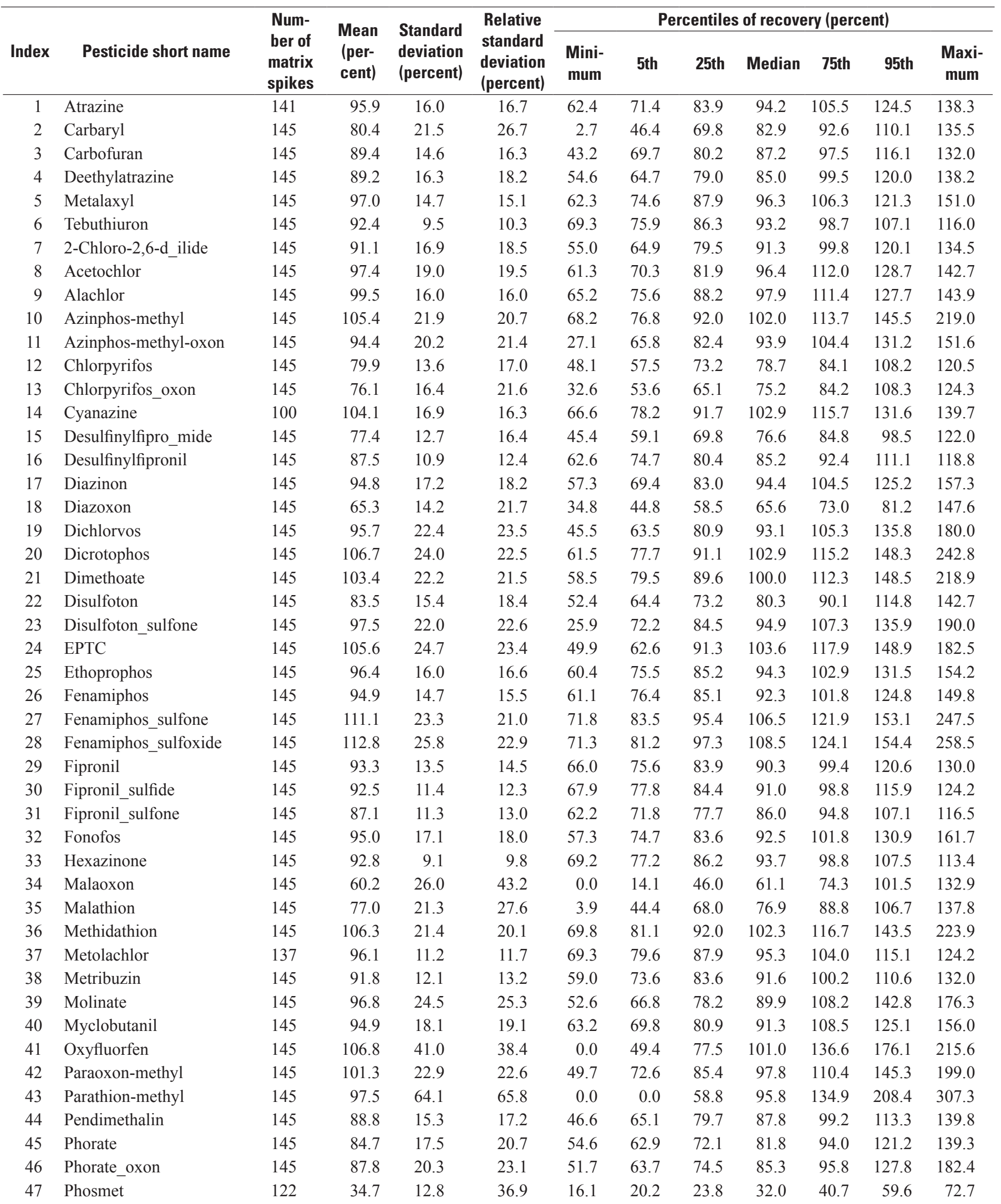


Table 6. Recovery of pesticides in stream-water matrix spikes analyzed by schedule 2437.-Continued

[Index, a numerical code assigned by the authors to facilitate identification of the same pesticide in different analytical schedules; nc, not calculated]

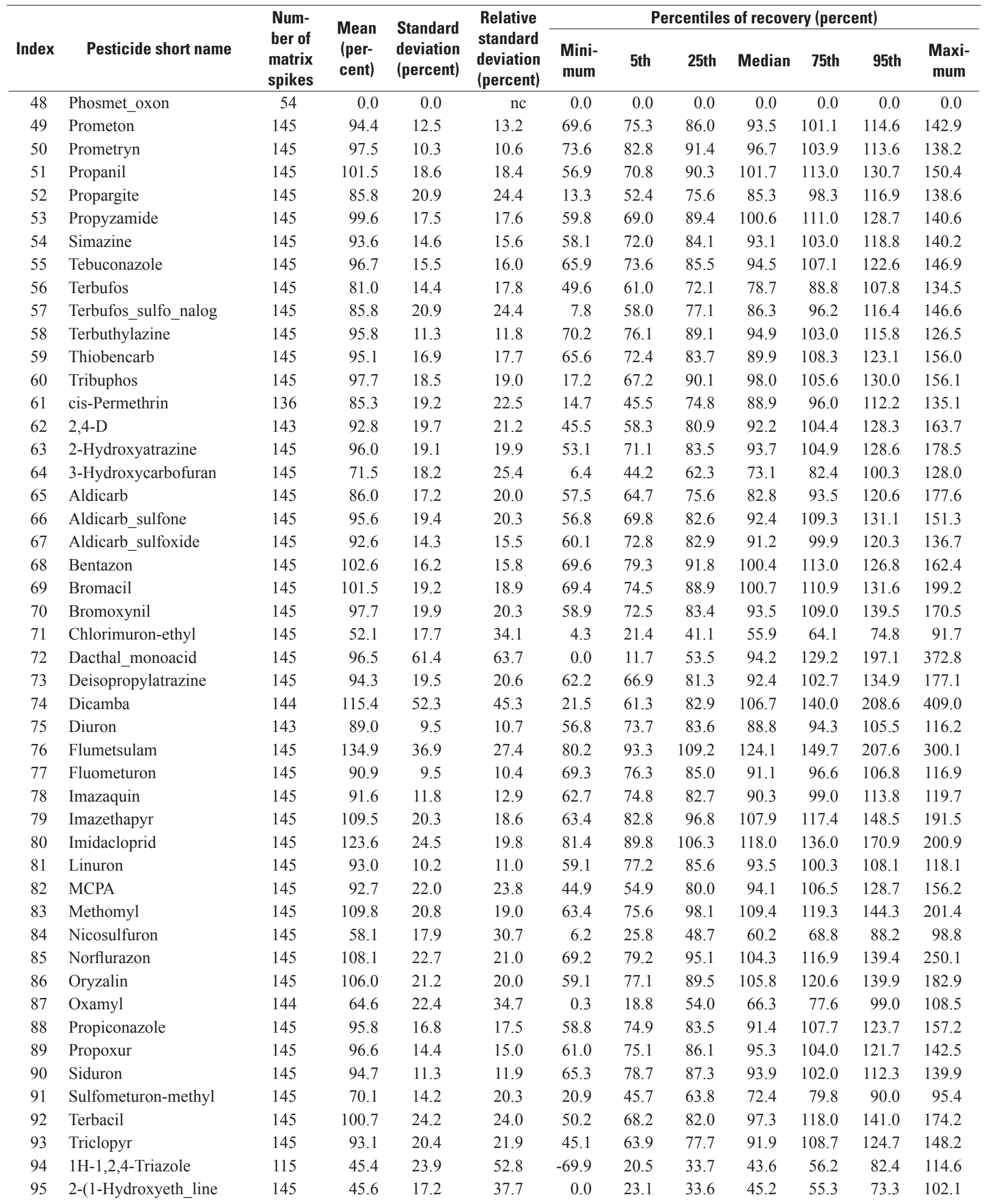


Table 6. Recovery of pesticides in stream-water matrix spikes analyzed by schedule 2437.-Continued

[Index, a numerical code assigned by the authors to facilitate identification of the same pesticide in different analytical schedules; nc, not calculated]

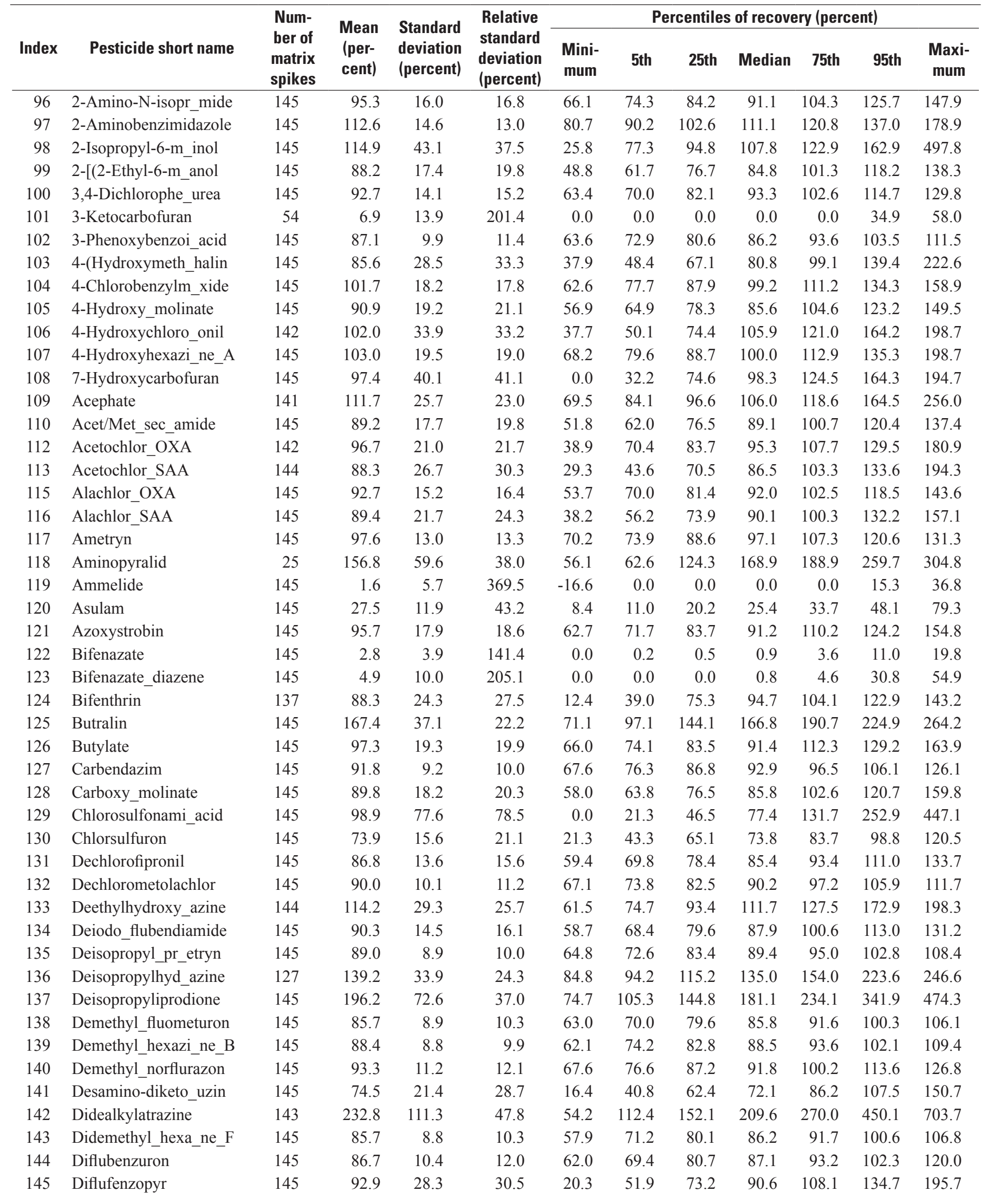


Table 6. Recovery of pesticides in stream-water matrix spikes analyzed by schedule 2437.-Continued

[Index, a numerical code assigned by the authors to facilitate identification of the same pesticide in different analytical schedules; nc, not calculated]

\begin{tabular}{|c|c|c|c|c|c|c|c|c|c|c|c|c|}
\hline \multirow[b]{2}{*}{ Index } & \multirow[b]{2}{*}{ Pesticide short name } & \multirow{2}{*}{$\begin{array}{l}\text { Num- } \\
\text { ber of } \\
\text { matrix } \\
\text { spikes }\end{array}$} & \multirow{2}{*}{$\begin{array}{c}\text { Mean } \\
\text { (per- } \\
\text { cent) }\end{array}$} & \multirow{2}{*}{$\begin{array}{l}\text { Standard } \\
\text { deviation } \\
\text { (percent) }\end{array}$} & \multirow{2}{*}{$\begin{array}{l}\text { Relative } \\
\text { standard } \\
\text { deviation } \\
\text { (percent) }\end{array}$} & \multicolumn{7}{|c|}{ Percentiles of recovery (percent) } \\
\hline & & & & & & $\begin{array}{l}\text { Mini- } \\
\text { mum }\end{array}$ & 5th & 25th & Median & 75th & 95th & $\begin{array}{c}\text { Maxi- } \\
\text { mum }\end{array}$ \\
\hline 147 & Dimethenamid & 143 & 100.2 & 17.5 & 17.5 & 62.0 & 71.4 & 88.7 & 100.4 & 111.9 & 130.8 & 145.3 \\
\hline 148 & Dimethenamid_ESA & 145 & 86.7 & 15.1 & 17.4 & 35.6 & 60.7 & 76.2 & 86.5 & 98.2 & 108.1 & 122.9 \\
\hline 151 & Dimethoate_oxyg_alog & 145 & 80.1 & 23.6 & 29.5 & 6.5 & 45.8 & 68.0 & 78.1 & 89.2 & 122.9 & 158.4 \\
\hline 152 & Disulfoton_oxon & 145 & 109.3 & 22.8 & 20.8 & 68.2 & 82.1 & 95.3 & 105.9 & 116.7 & 151.3 & 232.6 \\
\hline 153 & Disulfoton_oxon_fone & 145 & 83.9 & 21.7 & 25.9 & 5.9 & 53.3 & 74.6 & 83.7 & 94.3 & 110.7 & 154.5 \\
\hline 154 & Disulfoton_oxon_xide & 145 & 109.8 & 22.3 & 20.3 & 64.5 & 81.1 & 94.5 & 106.5 & 119.1 & 148.5 & 220.5 \\
\hline 155 & Disulfoton_sulfoxide & 145 & 115.3 & 24.2 & 21.0 & 76.0 & 86.8 & 99.7 & 110.3 & 125.1 & 155.1 & 241.8 \\
\hline 159 & Fenbutatin_oxide & 145 & 87.8 & 34.6 & 39.5 & 23.1 & 43.1 & 65.9 & 83.3 & 103.7 & 150.8 & 268.0 \\
\hline 160 & Fentin & 145 & 92.1 & 19.0 & 20.7 & 40.1 & 64.6 & 79.6 & 92.5 & 105.2 & 124.9 & 141.0 \\
\hline 161 & Fipronil_amide & 145 & 92.7 & 19.0 & 20.5 & 37.7 & 65.0 & 79.7 & 93.3 & 103.2 & 130.9 & 154.5 \\
\hline 162 & Fipronil_sulfonate & 145 & 109.3 & 33.4 & 30.6 & 45.4 & 60.6 & 86.2 & 104.6 & 132.4 & 166.1 & 232.3 \\
\hline 163 & Flubendiamide & 145 & 130.2 & 29.3 & 22.5 & 67.0 & 88.4 & 108.9 & 130.2 & 149.7 & 181.3 & 198.8 \\
\hline 164 & Flumiclorac & 54 & 3.4 & 5.1 & 148.5 & 0.0 & 0.0 & 1.0 & 1.2 & 2.8 & 18.5 & 19.8 \\
\hline 165 & Formetanate & 122 & 12.0 & 10.6 & 88.5 & 0.0 & 1.7 & 3.9 & 7.2 & 18.0 & 33.8 & 42.0 \\
\hline 166 & Halosulfuron-methyl & 145 & 63.4 & 14.0 & 22.0 & 18.3 & 40.5 & 55.2 & 66.5 & 72.7 & 82.6 & 89.0 \\
\hline 167 & Hexazinone_Tran_ct_C & 145 & 107.6 & 22.1 & 20.6 & 63.0 & 78.5 & 93.4 & 104.1 & 117.1 & 149.6 & 222.9 \\
\hline 168 & Hexazinone_Tran_ct_D & 145 & 98.6 & 33.8 & 34.3 & 24.1 & 54.7 & 76.5 & 92.2 & 116.4 & 158.7 & 200.1 \\
\hline 169 & Hexazinone_Tran_ct_E & 145 & 62.8 & 19.2 & 30.6 & 14.8 & 30.9 & 49.1 & 62.0 & 76.3 & 94.1 & 109.6 \\
\hline 176 & Hydroxyfluometuron & 145 & 49.5 & 25.2 & 50.9 & 1.8 & 8.1 & 31.8 & 52.0 & 67.8 & 89.6 & 99.0 \\
\hline 177 & Hydroxymetolachlor & 145 & 92.1 & 11.6 & 12.6 & 64.9 & 76.4 & 85.2 & 89.5 & 99.2 & 113.9 & 138.1 \\
\hline 178 & Hydroxyphthalazinone & 145 & 90.2 & 14.3 & 15.8 & 53.7 & 68.9 & 80.4 & 89.1 & 101.8 & 112.7 & 126.2 \\
\hline 179 & Hydroxysimazine & 145 & 109.2 & 15.8 & 14.4 & 70.0 & 84.1 & 99.2 & 107.6 & 118.3 & 133.5 & 160.6 \\
\hline 180 & Hydroxytebuthurion & 145 & 72.3 & 17.6 & 24.3 & 5.8 & 37.1 & 64.1 & 74.7 & 83.6 & 97.1 & 102.6 \\
\hline 181 & Imazamox & 145 & 107.8 & 18.3 & 16.9 & 57.1 & 83.9 & 96.3 & 105.2 & 119.6 & 142.3 & 163.5 \\
\hline 182 & Indoxacarb & 145 & 67.1 & 23.6 & 35.2 & 0.0 & 23.1 & 54.8 & 68.3 & 81.5 & 101.6 & 126.0 \\
\hline 183 & Isoxaflutole & 145 & 74.7 & 21.3 & 28.4 & 4.5 & 39.5 & 63.1 & 77.6 & 89.8 & 104.7 & 124.6 \\
\hline 184 & Isoxaflutole_ac_3328 & 145 & 96.9 & 15.4 & 15.9 & 65.8 & 76.7 & 87.0 & 92.9 & 106.3 & 125.0 & 146.7 \\
\hline 185 & Kresoxim-methyl & 145 & 78.0 & 19.5 & 25.0 & 12.8 & 55.8 & 66.4 & 77.3 & 93.2 & 107.8 & 122.6 \\
\hline 186 & Lactofen & 145 & 70.3 & 26.2 & 37.2 & 1.3 & 19.1 & 55.9 & 72.0 & 85.8 & 113.5 & 138.3 \\
\hline 187 & Metconazole & 145 & 95.8 & 15.0 & 15.6 & 63.4 & 75.4 & 85.5 & 92.1 & 107.0 & 121.5 & 154.7 \\
\hline 188 & Methamidophos & 144 & 109.9 & 22.3 & 20.3 & 69.1 & 83.4 & 95.7 & 105.8 & 117.5 & 154.4 & 224.3 \\
\hline 189 & Methomyl_oxime & 145 & 93.9 & 24.8 & 26.4 & 55.3 & 64.9 & 78.7 & 90.3 & 101.5 & 140.0 & 200.3 \\
\hline 190 & Methoxyfenozide & 145 & 100.5 & 20.4 & 20.3 & 61.6 & 71.6 & 85.0 & 97.9 & 117.4 & 135.4 & 159.8 \\
\hline 191 & Metolachlor_ESA & 136 & 88.7 & 25.9 & 29.2 & 0.8 & 46.8 & 76.2 & 89.2 & 101.4 & 130.5 & 165.6 \\
\hline 192 & Metolachlor_OXA & 137 & 94.1 & 22.8 & 24.2 & 29.0 & 55.9 & 77.5 & 94.2 & 110.0 & 133.7 & 162.0 \\
\hline 193 & Metolachlor_hyd_none & 145 & 91.9 & 18.9 & 20.6 & 56.6 & 66.7 & 78.7 & 89.0 & 102.9 & 127.4 & 160.7 \\
\hline
\end{tabular}


Table 6. Recovery of pesticides in stream-water matrix spikes analyzed by schedule 2437.-Continued

[Index, a numerical code assigned by the authors to facilitate identification of the same pesticide in different analytical schedules; nc, not calculated]

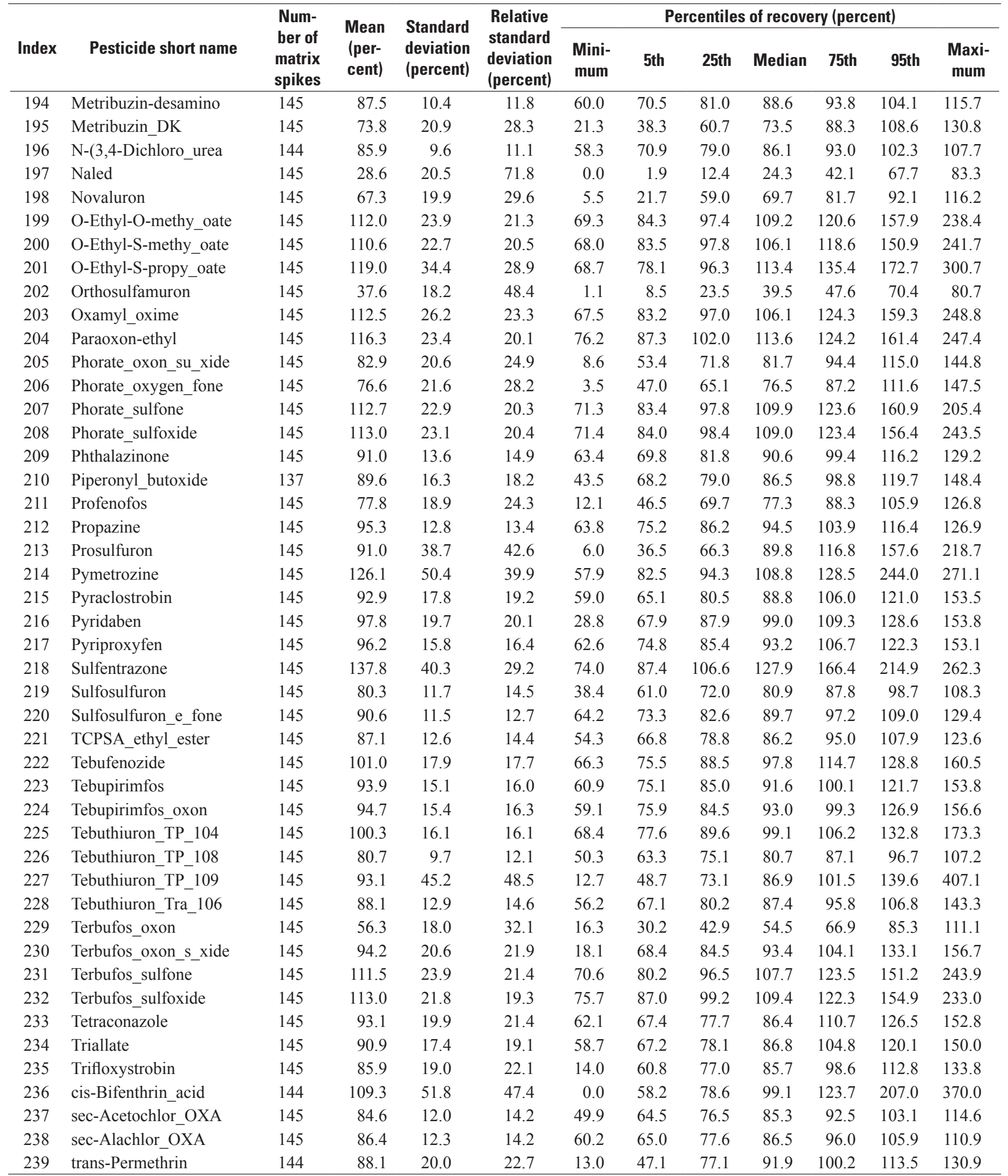



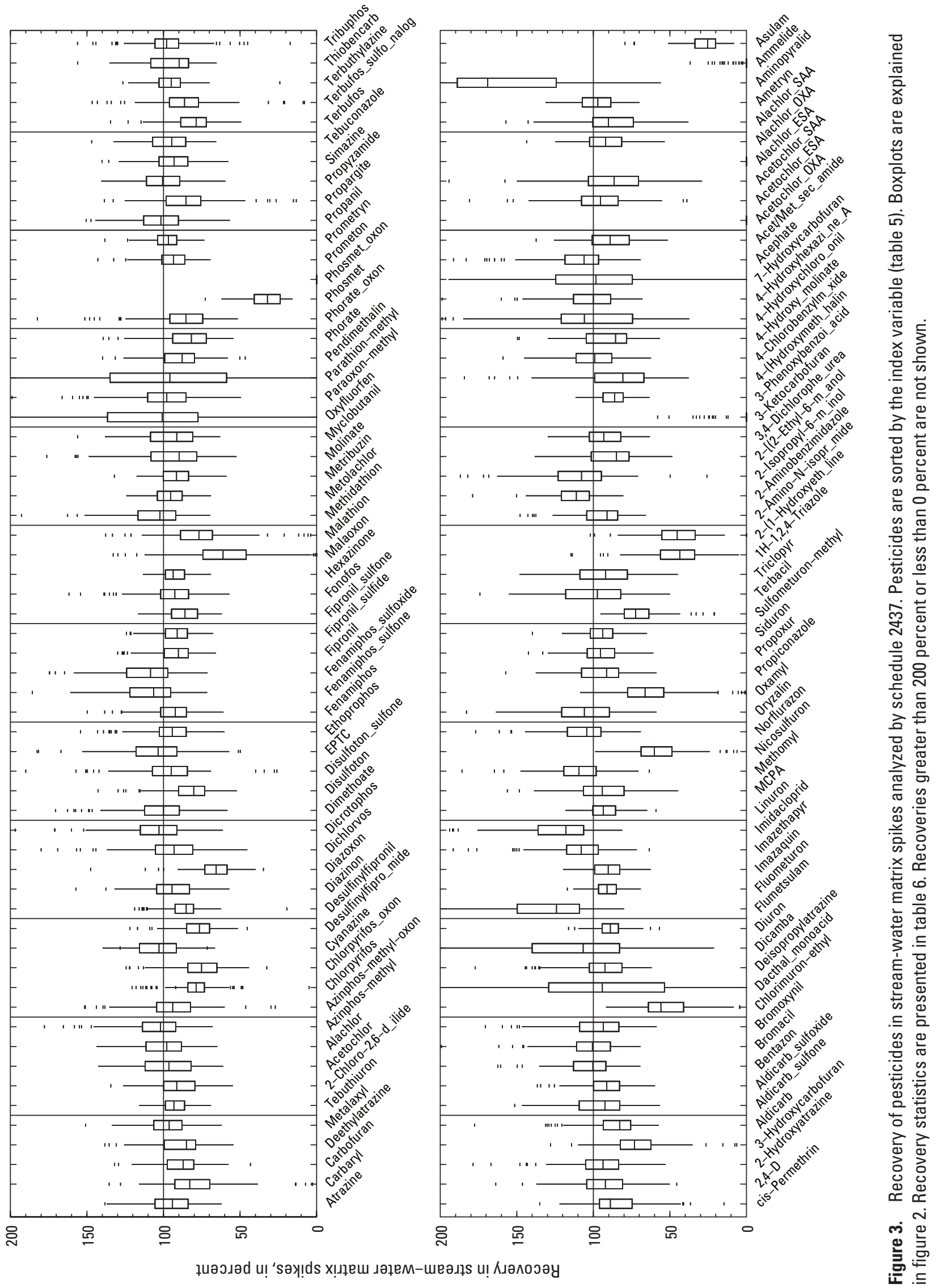


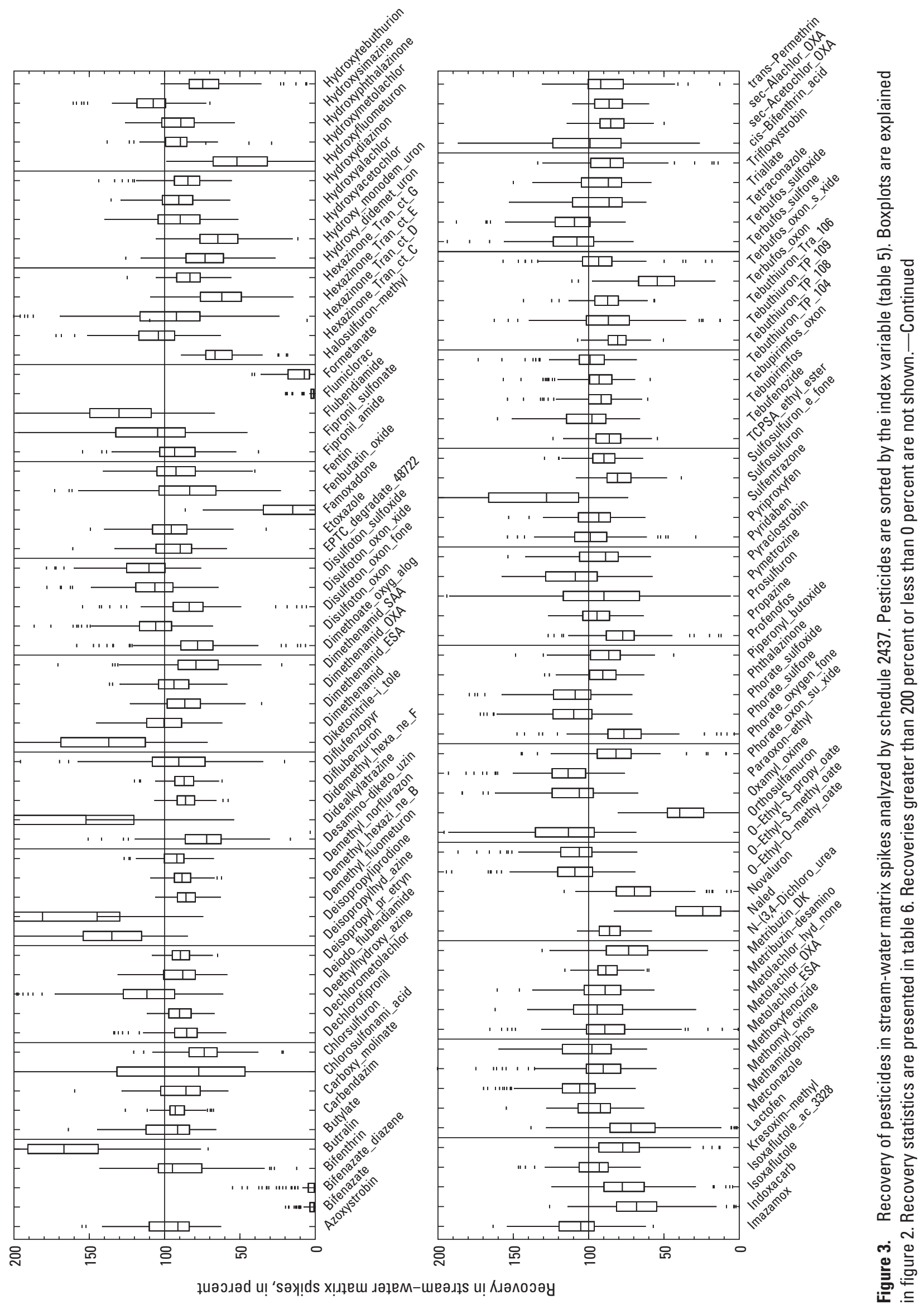




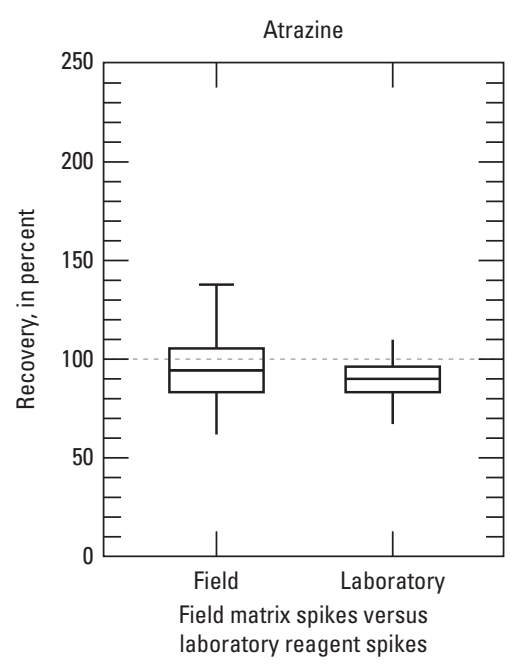

Figure 4. Distribution of recovery of atrazine in field matrix spikes and laboratory reagent spikes analyzed by the new analytical method (schedule 2437).

for use in this assessment are provided in Martin and Baker (2017, dataset 2). The metadata for Martin and Baker (2017, dataset 1) explains the wide variety of reasons why samples or results were not selected for use in the field study. Measurements of recovery in laboratory reagent spikes (and field matrix spikes selected for use in the assessment) are provided in Martin and Baker (2017, dataset 3).

The Wilcoxon rank-sum test was used to compare the median recovery of pesticides in field matrix spikes and laboratory reagent spikes. Of the 237 pesticides tested, median recovery was significantly greater in field matrix spikes for 50 pesticides and was significantly greater in laboratory reagent spikes for 58 pesticides (table 7). Although statistically significant, the difference in median recovery for 62 of the 108 pesticides was less than 15 percent. Levene's test was used to compare the variability of recovery of pesticides in field matrix spikes and laboratory reagent spikes. Of the 237 pesticides tested, recovery was significantly more variable in field matrix spikes for 30 pesticides and was significantly more variable in laboratory reagent spikes for 22 pesticides (table 8). On the basis of both of these test results, it is evident that field matrix spikes are preferable to laboratory reagent spikes for characterizing the performance of sh2437 in streamwater samples for many of the pesticides measured.

\section{Stream-Water Matrix Characteristics that Influence Recovery}

Analysis of the matrix characteristics that might influence recovery requires sophisticated regression analyses and model building that are beyond the scope of this report. Analytical water-quality data for the environmental stream-water matrix (for example, $\mathrm{pH}$, specific conductance, organic carbon, and so forth) and the pesticide recovery in the associated field matrix spikes are provided in Martin and Baker, 2017, dataset 4 to support future work on matrix effects.

\section{Comparisons of Pesticides Analyzed by Old and New Methods}

This section compares median values and variability of pesticide recovery in stream-water matrix spikes analyzed by old and new methods, compares pesticide detections and concentrations in paired environmental stream-water samples analyzed by old and new methods, and compares detections in field blank water samples analyzed by old and new methods. Analytical data for paired environmental concentrations, for background environmental pesticide concentrations, and for concentrations and recovery in the associated field matrix spikes are provided in Martin and Baker (2017, datasets 5 and 6).

\section{Recovery in Stream-Water Matrix Spikes}

The distributions of recovery in field matrix spikes analyzed by sh 2033 and sh 2437 for the 61 pesticides common to both methods are shown in side-by-side boxplots in figure 5 . These same data are shown by study unit, station number, and site visit sequence number in appendix 3 and for atrazine in figure 6 . The sign test was used to determine if recovery in paired field matrix spikes analyzed by sh2033 and sh2437 were statistically different. Of the 61 pesticides common to both schedules, recovery was significantly greater in samples analyzed by sh 2033 for 44 pesticides and was significantly greater in samples analyzed by sh 2437 for 12 pesticides (table 9). Median recovery was closer to 100 percent for 17 pesticides analyzed by sh 2033 and for 43 pesticides analyzed by sh2437.

Levene's test was used to compare the variability of recovery of pesticides analyzed by sh2033 and sh2437. Recovery was significantly more variable in spikes analyzed by sh2033 for 16 pesticides and was significantly more variable in spikes analyzed by sh2437 for 21 pesticides (table 10).

The distributions of recovery in field matrix spikes analyzed by sh2060 and sh 2437 for the 38 pesticides common to both methods are shown in side-by-side boxplots in figure 7. Recovery also is shown by study unit, station number, and site visit sequence number in appendix 4 and for atrazine in figure 8. Of the 38 pesticides common to both schedules, recovery was significantly greater in samples analyzed by sh2060 for 12 pesticides and was significantly greater in samples analyzed by sh2437 for 18 pesticides (table 11). Median recovery was closer to 100 percent for 17 pesticides analyzed by sh2060 and for 21 pesticides analyzed by sh2437. Recovery was significantly more variable in spikes analyzed by sh2060 for 12 pesticides and was significantly more variable in spikes analyzed by sh 2437 for 18 pesticides (table 12). 
Table 7. Comparison of median recovery of pesticides in stream-water matrix spikes and laboratory reagent-water spikes analyzed by schedule 2437.

[Pesticides are sorted by the test statistic. Probablity values less than 0.05 are shown in bold; $<$, less than]

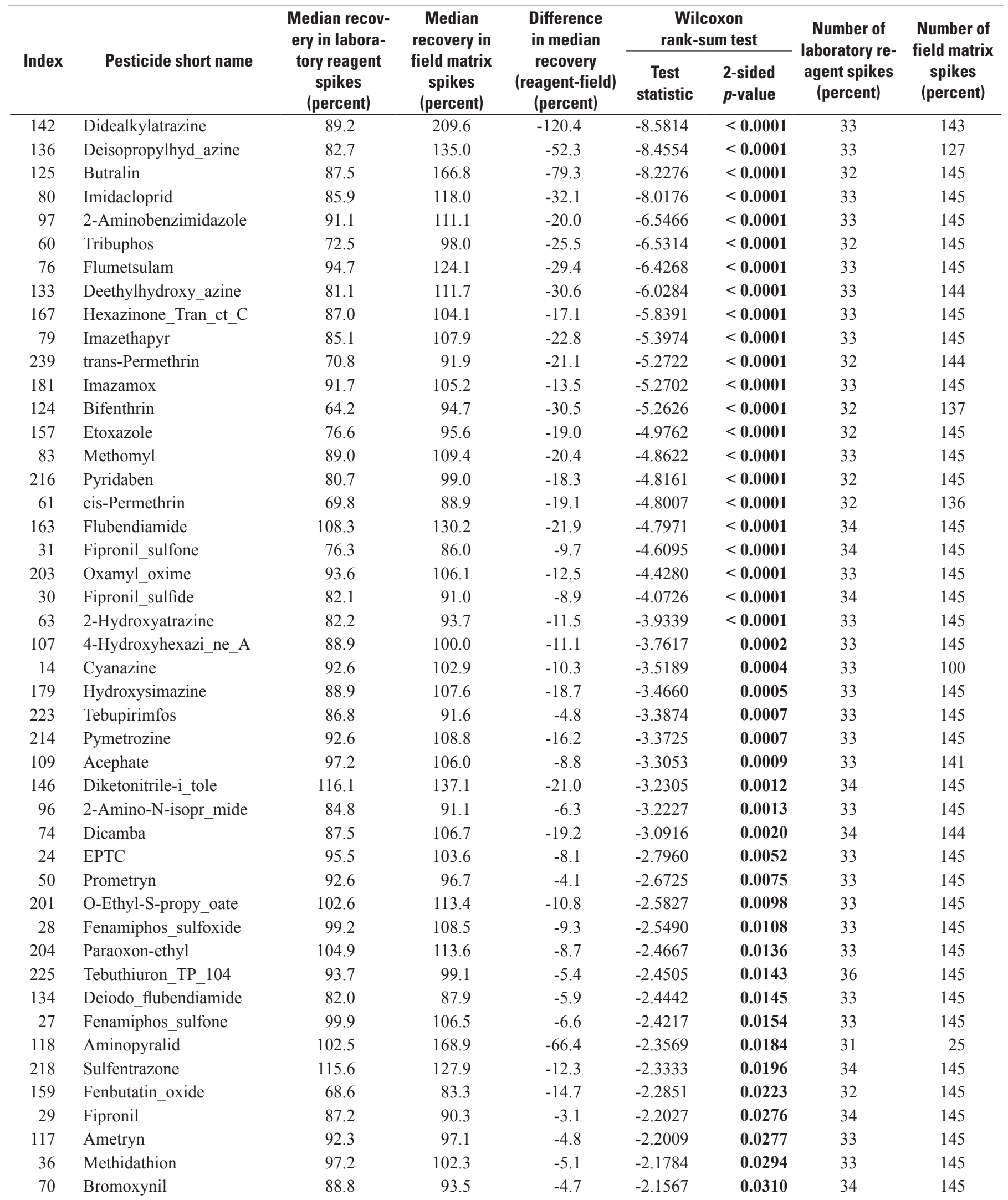


Table 7. Comparison of median recovery of pesticides in stream-water matrix spikes and laboratory reagent-water spikes analyzed by schedule 2437.-Continued

[Pesticides are sorted by the test statistic. Probablity values less than 0.05 are shown in bold; $<$, less than]

\begin{tabular}{|c|c|c|c|c|c|c|c|c|}
\hline \multirow[b]{2}{*}{ Index } & \multirow[b]{2}{*}{ Pesticide short name } & \multirow{2}{*}{$\begin{array}{l}\text { Median recov- } \\
\text { ery in labora- } \\
\text { tory reagent } \\
\text { spikes } \\
\text { (percent) }\end{array}$} & \multirow{2}{*}{$\begin{array}{l}\text { Median } \\
\text { recovery in } \\
\text { field matrix } \\
\text { spikes } \\
\text { (percent) }\end{array}$} & \multirow{2}{*}{$\begin{array}{c}\text { Difference } \\
\text { in median } \\
\text { recovery } \\
\text { (reagent-field) } \\
\text { (percent) }\end{array}$} & \multicolumn{2}{|c|}{$\begin{array}{l}\text { Wilcoxon } \\
\text { rank-sum test }\end{array}$} & \multirow{2}{*}{$\begin{array}{l}\text { Number of } \\
\text { laboratory re- } \\
\text { agent spikes } \\
\text { (percent) }\end{array}$} & \multirow{2}{*}{$\begin{array}{l}\text { Number of } \\
\text { field matrix } \\
\text { spikes } \\
\text { (percent) }\end{array}$} \\
\hline & & & & & $\begin{array}{c}\text { Test } \\
\text { statistic }\end{array}$ & $\begin{array}{l}2 \text {-sided } \\
p \text {-value }\end{array}$ & & \\
\hline 17 & Diazinon & 86.4 & 94.4 & -8.0 & -2.1560 & 0.0311 & 33 & 145 \\
\hline 162 & Fipronil_sulfonate & 95.4 & 104.6 & -9.2 & -2.0317 & 0.0422 & 34 & 145 \\
\hline 52 & Propargite & 81.1 & 85.3 & -4.2 & -1.9840 & 0.0473 & 32 & 145 \\
\hline 232 & Terbufos_sulfoxide & 103.4 & 109.4 & -6.0 & -1.8940 & 0.0582 & 33 & 145 \\
\hline 155 & Disulfoton_sulfoxide & 102.9 & 110.3 & -7.4 & -1.8790 & 0.0602 & 33 & 145 \\
\hline 82 & MCPA & 85.4 & 94.1 & -8.7 & -1.8736 & 0.0610 & 34 & 145 \\
\hline 199 & O-Ethyl-O-methy_oate & 103.2 & 109.2 & -6.0 & -1.8603 & 0.0628 & 33 & 145 \\
\hline 53 & Propyzamide & 94.9 & 100.6 & -5.7 & -1.8491 & 0.0644 & 33 & 145 \\
\hline 154 & Disulfoton_oxon_xide & 100.9 & 106.5 & -5.6 & -1.7480 & 0.0805 & 33 & 145 \\
\hline 58 & Terbuthylazine & 91.6 & 94.9 & -3.3 & -1.7255 & 0.0844 & 33 & 145 \\
\hline 126 & Butylate & 89.3 & 91.4 & -2.1 & -1.7068 & 0.0879 & 33 & 145 \\
\hline 208 & Phorate_sulfoxide & 104.9 & 109.0 & -4.1 & -1.6881 & 0.0914 & 33 & 145 \\
\hline 73 & Deisopropylatrazine & 86.9 & 92.4 & -5.5 & -1.6844 & 0.0921 & 33 & 145 \\
\hline 212 & Propazine & 91.8 & 94.5 & -2.7 & -1.6582 & 0.0973 & 33 & 145 \\
\hline 207 & Phorate_sulfone & 103.8 & 109.9 & -6.1 & -1.6282 & 0.1035 & 33 & 145 \\
\hline 1 & Atrazine & 90.3 & 94.2 & -3.9 & -1.5855 & 0.1129 & 33 & 141 \\
\hline 68 & Bentazon & 97.2 & 100.4 & -3.2 & -1.5647 & 0.1177 & 34 & 145 \\
\hline 41 & Oxyfluorfen & 86.3 & 101.0 & -14.7 & -1.4770 & 0.1397 & 32 & 145 \\
\hline 67 & Aldicarb_sulfoxide & 88.9 & 91.2 & -2.3 & -1.1491 & 0.2505 & 33 & 145 \\
\hline 127 & Carbendazim & 92.5 & 92.9 & -0.4 & -1.0593 & 0.2895 & 33 & 145 \\
\hline 100 & 3,4-Dichlorophe_urea & 88.0 & 93.3 & -5.3 & -1.0406 & 0.2981 & 33 & 145 \\
\hline 147 & Dimethenamid & 97.7 & 100.4 & -2.7 & -0.9779 & 0.3281 & 33 & 143 \\
\hline 224 & Tebupirimfos_oxon & 90.9 & 93.0 & -2.1 & -0.9769 & 0.3286 & 33 & 145 \\
\hline 25 & Ethoprophos & 94.1 & 94.3 & -0.2 & -0.9545 & 0.3398 & 33 & 145 \\
\hline 51 & Propanil & 96.5 & 101.7 & -5.2 & -0.9545 & 0.3398 & 33 & 145 \\
\hline 10 & Azinphos-methyl & 100.7 & 102.0 & -1.3 & -0.9395 & 0.3475 & 33 & 145 \\
\hline 106 & 4-Hydroxychloro_onil & 98.2 & 105.9 & -7.7 & -0.9350 & 0.3498 & 34 & 142 \\
\hline 8 & Acetochlor & 94.6 & 96.4 & -1.8 & -0.9096 & 0.3631 & 33 & 145 \\
\hline 152 & Disulfoton_oxon & 104.4 & 105.9 & -1.5 & -0.8983 & 0.3690 & 33 & 145 \\
\hline 131 & Dechlorofipronil & 85.0 & 85.4 & -0.4 & -0.8623 & 0.3885 & 34 & 145 \\
\hline 149 & Dimethenamid_OXA & 89.0 & 93.9 & -4.9 & -0.7704 & 0.4411 & 34 & 145 \\
\hline 32 & Fonofos & 89.8 & 92.5 & -2.7 & -0.7336 & 0.4632 & 33 & 145 \\
\hline 69 & Bromacil & 98.1 & 100.7 & -2.6 & -0.7149 & 0.4747 & 33 & 145 \\
\hline 135 & Deisopropyl_pr_etryn & 87.7 & 89.4 & -1.7 & -0.7112 & 0.4770 & 33 & 145 \\
\hline 192 & Metolachlor_OXA & 94.2 & 94.2 & 0.0 & -0.7024 & 0.4824 & 34 & 137 \\
\hline
\end{tabular}


Table 7. Comparison of median recovery of pesticides in stream-water matrix spikes and laboratory reagent-water spikes analyzed by schedule 2437.-Continued

[Pesticides are sorted by the test statistic. Probablity values less than 0.05 are shown in bold; $<$, less than]

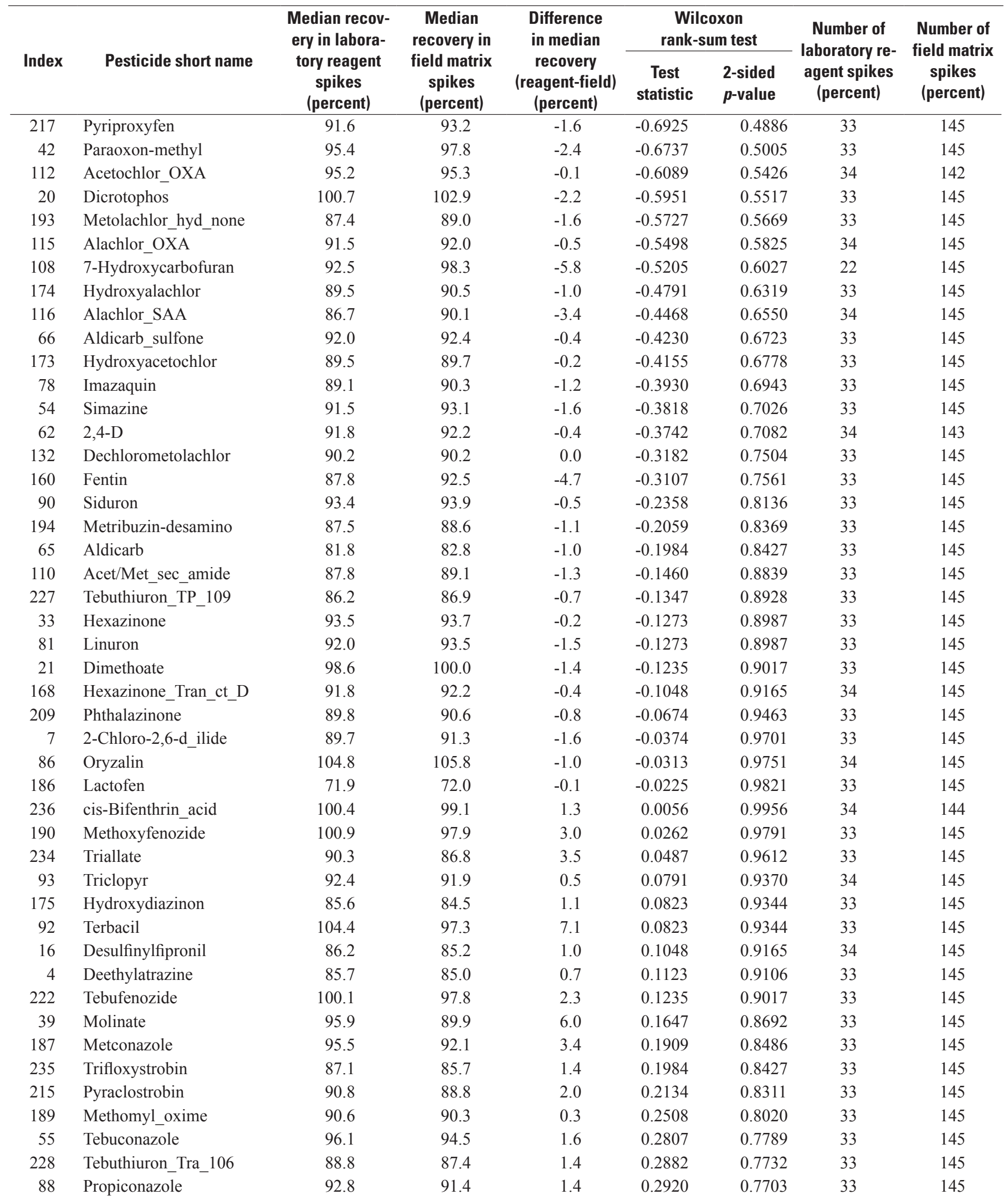


Table 7. Comparison of median recovery of pesticides in stream-water matrix spikes and laboratory reagent-water spikes analyzed by schedule 2437.-Continued

[Pesticides are sorted by the test statistic. Probablity values less than 0.05 are shown in bold; $<$, less than]

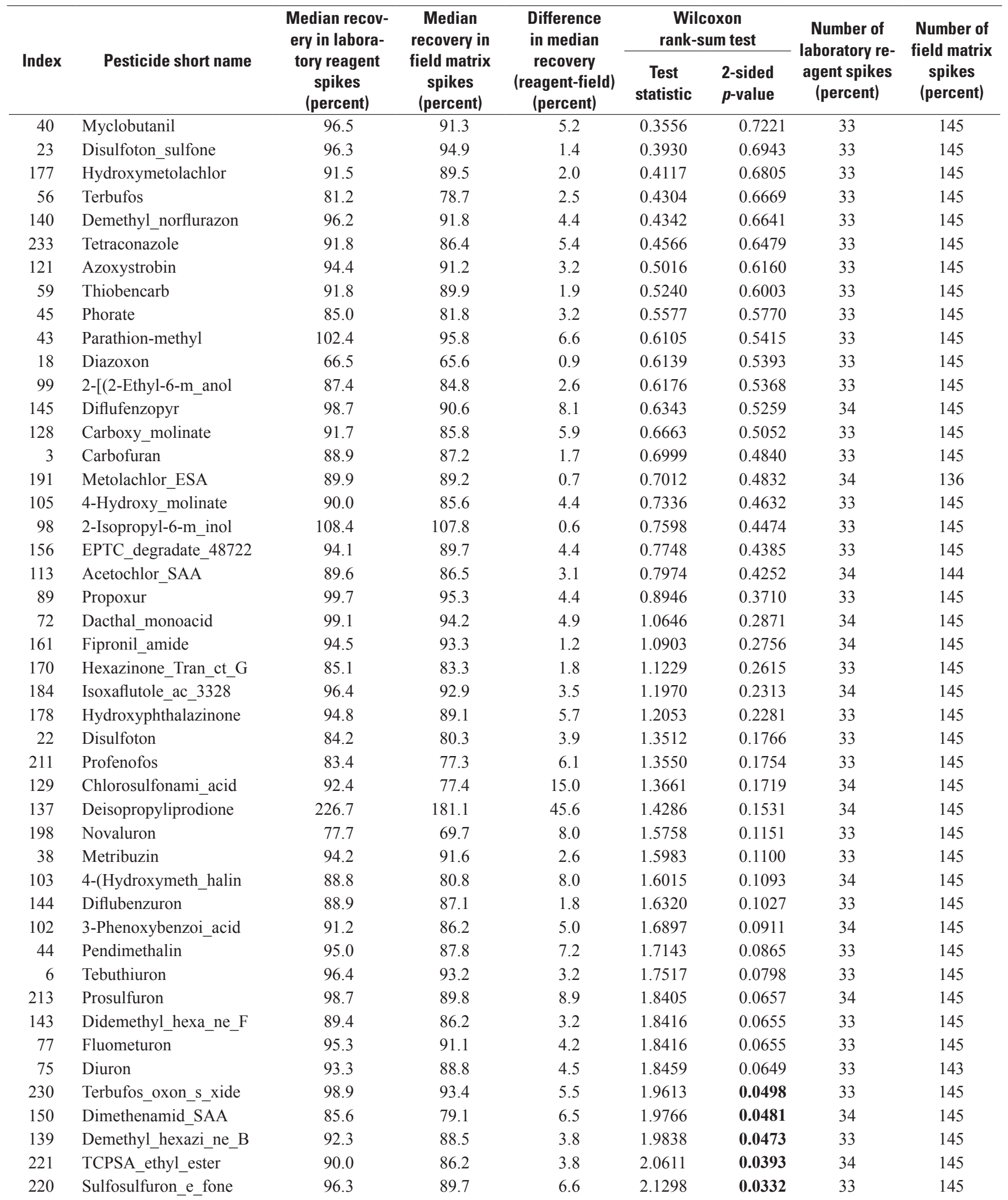


Table 7. Comparison of median recovery of pesticides in stream-water matrix spikes and laboratory reagent-water spikes analyzed by schedule 2437.-Continued

[Pesticides are sorted by the test statistic. Probablity values less than 0.05 are shown in bold; $<$, less than]

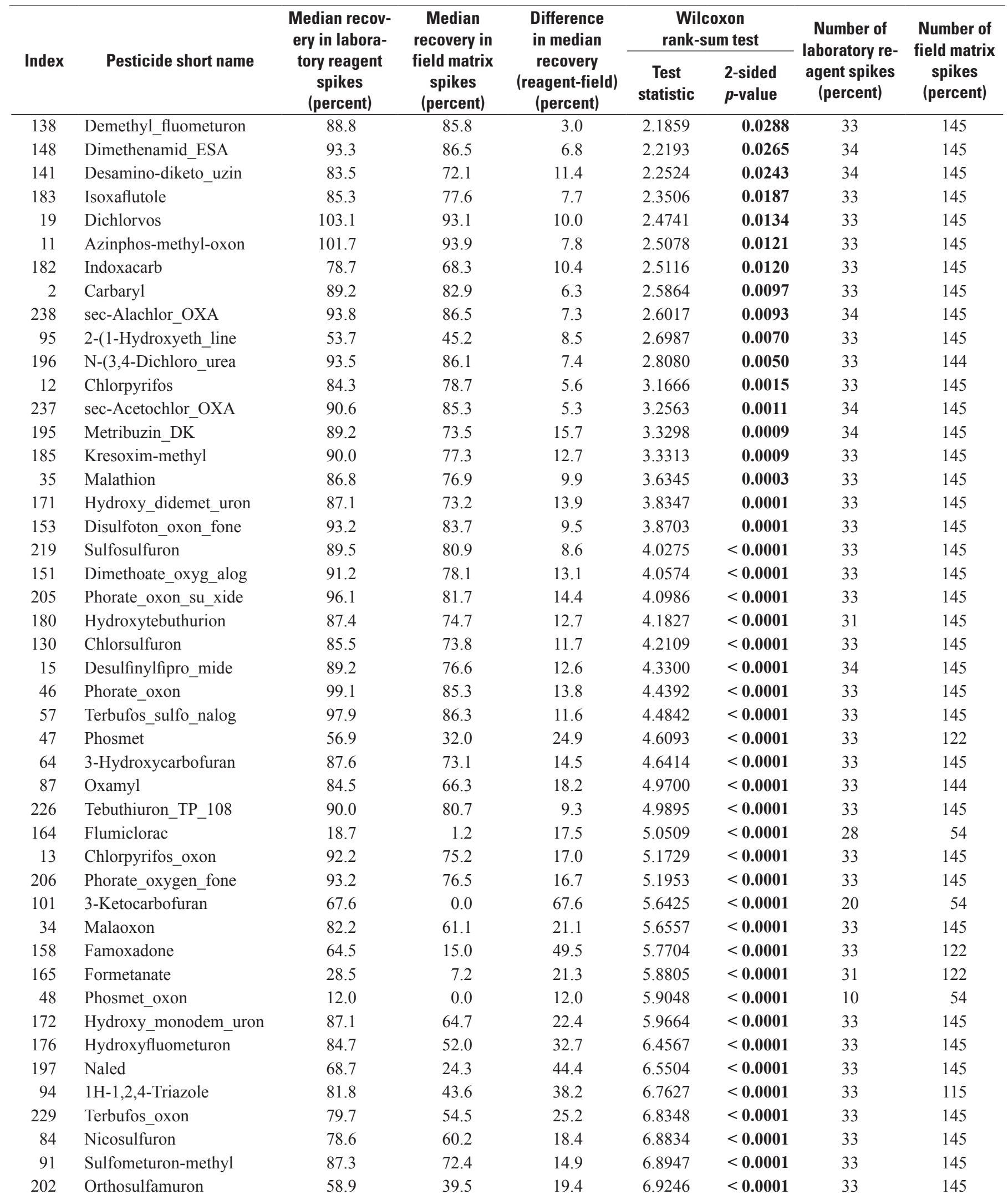


Table 7. Comparison of median recovery of pesticides in stream-water matrix spikes and laboratory reagent-water spikes analyzed by schedule 2437.-Continued

[Pesticides are sorted by the test statistic. Probablity values less than 0.05 are shown in bold; $<$, less than]

\begin{tabular}{|c|c|c|c|c|c|c|c|c|}
\hline \multirow[b]{2}{*}{ Index } & \multirow[b]{2}{*}{ Pesticide short name } & \multirow{2}{*}{$\begin{array}{l}\text { Median recov- } \\
\text { ery in labora- } \\
\text { tory reagent } \\
\text { spikes } \\
\text { (percent) }\end{array}$} & \multirow{2}{*}{$\begin{array}{l}\text { Median } \\
\text { recovery in } \\
\text { field matrix } \\
\text { spikes } \\
\text { (percent) }\end{array}$} & \multirow{2}{*}{$\begin{array}{c}\text { Difference } \\
\text { in median } \\
\text { recovery } \\
\text { (reagent-field) } \\
\text { (percent) }\end{array}$} & \multicolumn{2}{|c|}{$\begin{array}{l}\text { Wilcoxon } \\
\text { rank-sum test }\end{array}$} & \multirow{2}{*}{$\begin{array}{l}\text { Number of } \\
\text { laboratory re- } \\
\text { agent spikes } \\
\text { (percent) }\end{array}$} & \multirow{2}{*}{$\begin{array}{c}\text { Number of } \\
\text { field matrix } \\
\text { spikes } \\
\text { (percent) }\end{array}$} \\
\hline & & & & & $\begin{array}{c}\text { Test } \\
\text { statistic }\end{array}$ & $\begin{array}{l}2 \text {-sided } \\
p \text {-value }\end{array}$ & & \\
\hline 169 & Hexazinone_Tran_ct_E & 93.3 & 62.0 & 31.3 & 7.0549 & $<0.0001$ & 34 & 145 \\
\hline 71 & Chlorimuron-ethyl & 77.9 & 55.9 & 22.0 & 7.0781 & $<0.0001$ & 33 & 145 \\
\hline 166 & Halosulfuron-methyl & 82.9 & 66.5 & 16.4 & 7.2615 & $<0.0001$ & 33 & 145 \\
\hline 122 & Bifenazate & 83.5 & 0.9 & 82.6 & 8.5988 & $<0.0001$ & 31 & 145 \\
\hline 120 & Asulam & 97.1 & 25.4 & 71.7 & 8.9047 & $<0.0001$ & 33 & 145 \\
\hline 119 & Ammelide & 77.3 & 0.0 & 77.3 & 11.2986 & $<0.0001$ & 34 & 145 \\
\hline
\end{tabular}

Table 8. Comparison of variability of recovery of pesticides in stream-water matrix spikes and laboratory reagent-water spikes analyzed by schedule 2437 .

[Pesticides are sorted by the type of spikes with the largest standard deviation and by the test statistic. Probablity values less than 0.05 are shown in bold. $<$, less than; nc, not calculated]

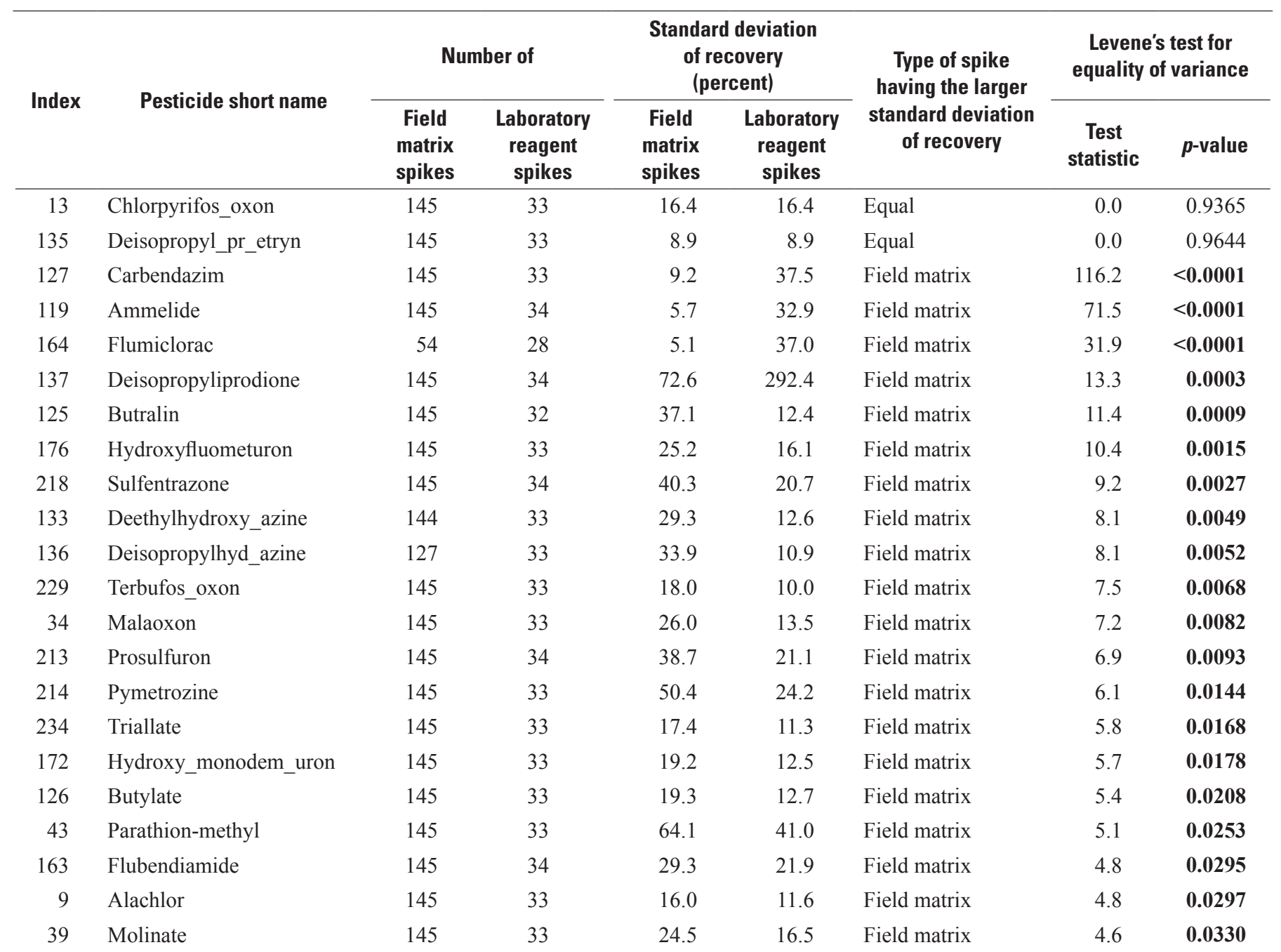


Table 8. Comparison of variability of recovery of pesticides in stream-water matrix spikes and laboratory reagent-water spikes analyzed by schedule 2437.-Continued

[Pesticides are sorted by the type of spikes with the largest standard deviation and by the test statistic. Probablity values less than 0.05 are shown in bold. $<$, less than; nc, not calculated]

\begin{tabular}{|c|c|c|c|c|c|c|c|c|}
\hline \multirow{2}{*}{ Index } & \multirow{2}{*}{ Pesticide short name } & \multicolumn{2}{|c|}{ Number of } & \multicolumn{2}{|c|}{$\begin{array}{c}\text { Standard deviation } \\
\text { of recovery } \\
\text { (percent) }\end{array}$} & \multirow{2}{*}{$\begin{array}{c}\text { Type of spike } \\
\text { having the larger } \\
\text { standard deviation } \\
\text { of recovery }\end{array}$} & \multicolumn{2}{|c|}{$\begin{array}{l}\text { Levene's test for } \\
\text { equality of variance }\end{array}$} \\
\hline & & $\begin{array}{c}\text { Field } \\
\text { matrix } \\
\text { spikes }\end{array}$ & $\begin{array}{l}\text { Laboratory } \\
\text { reagent } \\
\text { spikes }\end{array}$ & $\begin{array}{l}\text { Field } \\
\text { matrix } \\
\text { spikes }\end{array}$ & $\begin{array}{l}\text { Laboratory } \\
\text { reagent } \\
\text { spikes }\end{array}$ & & $\begin{array}{c}\text { Test } \\
\text { statistic }\end{array}$ & $p$-value \\
\hline 87 & Oxamyl & 144 & 33 & 22.4 & 13.7 & Field matrix & 4.4 & 0.0367 \\
\hline 35 & Malathion & 145 & 33 & 21.3 & 10.1 & Field matrix & 4.4 & 0.0378 \\
\hline 129 & Chlorosulfonami_acid & 145 & 34 & 77.6 & 26.3 & Field matrix & 4.3 & 0.0406 \\
\hline 45 & Phorate & 145 & 33 & 17.5 & 11.7 & Field matrix & 4.2 & 0.0410 \\
\hline 96 & 2-Amino-N-isopr_mide & 145 & 33 & 16.0 & 10.2 & Field matrix & 4.2 & 0.0421 \\
\hline 24 & EPTC & 145 & 33 & 24.7 & 16.4 & Field matrix & 4.2 & 0.0427 \\
\hline 151 & Dimethoate_oxyg_alog & 145 & 33 & 23.6 & 13.0 & Field matrix & 3.8 & 0.0534 \\
\hline 192 & Metolachlor_OXA & 137 & 34 & 22.8 & 16.6 & Field matrix & 3.8 & 0.0536 \\
\hline 105 & 4-Hydroxy_molinate & 145 & 33 & 19.2 & 14.2 & Field matrix & 3.7 & 0.0547 \\
\hline 206 & Phorate_oxygen_fone & 145 & 33 & 21.6 & 11.4 & Field matrix & 3.7 & 0.0561 \\
\hline 153 & Disulfoton_oxon_fone & 145 & 33 & 21.7 & 10.5 & Field matrix & 3.6 & 0.0581 \\
\hline 71 & Chlorimuron-ethyl & 145 & 33 & 17.7 & 13.1 & Field matrix & 3.6 & 0.0580 \\
\hline 63 & 2-Hydroxyatrazine & 145 & 33 & 19.1 & 10.1 & Field matrix & 3.5 & 0.0623 \\
\hline 233 & Tetraconazole & 145 & 33 & 19.9 & 15.2 & Field matrix & 3.5 & 0.0630 \\
\hline 52 & Propargite & 145 & 32 & 20.9 & 13.2 & Field matrix & 3.2 & 0.0746 \\
\hline 82 & MCPA & 145 & 34 & 22.0 & 16.6 & Field matrix & 3.2 & 0.0746 \\
\hline 4 & Deethylatrazine & 145 & 33 & 16.3 & 11.8 & Field matrix & 3.2 & 0.0752 \\
\hline 160 & Fentin & 145 & 33 & 19.0 & 14.2 & Field matrix & 3.2 & 0.0762 \\
\hline 230 & Terbufos_oxon_s_xide & 145 & 33 & 20.6 & 12.1 & Field matrix & 3.2 & 0.0763 \\
\hline 84 & Nicosulfuron & 145 & 33 & 17.9 & 12.8 & Field matrix & 3.2 & 0.0769 \\
\hline 162 & Fipronil_sulfonate & 145 & 34 & 33.4 & 23.6 & Field matrix & 3.2 & 0.0775 \\
\hline 93 & Triclopyr & 145 & 34 & 20.4 & 15.2 & Field matrix & 3.1 & 0.0788 \\
\hline 216 & Pyridaben & 145 & 32 & 19.7 & 13.5 & Field matrix & 3.0 & 0.0868 \\
\hline 167 & Hexazinone_Tran_ct_C & 145 & 33 & 22.1 & 11.0 & Field matrix & 2.9 & 0.0925 \\
\hline 183 & Isoxaflutole & 145 & 33 & 21.3 & 14.6 & Field matrix & 2.8 & 0.0950 \\
\hline 239 & trans-Permethrin & 144 & 32 & 20.0 & 13.8 & Field matrix & 2.8 & 0.0950 \\
\hline 157 & Etoxazole & 145 & 32 & 18.4 & 13.4 & Field matrix & 2.7 & 0.1005 \\
\hline 32 & Fonofos & 145 & 33 & 17.1 & 11.3 & Field matrix & 2.7 & 0.1013 \\
\hline
\end{tabular}


Table 8. Comparison of variability of recovery of pesticides in stream-water matrix spikes and laboratory reagent-water spikes analyzed by schedule 2437.-Continued

[Pesticides are sorted by the type of spikes with the largest standard deviation and by the test statistic. Probablity values less than 0.05 are shown in bold. $<$, less than; nc, not calculated]

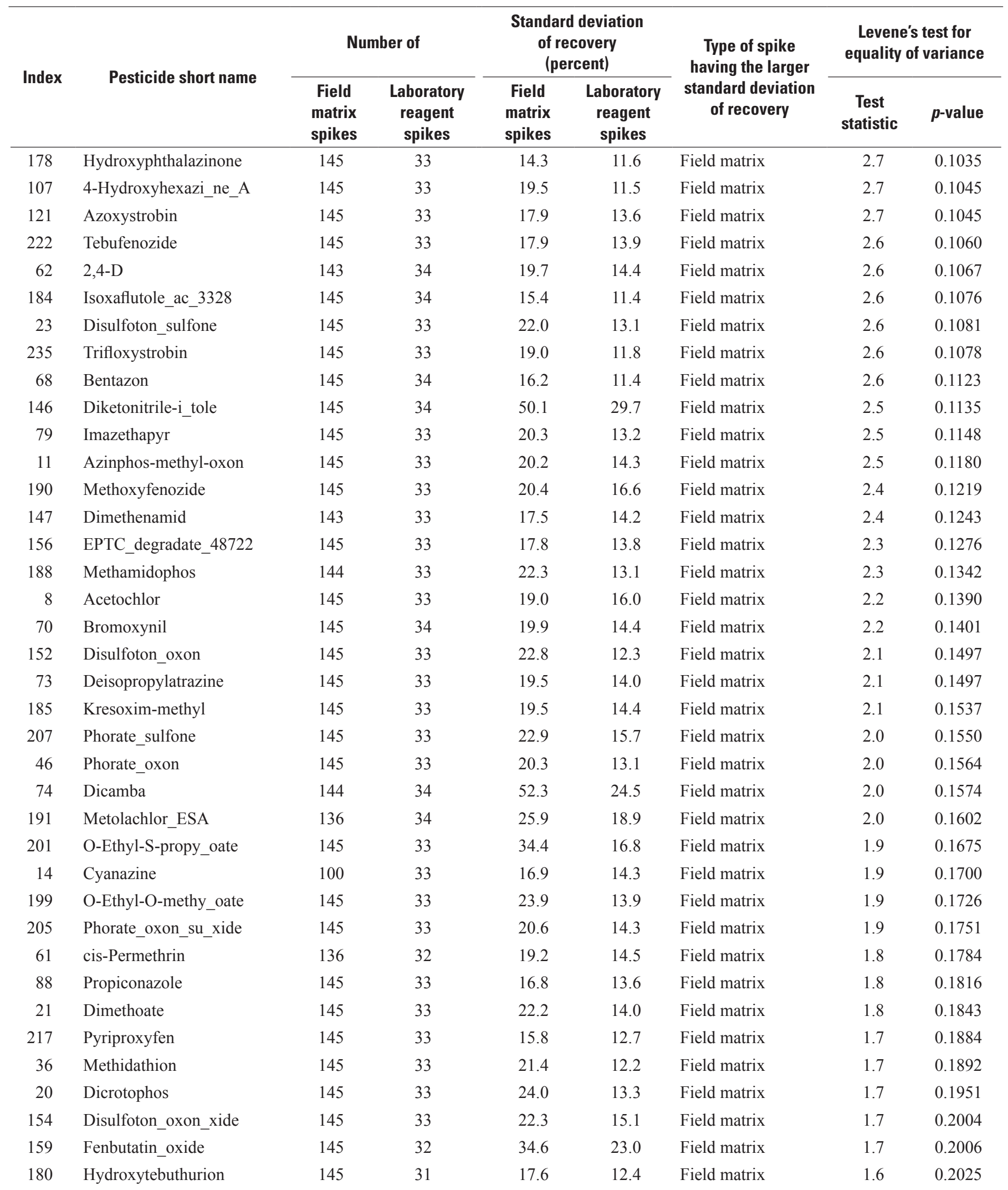


Table 8. Comparison of variability of recovery of pesticides in stream-water matrix spikes and laboratory reagent-water spikes analyzed by schedule 2437. - Continued

[Pesticides are sorted by the type of spikes with the largest standard deviation and by the test statistic. Probablity values less than 0.05 are shown in bold. $<$, less than; nc, not calculated]

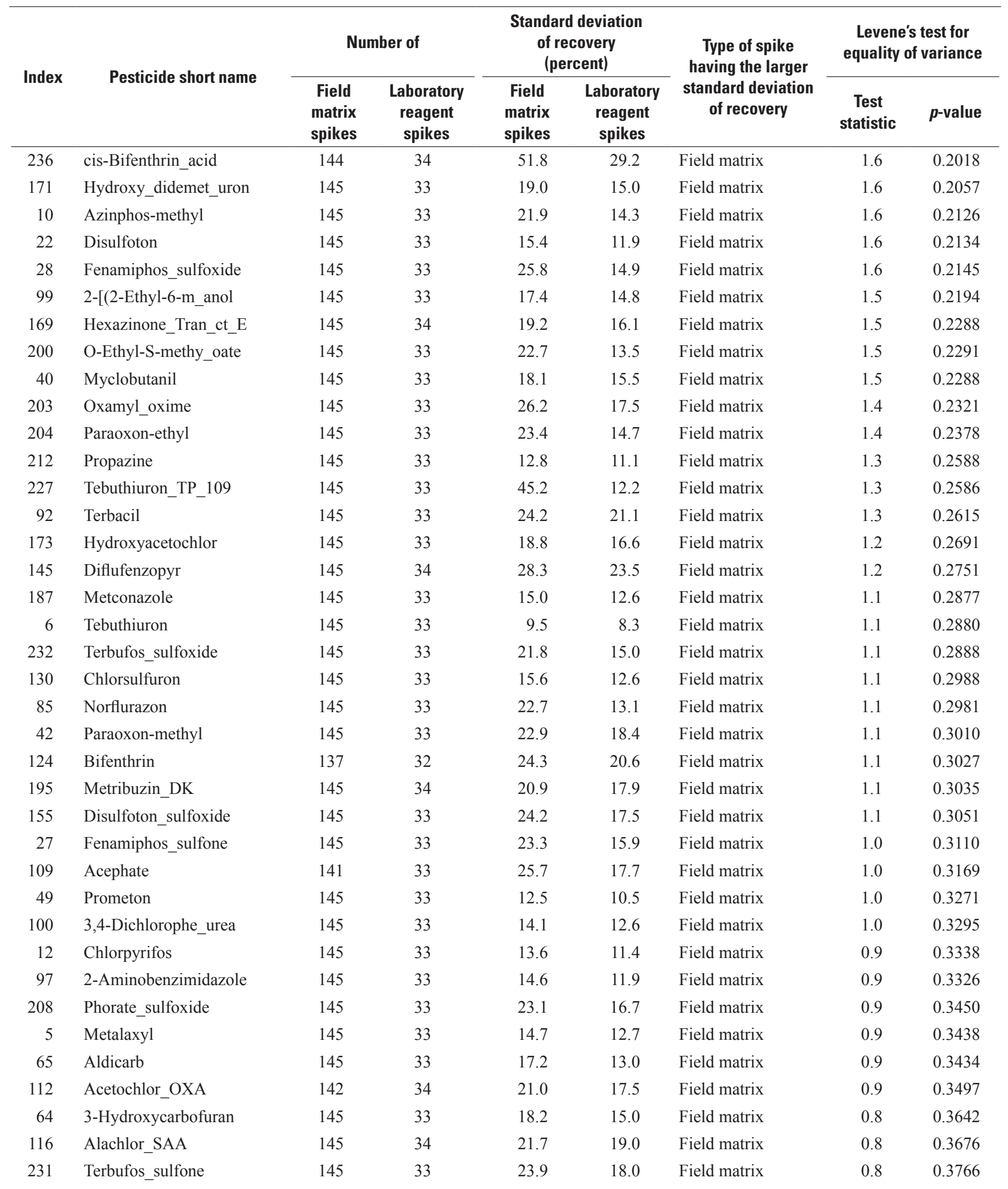


Table 8. Comparison of variability of recovery of pesticides in stream-water matrix spikes and laboratory reagent-water spikes analyzed by schedule 2437.-Continued

[Pesticides are sorted by the type of spikes with the largest standard deviation and by the test statistic. Probablity values less than 0.05 are shown in bold. $<$, less than; nc, not calculated]

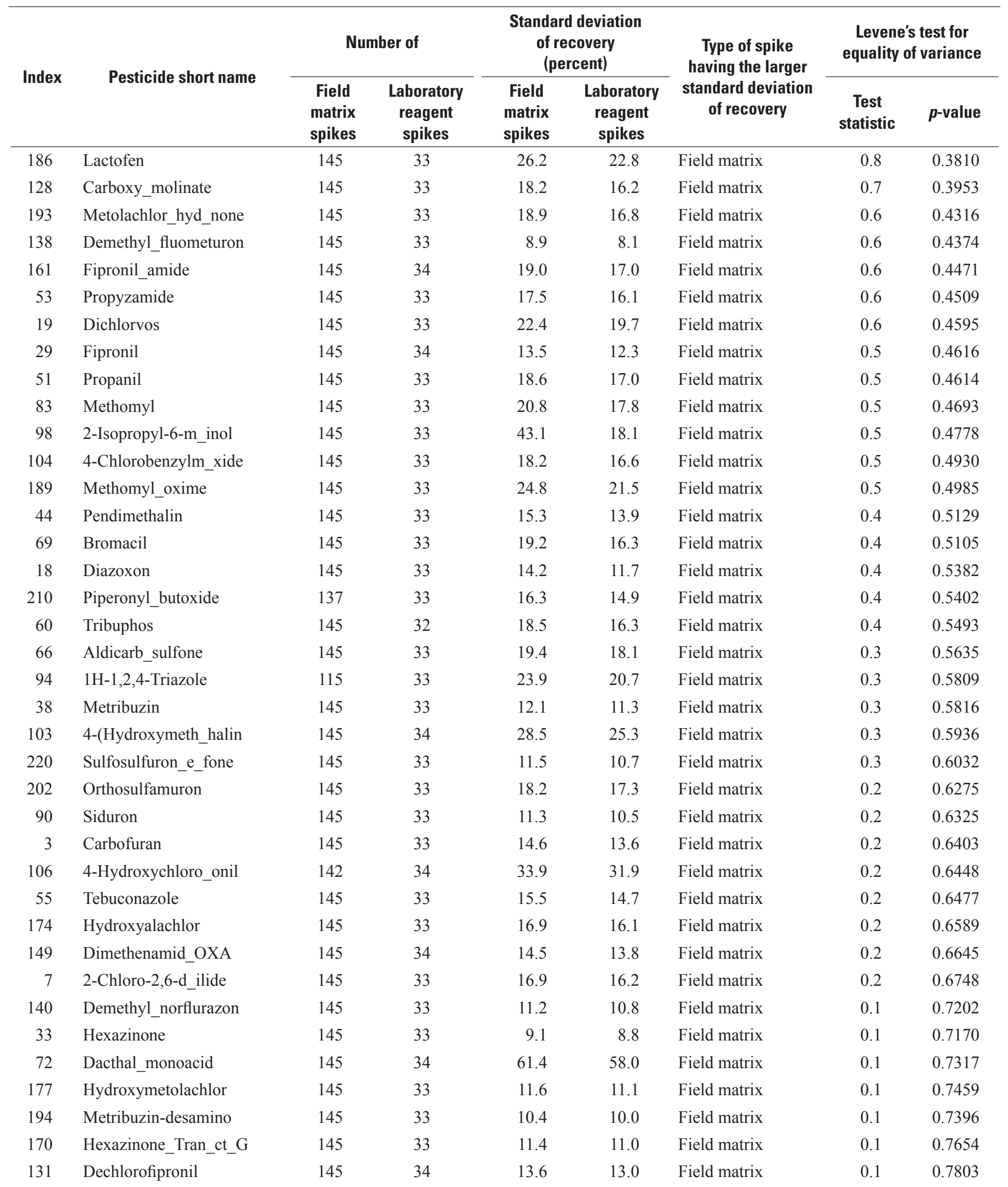


Table 8. Comparison of variability of recovery of pesticides in stream-water matrix spikes and laboratory reagent-water spikes analyzed by schedule 2437. - Continued

[Pesticides are sorted by the type of spikes with the largest standard deviation and by the test statistic. Probablity values less than 0.05 are shown in bold. $<$, less than; nc, not calculated]

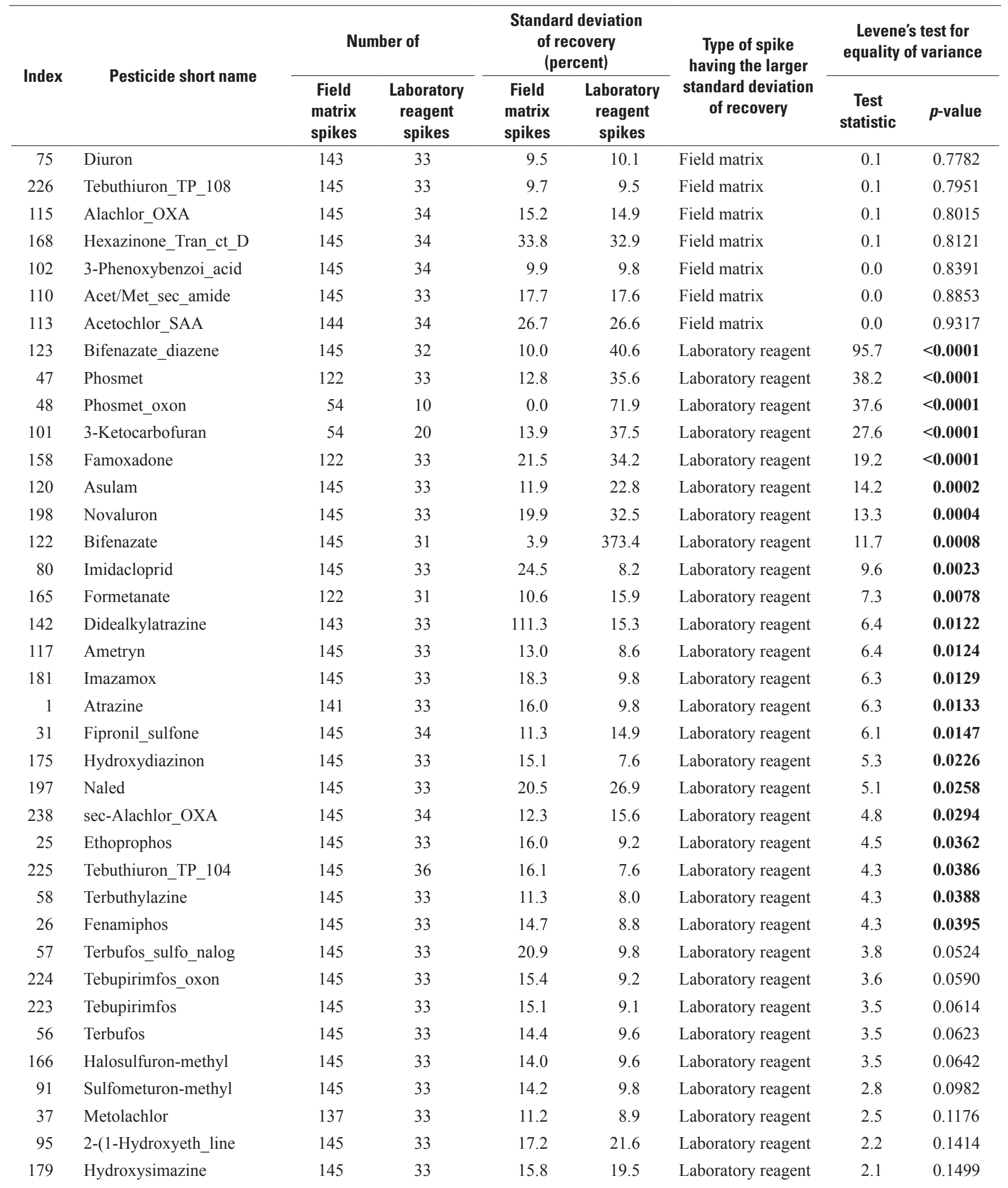


Table 8. Comparison of variability of recovery of pesticides in stream-water matrix spikes and laboratory reagent-water spikes analyzed by schedule 2437.-Continued

[Pesticides are sorted by the type of spikes with the largest standard deviation and by the test statistic. Probablity values less than 0.05 are shown in bold. $<$, less than; nc, not calculated]

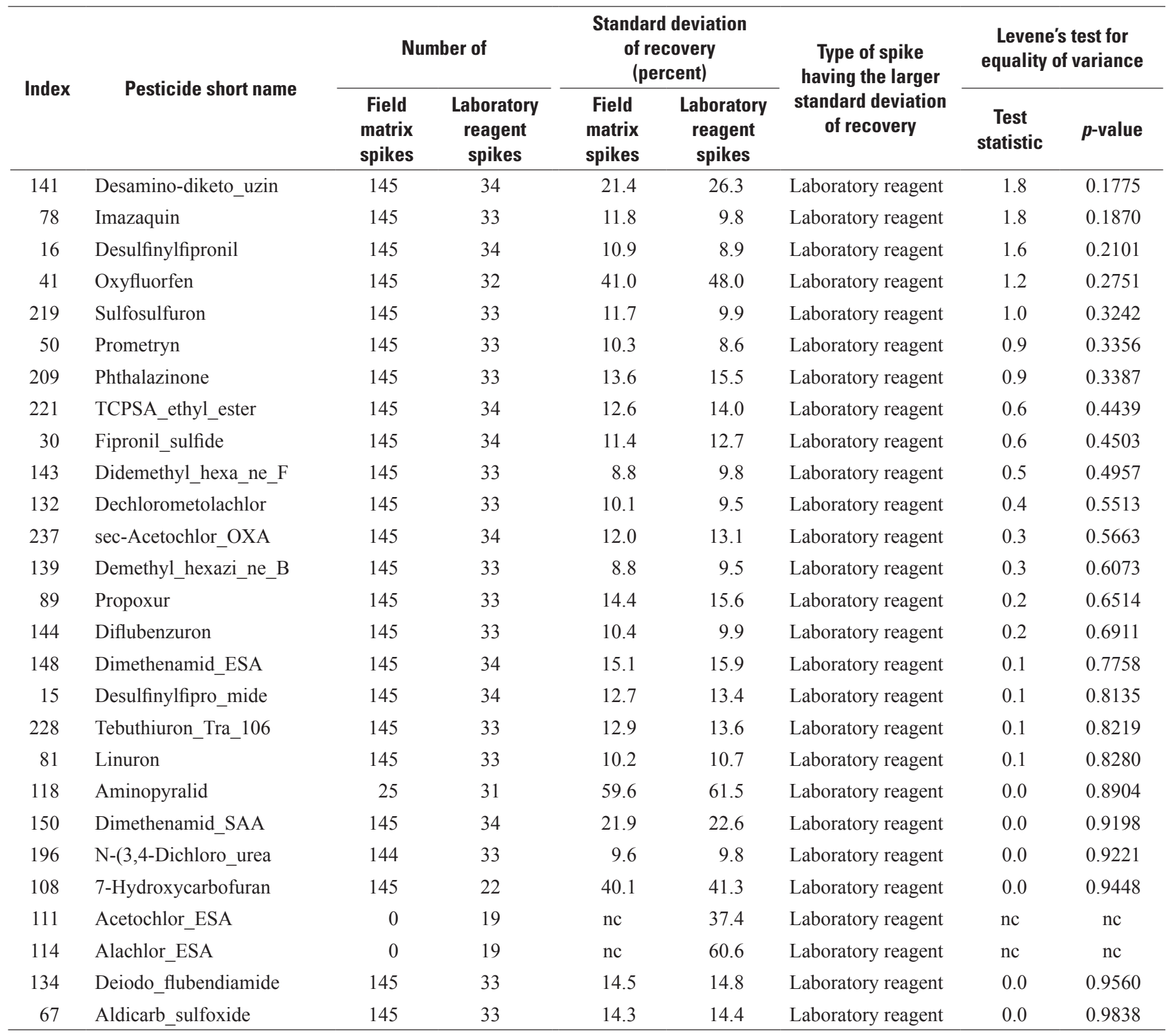



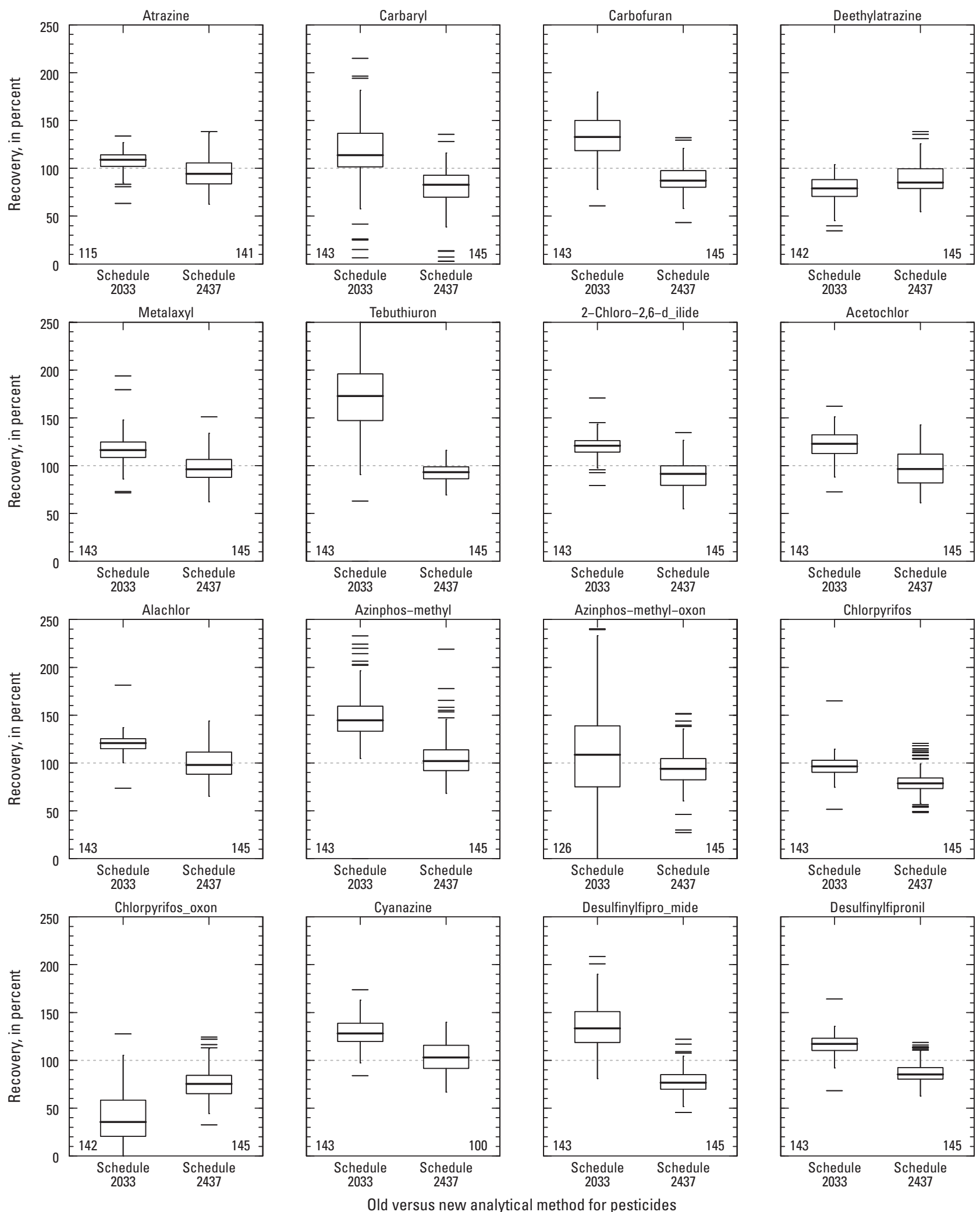

Figure 5. Distribution of recovery of pesticides in stream-water matrix spikes analyzed by schedule 2033 (old method) and by schedule 2437 (new method). The number of matrix spikes is shown at the bottom of the boxplot. Boxplots are explained in figure 2. Recoveries greater than 250 percent are not shown. 

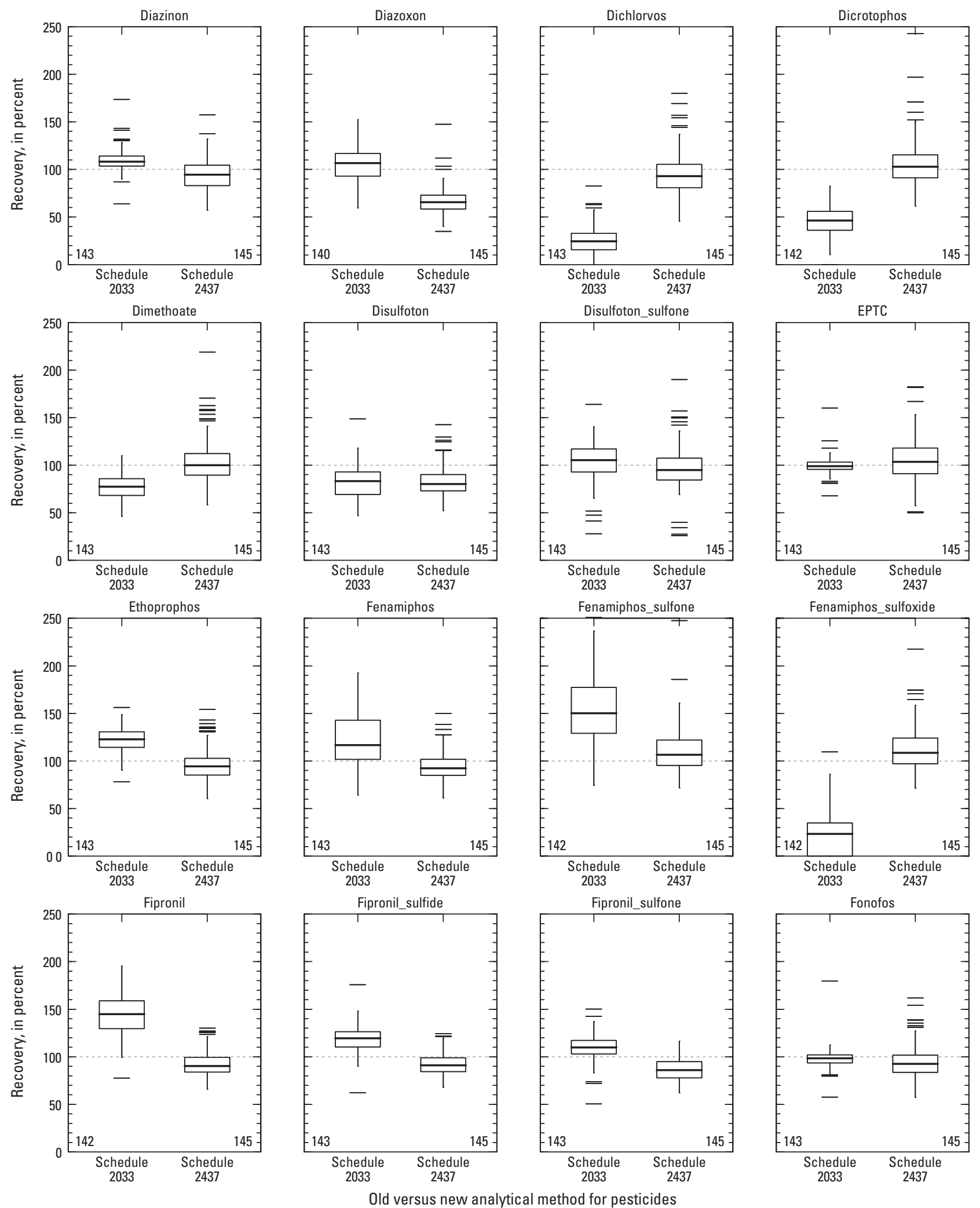

Figure 5. Distribution of recovery of pesticides in stream-water matrix spikes analyzed by schedule 2033 (old method) and by schedule 2437 (new method). The number of matrix spikes is shown at the bottom of the boxplot. Boxplots are explained in figure 2. Recoveries greater than 250 percent are not shown.-Continued 

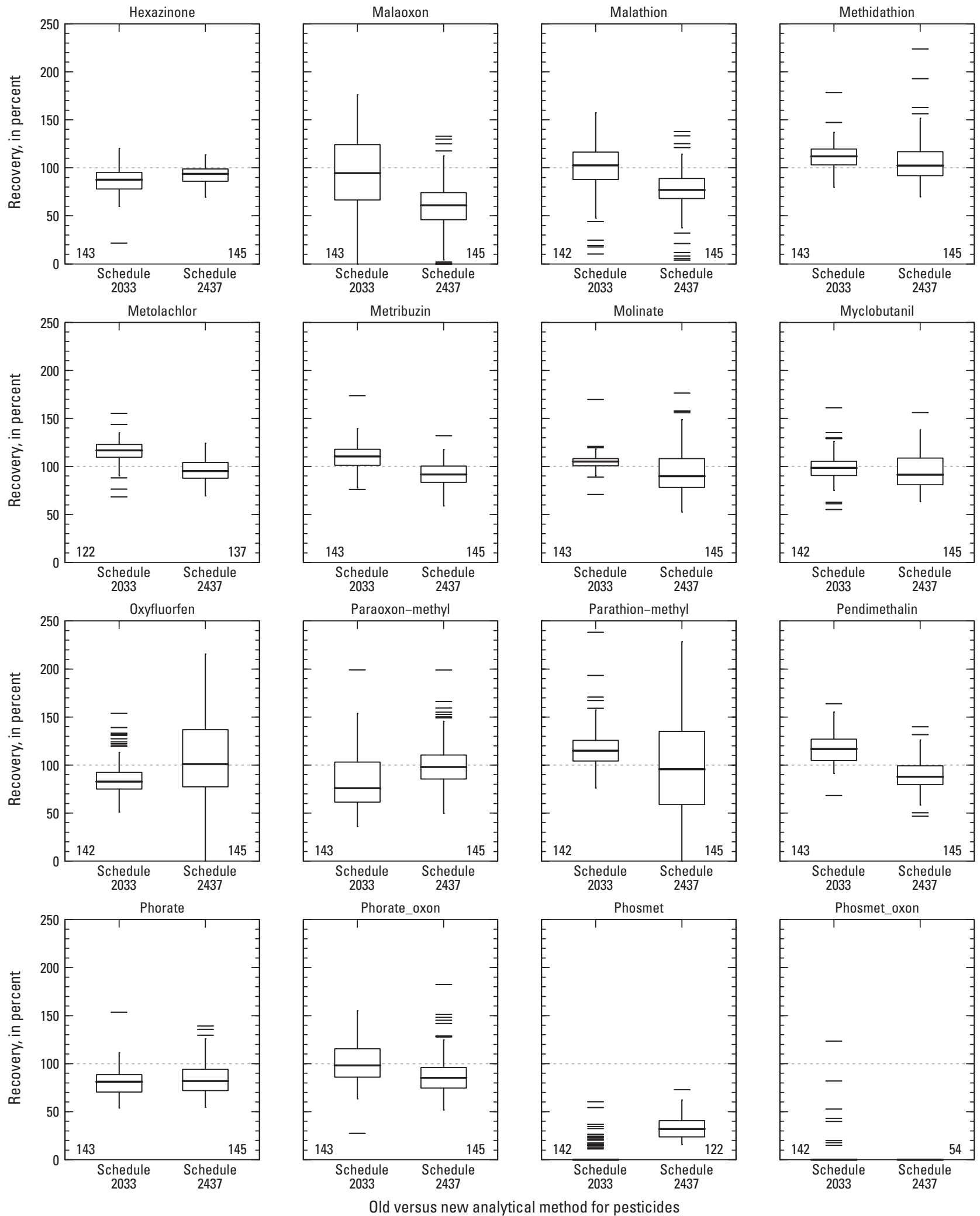

Figure 5. Distribution of recovery of pesticides in stream-water matrix spikes analyzed by schedule 2033 (old method) and by schedule 2437 (new method). The number of matrix spikes is shown at the bottom of the boxplot. Boxplots are explained in figure 2. Recoveries greater than 250 percent are not shown.-Continued 

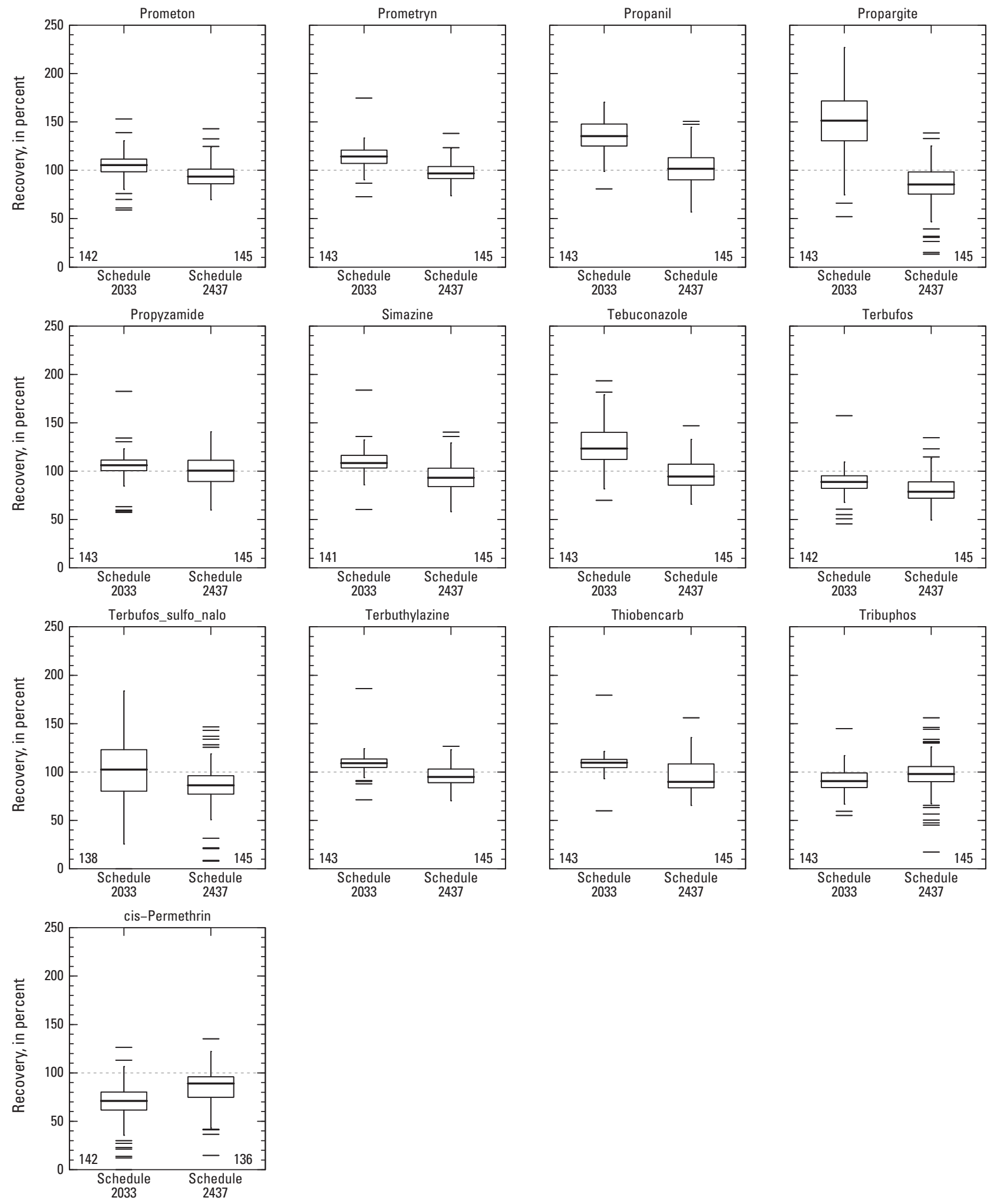

Old versus new analytical method for pesticides

Figure 5. Distribution of recovery of pesticides in stream-water matrix spikes analyzed by schedule 2033 (old method) and by schedule 2437 (new method). The number of matrix spikes is shown at the bottom of the boxplot. Boxplots are explained in figure 2. Recoveries greater than 250 percent are not shown.-Continued 

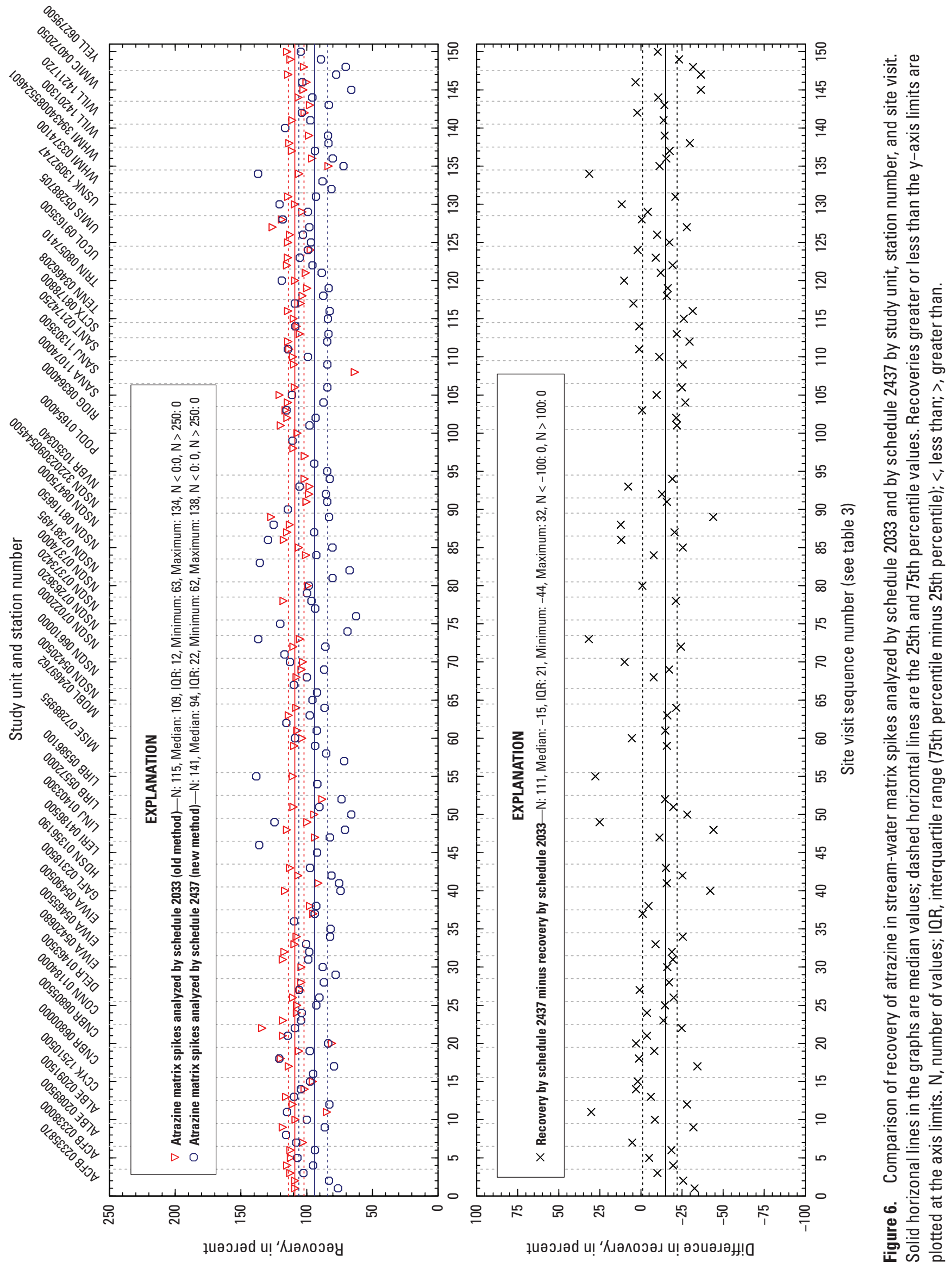
Table 9. Comparison of median recovery of pesticides in stream-water matrix spikes analyzed by both schedule 2033 and schedule 2437.

[Pesticides are sorted by the method with the largest standard deviation and by the test statistic. Probability values less than 0.05 are shown in bold. $<$, less than]

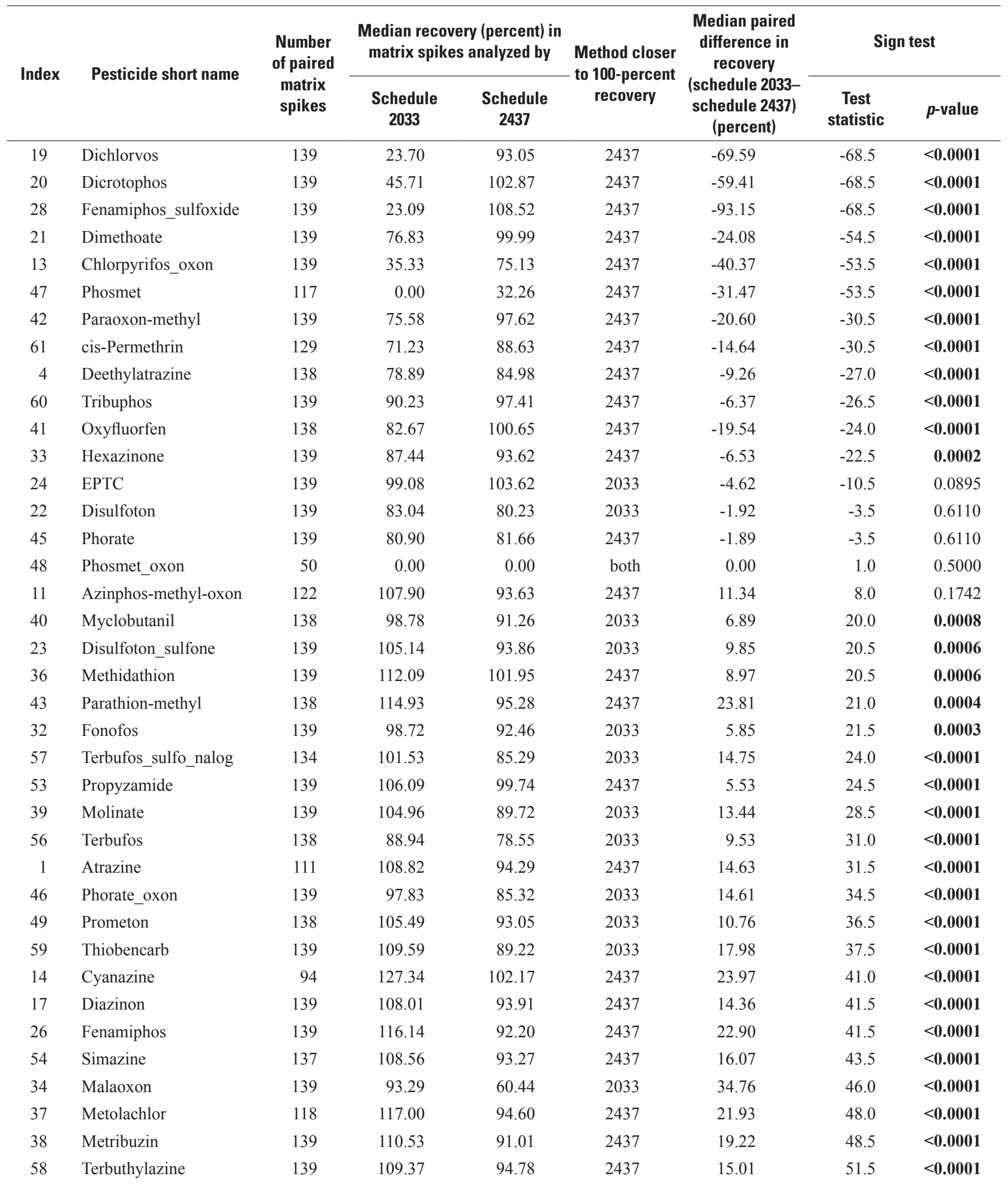


Table 9. Comparison of median recovery of pesticides in stream-water matrix spikes analyzed by both schedule 2033 and schedule 2437.-Continued

[Pesticides are sorted by the method with the largest standard deviation and by the test statistic. Probability values less than 0.05 are shown in bold. $<$, less than]

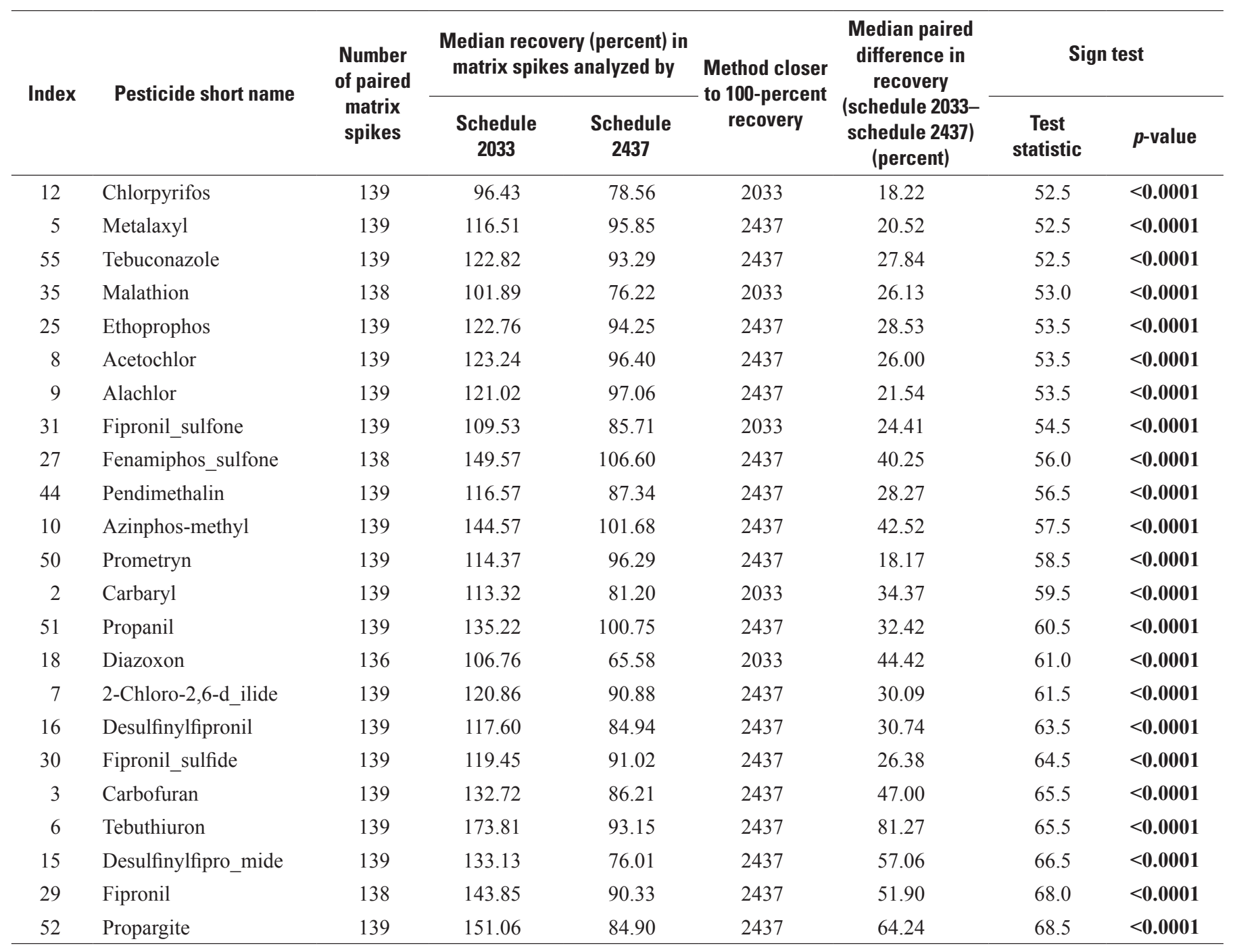


Table 10. Comparison of variability of recovery of pesticides in stream-water matrix spikes analyzed by both schedule 2033 and schedule 2437.

[Pesticides are sorted by the method with the largest standard deviation and by the test statistic. Probablity values less than 0.05 are shown in bold. $<$, less than]

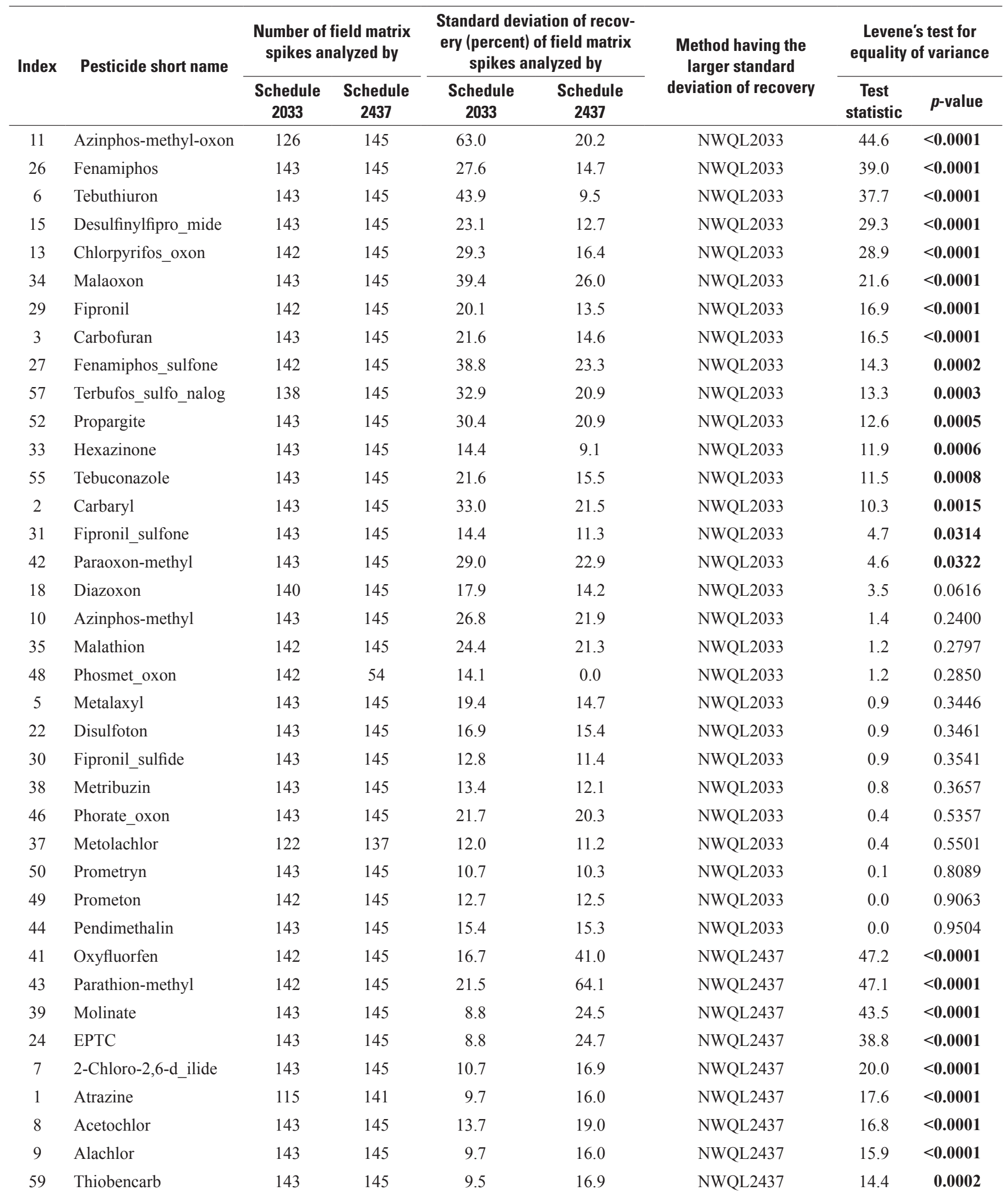


Table 10. Comparison of variability of recovery of pesticides in stream-water matrix spikes analyzed by both schedule 2033 and schedule 2437.-Continued

[Pesticides are sorted by the method with the largest standard deviation and by the test statistic. Probablity values less than 0.05 are shown in bold. $<$, less than]

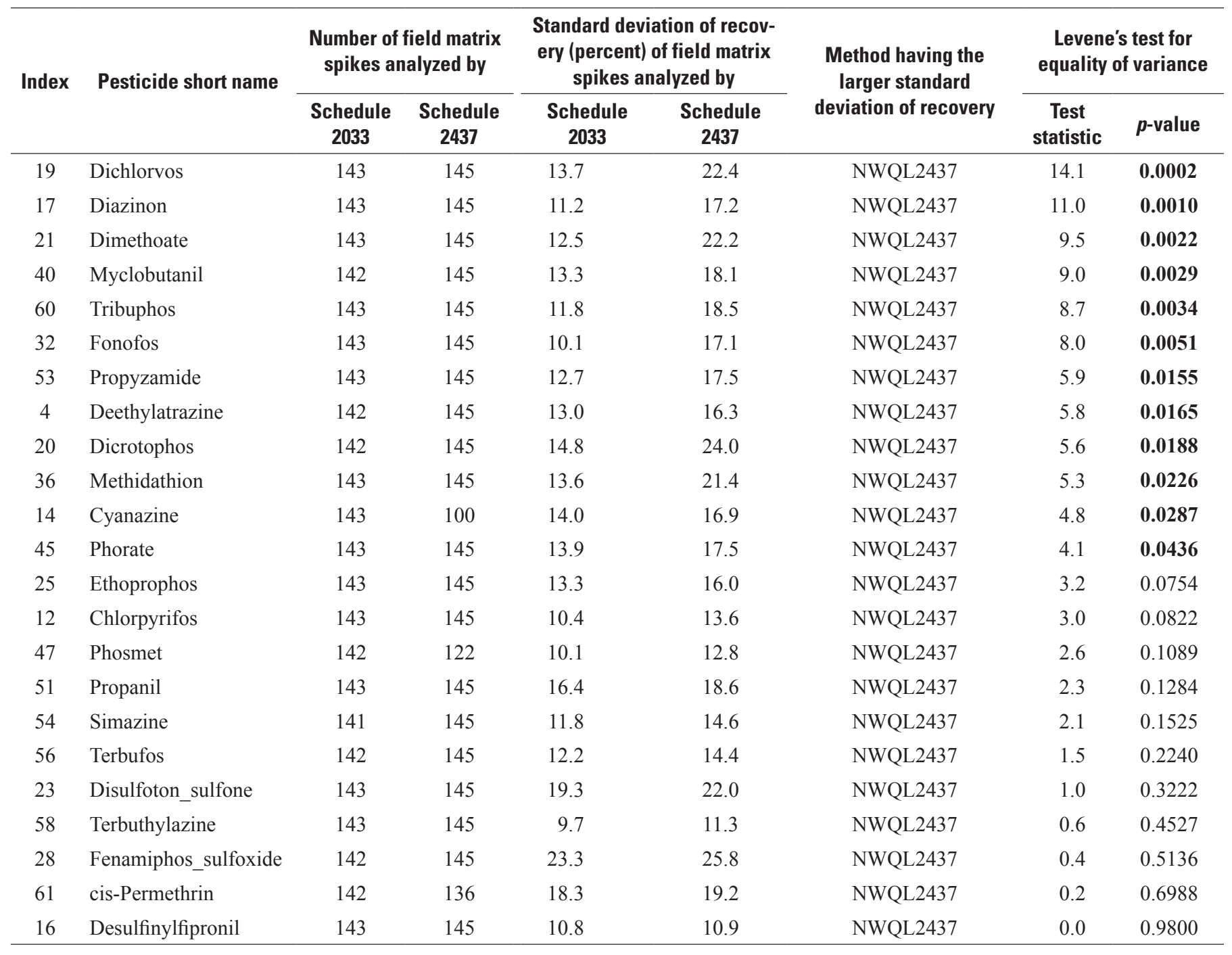



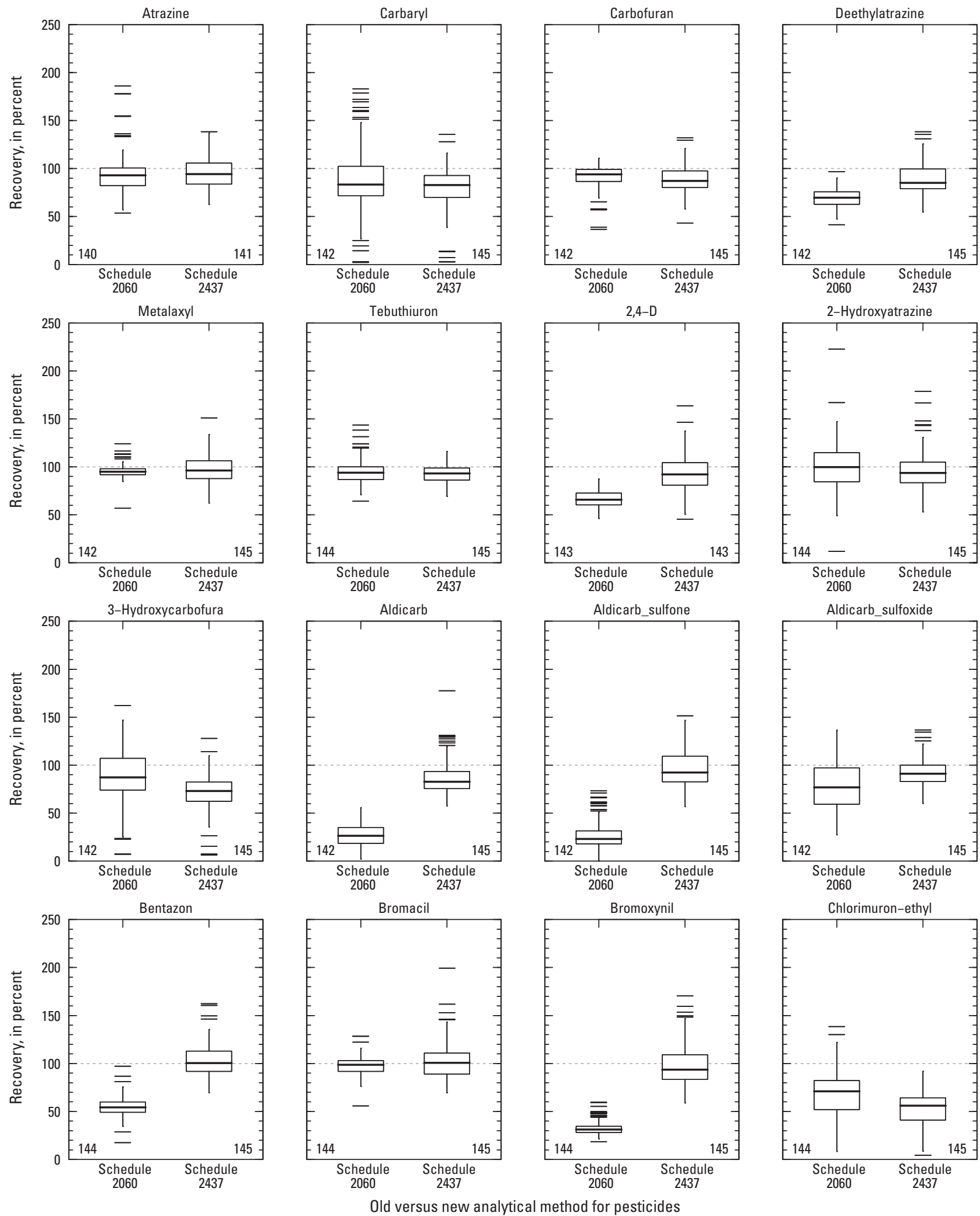

Figure 7. Distribution of recovery of pesticides in stream-water matrix spikes analyzed by schedule 2060 (old method) and by schedule 2437 (new method). The number of matrix spikes is shown at the bottom of the boxplot. Boxplots are explained in figure 2. Recoveries greater than 250 percent are not shown. 

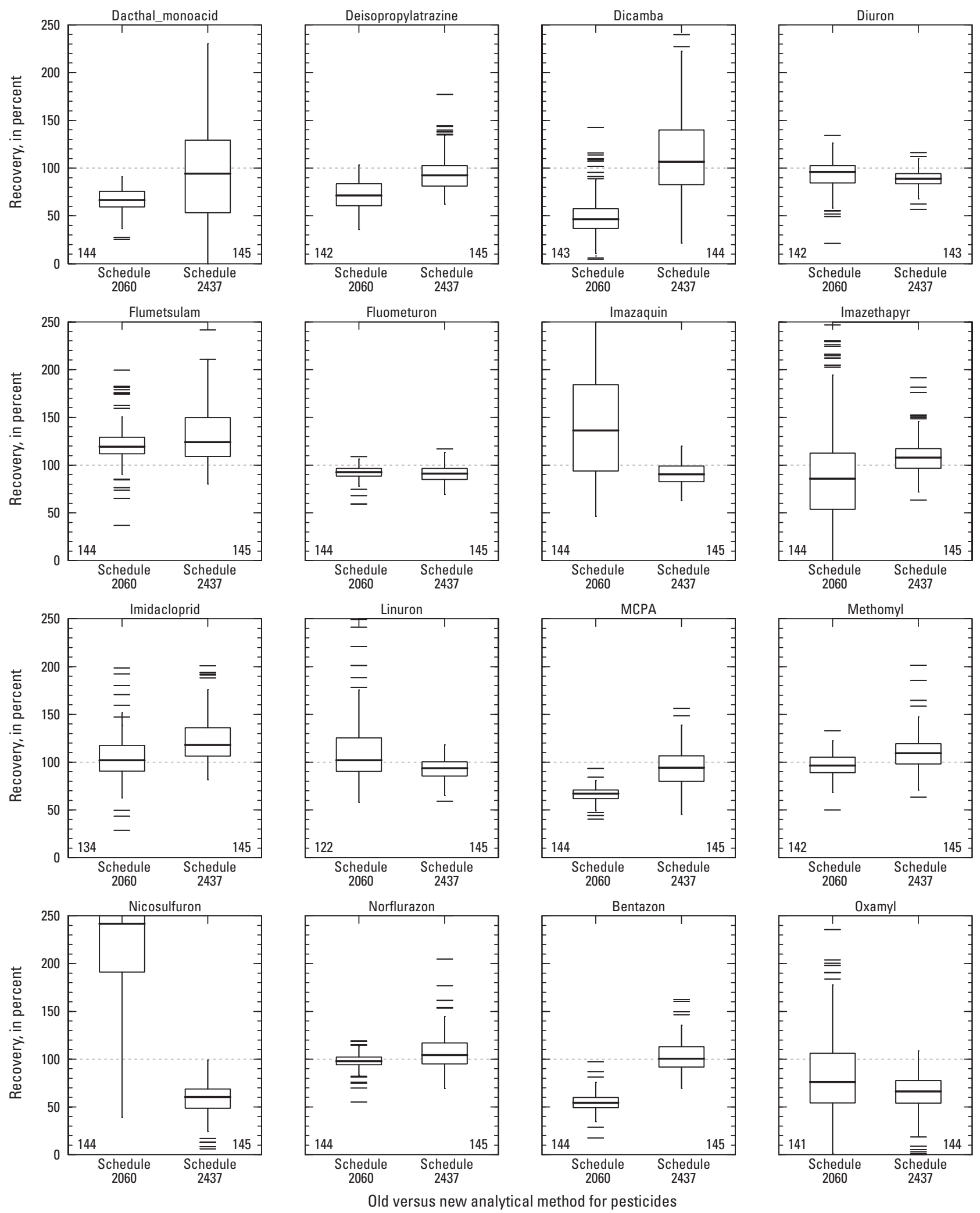

Figure 7. Distribution of recovery of pesticides in stream-water matrix spikes analyzed by schedule 2060 (old method) and by schedule 2437 (new method). The number of matrix spikes is shown at the bottom of the boxplot. Boxplots are explained in figure 2. Recoveries greater than 250 percent are not shown.-Continued 

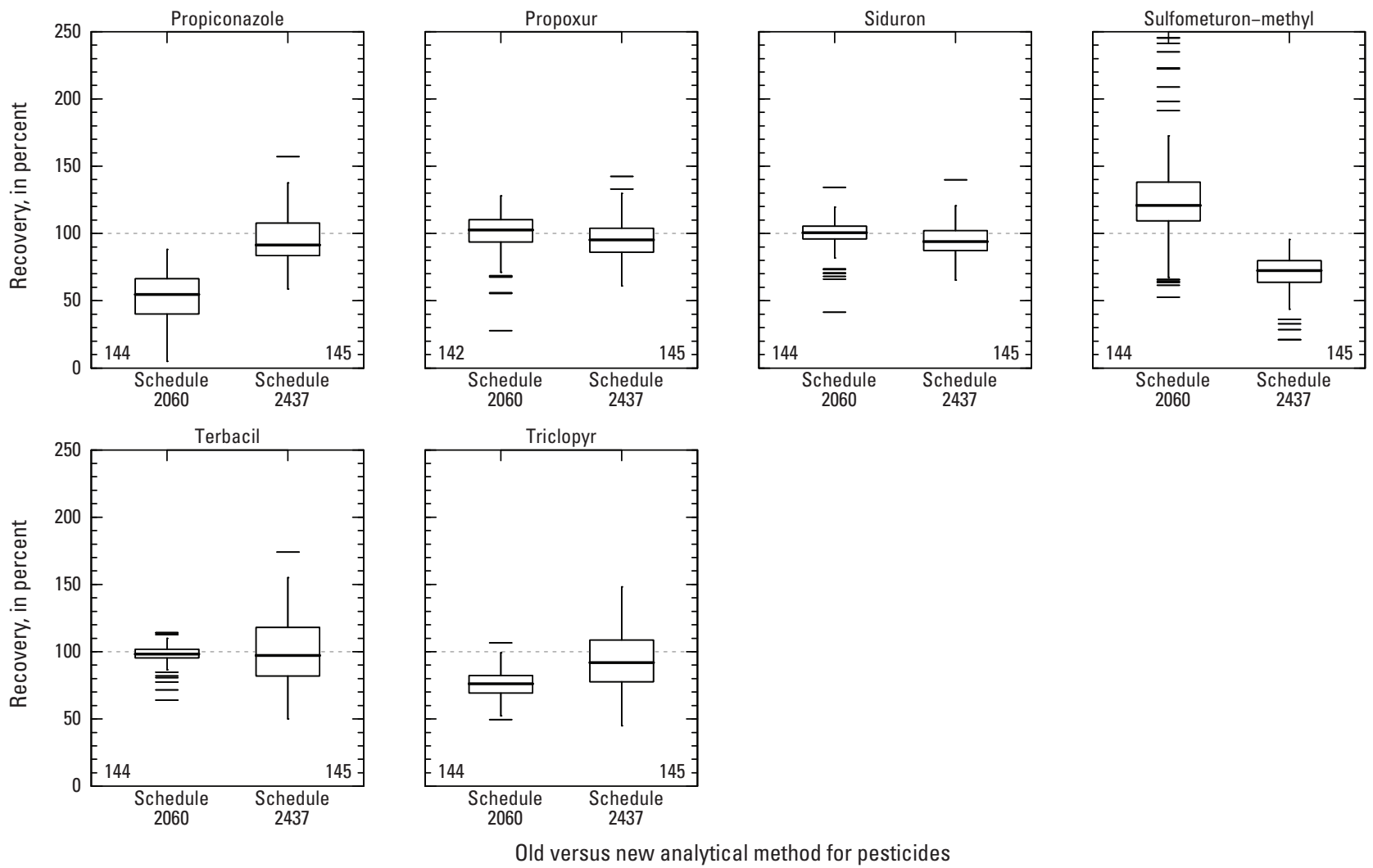

Figure 7. Distribution of recovery of pesticides in stream-water matrix spikes analyzed by schedule 2060 (old method) and by schedule 2437 (new method). The number of matrix spikes is shown at the bottom of the boxplot. Boxplots are explained in figure 2. Recoveries greater than 250 percent are not shown.-Continued 

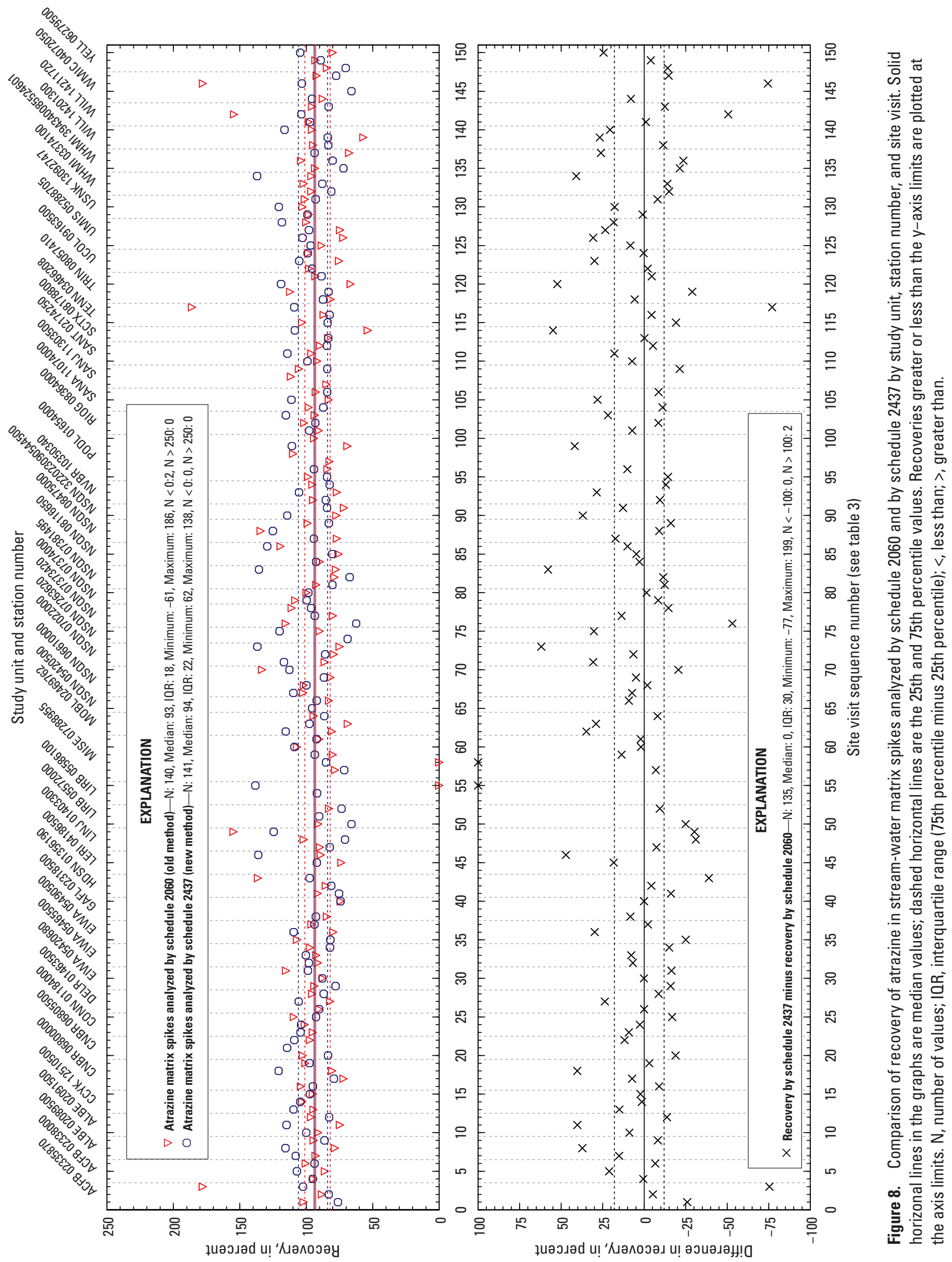
Table 11. Comparison of median recovery of pesticides in stream-water matrix spikes analyzed by both schedule 2060 and schedule 2437.

[Pesticides are sorted by the sign test statistic. Probablity values less than 0.05 are shown in bold. $<$, less than]

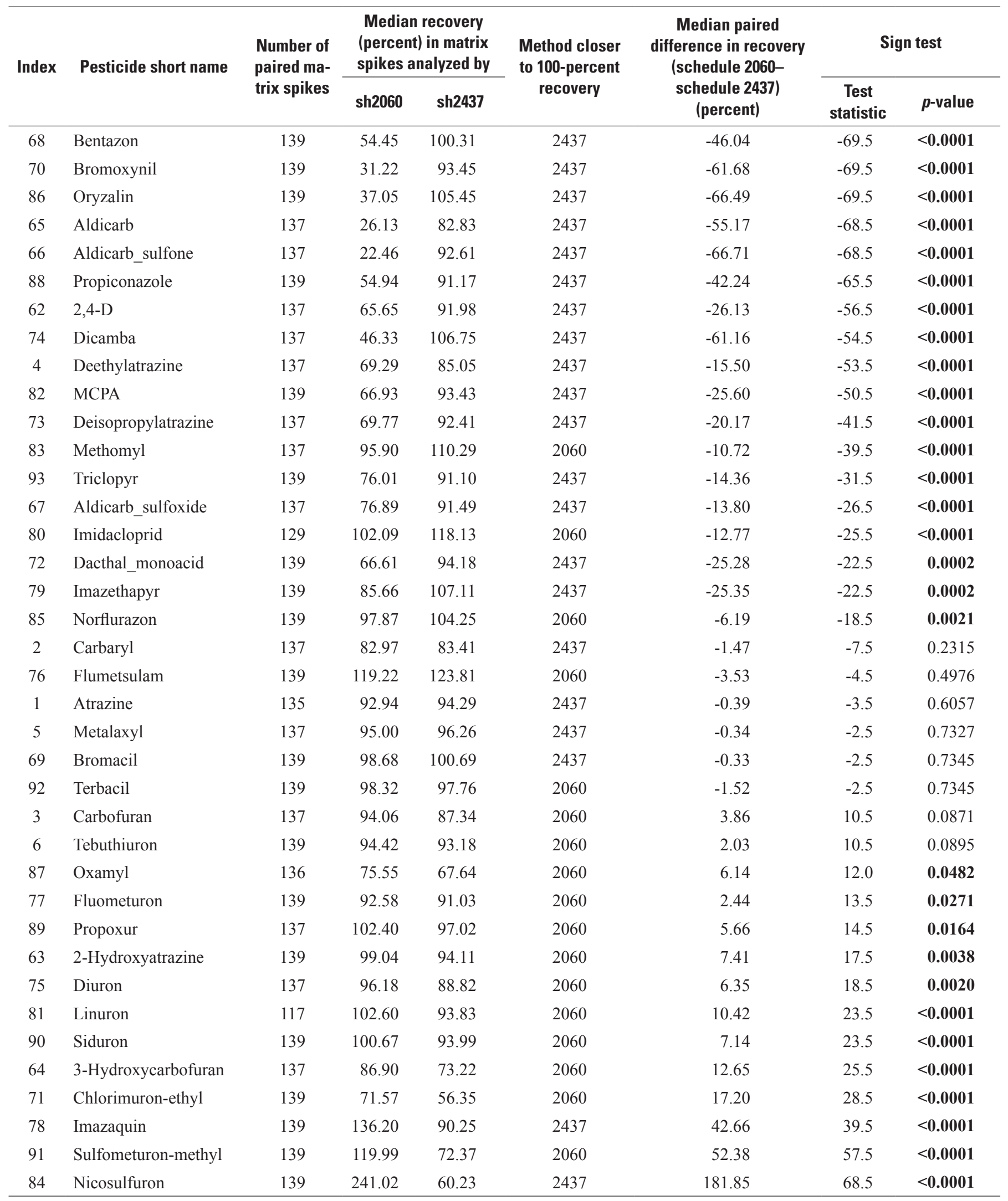


Table 12. Comparison of variability of recovery of pesticides in stream-water matrix spikes analyzed by both schedule 2060 and schedule 2437.

[Pesticides are sorted by the method with the largest standard deviation and by the test statistic. Probablity values less than 0.05 are shown in bold. $<$, less than]

\begin{tabular}{|c|c|c|c|c|c|c|c|c|}
\hline \multirow[t]{2}{*}{ Index } & \multirow[t]{2}{*}{ Pesticide short name } & \multicolumn{2}{|c|}{$\begin{array}{l}\text { Number of field } \\
\text { matrix spikes } \\
\text { analyzed by }\end{array}$} & \multicolumn{2}{|c|}{$\begin{array}{l}\text { Standard deviation of recov- } \\
\text { ery (percent) of field matrix } \\
\text { spikes analyzed by }\end{array}$} & \multirow{2}{*}{$\begin{array}{l}\text { Method having the } \\
\text { larger standard } \\
\text { deviation of recovery }\end{array}$} & \multicolumn{2}{|c|}{$\begin{array}{l}\text { Levene's test for } \\
\text { equality of variance }\end{array}$} \\
\hline & & $\begin{array}{c}\text { Schedule } \\
2060\end{array}$ & $\begin{array}{c}\text { Schedule } \\
2437\end{array}$ & $\begin{array}{c}\text { Schedule } \\
2060\end{array}$ & $\begin{array}{c}\text { Schedule } \\
2437\end{array}$ & & $\begin{array}{c}\text { Test } \\
\text { statistic }\end{array}$ & $p$-value \\
\hline 84 & Nicosulfuron & 144 & 145 & 91.1 & 17.9 & NWQL2060 & 62.9 & $<0.0001$ \\
\hline 78 & Imazaquin & 144 & 145 & 71.4 & 11.8 & NWQL2060 & 58.1 & $<0.0001$ \\
\hline 67 & Aldicarb_sulfoxide & 142 & 145 & 24.7 & 14.3 & NWQL2060 & 37.1 & $<0.0001$ \\
\hline 87 & Oxamyl & 141 & 144 & 52.6 & 22.4 & NWQL2060 & 32.5 & $<0.0001$ \\
\hline 79 & Imazethapyr & 144 & 145 & 62.8 & 20.3 & NWQL2060 & 27.1 & $<0.0001$ \\
\hline 91 & Sulfometuron-methyl & 144 & 145 & 45.8 & 14.2 & NWQL2060 & 24.9 & $<0.0001$ \\
\hline 81 & Linuron & 122 & 145 & 36.4 & 10.2 & NWQL2060 & 20.1 & $<0.0001$ \\
\hline 2 & Carbaryl & 142 & 145 & 35.4 & 21.5 & NWQL2060 & 19.5 & $<0.0001$ \\
\hline 75 & Diuron & 142 & 143 & 15.1 & 9.5 & NWQL2060 & 17.1 & $<0.0001$ \\
\hline 64 & 3-Hydroxycarbofuran & 142 & 145 & 28.5 & 18.2 & NWQL2060 & 16.7 & $<0.0001$ \\
\hline 71 & Chlorimuron-ethyl & 144 & 145 & 23.4 & 17.7 & NWQL2060 & 8.9 & 0.0031 \\
\hline 6 & Tebuthiuron & 144 & 145 & 12.9 & 9.5 & NWQL2060 & 7.5 & 0.0066 \\
\hline 88 & Propiconazole & 144 & 145 & 19.6 & 16.8 & NWQL2060 & 3.6 & 0.0591 \\
\hline 1 & Atrazine & 140 & 141 & 27.1 & 16.0 & NWQL2060 & 3.5 & 0.0626 \\
\hline 63 & 2-Hydroxyatrazine & 144 & 145 & 29.6 & 19.1 & NWQL2060 & 2.9 & 0.0905 \\
\hline 80 & Imidacloprid & 134 & 145 & 27.6 & 24.5 & NWQL2060 & 0.5 & 0.4785 \\
\hline 92 & Terbacil & 144 & 145 & 7.0 & 24.2 & NWQL2437 & 75.3 & $<0.0001$ \\
\hline 82 & MCPA & 144 & 145 & 7.6 & 22.0 & NWQL2437 & 57.0 & $<0.0001$ \\
\hline 93 & Triclopyr & 144 & 145 & 10.0 & 20.4 & NWQL2437 & 36.9 & $<0.0001$ \\
\hline 62 & $2,4-\mathrm{D}$ & 143 & 143 & 8.3 & 19.7 & NWQL2437 & 33.6 & $<0.0001$ \\
\hline 70 & Bromoxynil & 144 & 145 & 7.0 & 19.9 & NWQL2437 & 31.1 & $<0.0001$ \\
\hline 72 & Dacthal_monoacid & 144 & 145 & 12.7 & 61.4 & NWQL2437 & 30.1 & $<0.0001$ \\
\hline 5 & Metalaxyl & 142 & 145 & 6.8 & 14.7 & NWQL2437 & 28.7 & $<0.0001$ \\
\hline 4 & Deethylatrazine & 142 & 145 & 9.3 & 16.3 & NWQL2437 & 25.6 & $<0.0001$ \\
\hline 66 & Aldicarb_sulfone & 142 & 145 & 13.8 & 19.4 & NWQL2437 & 12.7 & 0.0004 \\
\hline 69 & Bromacil & 144 & 145 & 9.8 & 19.2 & NWQL2437 & 12.0 & 0.0006 \\
\hline 83 & Methomyl & 142 & 145 & 12.3 & 20.8 & NWQL2437 & 11.6 & 0.0007 \\
\hline 68 & Bentazon & 144 & 145 & 10.5 & 16.2 & NWQL2437 & 11.3 & 0.0009 \\
\hline 74 & Dicamba & 143 & 144 & 22.8 & 52.3 & NWQL2437 & 8.9 & 0.0030 \\
\hline 85 & Norflurazon & 144 & 145 & 8.8 & 22.7 & NWQL2437 & 7.6 & 0.0063 \\
\hline 65 & Aldicarb & 142 & 145 & 12.3 & 17.2 & NWQL2437 & 4.7 & 0.0316 \\
\hline 77 & Fluometuron & 144 & 145 & 7.5 & 9.5 & NWQL2437 & 4.7 & 0.0317 \\
\hline 73 & Deisopropylatrazine & 142 & 145 & 15.5 & 19.5 & NWQL2437 & 4.5 & 0.0343 \\
\hline 76 & Flumetsulam & 144 & 145 & 25.7 & 36.9 & NWQL2437 & 4.5 & 0.0354 \\
\hline 3 & Carbofuran & 142 & 145 & 11.6 & 14.6 & NWQL2437 & 3.3 & 0.0686 \\
\hline 86 & Oryzalin & 144 & 145 & 18.4 & 21.2 & NWQL2437 & 2.9 & 0.0922 \\
\hline 90 & Siduron & 144 & 145 & 11.1 & 11.3 & NWQL2437 & 0.0 & 0.8837 \\
\hline 89 & Propoxur & 142 & 145 & 14.3 & 14.4 & NWQL2437 & 0.0 & 0.9147 \\
\hline
\end{tabular}




\section{Detections in Paired Environmental Stream- Water Samples}

Counts and percentages of samples with pesticide detections have been an important metric for water-quality assessments (Gilliom and others, 2006). The sign test was used to identify differences in pesticide detections in paired environmental water samples analyzed by old and new methods. Detected concentrations were assigned a value of 1 and nondetections were assigned a value of 0 for the purposes of the paired sign test. The sign test was applied to (1) all paired samples, regardless of the concentration detected, and (2) paired samples where concentrations detected were less than or equal to the concentration of the largest reporting level for either method.

A little more than one-half of the 61 pesticides common to sh2033 and sh2437 had one or more detections in paired water samples (table 13). For all concentrations, detection frequency was significantly greater by sh2033 for nine pesticides and significantly greater by sh 2437 for five pesticides. Sign test results were very similar for concentrations less than or equal to the concentration of the largest reporting level for either method. Only one additional pesticide, tebuconazole, had a significantly different frequency of detection for the low range of concentrations (greater by sh2437, table 13). About 60 percent of the pesticides had six or fewer detections by either method; consequently, difference in detection capability for these pesticides could not be readily assessed. The distributions of pesticide detections in paired environmental water samples analyzed by sh2033 and sh2437 are shown in scatterplots in appendix 5 and for atrazine in figure 9.

Most of the 38 pesticides common to sh2060 and sh2437 had one or more detections in paired water samples (table 14). For all concentrations, detection frequency was significantly greater by sh 2060 for 0 pesticides and significantly greater by sh 2437 for 22 pesticides. As above, sign test results were very similar for all concentrations and for concentrations less than or equal to the concentration of the largest reporting level for either method. No additional pesticides had a significantly different frequency of detection for the low range of concentrations. About 35 percent of the pesticides had six or fewer detections by either method; consequently, difference in detection capability for these pesticides could not be readily assessed. The distributions of pesticide detections in paired environmental water samples analyzed by sh2060 and sh2437 are shown in scatterplots in appendix 6 and for atrazine in figure 10 .

\section{Concentrations in Paired Environmental Stream- Water Samples}

The sign test was used to identify differences in pesticide concentrations in paired environmental water samples analyzed by old and new methods. Only pairs where the pesticide was detected by both methods were used in the tests. The sign test was done for the original concentrations as reported by the laboratory and for recovery-adjusted concentrations.

Only 27 of the 61 pesticides common to sh2033 and sh2437 had at least one pair of detections by both methods (table 15). Statistical test results for unadjusted and recoveryadjusted concentrations were similar. Of the 27 pesticides, 17 had significantly higher concentrations measured by sh2033 than by sh2437 (table 15). Based on the magnitude of the mean logical percent difference, and the lowess smooths in appendix 7 , recovery adjustment improved the agreement between schedules for 16 of the 17 pesticides with significant differences. Hexazinone was the lone exception (table 15). Statistical significance was a strong function of sample size as all pesticides with 6 or fewer paired samples with detections were not significant and all pesticides (except for deethylatrazine) with 11 or more paired samples with detections were significant (table 15).

Scatterplots of atrazine concentrations measured by both methods in paired environmental water samples showed that measurements by sh2033 were approximately 1.5 to 2.5 times greater than those measured by $\operatorname{sh} 2437$ at concentrations less than $10 \mathrm{ng} / \mathrm{L}$ (fig. 11). At concentrations greater than $100 \mathrm{ng} / \mathrm{L}$, the measurements by both methods were similar. This pattern of distinctly greater concentrations by sh2033 at the low range of concentrations and more similar concentrations at the high range of concentrations was exhibited by many of the pesticides with detections over a large range of concentrations (appendix 7).

Only 24 of the 38 pesticides common to sh 2060 and sh2437 had at least one pair of detections by both methods (table 16). For original, unadjusted concentrations, six pesticides had significantly higher concentrations measured by sh2060 and five had significantly higher concentrations measured by sh2437 (table 16). For recovery-adjusted concentrations, five pesticides had significantly higher concentrations measured by sh2060 and only two had significantly higher concentrations measured by sh2437. Statistical significance generally was a function of sample size, but less so than for the sh2033 method. Pesticides (except imidacloprid) with 17 or more paired samples with detections generally showed significant differences between methods, whereas pesticides with 6 or fewer paired samples with detections were not significantly different (table 16).

Scatterplots of atrazine concentrations measured by both methods in paired environmental water samples showed that measurements by sh 2060 generally were slightly greater than those measured by sh2437 at concentrations less than approximately $25 \mathrm{ng} / \mathrm{L}$ (fig. 12). At concentrations greater than $25 \mathrm{ng} / \mathrm{L}$, the measurements by both methods were similar, with some exceptions. This pattern of greater concentrations by sh2060 at the low range of concentrations and similar concentrations at the high range of concentrations was exhibited by several of the pesticides with detections over a large range of concentrations (appendix 8). 
Table 13. Comparison of pesticide detections in paired environmental stream-water samples analyzed by both schedule 2033 and schedule 2437.

[Pesticides are sorted by the paired sign test statistic for all concentrations. Probablity values less than 0.05 are shown in bold. ng/L, nanogram per liter; $<$, less than; NA, not applicable]

\begin{tabular}{|c|c|c|c|c|c|c|c|c|c|}
\hline \multirow[b]{3}{*}{ Index } & \multirow[b]{3}{*}{ Pesticide short name } & \multirow{2}{*}{\multicolumn{2}{|c|}{$\begin{array}{c}\text { Method } \\
\text { reporting level } \\
\text { (ng/L) }\end{array}$}} & \multicolumn{6}{|c|}{ Information for all concentrations } \\
\hline & & & & \multirow{2}{*}{$\begin{array}{l}\text { Number of } \\
\text { paired en- } \\
\text { vironmental } \\
\text { samples }\end{array}$} & \multirow{2}{*}{$\begin{array}{c}\text { Number } \\
\text { of paired } \\
\text { environmental } \\
\text { samples with } \\
\text { no detections } \\
\text { by either } \\
\text { method }\end{array}$} & \multirow{2}{*}{$\begin{array}{c}\begin{array}{c}\text { Number } \\
\text { of paired }\end{array} \\
\text { environmental } \\
\text { samples with } \\
\text { detections by } \\
\text { both methods }\end{array}$} & \multirow{2}{*}{$\begin{array}{c}\text { Number } \\
\text { of paired } \\
\text { environmen- } \\
\text { tal samples } \\
\text { with detec- } \\
\text { tions by } \\
\text { schedule } \\
2033 \text { only }\end{array}$} & \multirow{2}{*}{$\begin{array}{c}\text { Number } \\
\text { of paired } \\
\text { environmental } \\
\text { samples with } \\
\text { detections by } \\
\text { schedule } 2437 \\
\text { only }\end{array}$} & \multirow{2}{*}{$\begin{array}{l}\text { When } \\
\text { detected by } \\
\text { at least one } \\
\text { method, the } \\
\text { percentage o } \\
\text { samples with } \\
\text { detections by } \\
\text { both methods }\end{array}$} \\
\hline & & $\begin{array}{c}\text { Schedule } \\
2033\end{array}$ & $\begin{array}{c}\text { Schedule } \\
2437\end{array}$ & & & & & & \\
\hline 33 & Hexazinone & 12 & 3 & 150 & 90 & 12 & 1 & 47 & 20.0 \\
\hline 6 & Tebuthiuron & 28 & 3 & 150 & 72 & 27 & 3 & 48 & 34.6 \\
\hline 5 & Metalaxyl & 14 & 6 & 150 & 85 & 29 & 3 & 33 & 44.6 \\
\hline 20 & Dicrotophos & 80 & 4 & 150 & 132 & 2 & 0 & 16 & 11.1 \\
\hline 21 & Dimethoate & 10 & 3 & 150 & 133 & 6 & 0 & 11 & 35.3 \\
\hline 55 & Tebuconazole & 20 & 5 & 150 & 104 & 20 & 8 & 18 & 43.5 \\
\hline 17 & Diazinon & 6 & 3 & 150 & 144 & 2 & 0 & 4 & 33.3 \\
\hline 40 & Myclobutanil & 10 & 7 & 150 & 123 & 11 & 6 & 10 & 40.7 \\
\hline 49 & Prometon & 12 & 4 & 150 & 22 & 104 & 10 & 14 & 81.3 \\
\hline 25 & Ethoprophos & 16 & 5 & 150 & 146 & 1 & 0 & 3 & 25.0 \\
\hline 3 & Carbofuran & 60 & 4 & 150 & 147 & 0 & 0 & 3 & 0.0 \\
\hline 43 & Parathion-methyl & 8 & 500 & 150 & 148 & 0 & 0 & 2 & 0.0 \\
\hline 58 & Terbuthylazine & 8 & 3 & 150 & 115 & 27 & 3 & 5 & 77.1 \\
\hline 18 & Diazoxon & 12 & 4 & 150 & 149 & 0 & 0 & 1 & 0.0 \\
\hline 31 & Fipronil_sulfone & 24 & 4 & 150 & 115 & 12 & 11 & 12 & 34.3 \\
\hline 35 & Malathion & 16 & 6 & 149 & 147 & 1 & 0 & 1 & 50.0 \\
\hline 44 & Pendimethalin & 12 & 3 & 150 & 142 & 3 & 2 & 3 & 37.5 \\
\hline 53 & Propyzamide & 3.6 & 4 & 150 & 146 & 3 & 0 & 1 & 75.0 \\
\hline 61 & cis-Permethrin & 10 & 2 & 142 & 139 & 0 & 1 & 2 & 0.0 \\
\hline 10 & Azinphos-methyl & 120 & 8 & 150 & 150 & 0 & 0 & 0 & NA \\
\hline 11 & Azinphos-methyl-oxon & 42 & 15 & 150 & 150 & 0 & 0 & 0 & NA \\
\hline 13 & Chlorpyrifos_oxon & 80 & 4 & 150 & 150 & 0 & 0 & 0 & NA \\
\hline 14 & Cyanazine & 22 & 16 & 150 & 150 & 0 & 0 & 0 & NA \\
\hline 19 & Dichlorvos & 40 & 52 & 150 & 150 & 0 & 0 & 0 & NA \\
\hline 22 & Disulfoton & 40 & 13 & 150 & 150 & 0 & 0 & 0 & NA \\
\hline 23 & Disulfoton_sulfone & 14 & 9 & 150 & 150 & 0 & 0 & 0 & NA \\
\hline 26 & Fenamiphos & 30 & 2 & 150 & 150 & 0 & 0 & 0 & NA \\
\hline 27 & Fenamiphos_sulfone & 54 & 5 & 150 & 150 & 0 & 0 & 0 & NA \\
\hline 28 & Fenamiphos_sulfoxide & 80 & 5 & 150 & 150 & 0 & 0 & 0 & NA \\
\hline 32 & Fonofos & 4.8 & 11 & 150 & 150 & 0 & 0 & 0 & NA \\
\hline 34 & Malaoxon & 22 & 3 & 150 & 150 & 0 & 0 & 0 & NA \\
\hline 36 & Methidathion & 12 & 10 & 150 & 150 & 0 & 0 & 0 & NA \\
\hline 39 & Molinate & 4 & 18 & 150 & 150 & 0 & 0 & 0 & NA \\
\hline 42 & Paraoxon-methyl & 14 & 19 & 150 & 150 & 0 & 0 & 0 & NA \\
\hline
\end{tabular}




\begin{tabular}{|c|c|c|c|c|c|c|c|c|c|}
\hline & & \multicolumn{8}{|c|}{ Information for concentrations less than the largest reporting level of either method } \\
\hline \multicolumn{2}{|c|}{ Sign test } & \multirow{2}{*}{$\begin{array}{c}\text { Number } \\
\text { of paired } \\
\text { environ- } \\
\text { mental } \\
\text { samples }\end{array}$} & \multirow{2}{*}{$\begin{array}{c}\text { Number of } \\
\text { paired environ- } \\
\text { mental samples } \\
\text { with no detec- } \\
\text { tions by either } \\
\text { method }\end{array}$} & \multirow{2}{*}{$\begin{array}{c}\text { Number } \\
\text { of paired } \\
\text { environmental } \\
\text { samples with } \\
\text { detections by } \\
\text { both methods }\end{array}$} & \multirow{2}{*}{$\begin{array}{c}\text { Number } \\
\text { of paired } \\
\text { environmental } \\
\text { samples with } \\
\text { detections by } \\
\text { schedule } 2033 \\
\text { only }\end{array}$} & \multirow{2}{*}{$\begin{array}{c}\begin{array}{c}\text { Number } \\
\text { of paired }\end{array} \\
\text { environmental } \\
\text { samples with } \\
\text { detections by } \\
\text { schedule } 2437 \\
\text { only }\end{array}$} & \multirow{2}{*}{$\begin{array}{l}\text { When detected } \\
\text { by at least one } \\
\text { method, the } \\
\text { percentage of } \\
\text { samples with } \\
\text { detections by } \\
\text { both methods }\end{array}$} & \multicolumn{2}{|c|}{ Sign test } \\
\hline $\begin{array}{c}\text { Test } \\
\text { statistic }\end{array}$ & $p$-value & & & & & & & $\begin{array}{c}\text { Test } \\
\text { statistic }\end{array}$ & $p$-value \\
\hline-23.0 & $<0.0001$ & 145 & 90 & 8 & 0 & 47 & 14.5 & -23.5 & $<0.0001$ \\
\hline-22.5 & $<0.0001$ & 135 & 72 & 13 & 2 & 48 & 20.6 & -23.0 & $<0.0001$ \\
\hline-15.0 & $<0.0001$ & 138 & 84 & 18 & 3 & 33 & 33.3 & -15.0 & $<0.0001$ \\
\hline-8.0 & $<0.0001$ & 150 & 132 & 2 & 0 & 16 & 11.1 & -8.0 & $<0.0001$ \\
\hline-5.5 & 0.0010 & 146 & 133 & 2 & 0 & 11 & 15.4 & -5.5 & 0.0010 \\
\hline-5.0 & 0.0755 & 137 & 104 & 8 & 7 & 18 & 24.2 & -5.5 & 0.0433 \\
\hline-2.0 & 0.1250 & 148 & 144 & 0 & 0 & 4 & 0.0 & -2.0 & 0.1250 \\
\hline-2.0 & 0.4545 & 142 & 123 & 5 & 4 & 10 & 26.3 & -3.0 & 0.1796 \\
\hline-2.0 & 0.5413 & 114 & 22 & 70 & 10 & 12 & 76.1 & -1.0 & 0.8318 \\
\hline-1.5 & 0.2500 & 147 & 146 & 0 & 0 & 1 & 0.0 & -0.5 & 1.0000 \\
\hline-1.5 & 0.2500 & 150 & 147 & 0 & 0 & 3 & 0.0 & -1.5 & 0.2500 \\
\hline-1.0 & 0.5000 & 150 & 148 & 0 & 0 & 2 & 0.0 & -1.0 & 0.5000 \\
\hline-1.0 & 0.7266 & 138 & 115 & 15 & 3 & 5 & 65.2 & -1.0 & 0.7266 \\
\hline-0.5 & 1.0000 & 149 & 149 & 0 & 0 & 0 & NA & NA & NA \\
\hline-0.5 & 1.0000 & 148 & 115 & 11 & 10 & 12 & 33.3 & -1.0 & 0.8318 \\
\hline-0.5 & 1.0000 & 148 & 146 & 1 & 0 & 1 & 50.0 & -0.5 & 1.0000 \\
\hline-0.5 & 1.0000 & 146 & 142 & 0 & 2 & 2 & 0.0 & 0.0 & 1.0000 \\
\hline-0.5 & 1.0000 & 147 & 146 & 0 & 0 & 1 & 0.0 & -0.5 & 1.0000 \\
\hline-0.5 & 1.0000 & 140 & 139 & 0 & 1 & 0 & 0.0 & 0.5 & 1.0000 \\
\hline NA & NA & 150 & 150 & 0 & 0 & 0 & NA & NA & NA \\
\hline NA & NA & 150 & $150 \mathrm{w}$ & 0 & 0 & 0 & NA & NA & NA \\
\hline NA & NA & 150 & 150 & 0 & 0 & 0 & NA & NA & NA \\
\hline NA & NA & 101 & 101 & 0 & 0 & 0 & NA & NA & NA \\
\hline NA & NA & 150 & 150 & 0 & 0 & 0 & NA & NA & NA \\
\hline NA & NA & 150 & 150 & 0 & 0 & 0 & NA & NA & NA \\
\hline NA & NA & 150 & 150 & 0 & 0 & 0 & NA & NA & NA \\
\hline NA & NA & 150 & 150 & 0 & 0 & 0 & NA & NA & NA \\
\hline NA & NA & 150 & 150 & 0 & 0 & 0 & NA & NA & NA \\
\hline NA & NA & 150 & 150 & 0 & 0 & 0 & NA & NA & NA \\
\hline NA & NA & 150 & 150 & 0 & 0 & 0 & NA & NA & NA \\
\hline NA & NA & 150 & 150 & 0 & 0 & 0 & NA & NA & NA \\
\hline NA & NA & 150 & 150 & 0 & 0 & 0 & NA & NA & NA \\
\hline NA & NA & 150 & 150 & 0 & 0 & 0 & NA & NA & NA \\
\hline NA & NA & 150 & 150 & 0 & 0 & 0 & NA & NA & NA \\
\hline
\end{tabular}


Table 13. Comparison of pesticide detections in paired environmental stream-water samples analyzed by both schedule 2033 and schedule 2437.-Continued

[Pesticides are sorted by the paired sign test statistic for all concentrations. Probablity values less than 0.05 are shown in bold. ng/L, nanogram per liter; $<$, less than; NA, not applicable]

\begin{tabular}{|c|c|c|c|c|c|c|c|c|c|}
\hline \multirow[b]{3}{*}{ Index } & \multirow[b]{3}{*}{ Pesticide short name } & \multirow{2}{*}{\multicolumn{2}{|c|}{$\begin{array}{c}\text { Method } \\
\text { reporting level } \\
\text { (ng/L) }\end{array}$}} & \multicolumn{6}{|c|}{ Information for all concentrations } \\
\hline & & & & \multirow{2}{*}{$\begin{array}{l}\text { Number of } \\
\text { paired en- } \\
\text { vironmental } \\
\text { samples }\end{array}$} & \multirow{2}{*}{$\begin{array}{c}\text { Number } \\
\text { of paired } \\
\text { environmental } \\
\text { samples with } \\
\text { no detections } \\
\text { by either } \\
\text { method }\end{array}$} & \multirow{2}{*}{$\begin{array}{c}\text { Number } \\
\text { of paired } \\
\text { environmental } \\
\text { samples with } \\
\text { detections by } \\
\text { both methods }\end{array}$} & \multirow{2}{*}{$\begin{array}{c}\text { Number } \\
\text { of paired } \\
\text { environmen- } \\
\text { tal samples } \\
\text { with detec- } \\
\text { tions by } \\
\text { schedule } \\
2033 \text { only }\end{array}$} & \multirow{2}{*}{$\begin{array}{c}\text { Number } \\
\text { of paired } \\
\text { environmental } \\
\text { samples with } \\
\text { detections by } \\
\text { schedule } 2437 \\
\text { only }\end{array}$} & \multirow{2}{*}{$\begin{array}{l}\text { When } \\
\text { detected by } \\
\text { at least one } \\
\text { method, the } \\
\text { percentage o } \\
\text { samples with } \\
\text { detections by } \\
\text { both methods }\end{array}$} \\
\hline & & $\begin{array}{c}\text { Schedule } \\
2033\end{array}$ & $\begin{array}{c}\text { Schedule } \\
2437\end{array}$ & & & & & & \\
\hline 45 & Phorate & 20 & 6 & 150 & 150 & 0 & 0 & 0 & NA \\
\hline 46 & Phorate_oxon & 27 & 4 & 150 & 150 & 0 & 0 & 0 & NA \\
\hline 47 & Phosmet & 80 & 20 & 150 & 150 & 0 & 0 & 0 & NA \\
\hline 48 & Phosmet_oxon & 51.1 & 21 & 54 & 54 & 0 & 0 & 0 & NA \\
\hline 51 & Propanil & 10 & 11 & 150 & 150 & 0 & 0 & 0 & NA \\
\hline 56 & Terbufos & 18 & 4 & 150 & 150 & 0 & 0 & 0 & NA \\
\hline 57 & Terbufos_sulfo_nalog & 45 & 11 & 146 & 146 & 0 & 0 & 0 & NA \\
\hline 59 & Thiobencarb & 16 & 2 & 150 & 150 & 0 & 0 & 0 & NA \\
\hline 7 & 2-Chloro-2,6-d_ilide & 10 & 5 & 150 & 150 & 0 & 0 & 0 & NA \\
\hline 9 & Alachlor & 8 & 9 & 150 & 148 & 0 & 1 & 1 & 0.0 \\
\hline 52 & Propargite & 20 & 2 & 150 & 149 & 0 & 1 & 0 & 0.0 \\
\hline 60 & Tribuphos & 18 & 2 & 150 & 149 & 0 & 1 & 0 & 0.0 \\
\hline 41 & Oxyfluorfen & 10 & 500 & 149 & 147 & 0 & 2 & 0 & 0.0 \\
\hline 50 & Prometryn & 10 & 2 & 150 & 117 & 26 & 5 & 2 & 78.8 \\
\hline 1 & Atrazine & 8 & 5 & 150 & 14 & 122 & 9 & 5 & 89.7 \\
\hline 24 & EPTC & 5.6 & 206 & 150 & 145 & 0 & 5 & 0 & 0.0 \\
\hline 37 & Metolachlor & 20 & 9 & 150 & 24 & 112 & 10 & 4 & 88.9 \\
\hline 2 & Carbaryl & 60 & 6 & 150 & 129 & 11 & 9 & 1 & 52.4 \\
\hline 38 & Metribuzin & 12 & 20 & 150 & 136 & 6 & 8 & 0 & 42.9 \\
\hline 29 & Fipronil & 18 & 4 & 150 & 91 & 30 & 19 & 10 & 50.8 \\
\hline 4 & Deethylatrazine & 6 & 11 & 150 & 18 & 112 & 17 & 3 & 84.8 \\
\hline 12 & Chlorpyrifos & 3.6 & 4 & 150 & 133 & 2 & 15 & 0 & 11.8 \\
\hline 8 & Acetochlor & 10 & 10 & 150 & 92 & 36 & 21 & 1 & 62.1 \\
\hline 15 & Desulfinylfipro_mide & 29 & 9 & 150 & 128 & 0 & 22 & 0 & 0.0 \\
\hline 30 & Fipronil_sulfide & 12 & 4 & 150 & 87 & 23 & 38 & 2 & 36.5 \\
\hline 54 & Simazine & 6 & 10 & 150 & 44 & 62 & 42 & 2 & 58.5 \\
\hline 16 & Desulfinylfipronil & 12 & 4 & 150 & 63 & 38 & 48 & 1 & 43.7 \\
\hline
\end{tabular}


Information for concentrations less than the largest reporting level of either method

\begin{tabular}{|c|c|c|c|c|c|c|c|c|c|}
\hline \multicolumn{2}{|c|}{ Sign test } & \multirow{2}{*}{$\begin{array}{c}\text { Number } \\
\text { of paired } \\
\text { environ- } \\
\text { mental } \\
\text { samples }\end{array}$} & \multirow{2}{*}{$\begin{array}{c}\text { Number of } \\
\text { paired environ- } \\
\text { mental samples } \\
\text { with no detec- } \\
\text { tions by either } \\
\text { method }\end{array}$} & \multirow{2}{*}{$\begin{array}{c}\text { Number } \\
\text { of paired } \\
\text { environmental } \\
\text { samples with } \\
\text { detections by } \\
\text { both methods }\end{array}$} & \multirow{2}{*}{$\begin{array}{c}\begin{array}{c}\text { Number } \\
\text { of paired }\end{array} \\
\text { environmental } \\
\text { samples with } \\
\text { detections by } \\
\text { schedule } 2033 \\
\text { only }\end{array}$} & \multirow{2}{*}{$\begin{array}{c}\begin{array}{c}\text { Number } \\
\text { of paired } \\
\text { environmental }\end{array} \\
\text { samples with } \\
\text { detections by } \\
\text { schedule } 2437 \\
\text { only }\end{array}$} & \multirow{2}{*}{$\begin{array}{l}\text { When detected } \\
\text { by at least one } \\
\text { method, the } \\
\text { percentage of } \\
\text { samples with } \\
\text { detections by } \\
\text { both methods }\end{array}$} & \multicolumn{2}{|c|}{ Sign test } \\
\hline $\begin{array}{c}\text { Test } \\
\text { statistic }\end{array}$ & $p$-value & & & & & & & $\begin{array}{c}\text { Test } \\
\text { statistic }\end{array}$ & $p$-value \\
\hline NA & NA & 150 & 150 & 0 & 0 & 0 & NA & NA & NA \\
\hline NA & NA & 149 & 149 & 0 & 0 & 0 & NA & NA & NA \\
\hline NA & NA & 126 & 126 & 0 & 0 & 0 & NA & NA & NA \\
\hline NA & NA & 54 & 54 & 0 & 0 & 0 & NA & NA & NA \\
\hline NA & NA & 150 & 150 & 0 & 0 & 0 & NA & NA & NA \\
\hline NA & NA & 150 & 150 & 0 & 0 & 0 & NA & NA & NA \\
\hline NA & NA & 146 & 146 & 0 & 0 & 0 & NA & NA & NA \\
\hline NA & NA & 150 & 150 & 0 & 0 & 0 & NA & NA & NA \\
\hline NA & NA & 150 & 150 & 0 & 0 & 0 & NA & NA & NA \\
\hline 0.0 & 1.0000 & 150 & 148 & 0 & 1 & 1 & 0.0 & 0.0 & 1.0000 \\
\hline 0.5 & 1.0000 & 149 & 149 & 0 & 0 & 0 & NA & NA & NA \\
\hline 0.5 & 1.0000 & 149 & 148 & 0 & 1 & 0 & 0.0 & 0.5 & 1.0000 \\
\hline 1.0 & 0.5000 & 149 & 147 & 0 & 2 & 0 & 0.0 & 1.0 & 0.5000 \\
\hline 1.5 & 0.4531 & 137 & 117 & 13 & 5 & 2 & 65.0 & 1.5 & 0.4531 \\
\hline 2.0 & 0.4240 & 39 & 13 & 12 & 9 & 5 & 46.2 & 2.0 & 0.4240 \\
\hline 2.5 & 0.0625 & 150 & 145 & 0 & 5 & 0 & 0.0 & 2.5 & 0.0625 \\
\hline 3.0 & 0.1796 & 73 & 24 & 35 & 10 & 4 & 71.4 & 3.0 & 0.1796 \\
\hline 4.0 & 0.0215 & 149 & 129 & 10 & 9 & 1 & 50.0 & 4.0 & 0.0215 \\
\hline 4.0 & 0.0078 & 145 & 136 & 3 & 6 & 0 & 33.3 & 3.0 & 0.0313 \\
\hline 4.5 & 0.1360 & 141 & 91 & 21 & 19 & 10 & 42.0 & 4.5 & 0.1360 \\
\hline 7.0 & 0.0026 & 53 & 18 & 16 & 17 & 2 & 45.7 & 7.5 & 0.0007 \\
\hline 7.5 & $<0.0001$ & 138 & 132 & 0 & 6 & 0 & 0.0 & 3.0 & 0.0313 \\
\hline 10.0 & $<0.0001$ & 102 & 92 & 0 & 10 & 0 & 0.0 & 5.0 & 0.0020 \\
\hline 11.0 & $<0.0001$ & 150 & 128 & 0 & 22 & 0 & 0.0 & 11.0 & $<0.0001$ \\
\hline 18.0 & $<0.0001$ & 147 & 87 & 22 & 36 & 2 & 36.7 & 17.0 & $<0.0001$ \\
\hline 20.0 & $<0.0001$ & 84 & 44 & 4 & 34 & 2 & 10.0 & 16.0 & $<0.0001$ \\
\hline 23.5 & $<0.0001$ & 150 & 63 & 38 & 48 & 1 & 43.7 & 23.5 & $<0.0001$ \\
\hline
\end{tabular}



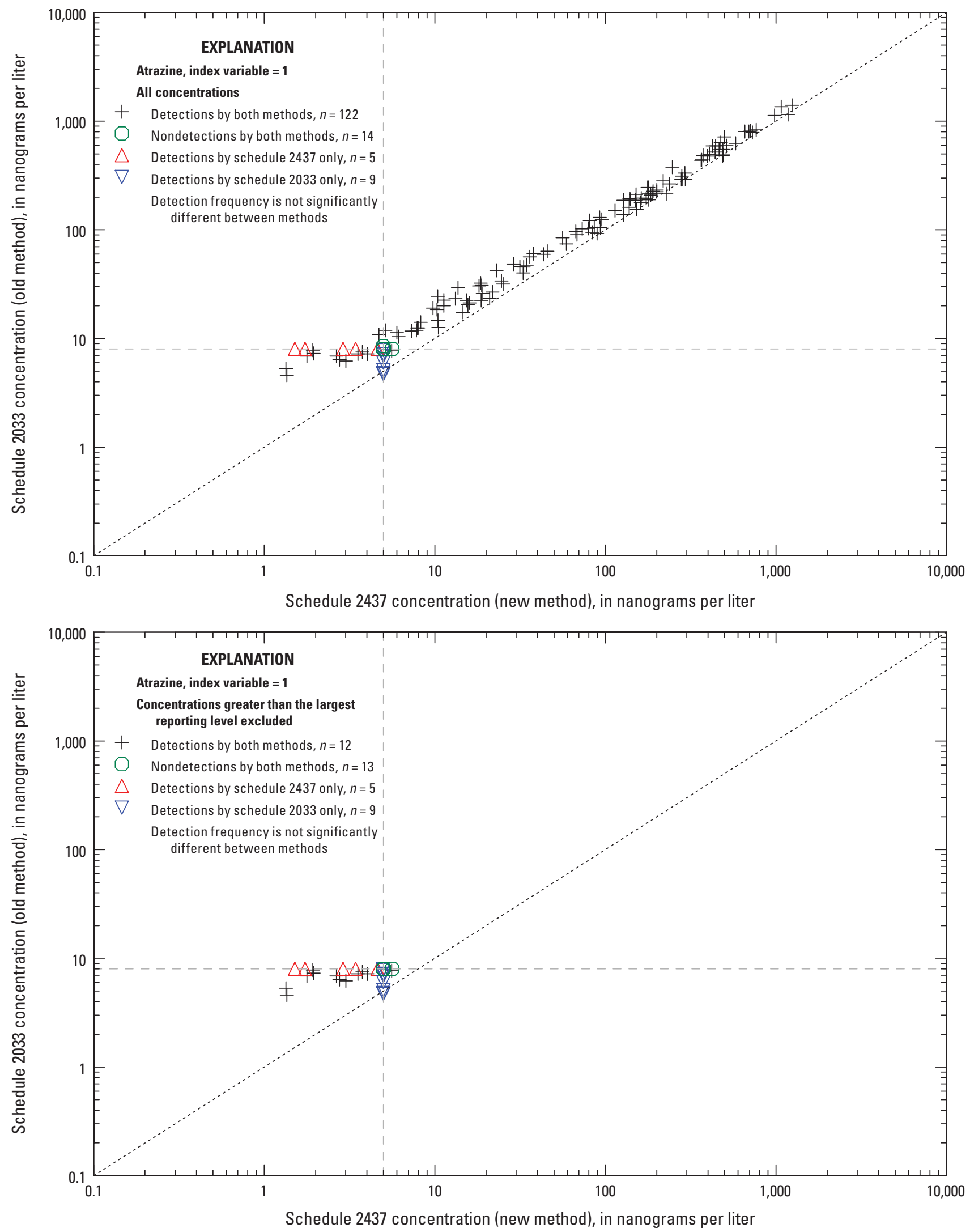

Figure 9. Comparison of atrazine detections in paired environmental stream-water samples analyzed by both schedule 2033 and schedule 2437. The horizontal dashed line is the reporting level for schedule 2033 and the vertical dashed line is the reporting level for schedule 2437. See table 13 for information on statistical differences between methods. 
Recovery adjustment generally improved agreement between methods; atrazine and metalaxyl, however, had mean logical percent differences closer to zero for unadjusted concentrations than for recovery-adjusted concentrations (table 16). The distributions of unadjusted and recoveryadjusted concentrations in paired environmental water samples analyzed by sh 2060 and sh 2437 are shown in scatterplots in appendix 8 .

\section{Contamination in Field Blank Water Samples}

Three field blank water samples were collected during the same site visit from almost every stream-water site. Each of the blank samples was analyzed by one of the three methods/ schedules. Only 16 of 283 pesticides were detected in field blank samples (table 17). The vast majority of pesticide detections were at concentrations less than the reporting level. Only tebuconazole, diuron, and 2-isopropyl-6-methyl-4-pyrimidinol were detected in blanks at concentrations greater than the reporting level (table 18).

Diuron was the most frequently detected pesticide and was detected in 3 of 44 ( 6.8 percent) blanks analyzed by sh2060 and by 1 of 43 (2.3 percent) blanks analyzed by sh2437. The frequency of detection of diuron, however, was not significantly different $(\mathrm{alpha}=0.05)$ from pesticides with no detections. A statistically significant difference would require 7 versus 0 detections in 44 field blanks and indicates insufficient evidence to identify a difference in contamination among pesticides or among analytical methods.

\section{Variability of Pesticides Analyzed by Schedule 2437}

Knowledge of the variability of pesticide detections or concentrations is critical for interpreting water-quality conditions, particularly when only one sample is used to characterize a particular condition. Variability of pesticide detections and concentrations typically is a function of concentration (Martin, 2002, p. 1) and is assessed as a function of concentration in the next two sections. Analytical data for duplicate environmental water samples analyzed by sh2437 are provided in Martin and Baker (2017, dataset 7).

\section{Variability of Detection}

"Inconsistent detection" is the term used to describe the condition where a pesticide is detected in one duplicate water sample but is not detected in the paired duplicate water sample. The rate of inconsistent detection of pesticides in duplicate environmental water samples was assessed as a function of concentration class. Duplicate sets were assigned to a concentration class on the basis of the median concentration of the duplicate set. Concentration classes are a function of the reporting level. Median concentrations less than the reporting level were assigned to class 1Low. Median concentrations greater than or equal to the reporting level but less than 10 times the reporting level were assigned to class $2 \mathrm{Med}$. Median concentrations greater than or equal to 10 times the reporting level were assigned to class 3 High. Nondetections were set to $0 \mathrm{ng} / \mathrm{L}$ for calculating the median concentration of duplicate sets.

Of the 239 pesticides analyzed by sh2437, 114 were detected at least once in at least one of the 52 sets of duplicate environmental water samples (table 19). The most pesticide detections in a concentration class were 28 for hydroxysimazine and for diuron in the class $2 \mathrm{Med}$. Inconsistent detection was 3.6 percent for hydroxysimazine and was 0.0 percent for diuron. The upper 90-percent confidence bound for inconsistent detection in this concentration class was 13.2 percent for hydroxysimazine and was 7.9 percent for diuron (table 19).

The frequency of inconsistent detection for pesticides analyzed by sh2437 is much less than that observed for older GC-MS and high-performance liquid chromatograph (HPLC) pesticide methods summarized in Martin (2002). Martin (2002, p. 32-33) used the thresholds of less than 25 percent inconsistent duplicate sets to indicate low variability of detection and more than 50 percent inconsistent duplicate sets to indicate high variability of detection. For the low range of concentration, older methods had only 3 of 50 pesticides that exhibited low detection variability and 45 of 50 pesticides that exhibited high detection variability. For sh2437 in the low range of concentration, 65 of 91 pesticides have low detection variability and only 8 of 91 pesticides have high detection variability (table 19).

Martin (2002) summed the numbers of replicate sets, by concentration class, for all pesticides measured by old GC-MS and HPLC pesticide methods. The overall frequency of inconsistent replicate sets was 60.0 percent in the low range, 13.7 percent in the medium range, and 1.1 percent in the high range of concentration (Martin, 2002, p. 33). For sh2437, the overall frequency of inconsistent replicate sets was 14.3 percent in the low range, 0.8 percent in the medium range, and 0.6 percent in the high range of concentration.

\section{Variability of Concentrations}

The variability of pesticide concentrations in duplicate environmental water samples was assessed as a function of 11 overlapping, "order of magnitude" concentration classes (for example, $<1 \mathrm{ng} / \mathrm{L}$ (CR01), 0.5 to $<5 \mathrm{ng} / \mathrm{L}$ (CR02), 1 to $<10 \mathrm{ng} / \mathrm{L}$ (CR03), and so forth). Duplicate sets typically were assigned to two concentration classes on the basis of the median concentration of the duplicate set. Nondetections were set to $0 \mathrm{ng} / \mathrm{L}$ for calculating the median concentration of duplicate sets. The most duplicates in a concentration class were 29 for prometon in CR03 (1 to less than $10 \mathrm{ng} / \mathrm{L}$ ) (table 20).

Variability estimates presented in table 20 are summarized by concentration class in table 21. Most duplicate sets with detections were in concentration classes CR02 to CR07 $(0.5$ to $<1,000 \mathrm{ng} / \mathrm{L})$. In these classes, median pooled standard deviation ranged from 0.47 to $13 \mathrm{ng} / \mathrm{L}$ and median pooled 
Table 14. Comparison of pesticide detections in paired environmental stream-water samples analyzed by both schedule 2060 and schedule 2437.

[Pesticides are sorted by the paired sign test statistic for all concentrations. Probablity values less than 0.05 are shown in bold. ng/L, nanogram per liter; $<$, less than; NA, not applicable]

\begin{tabular}{|c|c|c|c|c|c|c|c|c|c|}
\hline \multirow{3}{*}{ Index } & \multirow{3}{*}{ Pesticide short name } & \multirow{2}{*}{\multicolumn{2}{|c|}{$\begin{array}{c}\text { Method } \\
\text { reporting level } \\
\text { (ng/L) }\end{array}$}} & \multicolumn{6}{|c|}{ Information for all concentrations } \\
\hline & & & & \multirow{2}{*}{$\begin{array}{c}\text { Number } \\
\text { of paired } \\
\text { environ- } \\
\text { mental } \\
\text { samples }\end{array}$} & \multirow{2}{*}{$\begin{array}{c}\text { Number of } \\
\text { paired en- } \\
\text { vironmental } \\
\text { samples with } \\
\text { no detections } \\
\text { by either } \\
\text { method }\end{array}$} & \multirow{2}{*}{$\begin{array}{c}\text { Number } \\
\text { of paired } \\
\text { environmental } \\
\text { samples with } \\
\text { detections by } \\
\text { both methods }\end{array}$} & \multirow{2}{*}{$\begin{array}{l}\text { Number of } \\
\text { paired en- } \\
\text { vironmental } \\
\text { samples } \\
\text { with detec- } \\
\text { tions by } \\
\text { schedule } \\
2060 \text { only }\end{array}$} & \multirow{2}{*}{$\begin{array}{c}\text { Number } \\
\text { of paired } \\
\text { environmental } \\
\text { samples with } \\
\text { detections by } \\
\text { schedule } 2437 \\
\text { only }\end{array}$} & \multirow{2}{*}{$\begin{array}{l}\text { When detected } \\
\text { by at least one } \\
\text { method, the } \\
\text { percentage of } \\
\text { samples with } \\
\text { detections by } \\
\text { both methods }\end{array}$} \\
\hline & & $\begin{array}{c}\text { Schedule } \\
2060\end{array}$ & $\begin{array}{c}\text { Schedule } \\
2437\end{array}$ & & & & & & \\
\hline 69 & Bromacil & 60 & 6 & 147 & 79 & 3 & 0 & 65 & 4.4 \\
\hline 6 & Tebuthiuron & 60 & 3 & 147 & 73 & 11 & 1 & 62 & 14.9 \\
\hline 73 & Deisopropylatrazine & 80 & 20 & 147 & 53 & 33 & 0 & 61 & 35.1 \\
\hline 88 & Propiconazole & 38 & 6 & 147 & 86 & 7 & 0 & 54 & 11.5 \\
\hline 80 & Imidacloprid & 80 & 11 & 146 & 70 & 20 & 6 & 50 & 26.3 \\
\hline 5 & Metalaxyl & 40 & 6 & 147 & 86 & 19 & 0 & 42 & 31.1 \\
\hline 4 & Deethylatrazine & 60 & 11 & 147 & 34 & 73 & 0 & 40 & 64.6 \\
\hline 68 & Bentazon & 60 & 10 & 147 & 96 & 19 & 0 & 32 & 37.3 \\
\hline 75 & Diuron & 40 & 5 & 147 & 21 & 86 & 4 & 36 & 68.3 \\
\hline 76 & Flumetsulam & 80 & 17 & 147 & 119 & 1 & 0 & 27 & 3.6 \\
\hline 1 & Atrazine & 80 & 5 & 147 & 22 & 98 & 1 & 26 & 78.4 \\
\hline 91 & Sulfometuron-methyl & 60 & 4 & 147 & 102 & 18 & 1 & 26 & 40.0 \\
\hline 62 & $2,4-\mathrm{D}$ & 60 & 62 & 147 & 69 & 41 & 7 & 30 & 52.6 \\
\hline 85 & Norflurazon & 40 & 4 & 147 & 126 & 6 & 0 & 15 & 28.6 \\
\hline 93 & Triclopyr & 80 & 88 & 147 & 128 & 3 & 1 & 15 & 15.8 \\
\hline 89 & Propoxur & 60 & 4 & 147 & 131 & 3 & 0 & 13 & 18.8 \\
\hline 2 & Carbaryl & 40 & 6 & 147 & 136 & 0 & 0 & 11 & 0.0 \\
\hline 63 & 2-Hydroxyatrazine & 60 & 8 & 147 & 19 & 113 & 2 & 13 & 88.3 \\
\hline 79 & Imazethapyr & 80 & 20 & 147 & 117 & 12 & 4 & 14 & 40.0 \\
\hline 71 & Chlorimuron-ethyl & 80 & 8 & 147 & 139 & 1 & 0 & 7 & 12.5 \\
\hline 77 & Fluometuron & 40 & 3 & 147 & 116 & 17 & 4 & 10 & 54.8 \\
\hline 84 & Nicosulfuron & 320 & 14 & 147 & 140 & 1 & 0 & 6 & 14.3 \\
\hline 87 & Oxamyl & 120 & 2 & 147 & 140 & 1 & 0 & 6 & 14.3 \\
\hline 67 & Aldicarb_sulfoxide & 80 & 3 & 147 & 142 & 0 & 0 & 5 & 0.0 \\
\hline 83 & Methomyl & 120 & 3 & 147 & 142 & 0 & 0 & 5 & 0.0 \\
\hline 81 & Linuron & 40 & 6 & 144 & 140 & 0 & 0 & 4 & 0.0 \\
\hline 3 & Carbofuran & 40 & 4 & 147 & 144 & 0 & 0 & 3 & 0.0 \\
\hline 86 & Oryzalin & 40 & 11 & 147 & 144 & 0 & 0 & 3 & 0.0 \\
\hline 92 & Terbacil & 46 & 21 & 147 & 143 & 2 & 0 & 2 & 50.0 \\
\hline 70 & Bromoxynil & 120 & 79 & 147 & 146 & 0 & 0 & 1 & 0.0 \\
\hline 64 & 3-Hydroxycarbofuran & 60 & 16 & 147 & 147 & 0 & 0 & 0 & NA \\
\hline 65 & Aldicarb & 120 & 8 & 147 & 147 & 0 & 0 & 0 & NA \\
\hline 66 & Aldicarb_sulfone & 80 & 20 & 147 & 147 & 0 & 0 & 0 & NA \\
\hline 72 & Dacthal_monoacid & 40 & 500 & 147 & 147 & 0 & 0 & 0 & NA \\
\hline 74 & Dicamba & 60 & 500 & 147 & 147 & 0 & 0 & 0 & NA \\
\hline 82 & MCPA & 40 & 95 & 147 & 145 & 2 & 0 & 0 & 100.0 \\
\hline 90 & Siduron & 40 & 5 & 147 & 147 & 0 & 0 & 0 & NA \\
\hline 78 & Imazaquin & 100 & 19 & 147 & 142 & 0 & 4 & 1 & 0.0 \\
\hline
\end{tabular}




\begin{tabular}{|c|c|c|c|c|c|c|c|c|c|}
\hline \multirow{2}{*}{\multicolumn{2}{|c|}{ Sign test }} & \multicolumn{8}{|c|}{ Information for concentrations less than the largest reporting level of either method } \\
\hline & & \multirow{2}{*}{$\begin{array}{l}\text { Number of } \\
\text { paired en- } \\
\text { vironmental } \\
\text { samples }\end{array}$} & \multirow{2}{*}{$\begin{array}{c}\text { Number of } \\
\text { paired en- } \\
\text { vironmental } \\
\text { samples with } \\
\text { no detections } \\
\text { by either } \\
\text { method }\end{array}$} & \multirow{2}{*}{$\begin{array}{c}\text { Number } \\
\text { of paired } \\
\text { environmental } \\
\text { samples with } \\
\text { detections by } \\
\text { both methods }\end{array}$} & \multirow{2}{*}{$\begin{array}{c}\text { Number } \\
\text { of paired } \\
\text { environmental } \\
\text { samples with } \\
\text { detections by } \\
\text { schedule } 2060 \\
\text { only }\end{array}$} & \multirow{2}{*}{$\begin{array}{c}\text { Number } \\
\text { of paired } \\
\text { environmental } \\
\text { samples with } \\
\text { detections by } \\
\text { schedule } 2437 \\
\text { only }\end{array}$} & \multirow{2}{*}{$\begin{array}{l}\text { When detected } \\
\text { by at least one } \\
\text { method, the } \\
\text { percentage of } \\
\text { samples with } \\
\text { detections by } \\
\text { both methods }\end{array}$} & \multicolumn{2}{|c|}{ Sign test } \\
\hline $\begin{array}{c}\text { Test } \\
\text { statistic }\end{array}$ & $p$-value & & & & & & & $\begin{array}{c}\text { Test } \\
\text { statistic }\end{array}$ & $p$-value \\
\hline-32.5 & $<0.0001$ & 144 & 79 & 0 & 0 & 65 & 0.0 & -32.5 & $<0.0001$ \\
\hline-30.5 & $<0.0001$ & 147 & 73 & 11 & 1 & 62 & 14.9 & -30.5 & $<0.0001$ \\
\hline-30.5 & $<0.0001$ & 133 & 53 & 21 & 0 & 59 & 26.3 & -29.5 & $<0.0001$ \\
\hline-27.0 & $<0.0001$ & 141 & 86 & 3 & 0 & 52 & 5.5 & -26.0 & $<0.0001$ \\
\hline-22.0 & $<0.0001$ & 123 & 68 & 5 & 2 & 48 & 9.1 & -23.0 & $<0.0001$ \\
\hline-16.0 & $<0.0001$ & 114 & 21 & 53 & 4 & 36 & 57.0 & -16.0 & $<0.0001$ \\
\hline-13.5 & $<0.0001$ & 146 & 119 & 1 & 0 & 26 & 3.7 & -13.0 & $<0.0001$ \\
\hline-12.5 & $<0.0001$ & 85 & 22 & 36 & 1 & 26 & 57.1 & -12.5 & $<0.0001$ \\
\hline-12.5 & $<0.0001$ & 145 & 102 & 16 & 1 & 26 & 37.2 & -12.5 & $<0.0001$ \\
\hline-11.5 & 0.0002 & 112 & 69 & 11 & 4 & 28 & 25.6 & -12.0 & $<0.0001$ \\
\hline-7.5 & $<0.0001$ & 147 & 126 & 6 & 0 & 15 & 28.6 & -7.5 & $<0.0001$ \\
\hline-7.0 & 0.0005 & 125 & 110 & 1 & 1 & 13 & 6.7 & -6.0 & 0.0018 \\
\hline-6.5 & 0.0002 & 147 & 131 & 3 & 0 & 13 & 18.8 & -6.5 & 0.0002 \\
\hline-5.5 & 0.0010 & 147 & 136 & 0 & 0 & 11 & 0.0 & -5.5 & 0.0010 \\
\hline-2.5 & 0.0625 & 147 & 142 & 0 & 0 & 5 & 0.0 & -2.5 & 0.0625 \\
\hline-2.5 & 0.0625 & 147 & 142 & 0 & 0 & 5 & 0.0 & -2.5 & 0.0625 \\
\hline-2.0 & 0.1250 & 144 & 140 & 0 & 0 & 4 & 0.0 & -2.0 & 0.1250 \\
\hline-1.5 & 0.2500 & 147 & 144 & 0 & 0 & 3 & 0.0 & -1.5 & 0.2500 \\
\hline-1.5 & 0.2500 & 147 & 144 & 0 & 0 & 3 & 0.0 & -1.5 & 0.2500 \\
\hline-1.0 & 0.5000 & 147 & 143 & 2 & 0 & 2 & 50.0 & -1.0 & 0.5000 \\
\hline-0.5 & 1.0000 & 147 & 146 & 0 & 0 & 1 & 0.0 & -0.5 & 1.0000 \\
\hline NA & NA & 147 & 147 & 0 & 0 & 0 & NA & NA & NA \\
\hline NA & NA & 147 & 147 & 0 & 0 & 0 & NA & NA & NA \\
\hline NA & NA & 147 & 147 & 0 & 0 & 0 & NA & NA & NA \\
\hline NA & NA & 147 & 147 & 0 & 0 & 0 & NA & NA & NA \\
\hline NA & NA & 146 & 146 & 0 & 0 & 0 & NA & NA & NA \\
\hline NA & NA & 145 & 145 & 0 & 0 & 0 & NA & NA & NA \\
\hline NA & NA & 147 & 147 & 0 & 0 & 0 & NA & NA & NA \\
\hline 1.5 & 0.3750 & 147 & 142 & 0 & 4 & 1 & 0.0 & 1.5 & 0.3750 \\
\hline
\end{tabular}



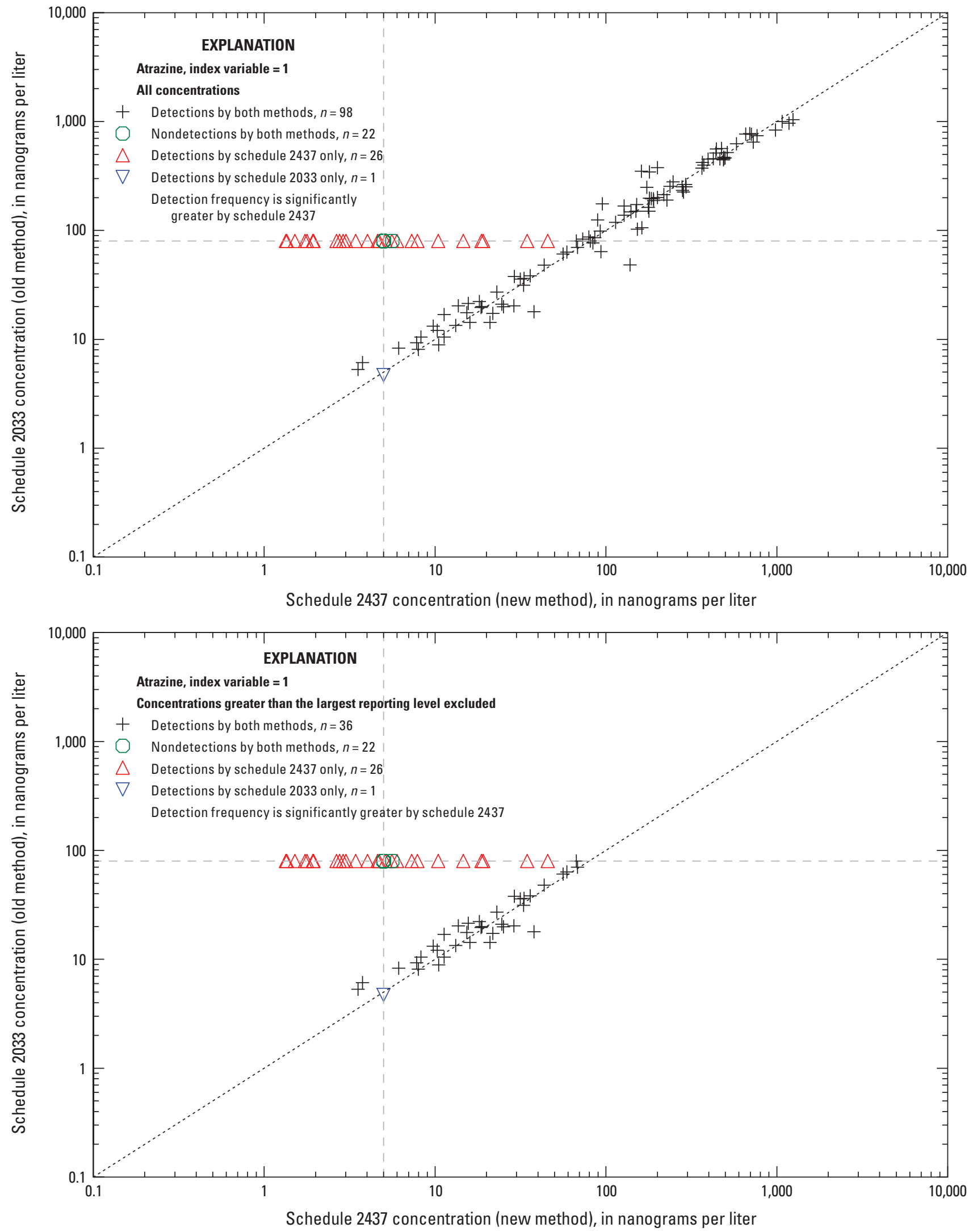

Figure 10. Comparison of atrazine detections in paired environmental stream-water samples analyzed by both schedule 2060 and schedule 2437. The horizontal dashed line is the reporting level for schedule 2060 and the vertical dashed line is the reporting level for schedule 2437. See table 14 for information on statistical differences between methods. 
Table 15. Comparison of pesticide concentrations in paired environmental stream-water samples analyzed by both schedule 2033 and schedule 2437.

[Pesticides are sorted by the paired sign test statistic for unadjusted concentrations. Probability values less than 0.05 are shown in bold. LPD; Logical percent difference (the natural logrithm of the ratio of the concentration measured by schedule 2033 divided by the concentration measured by schedule 2437 , times 100 percent). LPDs greater than zero indicate concentrations measured by schedule 2033 are greater than those measured by schedule 2437 . LPDs less than zero indicate concentrations measured by schedule 2437 are greater than those measured by schedule 2033. Recovery-adjusted concentrations are measured concentrations divided by the median recovery in matrix spikes. Median recovery in matrix spikes is shown in the figures in appendix $3 .<$, less than]

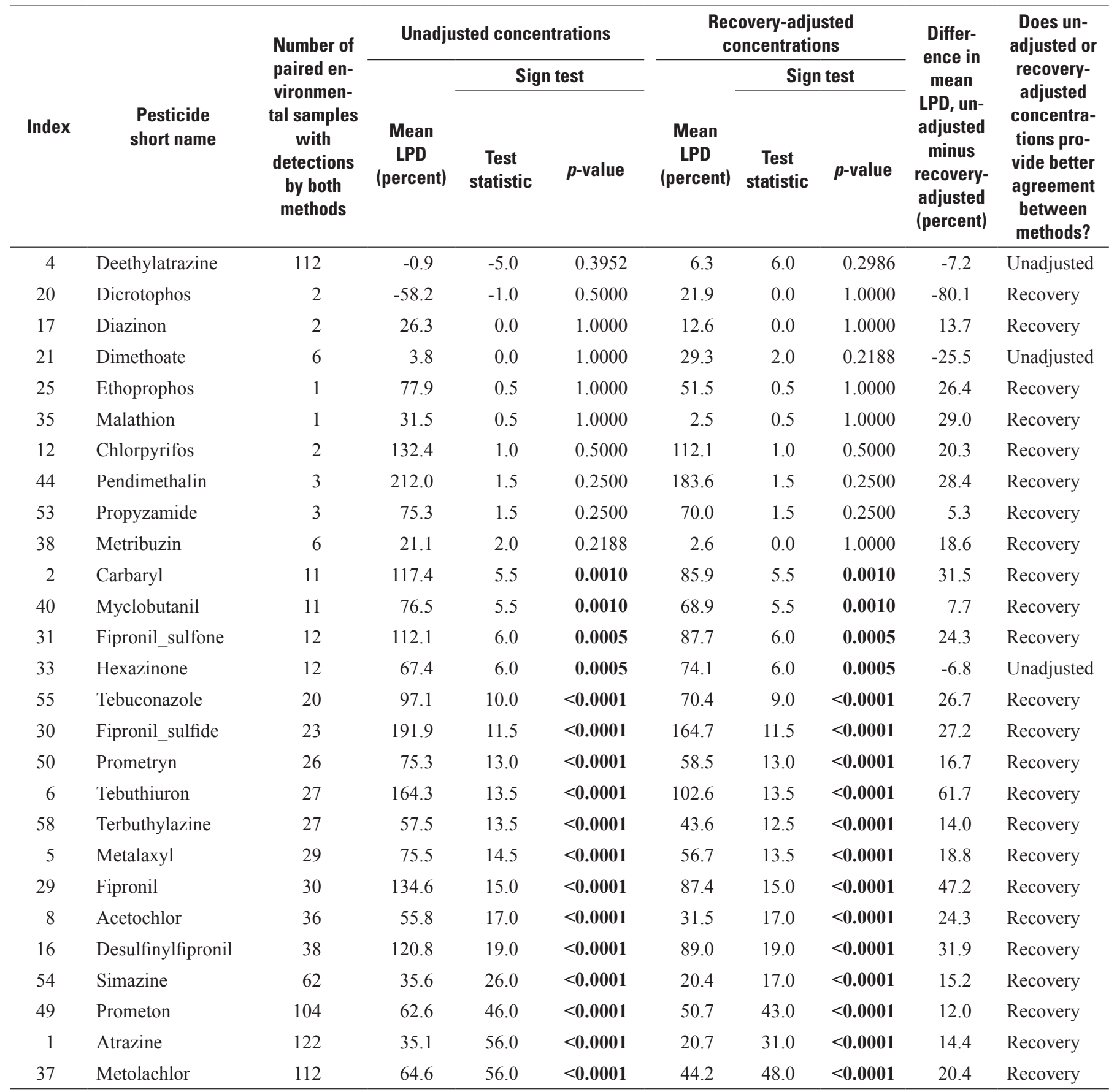



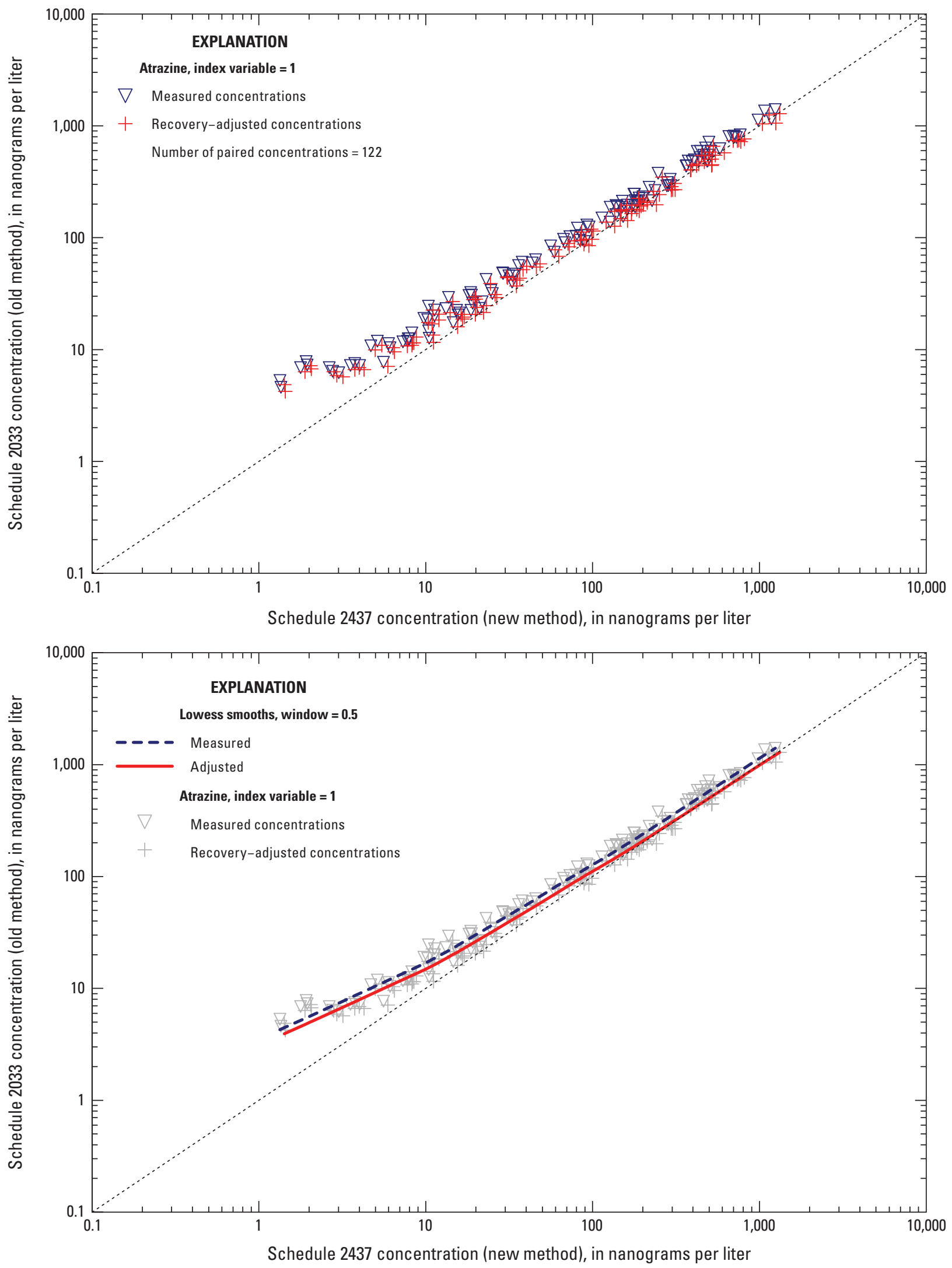

Figure 11. Comparison of atrazine concentrations in paired environmental stream-water samples analyzed by both schedule 2033 and schedule 2437. Recovery-adjusted concentrations are measured concentrations divided by the median recovery in field matrix spikes. Lowess smooths were not done for three or fewer measurements. 
Table 16. Comparison of pesticide concentrations in paired environmental stream-water samples analyzed by both schedule 2060 and schedule 2437.

[Pesticides are sorted by the paired sign test statistic for unadjusted concentrations. Probability values less than 0.05 are shown in bold. LPD, logical percent difference (the natural logrithm of the ratio of the concentration measured by schedule 2060 divided by the concentration measured by schedule 2437 , times 100 percent). LPDs greater than zero indicate concentrations measured by schedule 2060 are greater than those measured by schedule 2437 . LPDs less than zero indicate concentrations measured by schedule 2437 are greater than those measured by schedule 2060 . Recovery-adjusted concentrations are measured concentrations divided by the median recovery in matrix spikes. Median recovery in matrix spikes is shown in the figures in appendix $4 .<$, less than]

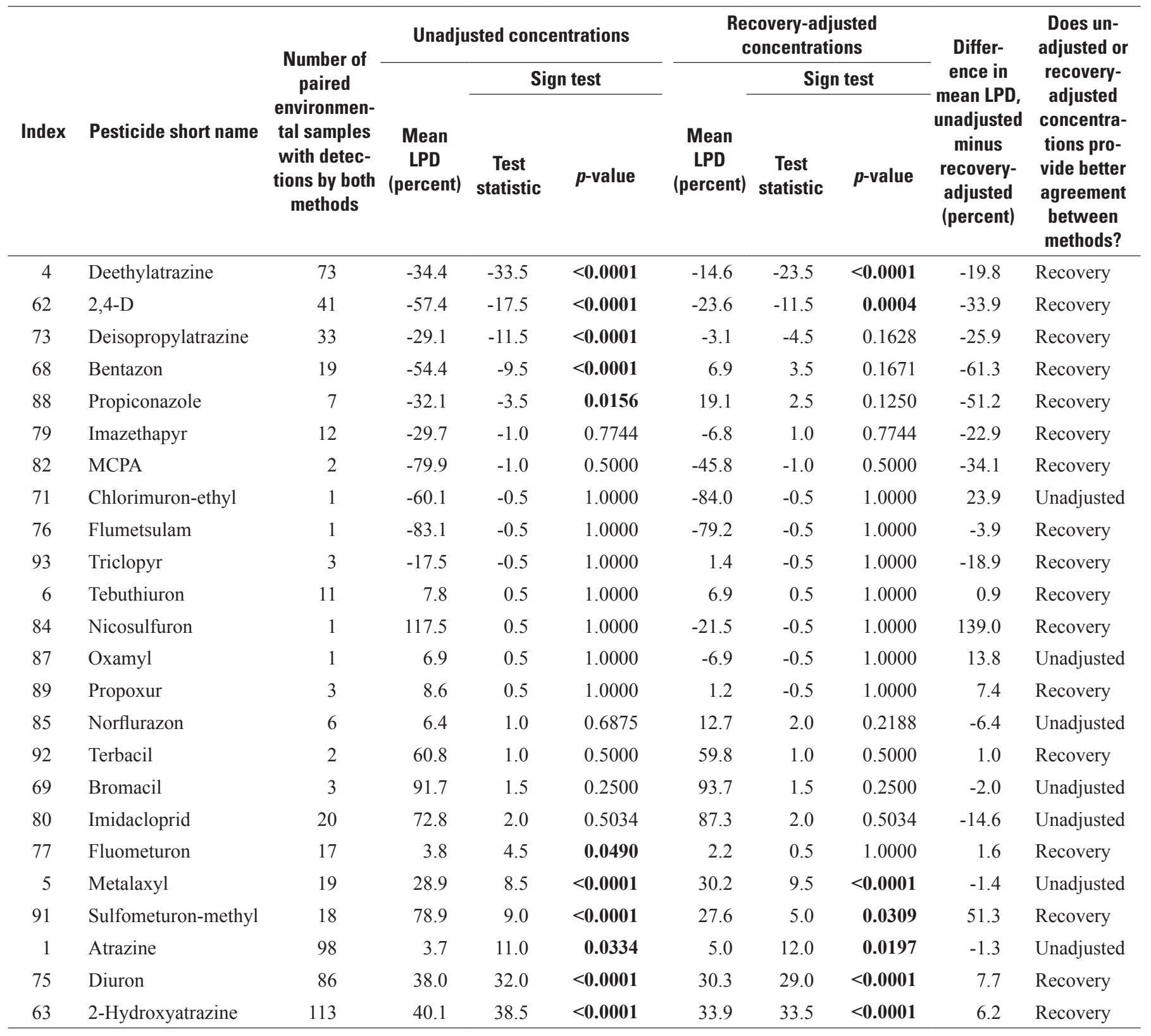




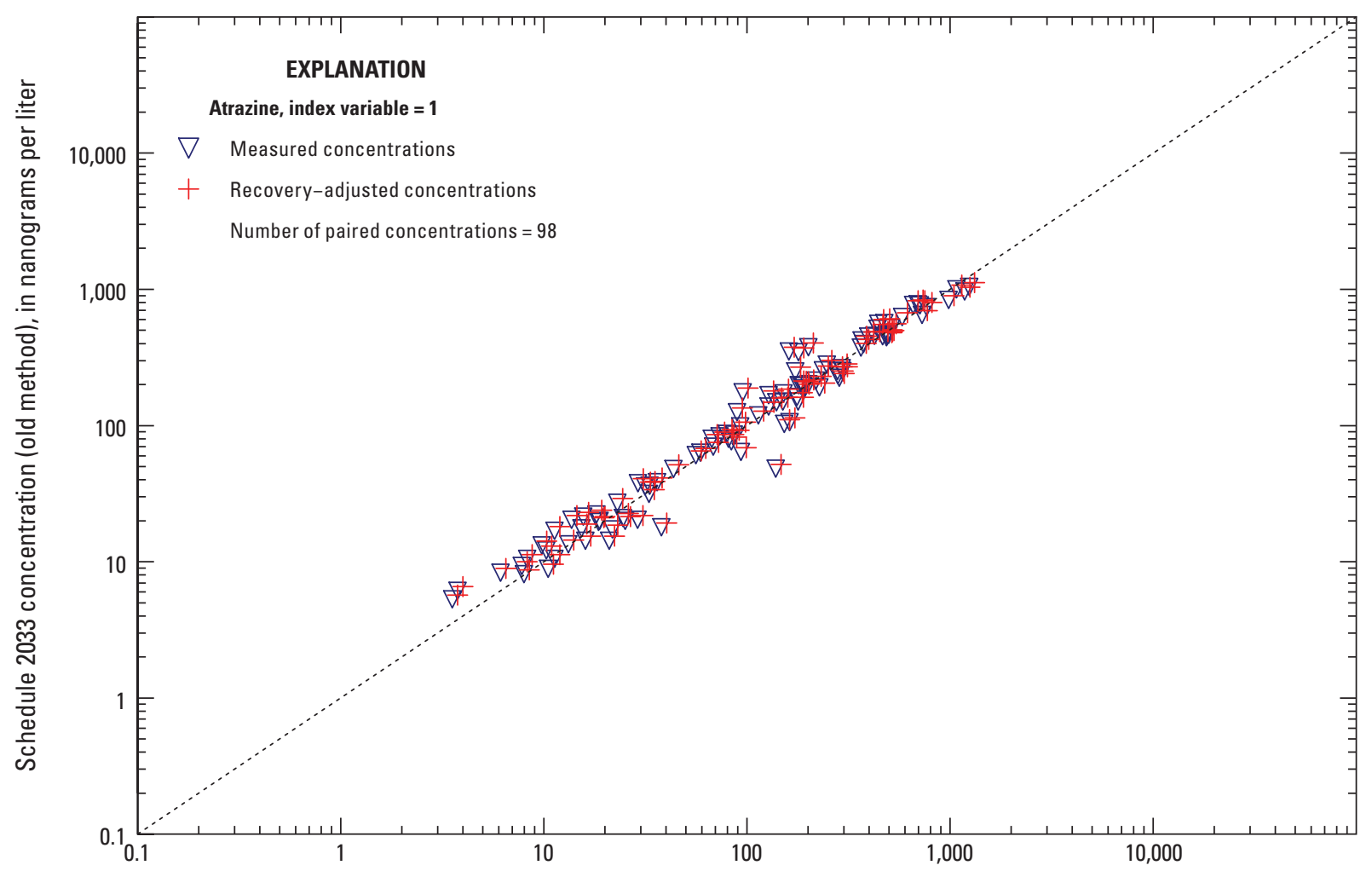

Schedule 2437 concentration (new method), in nanograms per liter

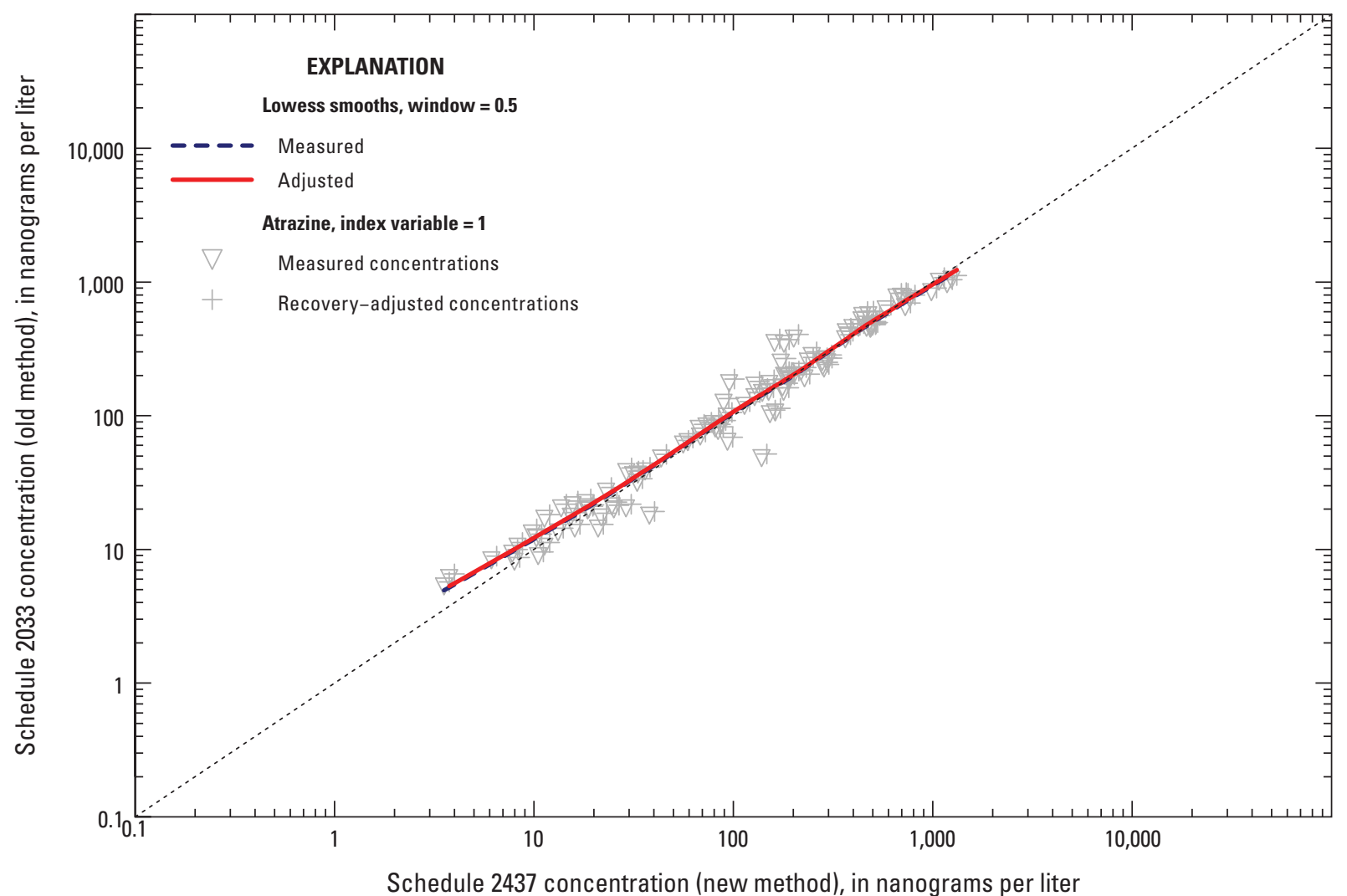

Figure 12. Comparison of atrazine concentrations in paired environmental stream-water samples analyzed by both schedule 2060 and schedule 2437. Recovery-adjusted concentrations are measured concentrations divided by the median recovery in field matrix spikes. Lowess smooths were not done for three or fewer measurements. 
Table 17. Summary of pesticide detections in field blank water samples analyzed by schedule 2033, schedule 2060, and schedule 2437.

[Pesticides not detected by a method are not shown in the table. Pesticides are sorted by index and analytical method. Index, A numerical code assigned by the authors to facilitate identification of the same pesticide in different analytical schedules. ng/L, nanogram per liter]

\begin{tabular}{|c|c|c|c|c|c|c|c|}
\hline Index & Pesticide short name & $\begin{array}{l}\text { Analytical } \\
\text { method }\end{array}$ & $\begin{array}{c}\text { Number of } \\
\text { field blank } \\
\text { water samples }\end{array}$ & $\begin{array}{l}\text { Number of } \\
\text { detections }\end{array}$ & $\begin{array}{l}\text { Percentage of } \\
\text { detections }\end{array}$ & $\begin{array}{c}\text { Maximum } \\
\text { concentration detected } \\
(\mathrm{ng} / \mathrm{L})\end{array}$ & $\begin{array}{c}\text { Reporting level } \\
\text { (ng/L) }\end{array}$ \\
\hline 37 & Metolachlor & NWQL2033 & 45 & 1 & 2.22 & 5.30 & 20 \\
\hline 37 & Metolachlor & NWQL2437 & 43 & 2 & 4.65 & 3.47 & 9 \\
\hline 55 & Tebuconazole & NWQL2437 & 43 & 1 & 2.33 & 7.90 & 5 \\
\hline 62 & $2,4-\mathrm{D}$ & NWQL2437 & 44 & 1 & 2.27 & 19.80 & 62 \\
\hline 63 & 2-Hydroxyatrazine & NWQL2060 & 44 & 1 & 2.27 & 10.20 & 60 \\
\hline 63 & 2-Hydroxyatrazine & NWQL2437 & 43 & 1 & 2.33 & 1.74 & 8 \\
\hline 67 & Aldicarb_sulfoxide & NWQL2437 & 43 & 1 & 2.33 & 1.70 & 3 \\
\hline 75 & Diuron & NWQL2060 & 44 & 3 & 6.82 & 9.30 & 40 \\
\hline 75 & Diuron & NWQL2437 & 43 & 1 & 2.33 & 5.19 & 5 \\
\hline 79 & Imazethapyr & NWQL2060 & 44 & 1 & 2.27 & 16.70 & 80 \\
\hline 84 & Nicosulfuron & NWQL2060 & 44 & 1 & 2.27 & 20.40 & 320 \\
\hline 84 & Nicosulfuron & NWQL2437 & 43 & 1 & 2.33 & 8.09 & 14 \\
\hline 98 & 2-Isopropyl-6-m_inol & NWQL2437 & 43 & 2 & 4.65 & 112.57 & 20 \\
\hline 121 & Azoxystrobin & NWQL2437 & 43 & 1 & 2.33 & 0.54 & 3 \\
\hline 133 & Deethylhydroxy_azine & NWQL2437 & 43 & 1 & 2.33 & 2.57 & 4 \\
\hline 163 & Flubendiamide & NWQL2437 & 44 & 1 & 2.27 & 1.90 & 5 \\
\hline 190 & Methoxyfenozide & NWQL2437 & 43 & 2 & 4.65 & 1.14 & 2 \\
\hline 249 & Dacthal & NWQL2033 & 45 & 1 & 2.22 & 1.50 & 7.6 \\
\hline 257 & Trifluralin & NWQL2033 & 45 & 1 & 2.22 & 1.70 & 18 \\
\hline 270 & Caffeine & NWQL2060 & 44 & 1 & 2.27 & 38.80 & 80 \\
\hline
\end{tabular}

relative standard deviation ranged from 6.1 to 21 percent (table 21). The estimates of variability of pesticide concentrations analyzed by sh 2437 are comparable to those for similar concentration ranges analyzed by older GC-MS and HPLC pesticide methods summarized in Martin (2002, p. 56).
In general, pooled estimates of RSD rather than pooled estimates of SD should be used to characterize variability of concentrations because RSD is a more robust estimate of variability (less affected by heteroscedasticity) than SD (Martin, 2002, p. 45). Examples of the use of estimates of variability of concentration measurements are given in Martin (2002, p. 49-55). 


\section{A Field Study of Selected U.S. Geological Survey Analytical Methods for Measuring Pesticides in Filtered Stream Water}

Table 18. Concentrations of pesticides detected in field blank water samples analyzed by schedule 2033, schedule 2060, and schedule 2437.

[Pesticides sorted by station number, date, index, and method. Index, A numerical code assigned by the authors to facilitate identification of the same pesticide in different analytical schdeules. See table 17 for a summary of detections by all three methods. ng/L, nanogram per liter]

\begin{tabular}{|c|c|c|c|c|c|c|c|}
\hline $\begin{array}{l}\text { Station number } \\
\text { (table 2) }\end{array}$ & $\begin{array}{l}\text { Study unit } \\
\text { abbreviation } \\
\text { (table 1) }\end{array}$ & $\begin{array}{l}\text { Sampling } \\
\text { date }\end{array}$ & Index & Pesticide short name & $\begin{array}{l}\text { Analytical } \\
\text { method }\end{array}$ & $\begin{array}{l}\text { Concentration } \\
\text { detected } \\
\text { (ng/L) }\end{array}$ & $\begin{array}{c}\text { Reporting } \\
\text { limit } \\
\text { (ng/L) }\end{array}$ \\
\hline 01403300 & LINJ & $8 / 22 / 2012$ & 55 & Tebuconazole & NWQL2437 & 7.900 & 5 \\
\hline 01403300 & LINJ & $8 / 22 / 2012$ & 79 & Imazethapyr & NWQL2060 & 0.017 & 80 \\
\hline 01403300 & LINJ & $8 / 22 / 2012$ & 249 & Dacthal & NWQL2033 & 0.002 & 7.6 \\
\hline 02089500 & ALBE & $7 / 10 / 2012$ & 163 & Flubendiamide & NWQL2437 & 1.899 & 5 \\
\hline 02174250 & SANT & $8 / 6 / 2012$ & 75 & Diuron & NWQL2437 & 5.193 & 5 \\
\hline 04186500 & LERI & $8 / 21 / 2012$ & 75 & Diuron & NWQL2060 & 0.009 & 40 \\
\hline 05420500 & NSQN & $6 / 26 / 2012$ & 98 & 2-Isopropyl-6-m_inol & NWQL2437 & 112.570 & 20 \\
\hline 05465500 & EIWA & 9/5/2012 & 98 & 2-Isopropyl-6-m_inol & NWQL2437 & 68.848 & 20 \\
\hline 05572000 & LIRB & $8 / 6 / 2012$ & 84 & Nicosulfuron & NWQL2437 & 8.087 & 14 \\
\hline 05572000 & LIRB & $8 / 6 / 2012$ & 190 & Methoxyfenozide & NWQL2437 & 1.143 & 2 \\
\hline 05586100 & LIRB & $8 / 21 / 2012$ & 63 & 2-Hydroxyatrazine & NWQL2437 & 1.743 & 8 \\
\hline 05586100 & LIRB & $8 / 21 / 2012$ & 67 & Aldicarb_sulfoxide & NWQL2437 & 1.696 & 3 \\
\hline 05586100 & LIRB & $8 / 21 / 2012$ & 75 & Diuron & NWQL2060 & 0.008 & 40 \\
\hline 05586100 & LIRB & $8 / 21 / 2012$ & 133 & Deethylhydroxy_azine & NWQL2437 & 2.573 & 4 \\
\hline 05586100 & LIRB & $8 / 21 / 2012$ & 190 & Methoxyfenozide & NWQL2437 & 0.514 & 2 \\
\hline 06279500 & YELL & $7 / 9 / 2012$ & 37 & Metolachlor & NWQL2437 & 3.468 & 9 \\
\hline 06800000 & CNBR & $8 / 21 / 2012$ & 37 & Metolachlor & NWQL2437 & 0.707 & 9 \\
\hline 07022000 & NSQN & $6 / 25 / 2012$ & 62 & $2,4-\mathrm{D}$ & NWQL2437 & 19.801 & 62 \\
\hline 07022000 & NSQN & $6 / 25 / 2012$ & 270 & Caffeine & NWQL2060 & 0.039 & 80 \\
\hline 07288955 & MISE & $8 / 23 / 2012$ & 257 & Trifluralin & NWQL2033 & 0.002 & 18 \\
\hline 07374000 & NSQN & $6 / 11 / 2012$ & 63 & 2-Hydroxyatrazine & NWQL2060 & 0.010 & 60 \\
\hline 07381495 & NSQN & $6 / 12 / 2012$ & 37 & Metolachlor & NWQL2033 & 0.005 & 20 \\
\hline 08364000 & RIOG & $7 / 12 / 2012$ & 84 & Nicosulfuron & NWQL2060 & 0.020 & 320 \\
\hline 08364000 & RIOG & $7 / 12 / 2012$ & 121 & Azoxystrobin & NWQL2437 & 0.536 & 3 \\
\hline 14211720 & WILL & $8 / 21 / 2012$ & 75 & Diuron & NWQL2060 & 0.008 & 40 \\
\hline
\end{tabular}


Table 19. Variability of pesticide detections in field duplicate environmental water samples analyzed by schedule 2437 .

[Consistent detection is the case where a pesticide is detected in both duplicates. Inconsistent detection is the case where a pesticide is detected in only one of the duplicates. Duplicate sets where both measurements were nondetections were deleted from the analysis. Nondetections were set to 0 nanogram per liter for the purpose of calculating the median concentration of duplicate sets. Duplicate sets were assigned to a concentration class on the basis of the median concentration of the duplicate set. Concentration classes are a function of the reporting limit. Median concentrations less than the reporting limit were assigned to class 1 Low. Median concentrations greater than or equal to the reporting limit but less than 10 times the reporting limit were assigned to class 2 Med. Median concentrations greater than or equal to 10 times the reporting limit were assigned to class $3 \mathrm{High}$. ng/L, nanogram per liter; Index, a numerical code assigned by the authors to facilitate identification of the same pesticide in different analytical schedules]

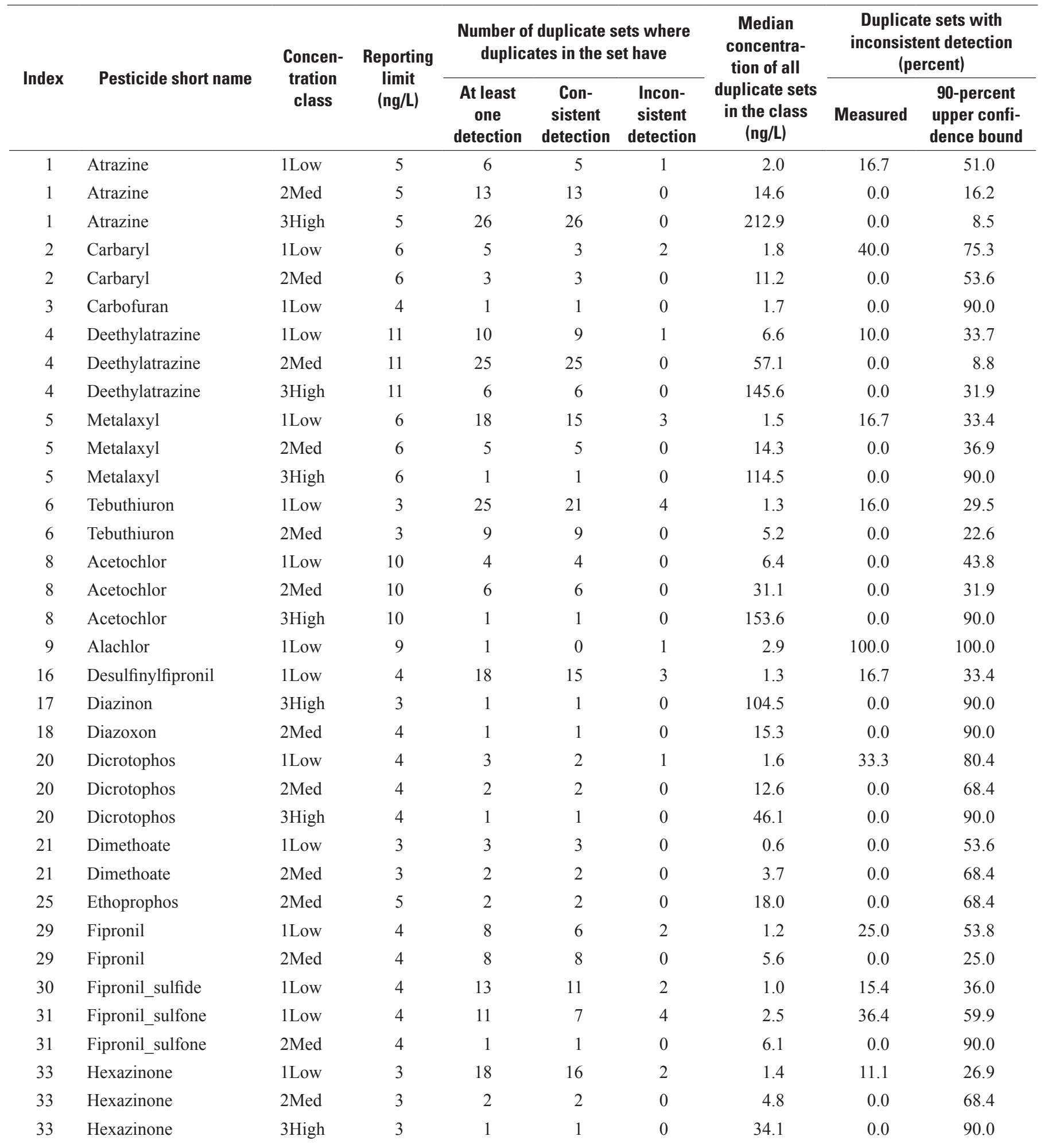


Table 19. Variability of pesticide detections in field duplicate environmental water samples analyzed by schedule 2437.—Continued

[Consistent detection is the case where a pesticide is detected in both duplicates. Inconsistent detection is the case where a pesticide is detected in only one of the duplicates. Duplicate sets where both measurements were nondetections were deleted from the analysis. Nondetections were set to 0 nanogram per liter for the purpose of calculating the median concentration of duplicate sets. Duplicate sets were assigned to a concentration class on the basis of the median concentration of the duplicate set. Concentration classes are a function of the reporting limit. Median concentrations less than the reporting limit were assigned to class 1 Low. Median concentrations greater than or equal to the reporting limit but less than 10 times the reporting limit were assigned to class 2 Med. Median concentrations greater than or equal to 10 times the reporting limit were assigned to class $3 \mathrm{High}$. ng/L, nanogram per liter; Index, a numerical code assigned by the authors to facilitate identification of the same pesticide in different analytical schedules]

\begin{tabular}{|c|c|c|c|c|c|c|c|c|c|}
\hline \multirow{2}{*}{ Index } & \multirow{2}{*}{ Pesticide short name } & \multirow{2}{*}{$\begin{array}{l}\text { Concen- } \\
\text { tration } \\
\text { class }\end{array}$} & \multirow{2}{*}{$\begin{array}{l}\text { Reporting } \\
\text { limit } \\
\text { (ng/L) }\end{array}$} & \multicolumn{3}{|c|}{$\begin{array}{l}\text { Number of duplicate sets where } \\
\text { duplicates in the set have }\end{array}$} & \multirow{2}{*}{$\begin{array}{c}\text { Median } \\
\text { concentra- } \\
\text { tion of all } \\
\text { duplicate sets } \\
\text { in the class } \\
\text { (ng/L) }\end{array}$} & \multicolumn{2}{|c|}{$\begin{array}{c}\text { Duplicate sets with } \\
\text { inconsistent detection } \\
\text { (percent) }\end{array}$} \\
\hline & & & & $\begin{array}{l}\text { At least } \\
\text { one } \\
\text { detection }\end{array}$ & $\begin{array}{c}\text { Con- } \\
\text { sistent } \\
\text { detection }\end{array}$ & $\begin{array}{l}\text { Incon- } \\
\text { sistent } \\
\text { detection }\end{array}$ & & Measured & $\begin{array}{l}\text { 90-percent } \\
\text { upper confi- } \\
\text { dence bound }\end{array}$ \\
\hline 35 & Malathion & $2 \mathrm{Med}$ & 6 & 2 & 2 & 0 & 6.4 & 0.0 & 68.4 \\
\hline 37 & Metolachlor & $2 \mathrm{Med}$ & 9 & 13 & 13 & 0 & 37.5 & 0.0 & 16.2 \\
\hline 37 & Metolachlor & 3High & 9 & 12 & 12 & 0 & 287.8 & 0.0 & 17.5 \\
\hline 38 & Metribuzin & 1Low & 20 & 1 & 1 & 0 & 17.4 & 0.0 & 90.0 \\
\hline 40 & Myclobutanil & 1Low & 7 & 6 & 6 & 0 & 1.5 & 0.0 & 31.9 \\
\hline 40 & Myclobutanil & $2 \mathrm{Med}$ & 7 & 2 & 2 & 0 & 7.7 & 0.0 & 68.4 \\
\hline 49 & Prometon & 1Low & 4 & 18 & 18 & 0 & 2.4 & 0.0 & 12.0 \\
\hline 49 & Prometon & $2 \mathrm{Med}$ & 4 & 20 & 19 & 1 & 7.1 & 5.0 & 18.1 \\
\hline 49 & Prometon & 3High & 4 & 3 & 3 & 0 & 45.2 & 0.0 & 53.6 \\
\hline 50 & Prometryn & 1Low & 2 & 1 & 1 & 0 & 1.8 & 0.0 & 90.0 \\
\hline 50 & Prometryn & $2 \mathrm{Med}$ & 2 & 6 & 6 & 0 & 4.3 & 0.0 & 31.9 \\
\hline 50 & Prometryn & 3High & 2 & 1 & 1 & 0 & 31.5 & 0.0 & 90.0 \\
\hline 53 & Propyzamide & $2 \mathrm{Med}$ & 4 & 1 & 1 & 0 & 10.0 & 0.0 & 90.0 \\
\hline 54 & Simazine & 1Low & 10 & 4 & 4 & 0 & 6.6 & 0.0 & 43.8 \\
\hline 58 & Terbuthylazine & 3High & 3 & 2 & 2 & 0 & 42.8 & 0.0 & 68.4 \\
\hline 62 & $2,4-\mathrm{D}$ & 1Low & 62 & 19 & 12 & 7 & 27.6 & 36.8 & 54.1 \\
\hline 62 & $2,4-\mathrm{D}$ & $2 \mathrm{Med}$ & 62 & 14 & 14 & 0 & 108.4 & 0.0 & 15.2 \\
\hline 62 & $2,4-\mathrm{D}$ & 3High & 62 & 1 & 1 & 0 & 850.1 & 0.0 & 90.0 \\
\hline 63 & 2-Hydroxyatrazine & 1Low & 8 & 12 & 10 & 2 & 4.2 & 16.7 & 38.6 \\
\hline 63 & 2-Hydroxyatrazine & 2Med & 8 & 16 & 16 & 0 & 52.6 & 0.0 & 13.4 \\
\hline 63 & 2-Hydroxyatrazine & 3High & 8 & 17 & 17 & 0 & 124.5 & 0.0 & 12.7 \\
\hline 67 & Aldicarb_sulfoxide & 1Low & 3 & 1 & 0 & 1 & 0.5 & 100.0 & 100.0 \\
\hline 68 & Bentazon & 1Low & 10 & 15 & 13 & 2 & 5.9 & 13.3 & 31.7 \\
\hline 68 & Bentazon & $2 \mathrm{Med}$ & 10 & 6 & 6 & 0 & 12.0 & 0.0 & 31.9 \\
\hline 68 & Bentazon & 3High & 10 & 1 & 1 & 0 & 141.4 & 0.0 & 90.0 \\
\hline
\end{tabular}


Table 19. Variability of pesticide detections in field duplicate environmental water samples analyzed by schedule 2437.-Continued

[Consistent detection is the case where a pesticide is detected in both duplicates. Inconsistent detection is the case where a pesticide is detected in only one of the duplicates. Duplicate sets where both measurements were nondetections were deleted from the analysis. Nondetections were set to 0 nanogram per liter for the purpose of calculating the median concentration of duplicate sets. Duplicate sets were assigned to a concentration class on the basis of the median concentration of the duplicate set. Concentration classes are a function of the reporting limit. Median concentrations less than the reporting limit were assigned to class 1 Low. Median concentrations greater than or equal to the reporting limit but less than 10 times the reporting limit were assigned to class 2 Med. Median concentrations greater than or equal to 10 times the reporting limit were assigned to class 3 High. ng/L, nanogram per liter; Index, a numerical code assigned by the authors to facilitate identification of the same pesticide in different analytical schedules]

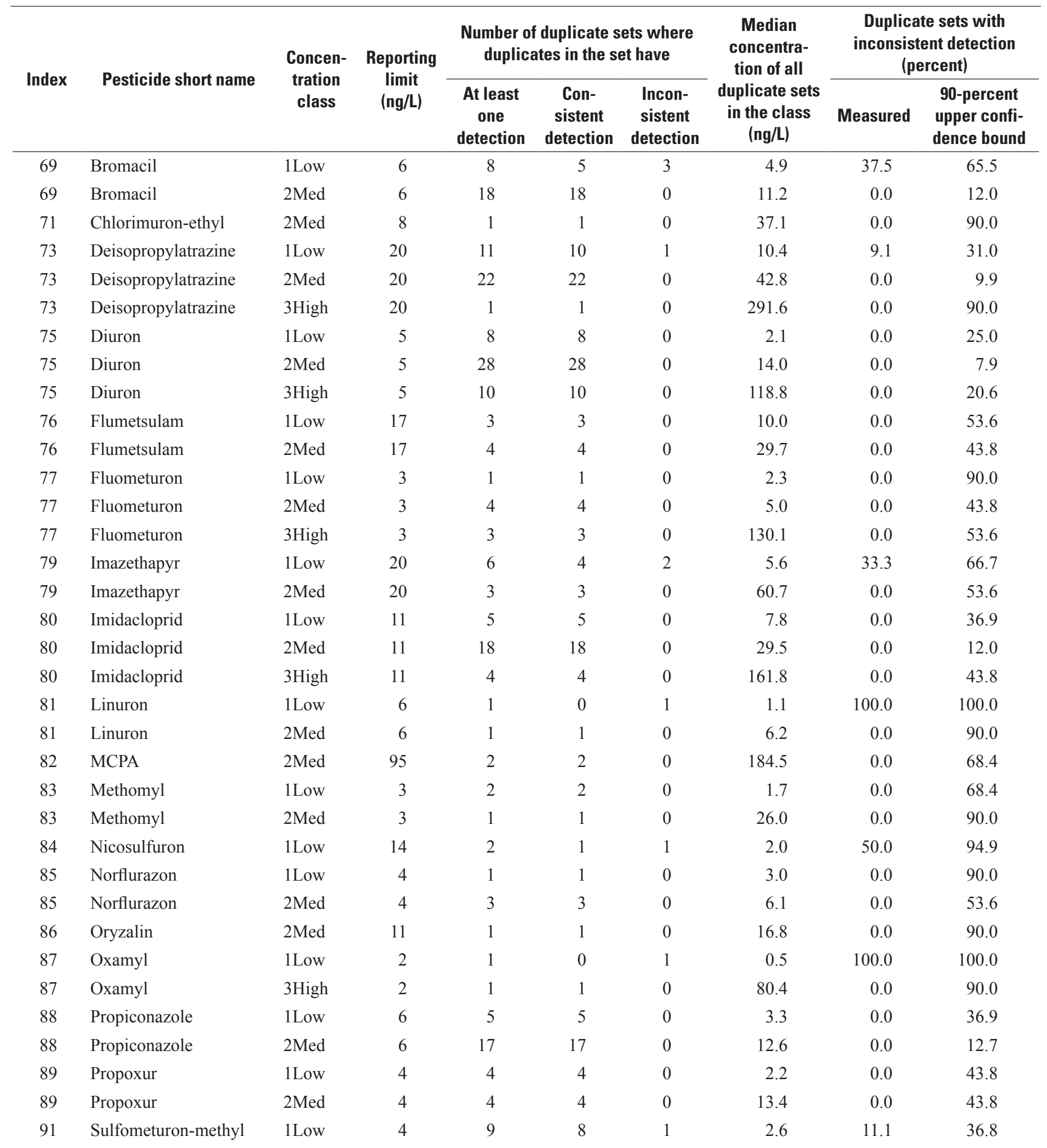


Table 19. Variability of pesticide detections in field duplicate environmental water samples analyzed by schedule 2437.—Continued

[Consistent detection is the case where a pesticide is detected in both duplicates. Inconsistent detection is the case where a pesticide is detected in only one of the duplicates. Duplicate sets where both measurements were nondetections were deleted from the analysis. Nondetections were set to 0 nanogram per liter for the purpose of calculating the median concentration of duplicate sets. Duplicate sets were assigned to a concentration class on the basis of the median concentration of the duplicate set. Concentration classes are a function of the reporting limit. Median concentrations less than the reporting limit were assigned to class 1 Low. Median concentrations greater than or equal to the reporting limit but less than 10 times the reporting limit were assigned to class 2 Med. Median concentrations greater than or equal to 10 times the reporting limit were assigned to class $3 \mathrm{High}$. ng/L, nanogram per liter; Index, a numerical code assigned by the authors to facilitate identification of the same pesticide in different analytical schedules]

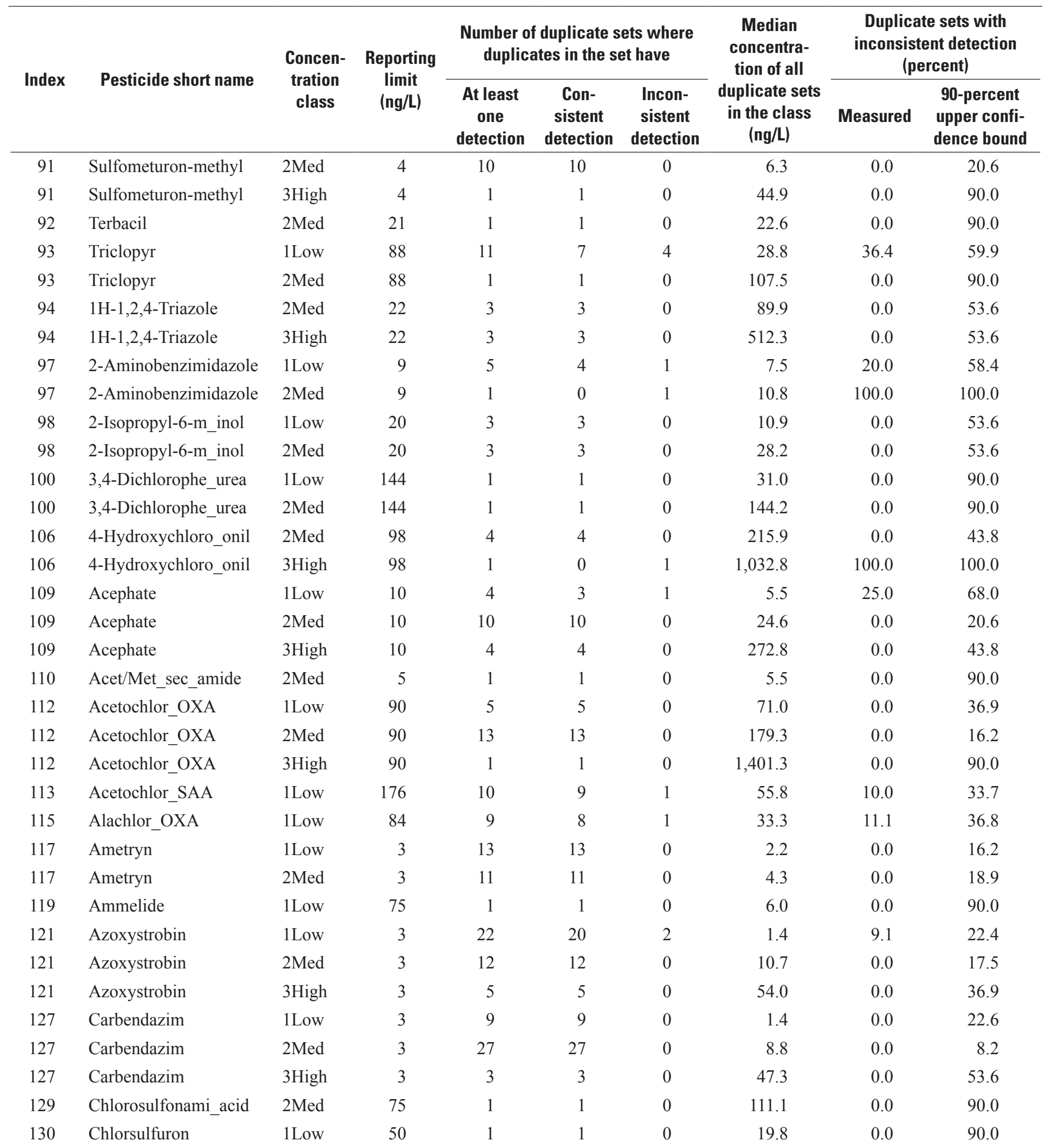


Table 19. Variability of pesticide detections in field duplicate environmental water samples analyzed by schedule 2437.-Continued

[Consistent detection is the case where a pesticide is detected in both duplicates. Inconsistent detection is the case where a pesticide is detected in only one of the duplicates. Duplicate sets where both measurements were nondetections were deleted from the analysis. Nondetections were set to 0 nanogram per liter for the purpose of calculating the median concentration of duplicate sets. Duplicate sets were assigned to a concentration class on the basis of the median concentration of the duplicate set. Concentration classes are a function of the reporting limit. Median concentrations less than the reporting limit were assigned to class 1 Low. Median concentrations greater than or equal to the reporting limit but less than 10 times the reporting limit were assigned to class 2 Med. Median concentrations greater than or equal to 10 times the reporting limit were assigned to class $3 \mathrm{High}$. ng/L, nanogram per liter; Index, a numerical code assigned by the authors to facilitate identification of the same pesticide in different analytical schedules]

\begin{tabular}{|c|c|c|c|c|c|c|c|c|c|}
\hline \multirow{2}{*}{ Index } & \multirow{2}{*}{ Pesticide short name } & \multirow{2}{*}{$\begin{array}{l}\text { Concen- } \\
\text { tration } \\
\text { class }\end{array}$} & \multirow{2}{*}{$\begin{array}{l}\text { Reporting } \\
\text { limit } \\
\text { (ng/L) }\end{array}$} & \multicolumn{3}{|c|}{$\begin{array}{l}\text { Number of duplicate sets where } \\
\text { duplicates in the set have }\end{array}$} & \multirow{2}{*}{$\begin{array}{c}\text { Median } \\
\text { concentra- } \\
\text { tion of all } \\
\text { duplicate sets } \\
\text { in the class } \\
\text { (ng/L) }\end{array}$} & \multicolumn{2}{|c|}{$\begin{array}{c}\text { Duplicate sets with } \\
\text { inconsistent detection } \\
\text { (percent) }\end{array}$} \\
\hline & & & & $\begin{array}{l}\text { At least } \\
\text { one } \\
\text { detection }\end{array}$ & $\begin{array}{c}\text { Con- } \\
\text { sistent } \\
\text { detection }\end{array}$ & $\begin{array}{l}\text { Incon- } \\
\text { sistent } \\
\text { detection }\end{array}$ & & Measured & $\begin{array}{l}\text { 90-percent } \\
\text { upper confi- } \\
\text { dence bound }\end{array}$ \\
\hline 132 & Dechlorometolachlor & 1Low & 2 & 5 & 5 & 0 & 1.3 & 0.0 & 36.9 \\
\hline 132 & Dechlorometolachlor & 3 High & 2 & 5 & 5 & 0 & 123.6 & 0.0 & 36.9 \\
\hline 133 & Deethylhydroxy_azine & 1Low & 4 & 6 & 6 & 0 & 3.8 & 0.0 & 31.9 \\
\hline 133 & Deethylhydroxy_azine & $2 \mathrm{Med}$ & 4 & 27 & 27 & 0 & 12.5 & 0.0 & 8.2 \\
\hline 133 & Deethylhydroxy_azine & 3High & 4 & 1 & 1 & 0 & 81.7 & 0.0 & 90.0 \\
\hline 134 & Deiodo_flubendiamide & $2 \mathrm{Med}$ & 4 & 1 & 1 & 0 & 7.0 & 0.0 & 90.0 \\
\hline 138 & Demethyl_fluometuron & 3High & 2 & 3 & 3 & 0 & 40.8 & 0.0 & 53.6 \\
\hline 139 & Demethyl_hexazi_ne_B & 1Low & 3 & 1 & 1 & 0 & 1.1 & 0.0 & 90.0 \\
\hline 139 & Demethyl_hexazi_ne_B & $2 \mathrm{Med}$ & 3 & 1 & 1 & 0 & 5.7 & 0.0 & 90.0 \\
\hline 140 & Demethyl_norflurazon & $2 \mathrm{Med}$ & 4 & 3 & 3 & 0 & 18.6 & 0.0 & 53.6 \\
\hline 141 & Desamino-diketo_uzin & 1Low & 200 & 4 & 4 & 0 & 63.1 & 0.0 & 43.8 \\
\hline 142 & Didealkylatrazine & 1Low & 24 & 2 & 2 & 0 & 18.9 & 0.0 & 68.4 \\
\hline 142 & Didealkylatrazine & $2 \mathrm{Med}$ & 24 & 20 & 19 & 1 & 123.7 & 5.0 & 18.1 \\
\hline 142 & Didealkylatrazine & 3High & 24 & 8 & 8 & 0 & 303.4 & 0.0 & 25.0 \\
\hline 148 & Dimethenamid_ESA & $2 \mathrm{Med}$ & 79 & 1 & 1 & 0 & 204.4 & 0.0 & 90.0 \\
\hline 149 & Dimethenamid_OXA & 1Low & 85 & 1 & 1 & 0 & 30.3 & 0.0 & 90.0 \\
\hline 149 & Dimethenamid_OXA & $2 \mathrm{Med}$ & 85 & 1 & 1 & 0 & 198.0 & 0.0 & 90.0 \\
\hline 150 & Dimethenamid_SAA & 1Low & 189 & 1 & 1 & 0 & 88.8 & 0.0 & 90.0 \\
\hline 161 & Fipronil_amide & 1Low & 9 & 6 & 4 & 2 & 5.5 & 33.3 & 66.7 \\
\hline 163 & Flubendiamide & 1Low & 5 & 1 & 1 & 0 & 1.0 & 0.0 & 90.0 \\
\hline 163 & Flubendiamide & $2 \mathrm{Med}$ & 5 & 4 & 4 & 0 & 9.5 & 0.0 & 43.8 \\
\hline 166 & Halosulfuron-methyl & 1Low & 22 & 1 & 0 & 1 & 14.4 & 100.0 & 100.0 \\
\hline 173 & Hydroxyacetochlor & 1Low & 9 & 1 & 1 & 0 & 7.1 & 0.0 & 90.0 \\
\hline 173 & Hydroxyacetochlor & $2 \mathrm{Med}$ & 9 & 14 & 14 & 0 & 20.6 & 0.0 & 15.2 \\
\hline 173 & Hydroxyacetochlor & 3High & 9 & 1 & 1 & 0 & 156.0 & 0.0 & 90.0 \\
\hline
\end{tabular}


Table 19. Variability of pesticide detections in field duplicate environmental water samples analyzed by schedule 2437.—Continued

[Consistent detection is the case where a pesticide is detected in both duplicates. Inconsistent detection is the case where a pesticide is detected in only one of the duplicates. Duplicate sets where both measurements were nondetections were deleted from the analysis. Nondetections were set to 0 nanogram per liter for the purpose of calculating the median concentration of duplicate sets. Duplicate sets were assigned to a concentration class on the basis of the median concentration of the duplicate set. Concentration classes are a function of the reporting limit. Median concentrations less than the reporting limit were assigned to class 1Low. Median concentrations greater than or equal to the reporting limit but less than 10 times the reporting limit were assigned to class 2 Med. Median concentrations greater than or equal to 10 times the reporting limit were assigned to class $3 \mathrm{High}$. ng/L, nanogram per liter; Index, a numerical code assigned by the authors to facilitate identification of the same pesticide in different analytical schedules]

\begin{tabular}{|c|c|c|c|c|c|c|c|c|c|}
\hline \multirow{2}{*}{ Index } & \multirow{2}{*}{ Pesticide short name } & \multirow{2}{*}{$\begin{array}{l}\text { Concen- } \\
\text { tration } \\
\text { class }\end{array}$} & \multirow{2}{*}{$\begin{array}{l}\text { Reporting } \\
\text { limit } \\
\text { (ng/L) }\end{array}$} & \multicolumn{3}{|c|}{$\begin{array}{l}\text { Number of duplicate sets where } \\
\text { duplicates in the set have }\end{array}$} & \multirow{2}{*}{$\begin{array}{c}\text { Median } \\
\text { concentra- } \\
\text { tion of all } \\
\text { duplicate sets } \\
\text { in the class } \\
\text { (ng/L) }\end{array}$} & \multicolumn{2}{|c|}{$\begin{array}{c}\text { Duplicate sets with } \\
\text { inconsistent detection } \\
\text { (percent) }\end{array}$} \\
\hline & & & & $\begin{array}{l}\text { At least } \\
\text { one } \\
\text { detection }\end{array}$ & $\begin{array}{c}\text { Con- } \\
\text { sistent } \\
\text { detection }\end{array}$ & $\begin{array}{l}\text { Incon- } \\
\text { sistent } \\
\text { detection }\end{array}$ & & Measured & $\begin{array}{l}\text { 90-percent } \\
\text { upper confi- } \\
\text { dence bound }\end{array}$ \\
\hline 174 & Hydroxyalachlor & 1Low & 8 & 7 & 7 & 0 & 4.2 & 0.0 & 28.0 \\
\hline 177 & Hydroxymetolachlor & $2 \mathrm{Med}$ & 2 & 21 & 21 & 0 & 12.8 & 0.0 & 10.4 \\
\hline 177 & Hydroxymetolachlor & 3 High & 2 & 5 & 5 & 0 & 106.6 & 0.0 & 36.9 \\
\hline 179 & Hydroxysimazine & 1Low & 3 & 6 & 5 & 1 & 2.8 & 16.7 & 51.0 \\
\hline 179 & Hydroxysimazine & $2 \mathrm{Med}$ & 3 & 28 & 27 & 1 & 8.0 & 3.6 & 13.2 \\
\hline 179 & Hydroxysimazine & 3High & 3 & 5 & 5 & 0 & 72.7 & 0.0 & 36.9 \\
\hline 188 & Methamidophos & 2Med & 3 & 4 & 4 & 0 & 13.1 & 0.0 & 43.8 \\
\hline 188 & Methamidophos & 3 High & 3 & 4 & 4 & 0 & 40.9 & 0.0 & 43.8 \\
\hline 190 & Methoxyfenozide & 1Low & 2 & 8 & 7 & 1 & 0.6 & 12.5 & 40.6 \\
\hline 190 & Methoxyfenozide & $2 \mathrm{Med}$ & 2 & 3 & 3 & 0 & 12.8 & 0.0 & 53.6 \\
\hline 191 & Metolachlor_ESA & 1Low & 68 & 9 & 6 & 3 & 20.1 & 33.3 & 59.9 \\
\hline 191 & Metolachlor_ESA & $2 \mathrm{Med}$ & 68 & 22 & 22 & 0 & 191.3 & 0.0 & 9.9 \\
\hline 191 & Metolachlor_ESA & 3High & 68 & 4 & 4 & 0 & 840.9 & 0.0 & 43.8 \\
\hline 192 & Metolachlor_OXA & 1Low & 149 & 17 & 17 & 0 & 73.8 & 0.0 & 12.7 \\
\hline 196 & N-(3,4-Dichloro_urea & 1Low & 5 & 8 & 8 & 0 & 3.6 & 0.0 & 25.0 \\
\hline 196 & N-(3,4-Dichloro_urea & $2 \mathrm{Med}$ & 5 & 19 & 19 & 0 & 13.1 & 0.0 & 11.4 \\
\hline 196 & N-(3,4-Dichloro_urea & 3High & 5 & 2 & 2 & 0 & 583.6 & 0.0 & 68.4 \\
\hline 203 & Oxamyl_oxime & $2 \mathrm{Med}$ & 2 & 1 & 1 & 0 & 2.4 & 0.0 & 90.0 \\
\hline 203 & Oxamyl_oxime & 3High & 2 & 1 & 1 & 0 & 57.4 & 0.0 & 90.0 \\
\hline 210 & Piperonyl_butoxide & 1Low & 4 & 1 & 1 & 0 & 2.1 & 0.0 & 90.0 \\
\hline 210 & Piperonyl_butoxide & $2 \mathrm{Med}$ & 4 & 4 & 4 & 0 & 5.7 & 0.0 & 43.8 \\
\hline 212 & Propazine & 1Low & 4 & 11 & 11 & 0 & 3.2 & 0.0 & 18.9 \\
\hline 212 & Propazine & $2 \mathrm{Med}$ & 4 & 6 & 6 & 0 & 5.9 & 0.0 & 31.9 \\
\hline 215 & Pyraclostrobin & 1Low & 3 & 3 & 2 & 1 & 1.8 & 33.3 & 80.4 \\
\hline 215 & Pyraclostrobin & $2 \mathrm{Med}$ & 3 & 2 & 2 & 0 & 6.7 & 0.0 & 68.4 \\
\hline
\end{tabular}


Table 19. Variability of pesticide detections in field duplicate environmental water samples analyzed by schedule 2437.—Continued

[Consistent detection is the case where a pesticide is detected in both duplicates. Inconsistent detection is the case where a pesticide is detected in only one of the duplicates. Duplicate sets where both measurements were nondetections were deleted from the analysis. Nondetections were set to 0 nanogram per liter for the purpose of calculating the median concentration of duplicate sets. Duplicate sets were assigned to a concentration class on the basis of the median concentration of the duplicate set. Concentration classes are a function of the reporting limit. Median concentrations less than the reporting limit were assigned to class 1 Low. Median concentrations greater than or equal to the reporting limit but less than 10 times the reporting limit were assigned to class 2 Med. Median concentrations greater than or equal to 10 times the reporting limit were assigned to class 3 High. ng/L, nanogram per liter; Index, a numerical code assigned by the authors to facilitate identification of the same pesticide in different analytical schedules]

\begin{tabular}{|c|c|c|c|c|c|c|c|c|c|}
\hline \multirow{2}{*}{ Index } & \multirow{2}{*}{ Pesticide short name } & \multirow{2}{*}{$\begin{array}{l}\text { Concen- } \\
\text { tration } \\
\text { class }\end{array}$} & \multirow{2}{*}{$\begin{array}{l}\text { Reporting } \\
\text { limit } \\
\text { (ng/L) }\end{array}$} & \multicolumn{3}{|c|}{$\begin{array}{l}\text { Number of duplicate sets where } \\
\text { duplicates in the set have }\end{array}$} & \multirow{2}{*}{$\begin{array}{c}\text { Median } \\
\text { concentra- } \\
\text { tion of all } \\
\text { duplicate sets } \\
\text { in the class } \\
\text { (ng/L) }\end{array}$} & \multicolumn{2}{|c|}{$\begin{array}{l}\text { Duplicate sets with } \\
\text { inconsistent detection } \\
\text { (percent) }\end{array}$} \\
\hline & & & & $\begin{array}{c}\text { At least } \\
\text { one } \\
\text { detection }\end{array}$ & $\begin{array}{c}\text { Con- } \\
\text { sistent } \\
\text { detection }\end{array}$ & $\begin{array}{l}\text { Incon- } \\
\text { sistent } \\
\text { detection }\end{array}$ & & Measured & $\begin{array}{l}\text { 90-percent } \\
\text { upper confi- } \\
\text { dence bound }\end{array}$ \\
\hline 218 & Sulfentrazone & 1Low & 11 & 3 & 2 & 1 & 7.1 & 33.3 & 80.4 \\
\hline 218 & Sulfentrazone & $2 \mathrm{Med}$ & 11 & 5 & 5 & 0 & 17.9 & 0.0 & 36.9 \\
\hline 218 & Sulfentrazone & 3High & 11 & 1 & 1 & 0 & 340.1 & 0.0 & 90.0 \\
\hline 219 & Sulfosulfuron & 2Med & 9 & 2 & 2 & 0 & 19.6 & 0.0 & 68.4 \\
\hline 222 & Tebufenozide & 1Low & 2 & 1 & 1 & 0 & 1.3 & 0.0 & 90.0 \\
\hline 225 & Tebuthiuron_TP_104 & 1Low & 6 & 3 & 0 & 3 & 0.9 & 100.0 & 100.0 \\
\hline 226 & Tebuthiuron_TP_108 & 1Low & 10 & 5 & 3 & 2 & 1.4 & 40.0 & 75.3 \\
\hline 226 & Tebuthiuron_TP_108 & 2Med & 10 & 5 & 5 & 0 & 46.5 & 0.0 & 36.9 \\
\hline 226 & Tebuthiuron_TP_108 & 3High & 10 & 1 & 1 & 0 & 111.9 & 0.0 & 90.0 \\
\hline 232 & Terbufos_sulfoxide & 2Med & 3 & 1 & 1 & 0 & 3.2 & 0.0 & 90.0 \\
\hline 233 & Tetraconazole & $2 \mathrm{Med}$ & 6 & 2 & 2 & 0 & 11.5 & 0.0 & 68.4 \\
\hline 235 & Trifloxystrobin & 1Low & 2 & 3 & 2 & 1 & 0.7 & 33.3 & 80.4 \\
\hline 237 & sec-Acetochlor_OXA & 1Low & 52 & 3 & 3 & 0 & 39.2 & 0.0 & 53.6 \\
\hline 237 & sec-Acetochlor_OXA & $2 \mathrm{Med}$ & 52 & 1 & 1 & 0 & 72.7 & 0.0 & 90.0 \\
\hline
\end{tabular}


Table 20. Variability of pesticide concentrations in field duplicate environmental water samples analyzed by schedule 2437.

[Duplicate sets where one or both measurements were nondetections were deleted from the analysis. Eleven overlapping concentration classes were used to characterize variability. Duplicate sets were assigned to a concentration classes on the basis of the median concentration of the duplicate set. ng/L, nanogram per liter; Index, a numerical code assigned by the authors to facilitate identification of the same pesticide in different analytical schedules; nc, not calculated; <, less than]

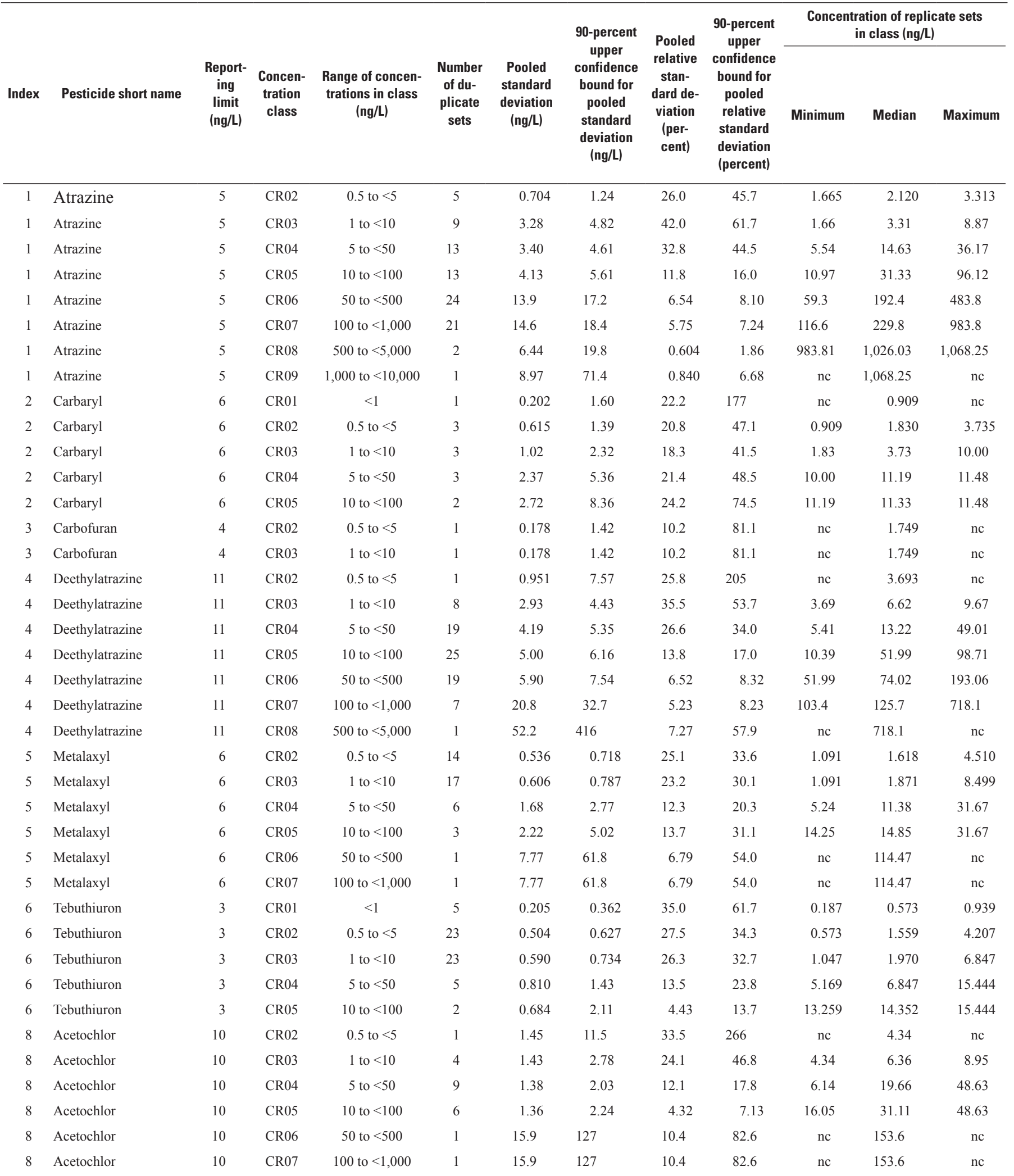


Table 20. Variability of pesticide concentrations in field duplicate environmental water samples analyzed by schedule 2437.— Continued

[Duplicate sets where one or both measurements were nondetections were deleted from the analysis. Eleven overlapping concentration classes were used to characterize variability. Duplicate sets were assigned to a concentration classes on the basis of the median concentration of the duplicate set. ng/L, nanogram per liter; Index, a numerical code assigned by the authors to facilitate identification of the same pesticide in different analytical schedules; nc, not calculated; <, less than]

\begin{tabular}{|c|c|c|c|c|c|c|c|c|c|c|c|c|}
\hline \multirow[b]{2}{*}{ Index } & \multirow[b]{2}{*}{ Pesticide short name } & \multirow[b]{2}{*}{$\begin{array}{l}\text { Report- } \\
\text { ing } \\
\text { limit } \\
\text { (ng/L) }\end{array}$} & \multirow[b]{2}{*}{$\begin{array}{l}\text { Concen- } \\
\text { tration } \\
\text { class }\end{array}$} & \multirow[b]{2}{*}{$\begin{array}{l}\text { Range of concen- } \\
\text { trations in class } \\
\text { (ng/L) }\end{array}$} & \multirow[b]{2}{*}{$\begin{array}{l}\text { Number } \\
\text { of du- } \\
\text { plicate } \\
\text { sets }\end{array}$} & \multirow[b]{2}{*}{$\begin{array}{l}\text { Pooled } \\
\text { standard } \\
\text { deviation } \\
\text { (ng/L) }\end{array}$} & \multirow{2}{*}{$\begin{array}{c}\text { 90-percent } \\
\text { upper } \\
\text { confidence } \\
\text { bound for } \\
\text { pooled } \\
\text { standard } \\
\text { deviation } \\
\text { (ng/L) }\end{array}$} & \multirow{2}{*}{$\begin{array}{l}\text { Pooled } \\
\text { relative } \\
\text { stan- } \\
\text { dard de- } \\
\text { viation } \\
\text { (per- } \\
\text { cent) }\end{array}$} & \multirow{2}{*}{$\begin{array}{c}\text { 90-percent } \\
\text { upper } \\
\text { confidence } \\
\text { bound for } \\
\text { pooled } \\
\text { relative } \\
\text { standard } \\
\text { deviation } \\
\text { (percent) }\end{array}$} & \multicolumn{3}{|c|}{$\begin{array}{l}\text { Concentration of replicate sets } \\
\text { in class (ng/L) }\end{array}$} \\
\hline & & & & & & & & & & Minimum & Median & Maximum \\
\hline 16 & Desulfinylfipronil & 4 & CR02 & 0.5 to $<5$ & 15 & 0.344 & 0.456 & 21.4 & 28.4 & 0.757 & 1.547 & 3.478 \\
\hline 16 & Desulfinylfipronil & 4 & CR03 & 1 to $<10$ & 13 & 0.368 & 0.499 & 22.5 & 30.5 & 1.055 & 1.577 & 3.478 \\
\hline 17 & Diazinon & 3 & CR06 & 50 to $<500$ & 1 & 2.03 & 16.1 & 1.94 & 15.4 & $\mathrm{nc}$ & 104.51 & $\mathrm{nc}$ \\
\hline 17 & Diazinon & 3 & CR07 & 100 to $<1,000$ & 1 & 2.03 & 16.1 & 1.94 & 15.4 & $\mathrm{nc}$ & 104.51 & $\mathrm{nc}$ \\
\hline 18 & Diazoxon & 4 & CR04 & 5 to $<50$ & 1 & 0.459 & 3.65 & 3.01 & 23.9 & $\mathrm{nc}$ & 15.252 & $\mathrm{nc}$ \\
\hline 20 & Dicrotophos & 4 & CR04 & 5 to $<50$ & 2 & 1.44 & 4.43 & 4.21 & 13.0 & 20.75 & 33.45 & 46.14 \\
\hline 20 & Dicrotophos & 4 & CR05 & 10 to $<100$ & 2 & 1.44 & 4.43 & 4.21 & 13.0 & 20.75 & 33.45 & 46.14 \\
\hline 21 & Dimethoate & 3 & CR01 & $<1$ & 2 & 0.0774 & 0.238 & 13.3 & 41.0 & 0.4875 & 0.5418 & 0.5962 \\
\hline 21 & Dimethoate & 3 & CR02 & 0.5 to $<5$ & 4 & 0.294 & 0.569 & 12.4 & 24.1 & 0.596 & 2.389 & 4.141 \\
\hline 21 & Dimethoate & 3 & CR03 & 1 to $<10$ & 3 & 0.334 & 0.756 & 10.2 & 23.2 & 1.430 & 3.349 & 4.141 \\
\hline 25 & Ethoprophos & 5 & CR04 & 5 to $<50$ & 2 & 2.24 & 6.89 & 12.1 & 37.2 & 13.99 & 17.95 & 21.91 \\
\hline 25 & Ethoprophos & 5 & CR05 & 10 to $<100$ & 2 & 2.24 & 6.89 & 12.1 & 37.2 & 13.99 & 17.95 & 21.91 \\
\hline 29 & Fipronil & 4 & CR01 & $<1$ & 1 & 0.464 & 3.69 & 50.7 & 404 & $\mathrm{nc}$ & 0.914 & $\mathrm{nc}$ \\
\hline 29 & Fipronil & 4 & CR02 & 0.5 to $<5$ & 7 & 0.372 & 0.584 & 24.4 & 38.3 & 0.914 & 1.237 & 4.443 \\
\hline 29 & Fipronil & 4 & CR03 & 1 to $<10$ & 13 & 0.693 & 0.941 & 14.8 & 20.1 & 1.108 & 5.246 & 7.908 \\
\hline 31 & Fipronil_sulfone & 4 & CR04 & 5 to $<50$ & 1 & 0.0130 & 0.104 & 0.213 & 1.69 & $\mathrm{nc}$ & 6.1156 & $\mathrm{nc}$ \\
\hline 33 & Hexazinone & 3 & CR01 & $<1$ & 2 & 0.102 & 0.314 & 12.2 & 37.5 & 0.833 & 0.862 & 0.891 \\
\hline 33 & Hexazinone & 3 & CR02 & 0.5 to $<5$ & 17 & 0.358 & 0.464 & 22.5 & 29.2 & 0.833 & 1.569 & 3.373 \\
\hline 33 & Hexazinone & 3 & CR03 & 1 to $<10$ & 16 & 0.375 & 0.491 & 22.8 & 29.9 & 1.001 & 1.627 & 6.284 \\
\hline 33 & Hexazinone & 3 & CR04 & 5 to $<50$ & 2 & 0.358 & 1.10 & 3.56 & 11.0 & 6.284 & 20.185 & 34.086 \\
\hline 33 & Hexazinone & 3 & CR05 & 10 to $<100$ & 1 & 0.402 & 3.20 & 1.18 & 9.39 & $\mathrm{nc}$ & 34.086 & $\mathrm{nc}$ \\
\hline 35 & Malathion & 6 & CR03 & 1 to $<10$ & 2 & 0.546 & 1.68 & 8.29 & 25.5 & 6.219 & 6.409 & 6.599 \\
\hline 35 & Malathion & 6 & CR04 & 5 to $<50$ & 2 & 0.546 & 1.68 & 8.29 & 25.5 & 6.219 & 6.409 & 6.599 \\
\hline 37 & Metolachlor & 9 & CR02 & 0.5 to $<5$ & 10 & 0.868 & 1.24 & 27.7 & 39.7 & 1.103 & 2.877 & 4.286 \\
\hline 37 & Metolachlor & 9 & CR03 & 1 to $<10$ & 14 & 0.759 & 1.02 & 23.6 & 31.6 & 1.103 & 3.379 & 8.759 \\
\hline 37 & Metolachlor & 9 & CR04 & 5 to $<50$ & 13 & 1.92 & 2.61 & 6.08 & 8.27 & 5.70 & 23.02 & 48.45 \\
\hline 37 & Metolachlor & 9 & CR05 & 10 to $<100$ & 14 & 3.05 & 4.09 & 5.84 & 7.84 & 13.84 & 39.08 & 95.82 \\
\hline 37 & Metolachlor & 9 & CR06 & 50 to $<500$ & 12 & 6.60 & 9.10 & 3.91 & 5.40 & 63.98 & 107.55 & 390.19 \\
\hline
\end{tabular}


Table 20. Variability of pesticide concentrations in field duplicate environmental water samples analyzed by schedule 2437.— Continued

[Duplicate sets where one or both measurements were nondetections were deleted from the analysis. Eleven overlapping concentration classes were used to characterize variability. Duplicate sets were assigned to a concentration classes on the basis of the median concentration of the duplicate set. ng/L, nanogram per liter; Index, a numerical code assigned by the authors to facilitate identification of the same pesticide in different analytical schedules; nc, not calculated; <, less than]

\begin{tabular}{|c|c|c|c|c|c|c|c|c|c|c|c|c|}
\hline \multirow[b]{2}{*}{ Index } & \multirow[b]{2}{*}{ Pesticide short name } & \multirow[b]{2}{*}{$\begin{array}{l}\text { Report- } \\
\text { ing } \\
\text { limit } \\
\text { (ng/L) }\end{array}$} & \multirow[b]{2}{*}{$\begin{array}{l}\text { Concen- } \\
\text { tration } \\
\text { class }\end{array}$} & \multirow[b]{2}{*}{$\begin{array}{l}\text { Range of concen- } \\
\text { trations in class } \\
\text { (ng/L) }\end{array}$} & \multirow[b]{2}{*}{$\begin{array}{l}\text { Number } \\
\text { of du- } \\
\text { plicate } \\
\text { sets }\end{array}$} & \multirow[b]{2}{*}{$\begin{array}{l}\text { Pooled } \\
\text { standard } \\
\text { deviation } \\
\text { (ng/L) }\end{array}$} & \multirow{2}{*}{$\begin{array}{l}\text { 90-percent } \\
\text { upper } \\
\text { confidence } \\
\text { bound for } \\
\text { pooled } \\
\text { standard } \\
\text { deviation } \\
\text { (ng/L) }\end{array}$} & \multirow{2}{*}{$\begin{array}{l}\text { Pooled } \\
\text { relative } \\
\text { stan- } \\
\text { dard de- } \\
\text { viation } \\
\text { (per- } \\
\text { cent) }\end{array}$} & \multirow{2}{*}{$\begin{array}{c}\text { 90-percent } \\
\text { upper } \\
\text { confidence } \\
\text { bound for } \\
\text { pooled } \\
\text { relative } \\
\text { standard } \\
\text { deviation } \\
\text { (percent) }\end{array}$} & \multicolumn{3}{|c|}{$\begin{array}{l}\text { Concentration of replicate sets } \\
\text { in class (ng/L) }\end{array}$} \\
\hline & & & & & & & & & & Minimum & Median & Maximum \\
\hline 37 & Metolachlor & 9 & CR08 & 500 to $<5,000$ & 4 & 70.9 & 138 & 3.18 & 6.17 & $1,144.6$ & $2,144.8$ & $3,221.7$ \\
\hline 37 & Metolachlor & 9 & CR09 & 1,000 to $<10,000$ & 4 & 70.9 & 138 & 3.18 & 6.17 & $1,144.6$ & $2,144.8$ & $3,221.7$ \\
\hline 38 & Metribuzin & 20 & CR04 & 5 to $<50$ & 1 & 5.17 & 41.2 & 29.8 & 237 & $\mathrm{nc}$ & 17.37 & $\mathrm{nc}$ \\
\hline 38 & Metribuzin & 20 & CR05 & 10 to $<100$ & 1 & 5.17 & 41.2 & 29.8 & 237 & $\mathrm{nc}$ & 17.37 & $\mathrm{nc}$ \\
\hline 40 & Myclobutanil & 7 & CR01 & $<1$ & 1 & 0.0653 & 0.519 & 11.2 & 89.0 & $\mathrm{nc}$ & 0.5836 & $\mathrm{nc}$ \\
\hline 40 & Myclobutanil & 7 & CR07 & 100 to $<1,000$ & 1 & 5.37 & 42.8 & 1.02 & 8.13 & $\mathrm{nc}$ & 526.27 & $\mathrm{nc}$ \\
\hline 40 & Myclobutanil & 7 & CR08 & 500 to $<5,000$ & 1 & 5.37 & 42.8 & 1.02 & 8.13 & $\mathrm{nc}$ & 526.27 & $\mathrm{nc}$ \\
\hline 44 & Pendimethalin & 3 & CR01 & $<1$ & 1 & 0.379 & 3.02 & 42.0 & 334 & $\mathrm{nc}$ & 0.904 & $\mathrm{nc}$ \\
\hline 44 & Pendimethalin & 3 & CR02 & 0.5 to $<5$ & 2 & 0.798 & 2.46 & 33.5 & 103 & 0.904 & 2.859 & 4.814 \\
\hline 44 & Pendimethalin & 3 & CR03 & 1 to $<10$ & 1 & 1.06 & 8.46 & 22.1 & 176 & $\mathrm{nc}$ & 4.81 & $\mathrm{nc}$ \\
\hline 49 & Prometon & 4 & CR02 & 0.5 to $<5$ & 19 & 0.425 & 0.543 & 16.0 & 20.4 & 1.064 & 2.372 & 4.509 \\
\hline 49 & Prometon & 4 & CR03 & 1 to $<10$ & 29 & 0.596 & 0.722 & 15.2 & 18.4 & 1.064 & 3.173 & 7.812 \\
\hline 49 & Prometon & 4 & CR04 & 5 to $<50$ & 20 & 4.27 & 5.42 & 14.3 & 18.1 & 5.29 & 9.10 & 45.20 \\
\hline 49 & Prometon & 4 & CR05 & 10 to $<100$ & 10 & 5.99 & 8.59 & 15.0 & 21.5 & 10.38 & 20.57 & 45.20 \\
\hline 49 & Prometon & 4 & CR06 & 50 to $<500$ & 1 & 13.5 & 107 & 4.54 & 36.1 & $\mathrm{nc}$ & 296.4 & $\mathrm{nc}$ \\
\hline 53 & Propyzamide & 4 & CR04 & 5 to $<50$ & 1 & 1.35 & 10.7 & 13.5 & 108 & $\mathrm{nc}$ & 9.95 & $\mathrm{nc}$ \\
\hline 54 & Simazine & 10 & CR03 & 1 to $<10$ & 4 & 4.00 & 7.75 & 61.9 & 120 & 5.29 & 6.59 & 8.71 \\
\hline 54 & Simazine & 10 & CR04 & 5 to $<50$ & 17 & 3.52 & 4.58 & 35.1 & 45.5 & 5.29 & 13.86 & 44.55 \\
\hline 54 & Simazine & 10 & CR05 & 10 to $<100$ & 16 & 4.05 & 5.31 & 18.9 & 24.8 & 10.06 & 23.01 & 86.29 \\
\hline 54 & Simazine & 10 & CR06 & 50 to $<500$ & 5 & 6.66 & 11.7 & 6.43 & 11.3 & 65.55 & 86.29 & 155.10 \\
\hline 54 & Simazine & 10 & CR07 & 100 to $<1,000$ & 2 & 7.31 & 22.5 & 4.71 & 14.5 & 153.23 & 154.17 & 155.10 \\
\hline 55 & Tebuconazole & 5 & CR01 & $<1$ & 1 & 0.291 & 2.32 & 35.7 & 284 & $\mathrm{nc}$ & 0.815 & $\mathrm{nc}$ \\
\hline 55 & Tebuconazole & 5 & CR02 & 0.5 to $<5$ & 9 & 0.364 & 0.535 & 15.6 & 22.9 & 0.815 & 3.108 & 4.894 \\
\hline 55 & Tebuconazole & 5 & CR03 & 1 to $<10$ & 13 & 0.835 & 1.13 & 13.6 & 18.5 & 2.373 & 4.344 & 9.448 \\
\hline 55 & Tebuconazole & 5 & CR04 & 5 to $<50$ & 5 & 1.26 & 2.22 & 17.3 & 30.6 & 5.08 & 7.06 & 9.45 \\
\hline 58 & Terbuthylazine & 3 & CR02 & 0.5 to $<5$ & 5 & 0.175 & 0.309 & 8.50 & 15.0 & 1.183 & 1.611 & 4.737 \\
\hline 58 & Terbuthylazine & 3 & CR03 & 1 to $<10$ & 6 & 0.341 & 0.563 & 8.76 & 14.5 & 1.183 & 1.749 & 7.418 \\
\hline 58 & Terbuthylazine & 3 & CR04 & 5 to $<50$ & 6 & 2.24 & 3.70 & 10.8 & 17.9 & 7.42 & 16.93 & 47.86 \\
\hline
\end{tabular}


Table 20. Variability of pesticide concentrations in field duplicate environmental water samples analyzed by schedule 2437.— Continued

[Duplicate sets where one or both measurements were nondetections were deleted from the analysis. Eleven overlapping concentration classes were used to characterize variability. Duplicate sets were assigned to a concentration classes on the basis of the median concentration of the duplicate set. ng/L, nanogram per liter; Index, a numerical code assigned by the authors to facilitate identification of the same pesticide in different analytical schedules; nc, not calculated; <, less than]

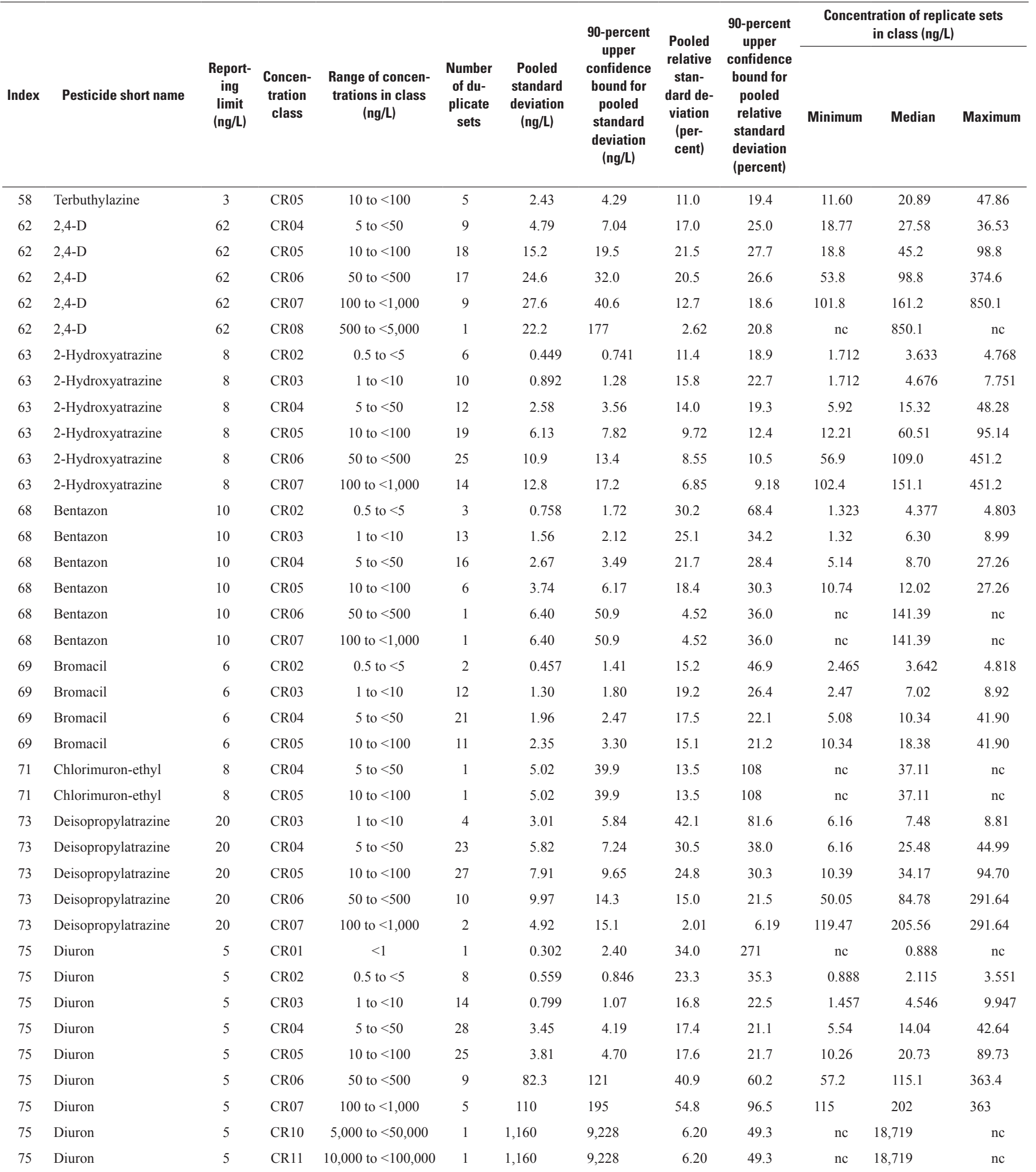


Table 20. Variability of pesticide concentrations in field duplicate environmental water samples analyzed by schedule 2437.Continued

[Duplicate sets where one or both measurements were nondetections were deleted from the analysis. Eleven overlapping concentration classes were used to characterize variability. Duplicate sets were assigned to a concentration classes on the basis of the median concentration of the duplicate set. ng/L, nanogram per liter; Index, a numerical code assigned by the authors to facilitate identification of the same pesticide in different analytical schedules; nc, not calculated; <, less than]

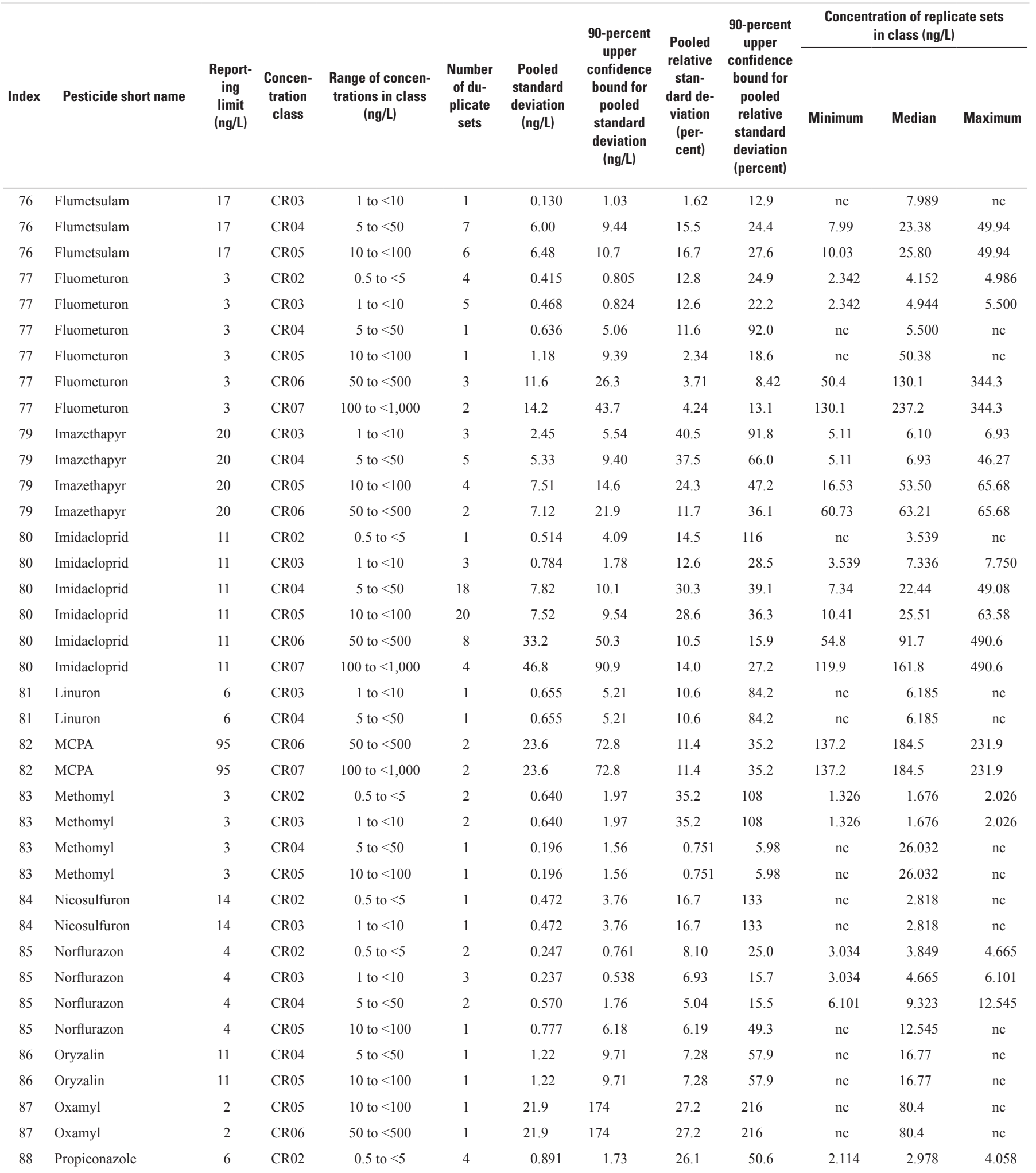


Table 20. Variability of pesticide concentrations in field duplicate environmental water samples analyzed by schedule 2437.Continued

[Duplicate sets where one or both measurements were nondetections were deleted from the analysis. Eleven overlapping concentration classes were used to characterize variability. Duplicate sets were assigned to a concentration classes on the basis of the median concentration of the duplicate set. ng/L, nanogram per liter; Index, a numerical code assigned by the authors to facilitate identification of the same pesticide in different analytical schedules; nc, not calculated; <, less than]

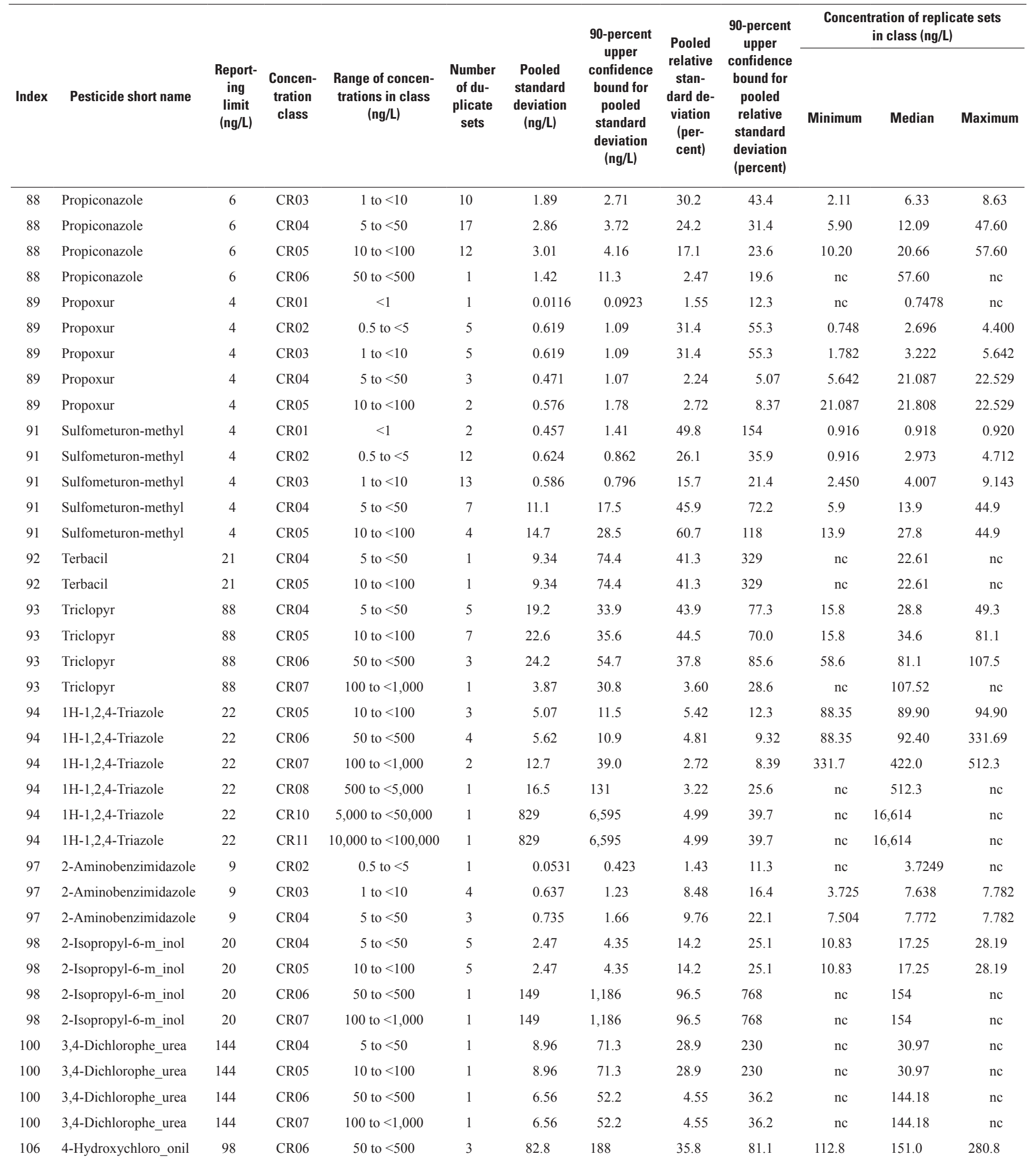


Table 20. Variability of pesticide concentrations in field duplicate environmental water samples analyzed by schedule 2437.Continued

[Duplicate sets where one or both measurements were nondetections were deleted from the analysis. Eleven overlapping concentration classes were used to characterize variability. Duplicate sets were assigned to a concentration classes on the basis of the median concentration of the duplicate set. ng/L, nanogram per liter; Index, a numerical code assigned by the authors to facilitate identification of the same pesticide in different analytical schedules; nc, not calculated; <, less than]

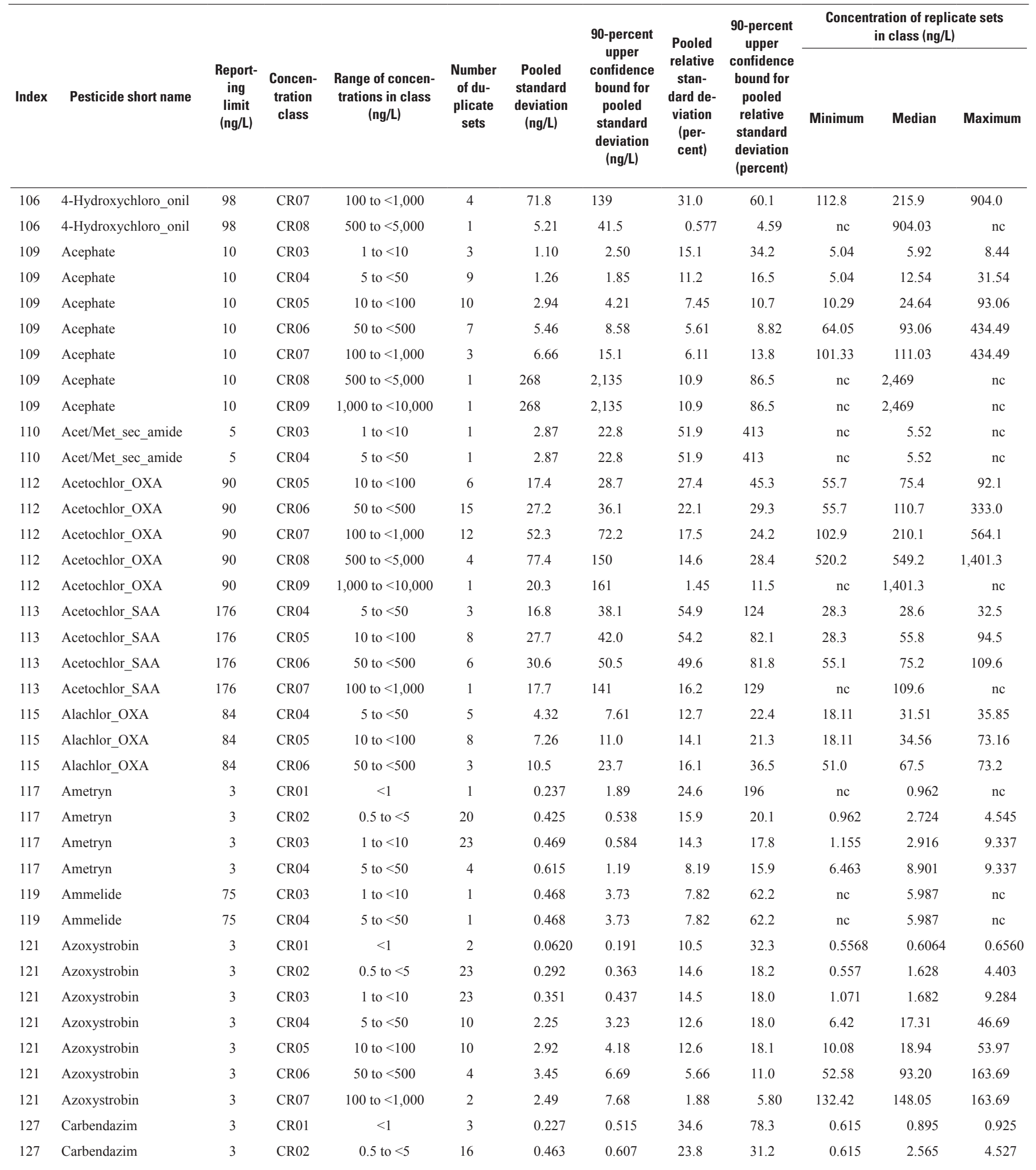


Table 20. Variability of pesticide concentrations in field duplicate environmental water samples analyzed by schedule 2437.Continued

[Duplicate sets where one or both measurements were nondetections were deleted from the analysis. Eleven overlapping concentration classes were used to characterize variability. Duplicate sets were assigned to a concentration classes on the basis of the median concentration of the duplicate set. ng/L, nanogram per liter; Index, a numerical code assigned by the authors to facilitate identification of the same pesticide in different analytical schedules; nc, not calculated; <, less than]

\begin{tabular}{|c|c|c|c|c|c|c|c|c|c|c|c|c|}
\hline \multirow[b]{2}{*}{ Index } & \multirow[b]{2}{*}{ Pesticide short name } & \multirow[b]{2}{*}{$\begin{array}{c}\text { Report- } \\
\text { ing } \\
\text { limit } \\
\text { (ng/L) }\end{array}$} & \multirow[b]{2}{*}{$\begin{array}{l}\text { Concen- } \\
\text { tration } \\
\text { class }\end{array}$} & \multirow[b]{2}{*}{$\begin{array}{l}\text { Range of concen- } \\
\text { trations in class } \\
\text { (ng/L) }\end{array}$} & \multirow[b]{2}{*}{$\begin{array}{l}\text { Number } \\
\text { of du- } \\
\text { plicate } \\
\text { sets }\end{array}$} & \multirow[b]{2}{*}{$\begin{array}{c}\text { Pooled } \\
\text { standard } \\
\text { deviation } \\
\text { (ng/L) }\end{array}$} & \multirow{2}{*}{$\begin{array}{c}\text { 90-percent } \\
\text { upper } \\
\text { confidence } \\
\text { bound for } \\
\text { pooled } \\
\text { standard } \\
\text { deviation } \\
\text { (ng/L) }\end{array}$} & \multirow{2}{*}{$\begin{array}{l}\text { Pooled } \\
\text { relative } \\
\text { stan- } \\
\text { dard de- } \\
\text { viation } \\
\text { (per- } \\
\text { cent) }\end{array}$} & \multirow{2}{*}{$\begin{array}{c}\text { 90-percent } \\
\text { upper } \\
\text { confidence } \\
\text { bound for } \\
\text { pooled } \\
\text { relative } \\
\text { standard } \\
\text { deviation } \\
\text { (percent) }\end{array}$} & \multicolumn{3}{|c|}{$\begin{array}{l}\text { Concentration of replicate sets } \\
\text { in class (ng/L) }\end{array}$} \\
\hline & & & & & & & & & & Minimum & Median & Maximum \\
\hline 127 & Carbendazim & 3 & CR04 & 5 to $<50$ & 22 & 8.24 & 10.3 & 36.3 & 45.4 & 5.11 & 18.32 & 47.35 \\
\hline 127 & Carbendazim & 3 & CR05 & 10 to $<100$ & 14 & 10.1 & 13.6 & 36.1 & 48.4 & 10.2 & 21.7 & 47.3 \\
\hline 127 & Carbendazim & 3 & CR06 & 50 to $<500$ & 1 & 1.60 & 12.7 & 1.53 & 12.2 & $\mathrm{nc}$ & 104.21 & $\mathrm{nc}$ \\
\hline 127 & Carbendazim & 3 & CR07 & 100 to $<1,000$ & 1 & 1.60 & 12.7 & 1.53 & 12.2 & $\mathrm{nc}$ & 104.21 & $\mathrm{nc}$ \\
\hline 129 & Chlorosulfonami_acid & 75 & CR06 & 50 to $<500$ & 1 & 18.3 & 146 & 16.5 & 131 & $\mathrm{nc}$ & 111.1 & $\mathrm{nc}$ \\
\hline 132 & Dechlorometolachlor & 2 & CR02 & 0.5 to $<5$ & 6 & 0.120 & 0.199 & 8.58 & 14.2 & 1.005 & 1.466 & 4.299 \\
\hline 132 & Dechlorometolachlor & 2 & CR03 & 1 to $<10$ & 13 & 0.420 & 0.570 & 7.92 & 10.8 & 1.005 & 6.844 & 9.647 \\
\hline 132 & Dechlorometolachlor & 2 & CR04 & 5 to $<50$ & 21 & 1.28 & 1.62 & 9.74 & 12.3 & 6.84 & 12.22 & 47.12 \\
\hline 132 & Dechlorometolachlor & 2 & CR05 & 10 to $<100$ & 14 & 1.52 & 2.04 & 10.7 & 14.4 & 10.40 & 13.67 & 47.12 \\
\hline 132 & Dechlorometolachlor & 2 & CR06 & 50 to $<500$ & 3 & 4.71 & 10.7 & 2.15 & 4.87 & 123.59 & 156.37 & 278.74 \\
\hline 132 & Dechlorometolachlor & 2 & CR07 & 100 to $<1,000$ & 3 & 4.71 & 10.7 & 2.15 & 4.87 & 123.59 & 156.37 & 278.74 \\
\hline 133 & Deethylhydroxy_azine & 4 & CR02 & 0.5 to $<5$ & 8 & 0.665 & 1.01 & 18.9 & 28.6 & 2.000 & 3.865 & 4.979 \\
\hline 133 & Deethylhydroxy_azine & 4 & CR03 & 1 to $<10$ & 15 & 0.679 & 0.900 & 15.0 & 19.8 & 2.000 & 4.979 & 9.903 \\
\hline 133 & Deethylhydroxy_azine & 4 & CR04 & 5 to $<50$ & 25 & 1.65 & 2.03 & 11.7 & 14.4 & 5.50 & 12.53 & 33.87 \\
\hline 133 & Deethylhydroxy_azine & 4 & CR05 & 10 to $<100$ & 19 & 1.86 & 2.38 & 12.4 & 15.8 & 10.33 & 15.55 & 81.66 \\
\hline 136 & Deisopropylhyd_azine & 6 & CR04 & 5 to $<50$ & 2 & 1.80 & 5.54 & 5.23 & 16.1 & 32.19 & 35.11 & 38.02 \\
\hline 136 & Deisopropylhyd_azine & 6 & CR05 & 10 to $<100$ & 2 & 1.80 & 5.54 & 5.23 & 16.1 & 32.19 & 35.11 & 38.02 \\
\hline 138 & Demethyl_fluometuron & 2 & CR02 & 0.5 to $<5$ & 1 & 0.669 & 5.32 & 53.4 & 425 & $\mathrm{nc}$ & 1.253 & $\mathrm{nc}$ \\
\hline 138 & Demethyl_fluometuron & 2 & CR03 & 1 to $<10$ & 1 & 0.669 & 5.32 & 53.4 & 425 & $\mathrm{nc}$ & 1.253 & $\mathrm{nc}$ \\
\hline 138 & Demethyl_fluometuron & 2 & CR04 & 5 to $<50$ & 2 & 2.03 & 6.25 & 7.87 & 24.3 & 20.96 & 30.88 & 40.79 \\
\hline 138 & Demethyl_fluometuron & 2 & CR05 & 10 to $<100$ & 3 & 4.77 & 10.8 & 8.42 & 19.1 & 20.96 & 40.79 & 82.33 \\
\hline 138 & Demethyl_fluometuron & 2 & CR06 & 50 to $<500$ & 1 & 7.76 & 61.7 & 9.42 & 75.0 & $\mathrm{nc}$ & 82.33 & $\mathrm{nc}$ \\
\hline 139 & Demethyl_hexazi_ne_B & 3 & CR02 & 0.5 to $<5$ & 1 & 0.00841 & 0.0670 & 0.747 & 5.94 & $\mathrm{nc}$ & 1.12655 & $\mathrm{nc}$ \\
\hline 139 & Demethyl_hexazi_ne_B & 3 & CR03 & 1 to $<10$ & 2 & 0.292 & 0.898 & 5.12 & 15.8 & 1.127 & 3.426 & 5.724 \\
\hline 139 & Demethyl_hexazi_ne_B & 3 & CR04 & 5 to $<50$ & 1 & 0.412 & 3.28 & 7.20 & 57.3 & $\mathrm{nc}$ & 5.724 & $\mathrm{nc}$ \\
\hline 140 & Demethyl_norflurazon & 4 & CR04 & 5 to $<50$ & 3 & 1.79 & 4.05 & 8.17 & 18.5 & 11.21 & 18.62 & 26.81 \\
\hline 140 & Demethyl_norflurazon & 4 & CR05 & 10 to $<100$ & 3 & 1.79 & 4.05 & 8.17 & 18.5 & 11.21 & 18.62 & 26.81 \\
\hline 141 & Desamino-diketo_uzin & 200 & CR04 & 5 to $<50$ & 1 & 1.01 & 8.01 & 4.95 & 39.4 & $\mathrm{nc}$ & 20.33 & $\mathrm{nc}$ \\
\hline
\end{tabular}


Table 20. Variability of pesticide concentrations in field duplicate environmental water samples analyzed by schedule 2437.Continued

[Duplicate sets where one or both measurements were nondetections were deleted from the analysis. Eleven overlapping concentration classes were used to characterize variability. Duplicate sets were assigned to a concentration classes on the basis of the median concentration of the duplicate set. ng/L, nanogram per liter; Index, a numerical code assigned by the authors to facilitate identification of the same pesticide in different analytical schedules; nc, not calculated; <, less than]

\begin{tabular}{|c|c|c|c|c|c|c|c|c|c|c|c|c|}
\hline \multirow[b]{2}{*}{ Index } & \multirow[b]{2}{*}{ Pesticide short name } & \multirow{2}{*}{$\begin{array}{l}\text { Report- } \\
\text { ing } \\
\text { limit } \\
\text { (ng/L) }\end{array}$} & \multirow[b]{2}{*}{$\begin{array}{l}\text { Concen- } \\
\text { tration } \\
\text { class }\end{array}$} & \multirow[b]{2}{*}{$\begin{array}{l}\text { Range of concen- } \\
\text { trations in class } \\
\text { (ng/L) }\end{array}$} & \multirow{2}{*}{$\begin{array}{l}\text { Number } \\
\text { of du- } \\
\text { plicate } \\
\text { sets }\end{array}$} & \multirow{2}{*}{$\begin{array}{c}\text { Pooled } \\
\text { standard } \\
\text { deviation } \\
\text { (ng/L) }\end{array}$} & \multirow{2}{*}{$\begin{array}{l}\text { 90-percent } \\
\text { upper } \\
\text { confidence } \\
\text { bound for } \\
\text { pooled } \\
\text { standard } \\
\text { deviation } \\
\text { (ng/L) }\end{array}$} & \multirow{2}{*}{$\begin{array}{c}\text { Pooled } \\
\text { relative } \\
\text { stan- } \\
\text { dard de- } \\
\text { viation } \\
\text { (per- } \\
\text { cent) }\end{array}$} & \multirow{2}{*}{$\begin{array}{l}90 \text {-percent } \\
\text { upper } \\
\text { confidence } \\
\text { bound for } \\
\text { pooled } \\
\text { relative } \\
\text { standard } \\
\text { deviation } \\
\text { (percent) }\end{array}$} & \multicolumn{3}{|c|}{$\begin{array}{c}\text { Concentration of replicate sets } \\
\text { in class (ng/L) }\end{array}$} \\
\hline & & & & & & & & & & Minimum & Median & Maximum \\
\hline 141 & Desamino-diketo_uzin & 200 & CR06 & 50 to $<500$ & 3 & 19.7 & 44.6 & 29.0 & 65.7 & 58.5 & 67.7 & 73.7 \\
\hline 142 & Didealkylatrazine & 24 & CR04 & 5 to $<50$ & 4 & 6.41 & 12.4 & 18.3 & 35.6 & 18.78 & 27.98 & 43.84 \\
\hline 142 & Didealkylatrazine & 24 & CR05 & 10 to $<100$ & 9 & 7.87 & 11.6 & 14.2 & 20.8 & 18.78 & 60.21 & 99.47 \\
\hline 142 & Didealkylatrazine & 24 & CR06 & 50 to $<500$ & 24 & 27.7 & 34.3 & 12.9 & 15.9 & 60.2 & 163.8 & 480.3 \\
\hline 142 & Didealkylatrazine & 24 & CR07 & 100 to $<1,000$ & 20 & 30.2 & 38.3 & 13.2 & 16.8 & 108.1 & 204.8 & 522.3 \\
\hline 146 & Diketonitrile-i_tole & 62 & CR05 & 10 to $<100$ & 4 & 9.60 & 18.6 & 18.0 & 34.8 & 15.42 & 35.14 & 88.84 \\
\hline 146 & Diketonitrile-i_tole & 62 & CR06 & 50 to $<500$ & 2 & 13.5 & 41.7 & 24.0 & 74.0 & 53.1 & 70.9 & 88.8 \\
\hline 147 & Dimethenamid & 3 & CR01 & $<1$ & 1 & 0.190 & 1.51 & 24.1 & 192 & $\mathrm{nc}$ & 0.790 & $\mathrm{nc}$ \\
\hline 147 & Dimethenamid & 3 & CR02 & 0.5 to $<5$ & 14 & 0.453 & 0.607 & 18.8 & 25.1 & 0.790 & 2.290 & 4.995 \\
\hline 147 & Dimethenamid & 3 & CR03 & 1 to $<10$ & 16 & 0.485 & 0.635 & 16.8 & 22.0 & 1.236 & 3.268 & 9.882 \\
\hline 147 & Dimethenamid & 3 & CR04 & 5 to $<50$ & 8 & 1.09 & 1.65 & 6.96 & 10.5 & 5.38 & 13.87 & 21.77 \\
\hline 147 & Dimethenamid & 3 & CR05 & 10 to $<100$ & 5 & 1.31 & 2.31 & 6.66 & 11.7 & 13.02 & 19.49 & 21.77 \\
\hline 147 & Dimethenamid & 3 & CR08 & 500 to $<5,000$ & 1 & 172 & 1,366 & 4.65 & 37.0 & $\mathrm{nc}$ & 3,694 & $\mathrm{nc}$ \\
\hline 147 & Dimethenamid & 3 & CR09 & 1,000 to $<10,000$ & 1 & 172 & 1,366 & 4.65 & 37.0 & $\mathrm{nc}$ & 3,694 & $\mathrm{nc}$ \\
\hline 148 & Dimethenamid_ESA & 79 & CR03 & 1 to $<10$ & 2 & 6.06 & 18.7 & 65.6 & 202 & 8.95 & 9.15 & 9.36 \\
\hline 149 & Dimethenamid_OXA & 85 & CR06 & 50 to $<500$ & 1 & 33.2 & 264 & 16.8 & 133 & $\mathrm{nc}$ & 198.0 & $\mathrm{nc}$ \\
\hline 149 & Dimethenamid_OXA & 85 & CR07 & 100 to $<1,000$ & 1 & 33.2 & 264 & 16.8 & 133 & $\mathrm{nc}$ & 198.0 & $\mathrm{nc}$ \\
\hline 150 & Dimethenamid_SAA & 189 & CR05 & 10 to $<100$ & 1 & 34.8 & 277 & 39.2 & 312 & $\mathrm{nc}$ & 88.8 & $\mathrm{nc}$ \\
\hline 150 & Dimethenamid_SAA & 189 & CR06 & 50 to $<500$ & 1 & 34.8 & 277 & 39.2 & 312 & $\mathrm{nc}$ & 88.8 & $\mathrm{nc}$ \\
\hline 161 & Fipronil_amide & 9 & CR02 & 0.5 to $<5$ & 1 & 2.66 & 21.2 & 71.7 & 570 & $\mathrm{nc}$ & 3.71 & $\mathrm{nc}$ \\
\hline 161 & Fipronil_amide & 9 & CR03 & 1 to $<10$ & 4 & 2.14 & 4.16 & 44.8 & 86.8 & 3.71 & 5.89 & 6.42 \\
\hline 161 & Fipronil_amide & 9 & CR04 & 5 to $<50$ & 3 & 1.94 & 4.40 & 31.0 & 70.2 & 5.57 & 6.21 & 6.42 \\
\hline 163 & Flubendiamide & 5 & CR02 & 0.5 to $<5$ & 1 & 0.603 & 4.80 & 57.6 & 458 & $\mathrm{nc}$ & 1.046 & $\mathrm{nc}$ \\
\hline 163 & Flubendiamide & 5 & CR03 & 1 to $<10$ & 3 & 0.461 & 1.04 & 33.7 & 76.5 & 1.046 & 5.186 & 5.473 \\
\hline 163 & Flubendiamide & 5 & CR04 & 5 to $<50$ & 4 & 2.65 & 5.14 & 12.7 & 24.6 & 5.19 & 9.51 & 23.51 \\
\hline 163 & Flubendiamide & 5 & CR05 & 10 to $<100$ & 2 & 3.73 & 11.5 & 16.6 & 51.0 & 13.55 & 18.53 & 23.51 \\
\hline 173 & Hydroxyacetochlor & 9 & CR03 & 1 to $<10$ & 1 & 0.292 & 2.32 & 4.11 & 32.7 & $\mathrm{nc}$ & 7.104 & $\mathrm{nc}$ \\
\hline 173 & Hydroxyacetochlor & 9 & CR04 & 5 to $<50$ & 14 & 5.29 & 7.09 & 22.5 & 30.2 & 7.10 & 18.03 & 46.49 \\
\hline
\end{tabular}


Table 20. Variability of pesticide concentrations in field duplicate environmental water samples analyzed by schedule 2437.Continued

[Duplicate sets where one or both measurements were nondetections were deleted from the analysis. Eleven overlapping concentration classes were used to characterize variability. Duplicate sets were assigned to a concentration classes on the basis of the median concentration of the duplicate set. ng/L, nanogram per liter; Index, a numerical code assigned by the authors to facilitate identification of the same pesticide in different analytical schedules; nc, not calculated; <, less than]

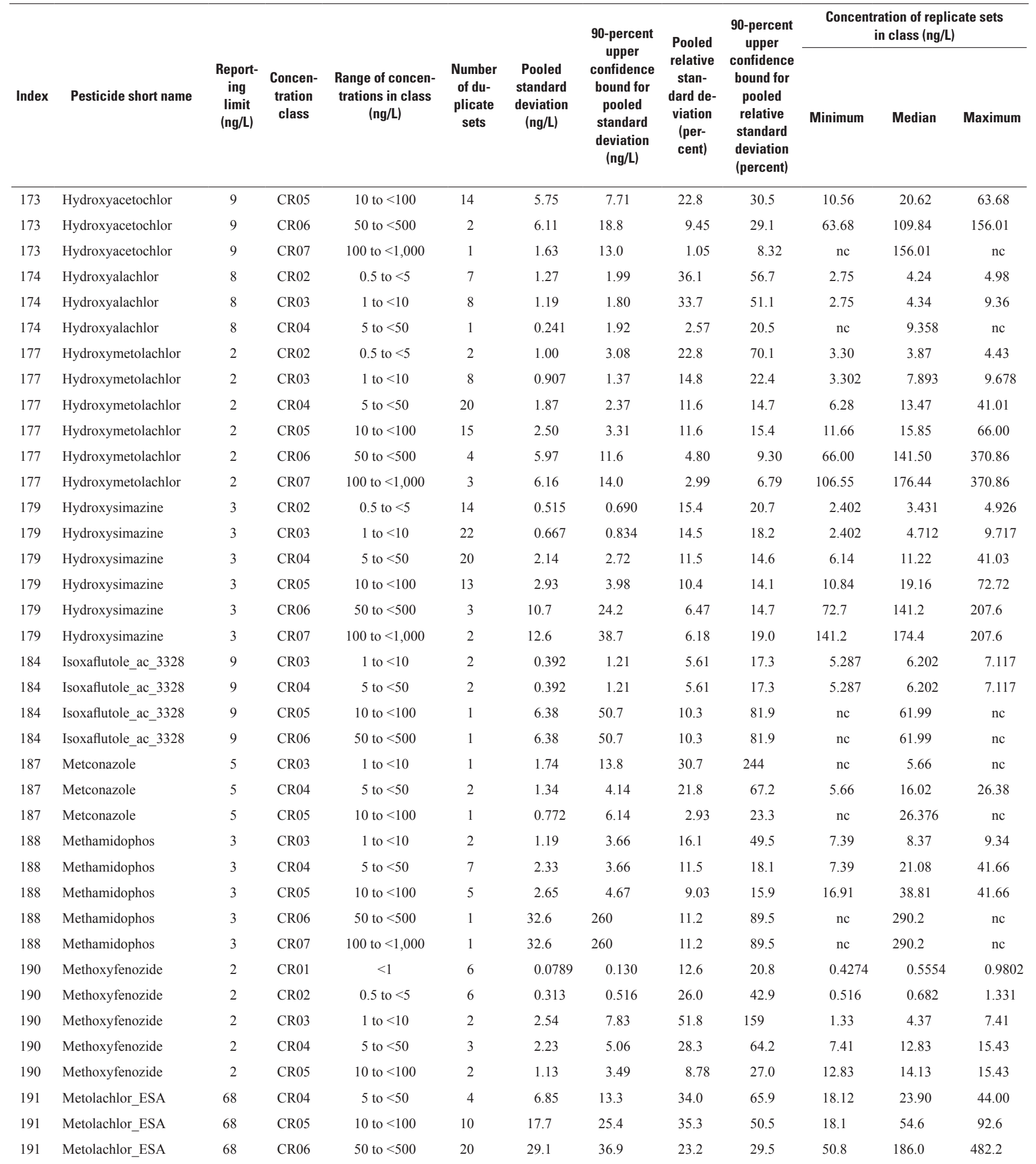


Table 20. Variability of pesticide concentrations in field duplicate environmental water samples analyzed by schedule 2437.Continued

[Duplicate sets where one or both measurements were nondetections were deleted from the analysis. Eleven overlapping concentration classes were used to characterize variability. Duplicate sets were assigned to a concentration classes on the basis of the median concentration of the duplicate set. ng/L, nanogram per liter; Index, a numerical code assigned by the authors to facilitate identification of the same pesticide in different analytical schedules; nc, not calculated; <, less than]

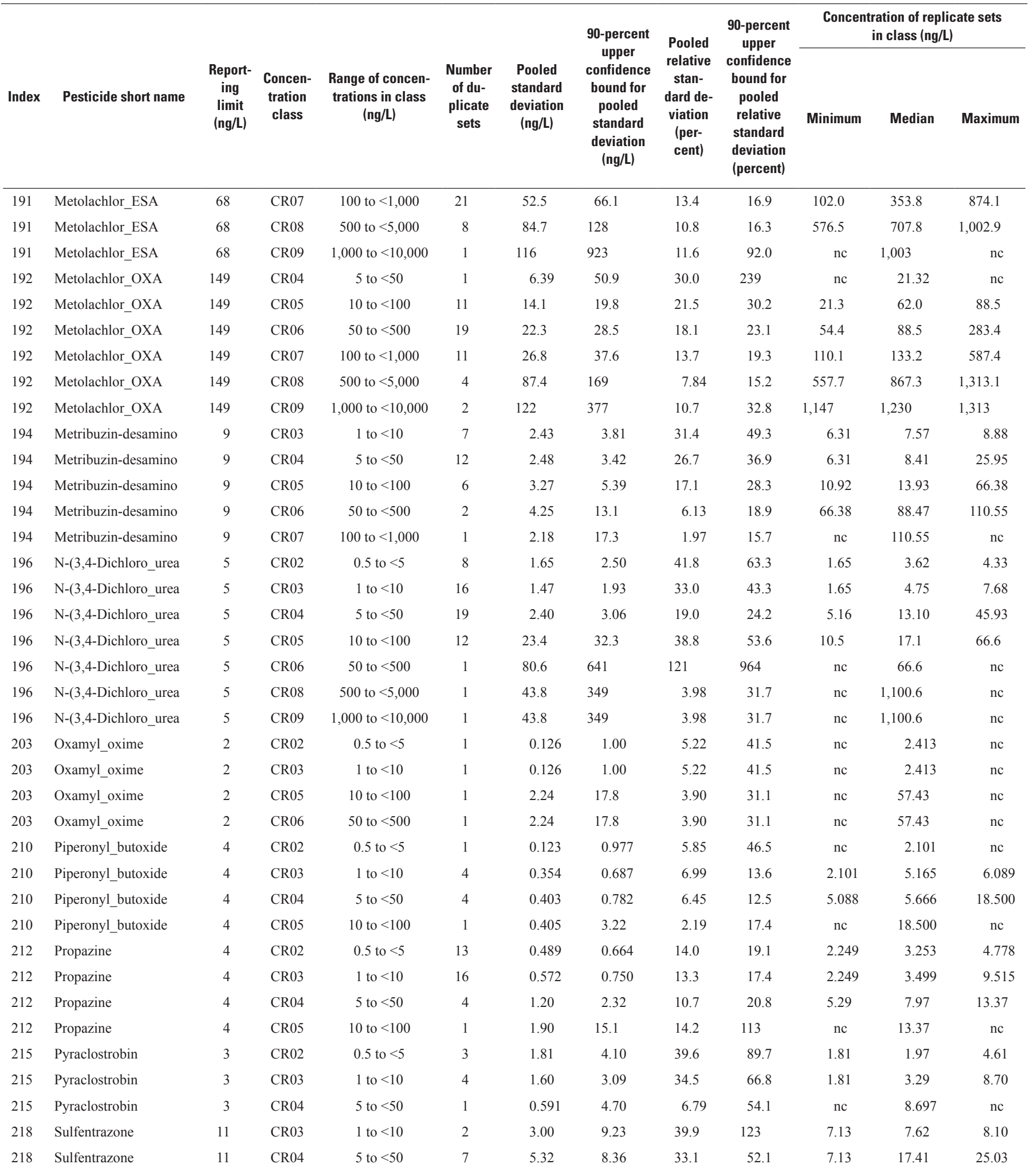


Table 20. Variability of pesticide concentrations in field duplicate environmental water samples analyzed by schedule 2437.Continued

[Duplicate sets where one or both measurements were nondetections were deleted from the analysis. Eleven overlapping concentration classes were used to characterize variability. Duplicate sets were assigned to a concentration classes on the basis of the median concentration of the duplicate set. ng/L, nanogram per liter; Index, a numerical code assigned by the authors to facilitate identification of the same pesticide in different analytical schedules; nc, not calculated; <, less than]

\begin{tabular}{|c|c|c|c|c|c|c|c|c|c|c|c|c|}
\hline \multirow[b]{2}{*}{ Index } & \multirow[b]{2}{*}{ Pesticide short name } & \multirow[b]{2}{*}{$\begin{array}{c}\text { Report- } \\
\text { ing } \\
\text { limit } \\
\text { (ng/L) }\end{array}$} & \multirow[b]{2}{*}{$\begin{array}{l}\text { Concen- } \\
\text { tration } \\
\text { class }\end{array}$} & \multirow[b]{2}{*}{$\begin{array}{l}\text { Range of concen- } \\
\text { trations in class } \\
\text { (ng/L) }\end{array}$} & \multirow[b]{2}{*}{$\begin{array}{c}\text { Number } \\
\text { of du- } \\
\text { plicate } \\
\text { sets }\end{array}$} & \multirow[b]{2}{*}{$\begin{array}{c}\text { Pooled } \\
\text { standard } \\
\text { deviation } \\
\text { (ng/L) }\end{array}$} & \multirow{2}{*}{$\begin{array}{l}\text { 90-percent } \\
\text { upper } \\
\text { confidence } \\
\text { bound for } \\
\text { pooled } \\
\text { standard } \\
\text { deviation } \\
\text { (ng/L) }\end{array}$} & \multirow{2}{*}{$\begin{array}{l}\text { Pooled } \\
\text { relative } \\
\text { stan- } \\
\text { dard de- } \\
\text { viation } \\
\text { (per- } \\
\text { cent) }\end{array}$} & \multirow{2}{*}{$\begin{array}{c}\text { 90-percent } \\
\text { upper } \\
\text { confidence } \\
\text { bound for } \\
\text { pooled } \\
\text { relative } \\
\text { standard } \\
\text { deviation } \\
\text { (percent) }\end{array}$} & \multicolumn{3}{|c|}{$\begin{array}{l}\text { Concentration of replicate sets } \\
\text { in class (ng/L) }\end{array}$} \\
\hline & & & & & & & & & & Minimum & Median & Maximum \\
\hline 218 & Sulfentrazone & 11 & CR06 & 50 to $<500$ & 1 & 16.7 & 133 & 4.92 & 39.2 & $\mathrm{nc}$ & 340.1 & $\mathrm{nc}$ \\
\hline 218 & Sulfentrazone & 11 & CR07 & 100 to $<1,000$ & 1 & 16.7 & 133 & 4.92 & 39.2 & $\mathrm{nc}$ & 340.1 & $\mathrm{nc}$ \\
\hline 219 & Sulfosulfuron & 9 & CR04 & 5 to $<50$ & 2 & 6.39 & 19.7 & 27.5 & 84.8 & 15.07 & 19.62 & 24.17 \\
\hline 219 & Sulfosulfuron & 9 & CR05 & 10 to $<100$ & 2 & 6.39 & 19.7 & 27.5 & 84.8 & 15.07 & 19.62 & 24.17 \\
\hline 222 & Tebufenozide & 2 & CR02 & 0.5 to $<5$ & 1 & 0.0331 & 0.263 & 2.46 & 19.6 & $\mathrm{nc}$ & 1.3461 & $\mathrm{nc}$ \\
\hline 226 & Tebuthiuron_TP_108 & 10 & CR04 & 5 to $<50$ & 4 & 2.78 & 5.39 & 33.2 & 64.4 & 6.46 & 21.18 & 46.47 \\
\hline 226 & Tebuthiuron_TP_108 & 10 & CR05 & 10 to $<100$ & 5 & 3.95 & 6.96 & 6.53 & 11.5 & 12.37 & 46.47 & 73.48 \\
\hline 226 & Tebuthiuron_TP_108 & 10 & CR06 & 50 to $<500$ & 3 & 6.11 & 13.9 & 7.27 & 16.5 & 73.22 & 73.48 & 111.86 \\
\hline 226 & Tebuthiuron_TP_108 & 10 & CR07 & 100 to $<1,000$ & 1 & 6.84 & 54.5 & 6.12 & 48.7 & $\mathrm{nc}$ & 111.86 & $\mathrm{nc}$ \\
\hline 232 & Terbufos_sulfoxide & 3 & CR02 & 0.5 to $<5$ & 1 & 0.0199 & 0.159 & 0.628 & 5.00 & $\mathrm{nc}$ & 3.1767 & $\mathrm{nc}$ \\
\hline 232 & Terbufos_sulfoxide & 3 & CR03 & 1 to $<10$ & 1 & 0.0199 & 0.159 & 0.628 & 5.00 & $\mathrm{nc}$ & 3.1767 & $\mathrm{nc}$ \\
\hline 233 & Tetraconazole & 6 & CR03 & 1 to $<10$ & 1 & 0.0469 & 0.373 & 0.493 & 3.93 & $\mathrm{nc}$ & 9.5033 & $\mathrm{nc}$ \\
\hline 233 & Tetraconazole & 6 & CR04 & 5 to $<50$ & 2 & 0.749 & 2.31 & 5.53 & 17.0 & 9.503 & 11.531 & 13.560 \\
\hline 233 & Tetraconazole & 6 & CR05 & 10 to $<100$ & 1 & 1.06 & 8.42 & 7.80 & 62.1 & $\mathrm{nc}$ & 13.56 & $\mathrm{nc}$ \\
\hline 235 & Trifloxystrobin & 2 & CR01 & $<1$ & 1 & 0.0242 & 0.192 & 3.67 & 29.2 & $\mathrm{nc}$ & 0.6583 & $\mathrm{nc}$ \\
\hline
\end{tabular}




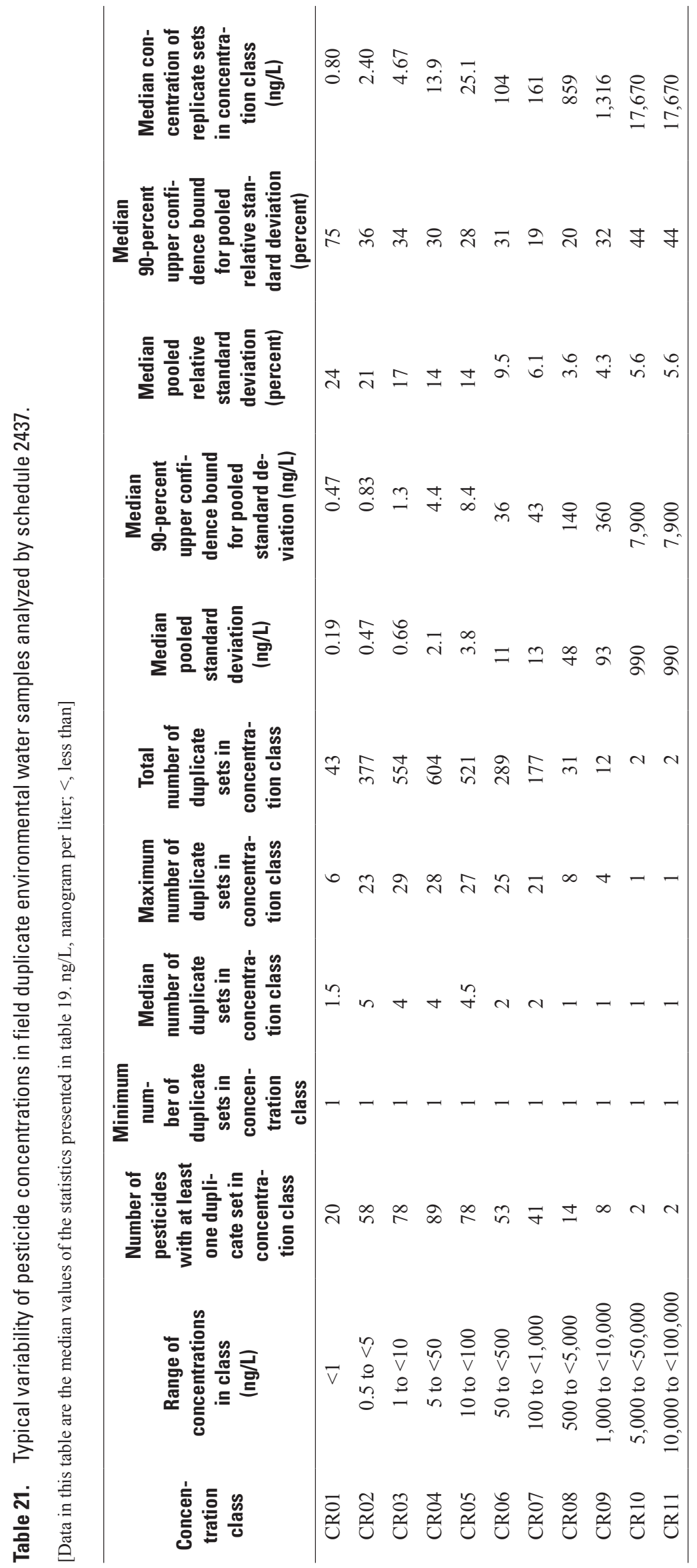




\section{Considerations for Analysis and Interpretation of Data Analyzed by Old and New Analytical Methods}

The results of the field study identified several challenges for the analysis and interpretation of data analyzed by both old and new methods, particularly when data span the change in methods and are combined for analysis of temporal trends in water quality. The main challenges identified are large (greater than 30 percent), statistically significant differences in analytical recovery; detection capability; and (or) measured concentrations for selected pesticides. These challenges are documented and discussed, but specific guidance or statistical methods to resolve these differences in methods are beyond the scope of the report.

Analytical recovery in paired stream-water matrix spikes typically was significantly different for most pesticides analyzed by both old and new methods (tables 9 and 11). In addition to statistical significance, the median difference in paired measurements of recovery often was large, frequently greater than 30 percent. Such differences are expected between different analytical methods. Adjusting measured concentrations for analytical recovery (as was done in Martin and others, 2009) may reduce or eliminate this bias for some pesticides.

Detection capability in paired environmental water samples differed significantly for several pesticides analyzed by old and new methods, particularly for pesticides analyzed by sh2060 (tables 13 and 14). Difference in detection capability was large, often greater than 30 percent. In addition, detection capability could not be confidently assessed for many pesticides because paired environmental water samples had few or no detections of these pesticides. Analysis of pooled datasets for selected pesticides with large differences in detection capability will introduce a bias in detection frequency where new measurements (typically) may more readily detect a pesticide. When comparing detection frequencies among old and new methods, care must be taken to select detection thresholds that are equally achievable by both methods.

Before adjustment for analytical recovery, concentrations measured in paired environmental water samples differed significantly for most pesticides with sufficient detections by both old and new methods (11 for sh2033 and 17 for sh2060, tables 15 and 16). When significantly different, the old methods typically reported higher concentrations, especially at low concentrations (appendix 7, 8). Recovery adjustment generally improved agreement between methods (reduced the mean logical percent difference between paired concentrations, and moved the lowess smooths closer to the line of equality between methods), but most of the pesticides that had statistically different concentrations also had statistically different recovery-adjusted concentrations, and the difference in concentrations was often greater than 30 percent. Analysis of pooled datasets for selected pesticides with large differences in concentrations or recovery-adjusted concentrations will introduce a bias where new measurements are typically smaller (or larger) than old measurements. The information on recovery-adjusted concentrations in paired environmental water samples provided in Martin and Baker (2017, dataset 6) could be used to construct empirical models (such as the lowess models in appendix 7 and 8) to adjust old method concentrations to new method concentrations (or vice versa) for selected pesticides with sufficient observed concentrations. For pesticides without sufficient paired concentrations to construct an empirical model, it is possible that a generalized model could be developed based on empirical models for other pesticides.

The results of the field study show that the implications of the change in analytical methods must be assessed individually for each pesticide and method. In addition, temporal changes in analytical recovery for a single method are common. Modeled temporal changes in recovery for 52 pesticides analyzed by GC-MS during 1992-2006 ranged from 17 to 139 percent (Martin and others, 2009, p. 12). The implications of potential temporal changes in analytical recovery are that the recoveries measured in samples collected for this field study in summer and fall 2012 might be different than those measured in samples collected in previous or future years. The potential for temporal changes in recovery emphasizes the need for the routine collection of field and laboratory qualitycontrol samples to assess data quality.

Understanding the possible causes of the systematic differences in concentrations between methods that remain after recovery adjustment might be necessary to determine how to account for the systematic differences during data analysis. Because recoveries for each method are independently determined from separate calibration standards and spiking solutions, the differences could have been caused by an error in one of the calibration standards or spike solutions or some other basic aspect of standard procedure in the analytical process. The standards and solutions for one method, however, were checked by analysis by the other method and all were measured within acceptable limits of error (within 20 percent of the expected value). The calibration models in the new method used weighted regression curves $(1 / x)$ for calibration, whereas the instrument software for the old methods did not offer this option. Weighted regression curves significantly improve the fit of the data at lower calibration levels. Unweighted regression curves will tend to fit points better at upper calibration levels than those points at lower calibration levels, and use of an unweighted regression curve tends to give less accurate results at lower calibration levels (U.S. Environmental Protection Agency, 2014). Differences in weighted versus unweighted calibration curves could be part of the cause of the systematic biases between methods for some pesticides, especially at low concentrations.

The systematic pattern of differences in recovery-adjusted concentrations across a wide range of water types, pesticides, and concentrations as was demonstrated in this field study is not what one would expect from differing recovery problems from various water matrices or sample processing in the field. 
Further investigation of the possible causes is needed, which will lead to specific decisions on how to compensate for these differences in concentrations in data analysis. Possible additional studies that could be performed include (1) a multiple regression analysis of the stream-water matrix characteristics measured in the field study and their effect on pesticide recovery (these data are provided in Martin and Baker, 2017, dataset 4), (2) a bench-scale spike study in reagent water for old and new analytical methods to characterize recovery across a range of concentrations near the reporting level, (3) a similar benchscale spike study in stream-water samples to characterize matrix effects on recovery at concentrations near the reporting level (perhaps matrix-enhanced recovery in the old method is more pronounced at very low concentrations), and (4) a comparison of weighted versus unweighted calibration curves.

In the event that further investigations do not provide insight into the causes of systematic differences in concentrations between methods, the authors recommend continuing to collect and analyze paired environmental water samples by both old and new methods. This effort should be targeted to seasons, sites, and expected concentrations to supplement those concentrations already assessed and to compare the ongoing analytical recovery of old and new methods to those observed in the summer and fall of 2012.

\section{Summary}

U.S. Geological Survey (USGS) monitoring programs have extensively used two analytical methods, gas chromatography/mass spectrometry (GC-MS) and liquid chromatography/mass spectrometry (LC-MS), to measure pesticides in filtered water samples from 1992 to 2012. In October 2012, monitoring programs began using a new analytical method for pesticides, direct aqueous-injection liquid chromatography tandem mass spectrometry (DAI LC-MS/MS). Changes in analytical methods may introduce changes in data quality. In this report the GC-MS method is referred to as schedule 2033 (sh2033), the LC-MS method is referred to as schedule 2060 (sh2060), and the DAI LC-MS/MS method is referred to as schedule 2437 (sh2437) (the analytical schedule numbers).

A field study was designed to document performance of the new method in a variety of stream-water matrices and to quantify any potential changes in measurement bias or variability that could be attributed to changes in analytical methods. The goals of the field study were to (1) summarize performance (bias and variability of pesticide recovery) of the new method in a variety of stream-water matrices; (2) compare performance of the new method in laboratory blank water (laboratory reagent spikes) to that in a variety of stream-water matrices; (3) compare performance (analytical recovery) of the new method to that of the old methods in a variety of streamwater matrices; (4) compare pesticide detections and concentrations measured by the new method to those of the old methods in a variety of stream-water matrices; (5) compare contamination measured by field blank water samples in old and new methods; (6) summarize the variability of pesticide detections and concentrations measured by the new method in field duplicate water samples; and (7) identify matrix characteristics of environmental water samples that adversely influence the performance of the new method. Stream-water samples and a variety of field quality-control samples were collected at 48 sites in the USGS monitoring networks during June-September 2012. Stream sites were located across the United States and included sites in agricultural and urban landuse settings, as well as sites on major rivers.

Recovery is the ratio of a measured concentration divided by a theoretical or "expected" concentration and is the principal measure of analytical method performance. The three analytical schedules used in the field study provided data for 283 pesticides. Analytical data stored in the National Water Information System are primarily managed by a 5-digit numerical parameter code. Parameter codes for the common pesticides measured by sh2437 are different than those for sh2033 and sh2060 because the units of measurement are different (nanograms per liter for sh2437 but micrograms per liter for sh2033 and sh2060). A variable (index) was created to facilitate management of data for pesticides with different parameter codes. Indexes 1-6 are pesticides common to all three schedules. Indexes 7-61 are pesticides common to sh2437 and sh2033 (61 common pesticides). Indexes 62-93 are pesticides common to sh2437 and sh2060 (38 common pesticides). Indexes $94-283$ are pesticides analyzed only by sh2437, sh2033, or sh2060.

The median recovery of pesticides in stream-water matrix spikes analyzed by sh 2437 ranged from 0 percent for 3-ketocarbofuran, ${ }^{5}$ ammelide, ${ }^{5}$ and phosmet_oxon ${ }^{5}$ to 209.6 percent for didealkylatrazine. The median recovery for all 237 pesticides was 91.3 percent. Relative standard deviation of pesticide recovery in stream-water matrix spikes analyzed by sh 2437 ranged from 9.8 percent for hexazinone to 369.5 percent for ammelide.

Pesticide recovery in stream-water matrix spikes was compared to recovery in laboratory reagent spikes in order to determine if recovery in laboratory reagent spikes would suitably characterize recovery in stream-water. The Wilcoxon rank-sum test was used to compare the median recovery of pesticides in field matrix spikes and laboratory reagent spikes. Of the 237 pesticides tested, median recovery was significantly (probability less than 5 percent) greater in field matrix spikes for 50 pesticides and in laboratory reagent spikes for 58 pesticides. Large differences in recovery reinforces the need for field matrix spikes to accurately describe the performance of sh2437 in stream-water samples for many of the pesticides measured.

Pesticide recovery in paired stream-water matrix spikes analyzed by old and new methods was compared using the sign test to determine if recovery of old and new methods was

\footnotetext{
${ }^{5}$ These compounds were subsequently deleted from the method.
} 
statistically different. Of the 61 pesticides common to schedules 2033 (old method) and 2437 (new method), recovery was significantly greater in samples analyzed by sh2033 for 44 pesticides and was significantly greater in samples analyzed by sh 2437 for 12 pesticides. Of the 38 pesticides common to schedules 2060 (old method) and 2437 (new method), recovery was significantly greater in samples analyzed by sh 2060 for 12 pesticides and was significantly greater in samples analyzed by sh 2437 for 18 pesticides.

The sign test was used to identify differences in pesticide detections in paired environmental water samples analyzed by old and new methods. Many of the pesticides had few or no detections by either the old or new methods; consequently, difference in detection capability for these pesticides and methods could not be readily assessed. A little more than one-half of the 61 pesticides common to sh2033 and sh2437 had one or more detections in paired water samples. Detection frequency was significantly greater by sh 2033 for 9 pesticides and significantly greater by sh 2437 for 5 pesticides. Most of the 38 pesticides common to sh2060 and sh2437 had one or more detections in paired water samples. Detection frequency was significantly greater by sh2060 for 0 pesticides and significantly greater by sh 2437 for 22 pesticides.

The sign test was used to identify differences in pesticide concentrations in paired environmental water samples analyzed by old and new methods. The sign test was done for the original concentrations as reported by the laboratory and for recovery-adjusted concentrations. Statistical significance generally was a function of sample size; the larger the sample size, the more likely the test was significant. Only 27 of the 61 pesticides common to sh2033 and sh2437 had at least one pair of detections by both methods. Statistical test results for unadjusted and recovery-adjusted concentrations were similar. Of the 27 pesticides, 17 had significantly higher concentrations measured by sh2033 than by sh2437. Only 24 of the 38 pesticides common to sh2060 and sh2437 had at least one pair of detections by both methods. For original, unadjusted concentrations, six pesticides had significantly higher concentrations measured by sh2060 and five had significantly higher concentrations measured by sh2437. For recovery-adjusted concentrations, five pesticides had significantly higher concentrations measured by sh2060 and only two had significantly higher concentrations measured by sh2437. Recovery adjustment generally improved the agreement between concentrations measured by both old and new methods/schedules.

The results of the field study identified several challenges for the analysis and interpretation of data analyzed by both old and new methods, particularly when data span the change in methods and are combined for analysis of temporal trends in water quality. The main challenges identified are large, statistically significant differences in analytical recovery, detection capability, and (or) measured concentrations for selected pesticides (large is greater than 30 percent). These challenges are documented and discussed, but specific guidance or statistical methods to resolve these differences in methods are beyond the scope of the report. The results of the field study show that the implications of the change in analytical methods must be assessed individually for each pesticide and method.

Understanding the possible causes of the systematic differences in concentrations between methods that remain after recovery adjustment might be necessary to determine how to account for the differences in data analysis. Because recoveries for each method are independently determined from separate calibration standards and spiking solutions, the differences could have been caused by an error in one of the calibration standards or spike solutions or some other basic aspect of standard procedure in the analytical process. The standards and solutions for one method, however, were checked by analysis by the other method and all were measured within acceptable limits of error (within 20 percent of the expected value).

The systematic pattern of differences in recovery-adjusted concentrations across a wide range of water types, pesticides, and concentrations as was demonstrated in this field study is not what one would expect from differing recovery problems from various water matrices or sample processing in the field. Further investigation of the possible causes is needed, which will lead to specific decisions on how to compensate for these differences in concentrations in data analysis. Possible additional studies that could be performed include (1) a multiple regression analysis of the stream-water matrix characteristics measured in the field study and their effect on pesticide recovery, (2) bench-scale spike study in reagent water for old and new analytical methods to characterize recovery across a range of concentrations near the reporting level, (3) a similar benchscale spike study in stream-water samples to characterize matrix effects on recovery at concentrations near the reporting level (perhaps matrix-enhanced recovery in the old method is more pronounced at very low concentrations), and (4) a comparison of weighted versus unweighted calibration curves.

In the event that further investigations do not provide insight into the causes of systematic differences in concentrations between methods, the authors recommend continuing to collect and analyze paired environmental water samples by both old and new methods. This effort should be targeted to seasons, sites, and expected concentrations to supplement those concentrations already assessed and to compare the ongoing analytical recovery of old and new methods to those observed in the summer and fall of 2012.

\section{Acknowledgments}

The authors thank the following U.S. Geological Survey employees for their contributions to the field study; Richard Coupe, Charles Crawford, and Robert Gilliom for their leadership in designing the field study; Michael Manning for developing sampling protocols and advising field teams; Jessica Thompson for her assistance in retrieving data from the National Water-Quality Assessment Data Warehouse; Christopher Kanagy, Leslie Kanagy, and Cyrissa Anderson for developing analytical reporting and review procedures at the 
National Water Quality Laboratory (NWQL); Thomas Bushly for his assistance in identifying and retrieving data from NWQL; Nancy Baker for assistance in developing figures for the report; the many NWQL chemists that analyzed the samples and reported the data; and to the many field teams and data managers that collected, managed, and reviewed the samples and data for the field study.

\section{References Cited}

Anderson, R.L., 1987, Practical statistics for analytical chemists: New York, Van Nostrand Reinhold Company, 316 p.

Childress, C.J., Foreman, W.T., Connor, B.F., and Maloney, T.J., 1999, New reporting procedures based on longterm method detection levels and some considerations for interpretations of water-quality data provided by the U.S. Geological Survey National Water Quality Laboratory: U.S. Geological Survey Open-File Report 99-193, 19 p. [Also available at https://pubs.er.usgs.gov/publication/ ofr99193.]

Cleveland, W.S., 1979, Robust locally weighted regression and smoothing scatterplots: Journal of the American Statistical Association, v. 74 , no. 368 , p. 829-836.

Cleveland, W.S., and McGill, Robert, 1985, Graphical perception and graphical methods for analyzing scientific data: Science, v. 229, no. 4716, p. 828-833.

Furlong, E.T., Anderson, B.D., Werner, S.L., Soliven, P.P., Coffey, L.J., and Burkhardt, M.R., 2001, Methods of analysis by the U.S. Geological Survey National Water Quality Laboratory-Determination of pesticides in water by graphitized carbon-based solid-phase extraction and high-performance liquid chromatography/mass spectrometry: U.S. Geological Survey Water-Resources Investigations Report 01-4134, 73 p. [Also available at https://nwql.usgs.gov/rpt.shtml?WRIR-01-4134.]

Gilliom, R.J., Barbash, J.E., Crawford, C.G., Hamilton, P.A., Martin, J.D., Nakagaki, Naomi, Nowell, L.H., Scott, J.C., Stackelberg, P.E., Thelin, G.P., and Wolock, D.M., 2006, The quality of our Nation's waters-Pesticides in the Nation's streams and ground water, 1992-2001: U.S. Geological Survey Circular 1291, 172 p. [Also available at https://pubs.er.usgs.gov/publication/cir1291.]

Hahn, G.J., and Meeker, W.Q., 1991, Statistical intervalsA guide for practitioners: New York, John Wiley \& Sons, $392 \mathrm{p}$.
Helsel, D.R., and Hirsch, R.M., 1992, Statistical methods in water resources: Amsterdam, Elsevier Science Publishers, $522 \mathrm{p}$.

Levene, Howard, 1960, Robust tests for equality of variances, in Olkin, Ingram, and Hotelling, Harold, eds., Contributions to probability and statistics: Stanford University Press, p. 278-292.

Lindley, C.E., Stewart, J.T., and Sandstrom, M.W., 1996, Determination of low concentrations of acetochlor in water by automated solid-phase extraction and gas chromatography with mass-selective detection: Journal of AOAC International, v. 79, no. 4, p. 962-966.

Madsen, J.E., Sandstrom, M.W., and Zaugg, S.D., 2003, Methods of analysis by the U.S. Geological Survey National Water Quality Laboratory-A method supplement for the determination of fipronil and degradates in water by gas chromatography/mass spectrometry: U.S. Geological Survey Open-File Report 02-462, 11 p. [Also available at https://pubs.er.usgs.gov/publication/ofr02462.]

Martin, J.D., 2002, Variability of pesticide detections and concentrations in field replicate water samples collected for the National Water-Quality Assessment Program, 1992-97: U.S. Geological Survey Water-Resources Investigations Report 01-4178, 84 p. [Also available at https://pubs.usgs.gov/wri/2001/wri01_4178/.]

Martin, J.D., and Baker, N.T., 2017, Data sets for the report entitled, "A Field Study of Selected U.S. Geological Survey Analytical Methods for Measuring Pesticides in Filtered Stream Water, June-September 2012," U.S Geological Survey data release, accessed July 2017 at https://doi.org/10.5066/F7RB732P.

Martin, J.D., and Eberle, Michael, 2011, Adjustment of pesticide concentrations for temporal changes in analytical recovery, 1992-2010: U.S. Geological Survey Data Series 630, 11 p., 5 app. [Also available at https://pubs.usgs.gov/ds/630/.]

Martin, J.D., Gilliom, R.J., and Schertz, T.J., 1999, Summary and evaluation of pesticides in field blanks collected for the National Water-Quality Assessment Program, 1992-95: U.S. Geological Survey Open-File Report 98-412, 102 p. [Also available at https://water.usgs.gov/nawqa/pnsp/pubs/ files/ofr98412.pdf.]

Martin, J.D., Stone, W.W, Wydoski, D.S., and Sandstrom, M.W., 2009, Adjustment of pesticide concentrations for temporal changes in analytical recovery, 1992-2006: U.S. Geological Survey Scientific Investigations Report 2009-5189, 23 p., 9 apps. [Also available at https://pubs.usgs.gov/sir/2009/5189/.] 
Mueller, D.K., Martin, J.D., and Lopes, T.J., 1997, Qualitycontrol design for surface-water sampling in the National Water-Quality Assessment Program: U.S. Geological Survey Open-File Report 97-223, 17 p. [Also available at https://water.usgs.gov/nawqa/protocols/OFR97-223/ index.html.]

Mueller, D.K., Schertz, T.L., Martin, J.D., and Sandstrom, M.W., 2015, Design, analysis, and interpretation of field quality-control data for water-sampling projects: U.S. Geological Survey Techniques and Methods, book 4, chap. C4, 54 p. [Also available at https://pubs.usgs.gov/tm/04/c04/.]

Natrella, M.G., 1963, Experimental statistics: U.S. Department of Commerce, National Bureau of Standards Handbook 91 [variously paged].

Sandstrom, M.W., Kanagy, L.K., Anderson, C.E., and Kanagy, C.J., 2015, Determination of pesticides and pesticide degradates in filtered water by direct aqueous injection liquid chromatography tandem mass spectrometry: U.S. Geological Survey Techniques and Methods, book 5, chap. B11, 54 p. [Also available at https://pubs.er.usgs.gov/publication/ tm5B11.]

Sandstrom, M.W., Stroppel, M.E., Foreman, W.T., and Schroeder, M.P., 2001, Methods of analysis by the U.S. Geological Survey National Water Quality Laboratory-Determination of moderate-use pesticides and selected degradates in water by C-18 solid-phase extraction and gas chromatography/mass spectrometry: U.S. Geological Survey WaterResources Investigations Report 01-4098, 70 p. [Also available at https://nwql.usgs.gov/Public/WRIR-01-4098.shtml.]

SAS Institute, Inc., 1990, SAS procedures guide-Version 6 (3d ed.): Cary, N.C., SAS Institute, Inc., 705 p.

SAS Institute, Inc., 1999, SAS/STAT User's guide-Version 8, volume 2: Cary, N.C., SAS Institute, Inc., p. 1,245-2,552.
Timme, P.J., 1995, National Water Quality Laboratory 1995 services catalog: U.S. Geological Survey Open-File Report 95-352, $120 \mathrm{p}$.

Tornqvist, Leo, Vartia, Pentti, and Vartia, Y.O., 1985, How should relative changes be measured?: American Statistician, v. 39, no. 1, p. 43-46.

Tukey, J.W., 1977, Exploratory data analysis: Reading, Massachusetts, Addison-Wesley Pub., 506 p.

U.S. Environmental Protection Agency, 2014, Method 8000D determinative chromatographic separations revision 4 , final update $\mathrm{V}$ to the third edition of the test methods for evaluating solid waste, physical/chemical methods: U.S. Environmental Protection Agency publication SW-846, 57 p.

U.S. Geological Survey, 2015, Supplemental guidance for coding and publishing data from NWQL Custom Method LS2437: Office of Water Quality Technical Memorandum 2016.02, accessed January 22, 2016, at https://water.usgs.gov/admin/memo/QW/qw2016.02.pdf.

Venables, W.N., and Ripley, B.D., 1999, Modern applied statistics with S-PLUS (3d ed.): New York, Springer-Verlag, $501 \mathrm{p}$.

Zaugg, S.D., Sandstrom, M.W., Smith, S.G., and Fehlberg, K.M., 1995, Methods of analysis by the U.S. Geological Survey National Water Quality Laboratory-Determination of pesticides in water by $\mathrm{C}-18$ solid-phase extraction and capillary-column gas chromatography/mass spectrometry with selected-ion monitoring: U.S. Geological Survey Open-File Report 95-181, 49 p. [Also available at https://pubs.er.usgs.gov/publication/ofr95181.] 



\section{Appendixes}

Two types of appendixes are provided: regular text (appendix 1) and figures of 15 or more pages (appendixes 2-8). Appendixes 2-8 are available online and can be downloaded from https://doi.org/10.3133/sir20175049.

Appendix 1. Instructions for the collection and processing of the field-study samples.

Appendix 2. Distribution of recovery of pesticides in field matrix spikes and laboratory reagent spikes analyzed by the new analytical method (schedule 2437) (15 pages of figures).

Appendix 3. Comparison of recovery of pesticides in stream-water matrix spikes analyzed by schedule 2033 and by schedule 2437 by study unit, station number, and site visit (61 pages of figures).

Appendix 4. Comparison of recovery of pesticides in stream-water matrix spikes analyzed by schedule 2060 and by schedule 2437 by study unit, station number, and site visit (38 pages of figures).

Appendix 5. Comparison of pesticide detections in paired environmental stream-water samples analyzed by both schedule 2033 and schedule 2437 (61 pages of figures).

Appendix 6. Comparison of pesticide detections in paired environmental stream-water samples analyzed by both schedule 2060 and schedule 2437 (38 pages of figures).

Appendix 7. Comparison of pesticide concentrations in paired environmental stream-water samples analyzed by both schedule 2033 and schedule 2437 (27 pages of figures).

Appendix 8. Comparison of pesticide concentrations in paired environmental stream-water samples analyzed by both schedule 2060 and schedule 2437 (24 pages of figures). 


\title{
Appendix 1. Instructions for the Collection and Processing of the Field-Study Samples.
}

\author{
Pesticide Method Schedule 2437 Evaluation and Comparison Study Field and Processing Protocol \\ for selected National Stream Quality Accounting Network (NASOAN), National Water Quality \\ Assessment (NAWQA), and National Monitoring Network (NMN) Sites
}

\section{Background}

The National Water Quality Laboratory (NWQL) has developed a new method for pesticide analysis, which requires a low volume sample. The new pesticide method will be requested as NWQL Schedule 2437 (S2437). Before S2437 can be accepted, an evaluation and comparison study must be performed to compare S2437 to the current 2033 and 2060 pesticide schedules (S2033 and S2060). This comparison study will ensure any bias and variability will be documented so that the data from the new and old methods can be merged for long-term analysis. S2437 differs from S2033 and S2060 in both analytical and field methods. This comparison study will require S2033, S2060, and S2437 samples to be collected concurrently.

This new method incorporates a pesticide filtering method designed to save time during sample processing, and should also reduce other preparation time by eliminating the amount of equipment used; thereby cleaning time should also be reduced. The FMI pump, corrugated Teflon tubing, aluminum filter plate, and 142-mm GF/Fused for S2033 and S2060 will be replaced with a graduated $30-\mathrm{ml}$ syringe, a large bore needle, and $25-\mathrm{mm} 0.7 \mathrm{um} \mathrm{GF/F}$ disposable disk syringe filter. Once the new method is approved, it will only require a $20-\mathrm{ml}$ sample to be shipped to the laboratory for analysis. However, for this evaluation study, (3)20-ml samples in 40-ml GCV vials (USGS One Stop product code N1560), must be collected.
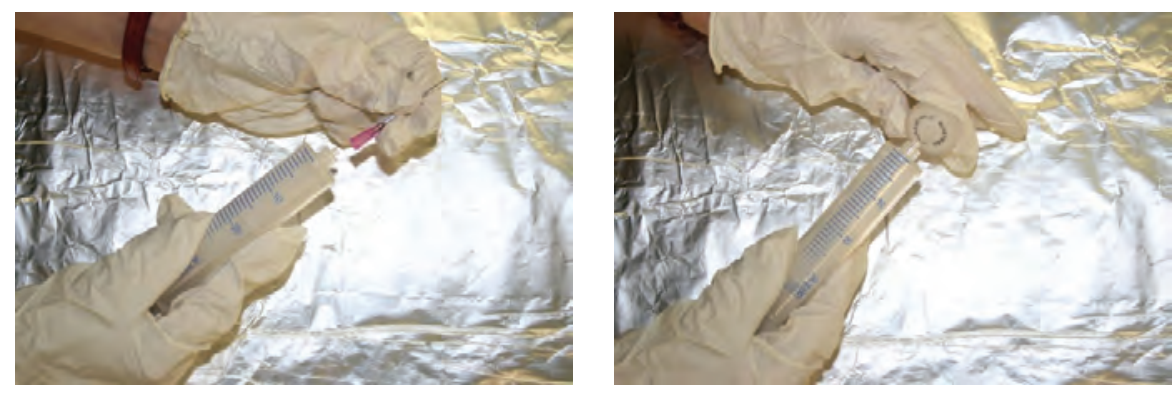

This comparison study will require the help of the experienced NAWQA/NASQAN field crews. Although complicated, the rewards of this new method outweigh the task.

Your site has been chosen to help field validate S2437 because of its past pesticide detections (concentration and variation of pesticide compounds) as well as its unique water matrix. Field crews are requested to collect samples for S2033 and S2060 analyses, and for the new method (S2437) at the listed site(s). Field crews are requested to perform this comparison sampling on 3 trips per site by the end of September 2012 (see sampling schedule).

This evaluation requires multiple spikes, and one S2033 blank at each site. These QA samples will be collected in conjunction with spike and blank samples for S2060 and S2437. If you have already collected your S2033 spike and blank samples, you will need to collect them again. If it fits your schedule, the additional S2033 QA samples required by this evaluation can take the place of your routine S2033 spike and blank.

Instructions for the collection and processing of these new samples are provided below. If you have questions, please contact either Mike Manning (mmanning@usgs.gov) or Claire Rose (cerose@usgs.gov).

The additional equipment and NWQL laboratory work should be charged to your usual/current NASQAN, NAWQA, or NMN account. Additional funds will be transferred to your account to cover these new supply and sampling expenses. New proposal numbers will need to be used on the analytical services request form (ASR). (Refer to account information in the ASR section). 


\section{Field Procedures}

(Please take these instructions to the field for reference)

\section{Collection}

1. Collect your samples as you usually would, as described in the standard methods. The additional pesticide samples for this evaluation will require about 5 liters of water. Be sure that your compositing container for the pesticide sample can accommodate the additional water.

\section{Processing}

As per the NFM (Chapter 5.2.2) " $\mathrm{CH} / \mathrm{DH}$ techniques and associated QA procedures for inorganic analytes with partsper- billion concentrations are not required for organic analytes but are recommended as good field practices to maintain the integrity of sample chemistry. Field personnel must wear disposable, powder-less gloves.

1. At the field site, cover the field bench or work area with a clean sheet of aluminum foil to prepare a clean work surface. Place plastic bag containing syringe, large bore needle, and disposable filter near the clean work surface. Change gloves.

2. Remove syringe, large bore needle, and syringe disk filter from the bag and its wrappings, and place on the clean foil. Attach needle to Luer-Lock fitting on syringe (The open female end of the syringe is twisted onto the male Luer-Lock fitting on the syringe to provide a secure fit).

3. Homogenize the composited pesticide sample in your standard manner.

A. If you usually use a glass carboy for your pesticide sample, you'll have to pump (using the FMI pump and tubing only) a raw, unfiltered subsample into a suitable container for pesticide analysis (such as a 125-ml glass baked amber bottle) for syringe filtering. The bore needle will not reach the bottom of this bottle, and refilling will be necessary throughout the process.

B. If you usually use the Teflon churn as your pesticide compositing device, you can withdraw the sample directly from the churn using the syringe and bore needle.

4. Rinse syringe, bore, and filter. Submerse the bore needle into the subsample or the churn and withdraw 10 -mL of sample through the needle into syringe. Invert syringe, pull stopper to the $30-\mathrm{mL}$ mark on the syringe and shake, ensuring full rinse of the syringe. Depress plunger, expelling water into a waste container. Again, submerse the attached bore needle into the subsample or churn, and withdraw 5-mL of sample into the syringe. Invert syringe and carefully remove needle. Place needle on clean piece of aluminum foil. Attach the filter to the syringe by pushing straight down and twisting until the filter is firmly in place on the syringe mechanism.

Invert syringe and slowly depress the plunger to force the sample water out of the syringe, through the filter to rinse the filter with sample water and expel the rinse water into a waste container. This completes the cleaning and conditioning steps.

5. Remove the filter and place on clean aluminum foil. Carefully reattach the needle to the syringe, and withdraw sample from the subsample as stated above, filling to the 30 -ml mark.

Invert syringe, while tapping and depressing plunger to expel air, push the plunger to about the 25-mL mark. Remove needle and attach rinsed filter. Invert syringe downward, and Filter 20-ml into a 40-ml glass vial by depressing the plunger slowly.

To collect as closely to $20 \mathrm{ml}$ as possible, it is suggested to move the plunger from the 25 - $\mathrm{ml}$ mark to the 5-ml mark. (expel the remaining 5-ml to waste).

Note: In the event that samples have extremely high suspended sediment, organic blank water (OBW) may be used to rinse and condition the filter instead of the $5 \mathrm{ml}$ sample. If OBW is used for rinsate, the OBW rinse must be followed with at least $2 \mathrm{~mL}$ of sample water (before collecting sample) to remove any remaining OBW. Pre-tests have shown that most high sediment sites can filter at least a 30-ml sample using this filter. If the syringe filter medium becomes clogged before a sufficient amount of sample has been filtered, re-filter with a new, conditioned filter by repeating steps 4 and 5 as necessary until at least $20-\mathrm{mL}$ have been collected. These additional steps must be documented on the field sheets. 
6. Repeat steps 4,5 , and 6 two times. Use a new filter for each vial. Repeat steps 5 and 6 two times on trips without a scheduled blank sample. This will result in three 40 -ml glass vials with 20 -ml of filtered sample in each vial. If a blank is scheduled, only repeat steps 5 and 6 one additional time, resulting in two 40-ml glass vials with 20-ml of filtered sample in each vial.

The 1 st of the 3 vials is the environmental sample for the S2437.

7. The 2 nd of the $\mathbf{3}$ vials is always a spike sample. Spike this sample using the new S2437 spike mixture. Use the same micropipette and glass bores as used for the S2033 and S2060 spikes. Instructions for spiking samples accompany each spike kit; also refer to NFM Chapter A4. (4.3.3) and Chapter A5 (5.3.2).

Note: When spiking samples remember to (1) use a new glass bore for each spiked sample, (2) rinse the micro-pipetor's Teflon tip before and after each use with pesticide-grade methanol, and (3) release the spike into the sample (by depressing the plunger) once the glass bore is under the surface. The plunger should remain depressed as the glass bore is withdrawn from the sample. Always dispose of used spike kits and used glass bores in proper hazardous waste containers.

8. The last of the $\mathbf{3}$ vials will be processed according to the quality assurance schedule for the additional QA/QC scheduled for 2437. This vial will either be an environmental replicate, a spike replicate or a field blank. (See sample schedule).

9. Label the vials with the appropriate station ID, date, time offset, (see table, and figure below), medium code, schedule number, and sample type. Ensure caps are on firmly. Do not freeze. Chill and maintain the sample at or below $4{ }^{\circ} \mathrm{C}$ without freezing during storage and shipment.

10. Discard the needle, syringe and filter. The syringes can be put into a plastic recycling bin. On field forms and in the field notes, document the number of filters used for each vial and any problems you encountered.

11. Collect a blank sample for both S2033 and S2060 only if a S2437 blank is scheduled This blank is done only once per site for this study, and at the same time as the blank for the S2437. The S2033 and 2060 blank will be in addition to the samples in step 12 below. On the blank sample date there will be a total of 3-S2033, and 3-S2060 bottles (one environmental, one spike, and one blank for both S2033, and S2060).

12. Filter the $\mathbf{S 2 0 3 3}$ and $\mathbf{S 2 0 6 0}$ samples using standard field methods and equipment. Filter four $1 \mathrm{~L}$ baked glass amber bottles, changing filters between each bottle, or more often if needed. (See NFM 5.2.2A and NAWQA SW QC OFR 97-223, p. 5).

13. The first two 1-L baked glass amber bottles are environmental samples for $\mathbf{S 2 0 3 3}$ and $\mathbf{S 2 0 6 0}$. No further processing or treatment is required.

14. The third and fourth 1-L baked glass amber bottles are spiked samples for $\mathbf{S 2 0 3 3}$ and $\mathbf{S 2 0 6 0}$. Spike one bottle using the S2033 spike kit. Spike the other bottle using the S2060 spike kit. Instructions for spiking samples accompany each spike kit; also refer to NFM Chapter A4. (4.3.3) and Chapter A5 (5.3.2).

Note: The 2060 spike kits have two vials of spike solution containing different pesticides. Be sure to use both for the 2060 spike. (See instructions included with the spike kits).

15. Label the 1L bottles with the appropriate station ID, date, time offsets,(refer to table, and figure below), medium code, schedule number, and sample type. Ensure caps are on firmly. Do not freeze. Chill and maintain the sample at or below $4^{\circ} \mathrm{C}$ without freezing during storage and shipment.

16. Ship all pesticide samples overnight to NWQL along with your other samples.

17. Due to the limited number of samples collected for this evaluation, it is of high importance that these samples are protected from breakage. Place each 40-ml vial in a foam sleeve purchased from USGS One Stop \# Q358FLD, or use the sleeve the new vials are shipped with. Seal all three foam sleeves in a zip-lock bag. Package each $1 \mathrm{~L}$ amber glass bottle in a $32 \mathrm{oz}$. styrofoam bottle shippers and secure with fiber tape. The $32 \mathrm{oz}$. styrofoam shippers are available from Label Master: http://www.labelmaster.com, item number: UNIP32F. Note: The styrofoam bottle shippers are designed for horizontal shipment, i.e. the bottle will be lying on its side in the cooler. 
Table 1-1. Sample overview.

[ASR, analytical service request form; NAWQA, National Water-Quality Assessment; NASQAN, National Stream Quality Accounting Network; 1-L, one-liter; WS, environmental surface water; SUID, study unit identification; WSQ, quality-control surface water; OAQ, quality-control artificial; OBW, organic blank water; min., minute; QA, quality assurance; 40-ml, 40-milliliter]

\begin{tabular}{|c|c|c|c|c|c|c|c|c|c|c|c|c|}
\hline 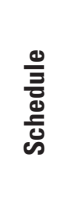 & 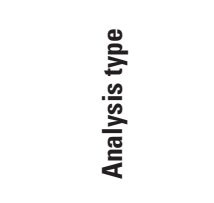 & 詞 & 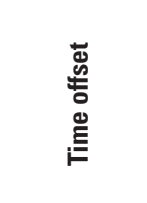 & 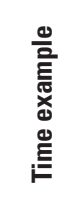 & $\begin{array}{l}\frac{0}{0} \\
0 \\
0 \\
\tilde{0} \\
\Sigma\end{array}$ & 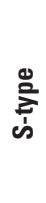 & 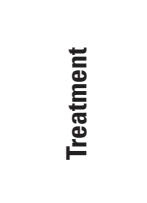 & 悉 & 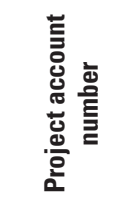 & 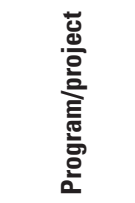 & 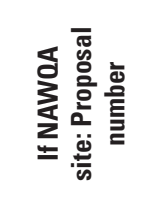 & 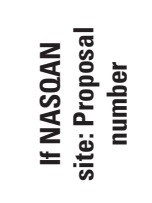 \\
\hline \multirow[t]{3}{*}{2033} & Environmental & 1-L glass & None & 1200 & WS & 9 & Sample & Routine & No change & No change & ${ }^{3}$ CL12 SUID & CL12001 \\
\hline & Spike & 1-L glass & None & 1200 & WSQ & 1 & $\begin{array}{l}2033 \text { Spike } \\
\text { kit }\end{array}$ & Separate & No change & No change & ${ }^{3}$ CL12 SUID & ${ }^{3}$ CL12 SUID \\
\hline & ${ }^{1}$ Blank & 1-L glass & None & 1200 & QAQ & 2 & OBW & Separate & No change & No change & ${ }^{3}$ CL12 SUID & ${ }^{3}$ CL12 SUID \\
\hline \multirow[t]{2}{*}{2060} & Environmental & 1-L glass & $\begin{array}{c}1 \text { min. after } \\
2033\end{array}$ & 1201 & WS & 9 & Sample & Separate & No change & No change & ${ }^{3}$ CL12 SUID & ${ }^{3}$ CL12 SUID \\
\hline & Spike & 1-L glass & $\begin{array}{l}1 \text { min. after } \\
2033\end{array}$ & 1201 & WSQ & 1 & $\begin{array}{l}2033 \text { Spike } \\
\text { kit }\end{array}$ & Separate & No change & No change & ${ }^{3}$ CL12 SUID & ${ }^{3}$ CL12 SUID \\
\hline \multirow{2}{*}{2437} & Vial \#2: Spike & 40-ml glass & $\begin{array}{c}3 \text { min. after } \\
2033\end{array}$ & 1202 & WSQ & 1 & $\begin{array}{l}2437 \text { Spike } \\
\text { kit }\end{array}$ & Separate & No change & No change & CL12023 & CL12023 \\
\hline & $\begin{array}{c}{ }^{2} \text { Vial \#3 QA: } \\
\text { Blank }^{1}\end{array}$ & 40-ml glass & $\begin{array}{c}3 \text { min. after } \\
2033\end{array}$ & 1202 & $\begin{array}{l}\text { QAQ } \\
\text { WSQ } \\
\text { WSQ }\end{array}$ & $\begin{array}{l}2 \\
7 \\
1\end{array}$ & $\begin{array}{l}\text { OBW } \\
\text { Sample } \\
2437 \text { Spike } \\
\quad \text { kit }\end{array}$ & Separate & No change & No change & CL12023 & CL12023 \\
\hline
\end{tabular}

${ }^{1}$ This 2437 vial will alternate between either a blank, an environmental sample, or a spike replicate.

${ }^{2}$ One blank per site. Blanks should be done on all 3 schedules on the same date. (See sample schedule.)

${ }^{3}$ SUID is your study unit's 4-letter ID.

\section{ASR Forms}

No changes will be necessary on the primary ASR for the environmental S2033 sample. Continue to use the same ASR you normally use for your site(s).Due to the overlap of parameters, and complexity for this evaluation, all other pesticide samples will require their own unique and separate ASR due to either medium codes, and/or time differences. This will result in as many as 9 ASRs.

The first time recorded (main sample) should be to the nearest $10 \mathrm{~min}$. (example: sch.2033 $=1200$, or 1210, or $1220 \ldots$ )

The new ASR's will use the usual (pesticide) NASQAN/NAWQA/ or NMN project account code (GX12DD009CE0000) or the NMN project account code (GX12DD009U2LA00), or in some cases your NAWQA S\&T account. Refer to the table above for ASR project account numbers and proposal numbers to use for your site. Note that NASQAN stations will have to use a NAWQA proposal code for some of their sample types.

In the Analytical Work Requests section of the ASR enter: "SCH 2437"

In the Field Comments section of the ASR enter: "S2437 vial \#1 environmental / S2437 vial \#2 spike / S2437 vial\#3 blank, or spike replicate, or environmental replicate" depending on the sample type. (See schedule).

Also, in the field comments section of the ASR, note the type of sample (environmental, spike, or blank) for the S2033 and S2060 as well. Record the blank water and spike lot numbers here. 
In the "shipping information" section of the S2437 ASRs, enter "1 PEST" for the number of vials and bottle type for S2437 samples only. All S2033 and S2060 bottle types will still be "GCC". "PEST" is the new bottle type assigned to the new schedule.

\section{Medium Codes, Time Offsets, and Sample Types}

Round the sample time for the primary environmental sample to the nearest 10 minutes, for example 0940,1200 , or 1320 . This sample time will be used for the environmental S2033 and your non-pesticide samples (nutrients, sediment, etc).

All S2060 and S2437 samples MUST use a time offset. Additionally, all S2033 spike, replicate, and blank samples MUST use a time offset. The time offset is required to prevent overwriting data in QWDATA due to identical parameter codes and multiple samples. Time offsets will be used in conjunction with medium codes to differentiate the samples. Sample times and medium codes are critical. Do not deviate from the coding in this guidance, even if your Water Science Center would not normally code samples in this manner.

Refer to the table above for the proper coding for each bottle and ASR.

\section{Blank Processing}

Field blanks should be processed using standard methods as stated in the National Field Manual (NFM) Chapter A4 (4.3.1). Blanks for S2437 should mirror those guidelines. Follow the procedures outlined in this document (steps 1-9), substituting OBW for environmental water. These blanks should be done in the field, but prior to collecting and processing the environmental samples. Only one field blank will be done per site. For each site, the field blanks for S2033, S2060, and S2437 should be collected on the same date.

\section{Spike Kits}

Use the appropriate spike mixture kit for each schedule (2033 spike kit for S2033 samples, 2060 spike kit for S2060 samples, and the new 2437 spike kit for S2437 samples).Please record lot number for each spike kit within the field notes. 2060 has two lot numbers.

\section{Sample Login}

When logging in samples, it is imperative that within the sample header under "field remarks"(Line 19) be filled out to indicate whether the 2437 schedule is an environmental replicate, spike replicate, or a blank. For example: Field Remarks: "New 2437 method- environmental sample"

The following parameter codes should be added when logging the samples into NWIS:

\section{Environmental Sample Coding}

(in addition to normal codes)

Pcode $99105=$ Replicate type $=30$ (split)

Pcode $99112=$ Purpose of topical QC $=200$ (variability due to laboratory)

Pcode 99111= QC Data Associated with Sample $=100=$ more than one type of QC 


\section{Environmental Replicates}

(in addition to normal codes)

Pcode $71999=$ Sample Purpose $=$ NAWQA $=15 /$ NASQAN $=20$, or NMN $=25$

Pcode $50280=$ Purpose of Visit $=1098(\mathrm{QA} / \mathrm{QC}$, surface water)

Pcode $99105=$ Replicate type $=30$ (split)

Pcode $99112=$ Purpose of topical QC $=200$ (variability due to laboratory)

\section{Spikes and Spike Replicates}

Pcode $71999=$ Sample Purpose $=$ either NAWQA $=15 /$ NASQAN $=20$, or $\mathrm{NMN}=25$

Pcode $50280=$ Purpose of Visit $=1098(\mathrm{QA} / \mathrm{QC}$, surface water)

Pcode $99105=$ Replicate type $=30$ (split) [Only use this Pcode if it is a replicate spike]

Pcode $99107=$ Source of Spike Solution $=10$ NWQL

Pcode $99106=$ Type of Spike Sample $=10$ Field

Pcode $82075=$ Amount of Rinse $=$ in L, $(20-\mathrm{ml}=0.02-\mathrm{L})$

Pcode $99108=$ Spike Volume $=(\mathrm{ml}) 100 \mathrm{u} / \mathrm{L}=.1 \mathrm{ml}$

Pcode $99104=$ Spike Lot number $=$ See Spike Kit for NWIS Lot number

Pcode $99112=$ (purpose of topical QC) $=200$ (variability due to laboratory)

\section{Blank Coding}

Pcode $71999=$ Sample Purpose $=$ either NAWQA $=15 /$ NASQAN $=20$, or NMN $=25$

Pcode $50280=$ Purpose of Visit $=1098$ (QA/QC, surface water)

Pcode $99100=$ Type of Blank Solution $=40$ Organic-Free water

Pcode $99101=$ Source of Blank Solution = 10 NWQL

Pcode $99102=$ Type of Blank Sample $=100$ Field

Pcode $82075=$ Amount of Rinse $=$ in L, $(20-\mathrm{ml}=0.02-\mathrm{L})$

Pcode $99202=$ Organic Blank Lot $=($ see container for NWIS Lot or NWQL web page $)$

Pcode $99112=$ Purpose of Topical QC $=200$ Variability due to Laboratory

\section{Equipment for Schedule 2437 Method Comparison Evaluation}

Contact Milton Marshall (memarsha@usgs.gov) with your name, shipping address, phone number, site number(s) chosen for this evaluation study, and account to charge. Tell him you are involved in the S2437 Comparison Evaluation. For every one site you are scheduled to sample for this evaluation study, you will need to order the following:

- 1 bag (of 50) Plastic syringes (Order from Milton Marshall)

- 1 bag (of 50) Large-bore needles (Order from Milton Marshall)

- 1 bag (of 20) $25 \mathrm{~mm} 0.7$ um glass-fiber syringe disk filters (Order from Milton Marshall)

- 3 S2437 spike mixtures (Order from Milton Marshall) 
Note: The orders can be made in no fewer amounts than 50 for syringes and needles, and 20 for filters. The actual amount of syringes, needles, and filters needed for one site are 9 of each (or 1 syringe, needle, and filter per S2437 vial). Keep this in mind when ordering supplies for more than one site- you may not have to order more than one bag of syringes or needles. Also, when vial\#3 is scheduled to be a spike replicate, take the spike and the spike replicate out of the same spike mixture, so that you only have to order 3 spike mixtures, rather than 4.

From USGS OneStop, Order: (for every one site scheduled to be sampled in this evaluation study)

- 3 S2033 spike mixtures (Order from USGS 1Stop, N1420)

- 3 S2060 spike mixtures (Order from USGS 1Stop, N1490)

You may also need to order the following from USGS OneStop if you are running low on supplies in your office:

- 10 142-mm 0.7 um glass-fiber filters (Order from USGS 1Stop, Q375FLD)

- 27 40-ml glass vials, GCV (Order from USGS 1Stop, N1560)

- 10 1-L baked glass amber bottles (Order from USGS 1Stop, Q27FLD)

- 4L Pesticide-grade blank water (Order from USGS 1Stop, N1590)

- Foam sleeves or shippers for glass bottles (Order from laboratory supplier such as Label Master http://www.labelmaster.com item number: "UNIP32F")

\section{Schedule 2437 Evaluation Procedure}

Schedule 2033

(Aluminum filter plate)
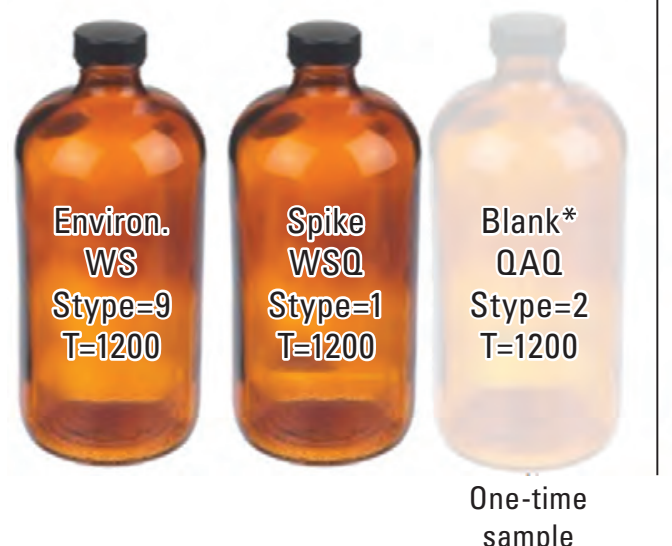

sample

*Note 2033 and 2060 Blanks are only collected when Schedule 2437 vial " $\mathrm{C}$ " is scheduled to be a blank. If Schedule 2437 vial "C" is scheduled to be a replicate or spike replicate, do not collect the 3rd 1-liter 2033 or 2060.
Schedule 2060

(Aluminum filter plate)
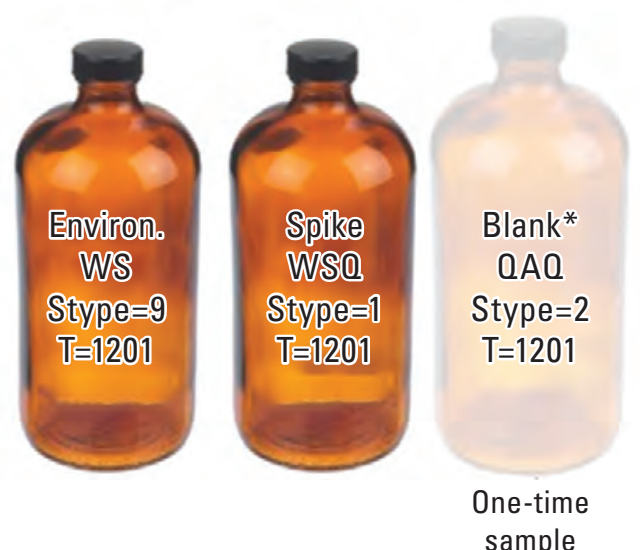

Schedule 2437

(Syringe and needle)

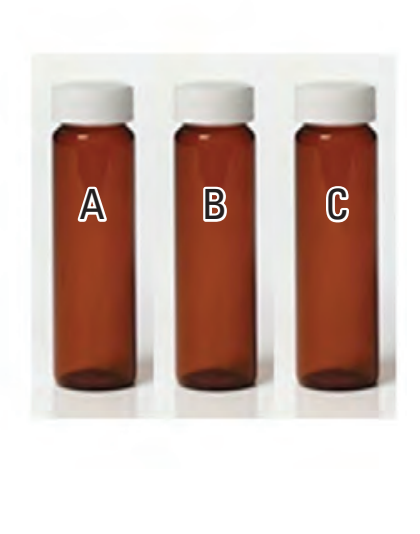

A. Environmental: WSQ-B ( $T=1202)$

B. Spike: WSO-1 ( $T=1203)$

C. Either: (See Schedule) Replicate: WSQ-7 (T=1204)

Spike Replicate: WSO-1 ( $\mathrm{T}=1204)$ Blank: 0AO-2 ( $T=1204$ ) 
Publishing support provided by:

Madison and Rolla Publishing Service Centers

For more information concerning this publication, contact: National Water-Quality Assessment Project

U.S. Geological Survey

5957 Lakeside Boulevard

Indianapolis, IN 46278

Or visit the NAWQA Project website at: https://water.usgs.gov/nawqa/ 


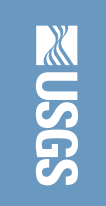

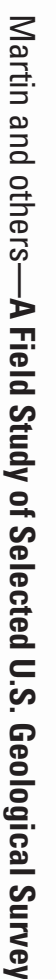

ISSN 2328-0328 (online) 